\title{
Métodos adaptativos de segmentação aplicados à recuperação de imagens por conteúdo ${ }^{1}$
}

\author{
André Guilherme Ribeiro Balan \\ Orientadora: Prof ${ }^{a}$ Dra Agma Juci Machado Traina
}

Tese apresentada ao Instituto de Ciências Matemáticas e de Computação - ICMC-USP, como parte dos requisitos para obtenção do título de Doutor em Ciências de Computação e Matemática Computacional.

USP - São Carlos

Março de 2007

\footnotetext{
${ }^{1}$ Apoio financeiro FAPESP, processo 03/01769-4
} 

à minha irmã Ana Carolina 



\section{Agradecimentos}

À minha orientadora Prof ${ }^{\mathrm{a}} \operatorname{Dr}^{\mathrm{a}}$ Agma J. M. Traina, por contribuir efetivamente na realização deste trabalho, por me ensinar atenciosamente, e por me incentivar em todos os momentos. Principalmente, por acreditar em mim e ter me dado a excelente oportunidade de trabalhar ao seu lado;

Aos meus pais, Ana e Antônio, por me ensinarem o caminho da determinação e perseverança desde o início. Por serem a minha maior referência da palavra amor. Por serem o meu apoio mais constante. Por serem meus heróis;

À minha namorada Elaine, agradeço todo carinho e dedicação. Por acompanhar meu trabalho e estar comigo em todos os momentos, não importando a distância.

Aos professores Christos Faloutsos e Eric Xing, pela orientação e grande apoio na realização do estágio na Carnegie Mellon University, pelas caronas aos finais de tarde e pelo imenso companheirismo;

Aos amigos José Fernando (Junior), Jia Yu (Tim), David e tia Aggie, que fizeram especialmente parte do excelente período nos Estados Unidos;

Ao Dr. David Araújo e ao professor Dr. Paulo M. A. Marques pelas reuniões em Ribeirão Preto que originaram diversas idéias para este trabalho, por disponibilizarem as imagens médicas utilizadas nos experimentos e por auxiliarem na validação dos resultados;

Ao professor Dr. Caetano Traina Junior pela ajuda na revisão dos trabalhos e por estar sempre disposto a ajudar;

A todos os amigos do Grupo de Bases de Dados e Imagens (GBDI), especialmente à Mônica, Marcela, Camila, e ao Humberto, que gentilmente auxiliaram na revisão deste documento;

Aos meus primos José Ricardo e Eduardo, sempre solícitos e companheiros;

A todos os meus amigos do ICMC-USP e da cidade de Mococa, pela amizade e companheirismo;

À Fapesp, Fundação de Amparo à Pesquisa, pelo apoio financeiro. 



\section{Resumo}

A possibilidade de armazenamento de imagens no formato digital favoreceu a evolução de diversos ramos de atividades, especialmente as áreas de pesquisa e clínica médica. Ao mesmo tempo, o volume crescente de imagens armazenadas deu origem a um problema de relevância e complexidade consideráveis: a Recuperação de Imagens Baseada em Conteúdo, que, em outras palavras, diz respeito à capacidade de um sistema de armazenamento processar operações de consulta de imagens a partir de características visuais, extraídas automaticamente por meio de métodos computacionais.

Das principais questões que constituem este problema, amplamente conhecido pelo termo CBIR - Content-Based Image Retrieval, fazem parte as seguintes: Como interpretar ou representar matematicamente o conteúdo de uma imagem? Quais medidas que podem caracterizar adequadamente este conteúdo? Como recuperar imagens de um grande repositório utilizando o conteúdo extraído? Como estabelecer um critério matemático de similaridade entre estas imagens?

O trabalho desenvolvido e apresentado nesta tese busca, exatamente, responder perguntas deste tipo, especialmente para os domínios de imagens médicas e da biologia genética, onde a demanda por sistemas computacionais que incorporam técnicas CBIR é consideravelmente alta por diversos motivos. Motivos que vão desde a necessidade de se buscar informação visual que estava até então inacessível pela falta de anotações textuais, até o interesse em poder contar com auxílio computacional confiável para a importante tarefa de diagnóstico clínico.

Neste trabalho são propostos métodos e soluções inovadoras para o problema de segmentação e extração de características de imagens médicas e imagens de padrões espaciais de expressão genética. A segmentação é o processo de delimitação automático de regiões de interesse da imagem que possibilita uma caracterização bem mais coerente do conteúdo visual, comparado com as tradicionais técnicas de caracterização global e direta da imagem. Partindo desta idéia, as técnicas de extração de características desenvolvidas neste trabalho empregam métodos adaptativos de segmentação de imagens e alcançam resultados excelentes na tarefa de recuperação baseada em conteúdo. 



\section{Abstract}

Storing images in digital format has supported the evolution of several branches of activities, specially the research area and medical clinic. At the same time, the increasing volume of stored images has originated a topic of considerable relevance and complexity: the ContentBased Imagem Retrieval, which, in other works, is related to the ability of a computational system in processing image queries based on visual features automatically extracted by computational methods.

Among the main questions that constitute this issue, widely known as CBIR, are these: How to mathematically express image content? What measures can suitably characterize this content? How to retrieve images from a large dataset employing the extracted content? How to establish a mathematical criterion of similarity among the imagens?

The work developed and presented in this thesis aims at answering questions like those, especially for the medical images domain and genetical biology, where the demand for computational systems that embody CBIR techniques is considerably high for several reasons. Reasons that range from the need for retrieving visual information that was until then inaccessible due to the lack of textual annotations, until the interest in having liable computational support for the important task of clinical diagnosis.

In this work are proposed innovative methods and solutions for the problem of image segmentation and feature extraction of medical images and images of gene expression patterns. Segmentation is the process that enables a more coherent representation of image's visual content than that provided by traditional methods of global and direct representation. Grounded in such idea, the feature extraction techniques developed in this work employ adaptive image segmentation methods, and achieve excellent results on the task of Content-Based Image Retrieval. 

1 Introdução 1

1.1 Motivação . . . . . . . . . . . . . . . . . . . . 2

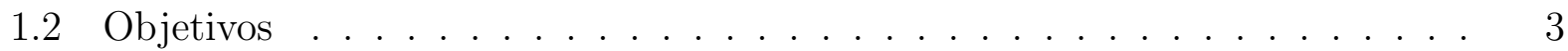

1.3 Principais contribuições . . . . . . . . . . . . . . . . . . . . . 3

1.4 Organização da tese . . . . . . . . . . . . . . . . . 4

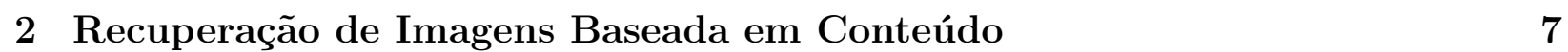

2.1 Tópicos em CBIR . . . . . . . . . . . . . . . . . . . . . . . . . 8

2.2 Extração de características . . . . . . . . . . . . . . . . . . . . 10

2.3 RBIR - Recuperação de imagens baseada em região . . . . . . . . . . . . . . 13

2.4 Avaliação de similaridade . . . . . . . . . . . . . . . . . . . 13

2.4.1 Funções de distâncias de Minkowski (família $L_{p}$ ) . . . . . . . . . . . . 14

2.4.2 Função de distância Cosseno . . . . . . . . . . . . . . . . . . . . 14

2.4 .3 Intersecção de histograma . . . . . . . . . . . . . . . . . . 15

2.4.4 Distância quadrática . . . . . . . . . . . . . . 15

2.4.5 Distância Mahalanobis . . . . . . . . . . . . . . . . . . . . . 16

2.5 Consultas por similaridade em espaços vetoriais . . . . . . . . . . . . . 16

2.5.1 Consulta por raio de abrangência (range query) . . . . . . . . . 16

2.5.2 Consulta aos k vizinhos mais próximos $(k N N$ query $)$. . . . . . . . . 17

2.6 Avaliação de eficiência . . . . . . . . . . . . . . . . . . . 17

2.6.1 Gráficos de Precisão versus Revocação . . . . . . . . . . . . . . . . . 18

2.7 Considerações finais . . . . . . . . . . . . . . . . . . . . . 20

3 Técnicas de extração de características de imagens 23

3.1 Assinaturas de forma . . . . . . . . . . . . . . . . . . . 23

3.1.1 Função distância do centróide . . . . . . . . . . . . . . . 23

3.1 .2 Função posição . . . . . . . . . . . . . . . . . . . . . . . . . . 24

3.2 Descritores de Fourier . . . . . . . . . . . . . . . . . . . . . . . . 24

3.2 .1 Transformada de Fourier . . . . . . . . . . . . . . . . . . . 24

3.2 .2 Obtenção do descritores . . . . . . . . . . . . . . . . . . 26 
3.3 Momentos de Zernike . . . . . . . . . . . . . . . . . . . . . 27

3.4 Matrizes de co-ocorrência . . . . . . . . . . . . . . . . . . . . . . . . 29

3.5 Análise da transformada de Fourier . . . . . . . . . . . . . . . . . . . . . 31

3.6 Análise da transformada de Wavelet . . . . . . . . . . . . . . . . . . . 31

3.6.1 Transformada de Wavelet . . . . . . . . . . . . . . . . 33

3.6 .2 Medidas da transformada de Wavelet . . . . . . . . . . . . . . . . . . 34

3.7 Considerações finais . . . . . . . . . . . . . . . . . . . . . . 35

4 Segmentação de imagens $\quad 37$

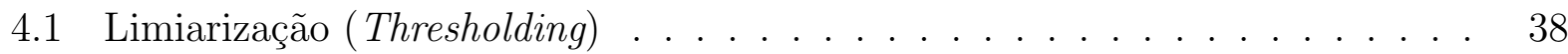

4.2 Métodos baseados na detecção de bordas . . . . . . . . . . . . . . . . . . 39

4.2.1 Algoritmos de Enlace (Edge Linking) . . . . . . . . . . . . . . 40

4.2.2 Modelos de contorno ativo - Snakes . . . . . . . . . . . . . . . 42

4.3 Métodos baseados em regiões . . . . . . . . . . . . . . . . . . . 43

4.3.1 Watersheds ....................... 44

4.4 Métodos baseados em Textura . . . . . . . . . . . . . . . . . . . . 48

4.5 Método de segmentação EM/MPM . . . . . . . . . . . . . . . . . . . 49

4.5.1 Modelos das Imagens . . . . . . . . . . . . . . . . . . . . . . 50

4.5.2 Abordagem MPM . . . . . . . . . . . . . . . . 54

4.5.3 Algoritmo EM . . . . . . . . . . . . . . . . . 55

4.5.4 Algoritmo EM/MPM . . . . . . . . . . . . . . . 56

4.6 Considerações finais . . . . . . . . . . . . . . . . . . . . . 58

5 Extração de características de imagens médicas $2 \mathrm{D}$ de ressonância magnética 59

5.1 Método proposto . . . . . . . . . . . . . . . . . 60

5.1 Segmentação de imagens . . . . . . . . . . . . . . . . . . 60

5.1 .2 Caracterização da imagem . . . . . . . . . . . . . . . . 62

5.1 .3 Função de distância . . . . . . . . . . . . . . . . . . . . . . . 68

5.2 Experimentos e resultados . . . . . . . . . . . . . . . . . . . . . . . 69

5.2.1 Avaliação quantitativa . . . . . . . . . . . . . . . . . . 70

5.2.2 Avaliação qualitativa . . . . . . . . . . . . . . . . . . 73

5.3 Tempo de processamento . . . . . . . . . . . . . . . . . . . . 74

5.4 Considerações Finais . . . . . . . . . . . . . . . . . . . . . . . . . . 75

6 Sistema FEMine - CBIR para padrões de expressão genética $\quad 77$

6.1 Motivação . . . . . . . . . . . . . . . . . . . . . . . . . . 78

6.2 Descrição do sistema . . . . . . . . . . . . . . . . . . . . . . . . . . . 79

6.3 Trabalhos correlatos e contribuição do projeto . . . . . . . . . . . . . . 80

6.4 Processamento das imagens . . . . . . . . . . . . . . . . . . . . 82

6.4.1 Identificação dos embriões . . . . . . . . . . . . . . . . . . . 82 
6.4.2 Isolando o embrião principal . . . . . . . . . . . . . . . . . . . . . . . 84

6.4.3 Alinhamento (registro) das imagens . . . . . . . . . . . . . . 90

6.4.4 Etapas finais na preparação de imagens . . . . . . . . . . . . . . . . 92

6.5 Extração de características da imagem . . . . . . . . . . . . . . . . 93

6.5.1 Análise dos Componentes Principais - PCA . . . . . . . . . . . . . . 94

6.5 .2 Vetor de características proposto . . . . . . . . . . . . . . 95

6.6 Experimentos e Resultados . . . . . . . . . . . . . . . . . . . . 95

6.6.1 Processamento das imagens . . . . . . . . . . . . . . . 96

6.6.2 Cálculo dos Eigen-Embryos . . . . . . . . . . . . . . . . . 97

6.6.3 Cálculo dos vetores de características . . . . . . . . . . . . . . . . . . 99

6.6.4 Recuperação de imagens por conteúdo . . . . . . . . . . . . . . . . . 99

6.7 Considerações finais . . . . . . . . . . . . . . . . . . . . 102

7 Método HEAD - the Human Encephalon Automatic Delimiter 105

7.1 Visão geral do método HEAD . . . . . . . . . . . . . . . . . . . 106

7.2 Trabalhos relacionados . . . . . . . . . . . . . . . . 106

7.2.1 Métodos baseados em região . . . . . . . . . . . . . . 107

7.2.2 Métodos baseados em bordas . . . . . . . . . . . . . 108

7.3 O método HEAD . . . . . . . . . . . . . . . . . . . . . . . . 109

7.3.1 Algoritmo de particionamento de histograma . . . . . . . . . . . . 109

7.3.2 Remoção do plano de fundo background . . . . . . . . . . . . . . . . . 111

7.3 .3 Delimitação do encéfalo . . . . . . . . . . . . . . . . 113

7.4 Experimentos e resultados . . . . . . . . . . . . . . . . . . 118

7.4.1 Avaliação quantitativa . . . . . . . . . . . . . . . . . 122

7.4 .2 Imagens Sintéticas . . . . . . . . . . . . . . . . . . . . . . 123

7.4.3 Tempo de processamento . . . . . . . . . . . . . . . . 125

7.5 Considerações finais . . . . . . . . . . . . . . . . . . . 125

8 Conclusão $r$

8.1 Considerações finais . . . . . . . . . . . . . . . . . . . . . . . . 129

8.2 Principais contribuições . . . . . . . . . . . . . . . . . . . 130

8.3 Trabalhos de extensão . . . . . . . . . . . . . . . . . . . . . . . . 132

$\begin{array}{ll}\text { A Teoria dos Fractais } & 135\end{array}$

B Revisão dos principais conceitos de genética 139

B.1 Análise de expressão genética . . . . . . . . . . . . . . . . . . 140

B.1.1 Microarray de DNA . . . . . . . . . . . . . . . . . 141

B.1.2 Hibridização in situ . . . . . . . . . . . . . . . . . . . . . . . . . . 141

$\begin{array}{ll}\text { Referências Bibliográficas } & 143\end{array}$ 

2.1 Visão geral de um sistema CBIR. . . . . . . . . . . . . . . . . . . . . 9

2.2 Configurações de um conjunto de pontos eqüidistantes para as distâncias $L_{1}$, $L_{2}$ e $L_{\text {infinity }}$ em um espaço bi-dimensional. . . . . . . . . . . . . . . . . . .

2.3 Exemplo de uma consulta por raio de abrangência onde o conjunto resposta contém 7 elementos sendo que $O$ não faz parte do resultado. . . . . . . . . . 17

2.4 Exemplo de uma consulta do tipo $\mathrm{kNN}$ onde o conjunto resposta contém 5

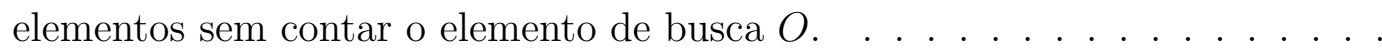

2.5 Conjuntos referentes às medidas de precisão e revocação para uma determinada operação de busca. . . . . . . . . . . . . . . . . . . . . . .

2.6 Exemplo de um gráfico de medidas Precisão versus Revocação para uma operação de busca $[1] \ldots \ldots$. . . . . . . . . . . . . . . . . . . .

3.1 Exemplo de matrizes de co-ocorrência. (a) imagem em tons de cinza; (b) matriz de co-ocorrência para ângulo 0 e $d=1$; (c) matriz de co-ocorrência para ângulo $135^{\circ}$ e $d=1$.

3.2 Extração de características a partir da transformada de Fourier (espaço das freqüências.) (a) energia ao longo de anéis; (b) energia ao longo de cunhas [2]. 31

3.3 As primeiras sete wavelets de Haar. . . . . . . . . . . . . . . . . . . . . . . . 32

3.4 Decomposição progressiva das linhas e colunas da imagem [3]. . . . . . . . . . 34

3.5 Exemplo de decomposição wavelet. (a) imagem original; (b) imagem decomposta em duas etapas a partir das wavelets de Haar; (c) configuração das regiões após a decomposição. . . . . . . . . . . . . . . . . . . . .

4.1 Seleção do limiar (threshold) ótimo para um histograma bimodal. . . . . . . . 39

4.2 Primeira e segunda derivada de uma amostra unidimensional de uma imagem. 40

4.3 Operadores de Sobel (a) máscara usada para computar $G_{y}$; (b) máscara usada para computar $G_{x} \ldots \ldots \ldots \ldots \ldots \ldots$

4.4 Exemplo da utilização dos operadores de Sobel. (a) imagem original; (b) imagem gradiente $\sqrt{G_{x}^{2}+G_{y}^{2}} \ldots \ldots \ldots$ 
4.5 Exemplo de segmentação utilizando snakes (a) imagem de ressonância magnética do ventrículo esquerdo de um coração humano; (b) mapa de fluxo do vetor gradiente (Gradient Vector Flow); (c) etapas de ajuste da snake até a posição de equilíbrio $[4] \ldots \ldots \ldots \ldots \ldots \ldots$

4.6 Ilustração dos divisores de água (watersheds) e represas (catchment basins). Visões sob perspectiva e "visão aérea" [5].

4.7 Ilustração do algoritmo de alagamento utilizando uma vizinhança 4-conectada (a) imagem original; (b-e) etapas da rotulação. . . . . . . . . . . . . . . . . .

4.8 Exemplo de super-segmentação. (a) imagem original (gel de electroforese); (b) imagem super-segmentada [5] . . . . . . . . . . . . . . . . .

4.9 Transformada de watershed a partir de marcadores. (a) marcadores da imagem da Figura 4.8a; (b) resultado da transformada de watershed [5]. . . . . . . .

4.10 Exemplo de transformada de distância para uma imagem binarizada. (a)imagem original; (b) transformada de distância. . . . . . . . . . . . . . . . . .

4.11 Exemplo de separação de partículas circulares parcialmente sobrepostas. (a) imagem binária das partículas; (b) negativo do mapa de distância euclidiano; (c) marcadores sobrepostos no mapa de distâncias (neste caso os marcadores são pontos de máximo local); (d) resultado da transformada de watershed.

4.12 Exemplos de texturas extraídas do álbum de Brodatz [6] (a)-(d) texturas de comportamento determinístico; (e)-(h) texturas de comportamento aleatório.

4.13 Estruturas de vizinhanças para os campos aleatórios de Markov, considerando o elemento central x. . . . . . . . . . . . . . . . . . . . . . .

4.14 Conjunto de cliques. (a) vizinhança de primeira ordem; (b) cliques correspondentes. . . . . . . . . . . . . . . . . . . 51

4.15 Diagrama simplificado do processo de segmentação EM/MPM. . . . . . . . . 57

5.1 Exemplo de segmentação realizada pelo método EM/MPM. (a) imagem original; (b) imagem segmentada com $L=5$; (c) região de classe 1 (fluido cérebro-espinhal); (d) região de classe 2 (massa cinzenta); (e) região de classe 3 (massa branca); (f) região de classe 4 (dura, medula óssea, gordura). . . . .

5.2 Cálculo da dimensão fractal das regiões da Figura 5.1 . . . . . . . . . . . . .

5.3 Exemplo de imagem da espinha segmentada pelo método EM/MPM. (a) imagem original; (b) imagem segmentada com $L=5$; (c) região de classe 1 ; (d) região de classe 2; (e) região de classe 3; (f) região de classe 4; (g) gráficos de correlação das regiões e respectivas dimensões fractais.

5.4 Vetor de características das imagens $-5(L-1)$ valores reais. . . . . . . . .

5.5 Exemplo de consulta aos 20 vizinhos mais próximos realizada pelo sistema desenvolvido sobre uma base de 704 imagens de variadas categorias. . . . . . 
5.6 Curvas médias de precisão vs. revocação ilustrando o comportamento na recuperação de imagens de diversos vetores de características, incluindo nossa abordagem, os momentos de Zernike e histogramas de brilho da imagem. . .

5.7 Comparação do vetor de características proposto para diferentes valores do parâmetro $L$ - o número de classes para segmentação da imagem. . . . . . . .

5.8 Curvas médias de precisão e revocação para cada categoria de imagens da base experimental descrita na Tabela 5.1. . . . . . . . . . . . . . . . . . . . . 74

5.9 Exemplo de consulta kNN $(k=25)$. Número total de imagens relevantes: 37.74

5.10 Exemplo de consulta kNN $(k=25)$. Número total de imagens relevantes: 58.75

6.1 Diagrama de módulos do sistema FEMine. . . . . . . . . . . . . . . . . . . 80

6.2 Vizinhança circular de 12 vizinhos definida para o filtro de variância local. 83

6.3 Identificação de embriões da Drosophila Melanogaster em imagem de ISH. (a) imagem original com o embrião principal ao centro e um embrião sobressalente interceptando parte de sua borda; (b) aplicação do filtro de variância local com uma vizinhança circular de 12 vizinhos (Fig. 6.2); (c) limiarização (threshold) do resultado do filtro de variância; (d) resultado da aplicação do operador morfológico binário de preenchimento de buracos (fill holes) e abertura binária. 83

6.4 Algoritmo de identificação dos embriões na imagem original. . . . . . . . . . 84

6.5 Exemplos da aplicação da transformada de watershed nas imagens binarizadas dos embriões. (a,d) imagens binárias dos embriões; (b,e) mapas de distâncias sobreposto com as respectivas regiões de máximo local; (c,f) resultados mal sucedidos na tentativa de separação dos embriões (as regiões dos embriões foram "quebradas"). . . . . . . . . . . . . . . . . . .

6.6 Processo iterativo de determinação de marcadores para aplicação da transformada de watershed. (a) imagem original (threshold=254); (b) threshold $=244$; (c) threshold=234; (d) threshold=224; (e) threshold=215 (duas regiões isoladas que serão os marcadores); (f) marcadores sobrepostas no mapa de distâncias euclidianas. . . . . . . . . . . . . . . . . . 8

6.7 Algoritmo de seleção de marcadores para a transformada de watershed . . . . 87

6.8 Passos do algoritmo de alagamento iniciado a partir dos marcadores da Figura

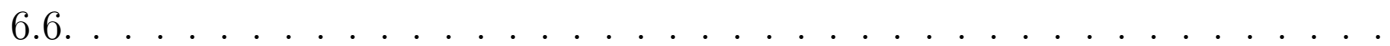

6.9 Exemplos de marcadores. (a) imagem com região não convexa, sem evidência de partículas conectadas; (b) marcadores (diferença do limiar final igual a 5); (c) imagem binária de embriões, com evidência de partículas a serem separadas; (d) marcadores (diferença do limiar final igual a 94). . . . . . . . 88

6.10 Algoritmo de particionamento recursivo de partículas binárias conectadas . .

6.11 Exemplo da aplicação do algoritmo da particionamento recursivo para uma imagem binária com dois embriões. . . . . . . . . . . . . . . . . . . . 89

6.12 Particionamento recursivo de uma imagem binária com três embriões. . . . 89 
6.13 Registro da máscara do embrião principal utilizando uma imagem canônica. (a) imagem alvo contendo uma elipse; (b) imagem fonte (máscara de embrião a ser transformada); (c) diferença entre as imagens alvo e fonte antes do registro; (d) imagem fonte ao final do processo de registro; (e) diferença entre as imagens alvo e fonte depois do registro. . . . . . . . . . . . . . .

6.14 Preparação das imagens para extração de características. (a,f,k) imagens originais; (b,g,l) embriões identificados utilizando o método descrito na seção 6.4.1); (c,h,m) regiões dos embriões separadas utilizando o método proposto de particionamento recursivo (seção 6.4.2); (d,i,n) imagens registradas utilizando o método descrito na seção 6.4.3; (e,j,o) imagens prontas para a extração de características, com a borda dos embriões levemente recortada.

6.15 Eigen-Embryos mais significativos de um conjunto de 2000 imagens de embriões. A imagem de número 1 ilustra o autovetor associado ao maior autovalor. As demais imagens estão dispostas em ordem decrescente de seus respectivos autovalores. . . . . . . . . . . . . . . . . . . . . . . . . . 95

6.16 Algoritmo para o cálculo dos Eigen-Embryos. . . . . . . . . . . . . . . 96

6.17 Exemplos de imagens da FlyBase. . . . . . . . . . . . . . . . . . . 97

6.18 Exemplos de imagens "ruins", automaticamente descartadas pelo sistema FEMine. (a) imagem com embrião incompleto; (b) embrião muito difuso com o plano de fundo; (c) embrião com formato não elíptico; (d) imagem onde não se pode dizer qual o é embrião principal. . . . . . . . . . . . . . . . . . 98

6.19 Exemplo de consulta por similaridade com o sistema FEMine. . . . . . . . . 100

6.20 Exemplo de consulta por similaridade com o sistema FEMine. . . . . . . . . 101

6.21 Exemplos de grupos de consulta. . . . . . . . . . . . . . . . . 101

6.22 Média aritmética das curvas de precisão e revocação de 20 operações de consultas kNN realizadas pelo sistema FEMine. . . . . . . . . . . . . . . . . . 102

7.1 Exemplo de particionamento utilizando a técnica proposta (Eq. 7.2). l o nível de particionamento. . . . . . . . . . . . . . . . 111

7.2 Uma comparação entre a técnica de particionamento de histogramas do método HEAD e a técnica de Otsu. . . . . . . . . . . . . . . . . . . 111

7.3 Determinação do limiar $l$ para remoção do plano de fundo da imagem. . . . . 112

7.4 Remoção do plano de fundo da imagem. (a) Corte mediano da imagem original; (b) Classificação inicial obtida com o limiar $l$ (voxels com nível de cinza maior que $l$ são brancos); (c) Máscara final da cabeça. . . . . . . . . . . . . .

7.5 Exemplos de histogramas de nível de cinza de imagens de cabeça (com plano de fundo removido). (a) Histograma de uma imagem real de $256 \times 256 \times 160$ voxels; (b) Histograma de uma imagem sintética de $181 \times 217 \times 182$ voxels do projeto BrainWeb (MNI) . . . . . . . . . . . . . . . . . 114 
7.6 Determinação de $l_{1}$ e $l_{2}$, os limites da saliência MB/MC, em histograma de uma imagem MRI real de $256 \times 256 \times 160$ voxels. . . . . . . . . . . 115

7.7 Computação de $l_{1}$ e $l_{2}$ no histograma de uma imagem sintética do projeto Brain Web $(\mathrm{MNI})$, de $181 \times 217 \times 182$ voxels. . . . . . . . . . . . . . 116

7.8 Classificações iniciais obtidas com os limiares $l_{1}$ e $l_{2}$. (a) Corte mediano original da imagem utilizada no exemplo da Figura 7.6; (b) Classificação binária correspondente; (c) Corte mediano original da imagem utilizada no exemplo da Figura 7.7, (d) Classificação binária correspondente. . . . . . . . . . . . . 117

7.9 Seqüência de operadores morfológicos binários aplicados para se obter a máscara final do cérebro. (a) corte mediano da imagem original; (b) classificação binária inicial obtida com base nos limiares $l_{1}$ e $l_{2}$; (c) erosão binária; (d) seleção do maior componente conexo; (e) dilatação binária; (f) fechamento de buracos (máscara final do cérebro) . . . . . . . . . . . . . . . . . 118

7.10 Resumo do método HEAD. . . . . . . . . . . . . . . . . . . . . . . 119

7.11 Uma comparação visual do método HEAD (coluna da esquerda) e o algoritmo BSE (coluna da direita). (a,b) Mapeamento 3D de erros nas máscaras resultantes (áreas em laranja indicam as falhas); (c,d) Corte da imagem original combinada com as máscaras resultantes; (e,f) Corte mediano da imagem original aplicado às máscaras resultantes. . . . . . . . . . . . . . . . . .

7.12 Comparação visual do método HEAD (coluna da esquerda) e do algoritmo BSE (coluna da direita), para uma imagem ruidosa do conjunto experimental. (a,b) Visão oblíqua das máscaras; (c,d) Mapeamento 3D dos erros mais salientes (desenhados na cor laranja) dada a segmentação manual de um especialista; (e,f) Corte de altura aleatória da imagem original aplicada às mascaras de saída. . . . . . . . . . . . . . . . . . . . . . . . . . 121

7.13 Exemplos de máscaras geradas pelos métodos HEAD e BSE (imagens reais) .

7.14 Mosaico ilustrando a influência da diferentes taxas de ruído gaussiano em imagens sintéticas do Brain Web: (a) $3 \%$ (b) $5 \%$ (c) $7 \%$ (d) $9 \%$. . . . . . .

7.15 Máscaras do cérebro geradas pelo BSE (linha superior) e pelo método HEAD (linha inferior) na segmentação de imagens sintéticas com diferentes intensidades de ruído. . . . . . . . . . . . . . . . . . . . . . 126

A.1 Exemplo de fractal - o Triângulo de Sierpinsky . . . . . . . . . . . . . . 135

B.1 Imagens provenientes da análise de Hibridização in situ (ISH) de embriões da Drosophila Melanogaster, a mosca da fruta. . . . . . . . . . . . . . . . . . . . 142 



\section{Lista de Tabelas}

3.1 Relação entre os tipos de função e respectivas transformadas de Fourier . . . 25

3.2 Propriedades da transformada de Fourier . . . . . . . . . . . . . . . . 26

5.1 Configuração da base de imagens preparada para experimentação. . . . . . . . 70

5.2 Exemplos de subgrupos de imagens similares . . . . . . . . . . . . . . . 71

5.3 Área sob as curvas de precisão vs. revocação do gráfico da Figura 5.6. . . . . 72

6.1 FlyBase - Base de imagens ISH da mosca Drosophila . . . . . . . . . . . . 96

6.2 Relação de imagens processadas com sucesso pelo módulo de processamento de imagens FEMine . . . . . . . . . . . . . . . . . . . . . 97

6.3 Número de Eigen-Embryos obtidos para cada amostra de 2.000 imagens de cada estágio de desenvolvimento. . . . . . . . . . . . . . . . 98

7.1 Precisão na segmentação de imagens clínicas reais . . . . . . . . . . . . . . . 122

7.2 Eficiência na segmentação de imagens sintéticas - BSE . . . . . . . . . . . 125

7.3 Eficiência na segmentação de imagens sintéticas - método HEAD . . . . . . . 125 



\section{Lista de abreviaturas}

$\begin{array}{ll}\text { ACM } & \text { Association for Computing Machinery } \\ \text { BDGP } & \text { Berkeley Drosophila Genome Project } \\ \text { BSE } & \text { Brain Surface Extractor } \\ \text { CBIR } & \text { Content-Based Image Retrieval } \\ \text { CBMS } & \text { Computer-Based Medical Systems } \\ \text { EM } & \text { Expectation and Maximization } \\ \text { FEMine } & \text { Fly Embryo Miner } \\ \text { GMM } & \text { Gaussian Mixture Model } \\ \text { HC } & \text { Hospital das Clínicas } \\ \text { HEAD } & \text { Human Encephalon Automatic Delimiter } \\ \text { HIS } & \text { Hospital Information System } \\ \text { INU } & \text { Intensity Non-Uniformity } \\ \text { ISH } & \text { In Situ Hybridization } \\ \text { KDD } & \text { Knowledge Discovery and Data Mining } \\ \text { kNN } & \text { k Nearest Neighbors } \\ \text { MNI } & \text { Montreal Neurology Institute } \\ \text { MPM } & \text { Maximization of the Posterior Marginals } \\ \text { MRF } & \text { Markov Random Fields } \\ \text { MRI } & \text { Magnetic Resonance Imaging } \\ \text { PACS } & \text { Picture Archiving and Communication System } \\ \text { PET } & \text { Positron Emission Tomography } \\ \text { PR } & \text { Precisão e Revocação } \\ \text { RBIR } & \text { Region-Based Image Retrieval } \\ \text { RM } & \text { Ressonância Magnética } \\ \text { SGBD } & \text { Sistema de Gerenciamento de Base de Dados }\end{array}$





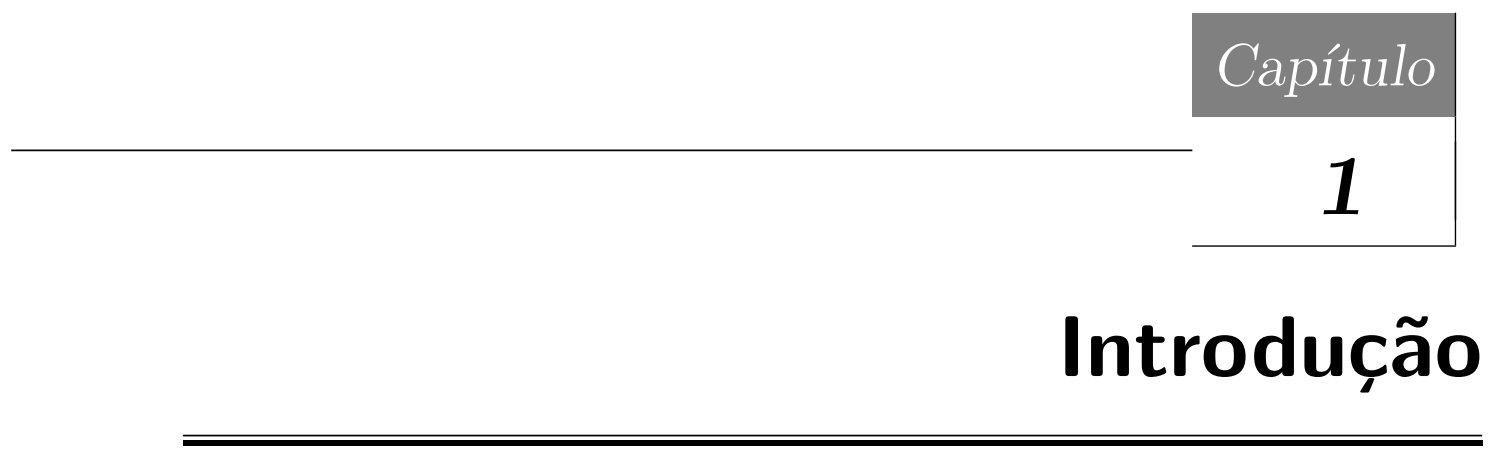

As imagens digitais têm desempenhado um papel importantíssimo em diversas áreas da ciência, especialmente na medicina. Elas introduzem versatilidade no processo de aquisição e troca de exames médicos, e possibilitam o armazenamento de imensas quantidades de exames que formam verdadeiras bases de conhecimento, essenciais para o estudo e aperfeiçoamento da ciência médica. Os PACS, do inglês Picture Archiving and Communication Systems, são os sistemas que realizam esse armazenamento possibilitam a distribuição das imagens médicas em terminais locais ou remotos de um hospital ou centro médico. Introduzidos no início da década de 80 [7], os PACS expandiram as possibilidades do sistema convencional de armazenamento de exames em filme, viabilizando, principalmente, a educação e o diagnóstico à distância, muito importantes para o auxílio às regiões mais remotas.

Nas últimas décadas, os equipamentos de coleta de exames no formato digital se tornaram extremamente populares e passaram a interagir diretamente com os PACS. Praticamente todas as modalidades de exame por imagem foram adaptadas a este esquema, incluindo a ultrasonografia, ressonância magnética, tomografia computadorizada, radiografia, mamografia, endoscopia, tomografia por emissão de positrons (PET), entre outras. Além disso, muitos centros médicos ainda realizam a digitalização dos filmes convencionais para integrar um único sistema de armazenamento digital. As informações e histórico hospitalar dos pacientes são gerenciados pelos Sistemas de Informação Hospitalares (HIS) que também possuem um canal de comunicação com os PACS.

A Genética é também uma ciência cuja introdução das imagens digitais vem permitindo seu avanço em diversos aspectos. A corrida pelo mapeamento dos genomas, incluindo o genoma humano, iniciou-se na década de 80 e durou quase 20 anos. Esta fase gerou um imenso volume de informação em diversos formatos, incluindo seqüências genéticas e imagens de mapeamento espacial e temporal dos incontáveis genes. Tais imagens são denominadas "imagens de expressão genética" e revelam, principalmente, quais genes estão por trás do desenvolvimento dos diversos órgãos e tecidos de um determinado organismo. 


\subsection{Motivação}

O crescente volume de imagens digitais que são adquiridas nos centros médicos e em muitas atividades de pesquisa deu origem a um desafio que vai além do problema do armazenamento. A organização dos dados e a possibilidade de acessá-los em um determinado momento são elementos fundamentais para os Sistemas de Gerenciamento de Bases de Dados, ou SGBD. Para informações textuais, a criação de índices é uma tarefa relativamente simples e proporciona uma forma eficiente de recuperação dos dados. As imagens digitais, entretanto, constituem dados complexos cujo conteúdo pode ser interpretado de diversas maneiras. Neste contexto, diversas questões podem ser levantadas, como por exemplo: Como interpretar ou representar o conteúdo de uma imagem? Quais medidas que podem caracterizar adequadamente este conteúdo? Como recuperar imagens de um grande repositório utilizando o conteúdo extraído? Como estabelecer um critério de similaridade entre estas imagens?

Estas e outras questões constituem o ramo de pesquisa computacional comumente conhecido por CBIR (Content Based Image Retrieval), ou Recuperação de Imagens por Conteúdo, que é o tema principal deste trabalho de pesquisa. A importância deste tema está no fato de que estabelecer um relacionamento entre as imagens a partir de seu conteúdo é a chave para se extrair informação relevante do repositório. Um médico diante de um exame, por exemplo, pode querer consultar outros exames parecidos com a intenção de reforçar o seu parecer clínico sobre um caso em análise. Em um hospital-escola, os alunos de medicina podem recuperar imagens similares de diversos pacientes visando compreender o padrão de uma determinada doença. Em um banco de imagens de expressão genética é possível descobrir quais genes de um organismo são correlacionados.

O principal desafio em CBIR consiste no desenvolvimento de técnicas computacionais eficientes para mapeamento automático do conteúdo da imagem em um conjunto/vetor de características compacto que possibilite estabelecer a similaridade entre as imagens. Diversas aplicações podem ser derivadas com base em determinado conjunto de características, incluindo a classificação e o agrupamento das imagens, com o objetivo de se revelar padrões relevantes dentro do repositório. Uma aplicação que merece destaque, e é de grande interesse no meio clínico, é a que envolve as operações de consultas por imagens similares [8, 9]. Em tais operações, um usuário que acessa o banco de imagens a partir de um terminal de consultas apresenta uma imagem de referência para que sejam localizadas as imagens mais semelhantes. Esse é o tipo de busca que o médico usualmente faz ao comparar mentalmente o caso que possui nas mãos com o conhecimento armazenado em seu cérebro durante anos de experiência. Por exemplo, dada uma imagem de Raio-X de tórax de um paciente deseja-se encontrar as $N$ imagens do repositório que são mais semelhantes a ela, segundo um critério de semelhança.

As técnicas que possibilitam a recuperação de imagens similares têm sido foco de estudo de um crescente número de pesquisas e demandam a integração de conhecimento das áreas de processamento de imagens, aprendizado de máquina, bases de dados, entre outras. Os 
PACS comerciais permitem recuperar as imagens de exames médicos apenas a partir de chaves textuais e numéricas, isto é, processam consultas do tipo "retorne os exames de Raio$\mathrm{X}$ de tórax do paciente José da Silva". Com o aperfeiçoamento de técnicas CBIR dedicadas à área médica os PACS poderão estender suas funcionalidades de recuperação de imagens passando a ser não apenas um sistema de armazenamento e transmissão de imagens, mas uma ferramenta importante para os médicos no apoio ao diagnóstico e também como instrumento de ensino para radiologia $[10,11]$.

\subsection{Objetivos}

O objetivo principal deste trabalho é o estudo e desenvolvimento de técnicas de extração de características e segmentação de imagens nos domínios de contexto clínico/médico e da biologia genética, buscando responder questões relacionadas com a desafiadora área de Recuperação de Imagens por Conteúdo. Mais especificamente, neste trabalho, a segmentação da imagem é considerada uma etapa fundamental na interpretação e representação da imagem, pois ela permite a extração de características de regiões de interesse da imagem, ao contrário dos métodos que buscam uma representação global e direta da mesma, que é inadequada para a maior parte dos domínios.

\subsection{Principais contribuições}

O trabalho desenvolvido e apresentado nesta tese traz os seguintes resultados como principais contribuições para a área de CBIR:

- Uma nova técnica de extração de características de imagens clínicas de ressonância magnética para realização de consultas por similaridade em sistemas CBIR. O ponto principal desta abordagem é a proposta de um vetor de características compacto, de tamanho fixo e altamente eficaz em consultas por similaridade de imagens. Este vetor de características agrupa medidas relevantes de regiões da imagem que correspondem aos diversos tecidos da parte do corpo examinada. Isto é possível devido à utilização de um método adequado de segmentação de imagens, que combina a técnica de agrupamento EM Expectation Maximization com o modelo espacial de Markov. Neste trabalho o método foi melhorado para fornecer uma convergência mais rápida do processo de segmentação. Em relação às características propostas, destaca-se a utilização da Dimensão Fractal, uma medida que possibilita com um único valor numérico, diferenciar regiões de formato linear, planares e puntiformes. O novo extrator de características proposto é apresentado em detalhes no Capítulo 5 incluindo os respectivos experimentos e resultados obtidos. Um artigo publicado e apresentado no CBMS'2005 [12] sintetiza a técnica proposta. 
- Um sistema para segmentação e extração de características de imagens de padrões de expressão genética contidos em imagens embrionárias da Drosophila Melanogaster, popularmente conhecida como "mosca da fruta". O sistema, denominado FEMine (Fly Embryo Miner), apresenta três módulos principais: um módulo de processamento automático das imagens que é responsável pela identificação, separação e registros dos embriões; um módulo de extração de características para representação do conteúdo visual dos padrões de expressão genética e um módulo de interface para realização de consultas de imagens por similaridade. Além de representar uma solução completa e inovadora para o um problema de grande relevância na área da biologia genética, o sistema FEMine inclui técnicas inovadoras por si só, como é o caso de uma nova técnica de separação de partículas sobrepostas em imagens binárias baseada nos conceitos da técnica de watershed e na seleção automática de marcadores das partículas. Para extração de características das imagens o sistema FEMine introduz os Eigen-Embryos, um novo espaço de características para os padrões de expressão que permite a realização eficiente de consultas por similaridade. O sistema FEMine é apresentado em detalhes no Capítulo 6, incluindo os respectivos experimentos e resultados obtidos. Um artigo publicado e apresentado no ACM KDD'2006 [13] sintetiza o sistema proposto.

- Um novo método para segmentação de imagens 3D de exames de cabeça. O método, denominado HEAD - the Human Encephalon Automatic Delimiter, é uma solução eficiente para o problema de delimitação automática do cérebro em exames clínicos. Ele combina técnicas da área de morfologia matemática e, especialmente, introduz uma nova abordagem de particionamento automático de histogramas que se sobressai entre conceituados métodos conhecidos na literatura, incluindo os métodos de Otsu e Rosenfeld. Esta técnica é aplicada diretamente no problema de segmentação para encontrar os limites de níveis de cinza dos tecidos do cérebro. O método HEAD foi desenvolvido visando a extração de características de mais alto nível das imagens médicas, incluindo a volumetria de tecidos do cérebro, medidas de simetria, e determinação de propriedades das estruturas anatômicas mais importantes no contexto médico. Em CBIR, esta é uma aplicação de grande importância pois está relacionada diretamente com um dos maiores problemas da área: o conhecido gap semântico. Um artigo [14] aceito recentemente para publicação no CBMS'2007, sintetiza o método HEAD, enquanto outro artigo submetido [15] apresenta o método com mais detalhes. Neste documento, o método HEAD, incluindo os respectivos experimentos realizados e resultados obtidos, é apresentado no Capítulo 7.

\subsection{Organização da tese}

Em resumo, este documento é organizado da seguinte maneira: 
- Capítulo 2 - apresenta os principais conceitos relacionados à área de recuperação de imagens por conteúdo (CBIR), envolvendo, principalmente aspectos relacionados com a extração de características da imagem, medidas de similaridade em espaços métricos e avaliação de desempenho.

- Capítulo 3 - apresenta em detalhes alguns dos principais métodos de extração de características de imagens baseados em textura e forma, que estão mais relacionados ao trabalho desenvolvido e apresentado nesta tese, incluindo os descritores de Fourier, os momentos de Zernike, e as medidas das transformadas bi-dimensionais de Wavelets e Fourier.

- Capítulo 4 - apresenta os principais conceitos relacionados à segmentação de imagens e descreve alguns dos principais técnicas da literatura, incluindo os métodos cujos conceitos são utilizados no desenvolvimento deste trabalho, especialmente o método EM/MPM e a segmentação pela transformada de watershed.

- Capítulo 5 - apresenta a proposta e desenvolvimento do novo extrator de características de imagens médicas de ressonância magnética que combina o método de segmentação EM/MPM e a extração de medidas de regiões relacionadas aos diferentes tecidos da parte do corpo examinada.

- Capítulo 6 - apresenta a proposta e desenvolvimento do sistema FEMine, para processamento e extração de características de imagens de padrões espaciais de expressão genética.

- Capítulo 7 - apresenta a proposta e desenvolvimento do método HEAD, para segmentação de imagens 3D de exames de cabeça para extração de medidas e características do cérebro.

- Capítulo 8 - apresenta as considerações finais, um resumo das principais contribuições deste trabalho e as propostas de trabalhos de extensão.

- Apêndice A - apresenta uma breve revisão dos conceitos da teoria dos Fractais empregados na realização deste trabalho.

- Apêndice B - apresenta uma revisão dos principais conceitos de genética e dos métodos utilizados para obtenção das imagens de padrões espaciais de expressão genética. 



\section{Recuperação de Imagens Baseada em Conteúdo}

A recuperação de imagens por conteúdo (CBIR) é um ramo da Ciência da Computação que aborda tecnologias e métodos voltados para organização de grandes repositórios de imagens digitais por meio do conteúdo visual. Deste modo, qualquer técnica desde uma função de similaridade de imagem até um sistema robusto de anotação automática de imagens são focos de estudo em CBIR. Muitas outras áreas da computação estão estreitamente ligadas com CBIR proporcionando uma integração que resulta em diversos estudos científicos [16]. Os principais exemplos são a visão computacional, aprendizado de máquina, interação usuáriocomputador, bases de dados, mineração de dados, teoria da informação, estatística, entre outras.

A década de 90 é considerada a etapa inicial dos estudos envolvendo CBIR. Grande parte do trabalho desenvolvido nesta fase foi discutido e apresentado na revisão (survey) de Smeulders et al. [17], que tem sido uma importante referência para trabalhos mais atuais. Outras revisões bastante abrangentes também trazem um panorama do estado da arte em CBIR até o ano de $2000[18,19,20]$. Outros trabalhos de revisão também se concentram em tópicos de CBIR mais específicos, como a realimentação por relevância (relevance feedback) [21, 22], reconhecimento de faces [23] e CBIR para imagens médicas [24]. Outro trabalho de revisão em CBIR desenvolvido por Datta et al. [25], aborda trabalhos mais recentes em CBIR na década atual até o ano de 2006, além de discutir os principais desafios em aberto e perspectivas de pesquisa para os próximos anos.

Neste Capítulo é apresentada uma visão geral da área de recuperação de imagens por conteúdo sendo abordados os aspectos de pesquisa mais relevantes, incluindo a extração de características de baixo nível da imagem, medidas de similaridade e principais métodos de validação para sistemas CBIR. 


\subsection{Tópicos em CBIR}

A metodologia em CBIR, pela própria natureza da tarefa que se propõe a realizar, está focalizada em dois problemas intrínsecos:

1. Como descrever matematicamente uma imagem?

2. Como inferir a similaridade entre duas imagens baseado em suas representações matemáticas?

O primeiro problema surge porque a representação original de uma imagem, essencialmente uma matriz de pixels, não agrega nenhum significado que possa corresponder diretamente à nossa percepção visual. Na perspectiva de projeto dos sistemas CBIR, a representação matemática da imagem pode ser vista como a "assinatura da imagem", ou um conjunto de características que refletem diversas propriedades da imagem. Neste caso, a imagem passa a ser um ponto no espaço definido pelas suas características. O segundo problema mencionado está relacionado diretamente com a métrica de distância entre os pontos adotada para o novo espaço da imagem.

Neste contexto, os principais tópicos em CBIR podem ser listados da seguinte maneira:

- Extração de características da imagem (feature extraction) - As características mais elementares das imagens são aquelas que possibilitam o próprio sistema de visão humana identificar e, posteriormente classificar em nível semântico, os objetos de uma determinada cena. São elas: a cor, a textura e a forma, que são medidas denominadas primitivas ou de baixo nível [26]. Tais características podem ser extraídas automaticamente ou semi-automaticamente através de um processo computacional. Um ou mais tipos de características podem ser agrupados para formar um conjunto que descreva adequadamente as imagens de um repositório específico;

- Definição de funções de distância - Uma vez extraídas as características da imagem, a operação que possibilita inferir o nível de semelhança entre duas imagens do repositório é baseada em uma função de distância. É importante definir uma métrica adequada ao conjunto de características proposto, para que a inferência de similaridade entre as imagens possa corresponder o mais próximo possível à similaridade que seria definida por um usuário do sistema;

- Indexação das características - Para facilitar e agilizar as operações de consultas e pesquisas é necessário criar índices de imagens e organizá-los em estruturas de dados apropriadas. Como estruturas mais utilizadas para se armazenar tais índices destacamse as árvores $\mathrm{k}-\mathrm{d}(k$ - $d$ trees) [27], as Slim-trees [28, 29], a família de árvores $\mathrm{R}(R$ trees) [30], árvores $\mathrm{R}^{*}[31]$ e as quadtrees [32]. 
- Interface com o usuário - Basicamente, a interação do sistema com o usuário é feita por meio de um interpretador de consultas e um navegador que possibilite visualizar os resultados. Funcionalidades comuns disponíveis na interface de um sistema CBIR incluem: a consulta por imagens similares dada uma imagem de referência, consultas a partir da seleção direta de características, realimentação de relevância e refinamento de consultas.

Um sistema CBIR padrão é constituído por módulos que integram técnicas desses quatro tópicos descritos. A Figura 2.1 apresenta uma visão geral de como esses módulos devem interagir para possibilitar, por exemplo, a consultas de imagens similares dada uma "imagem de referência".

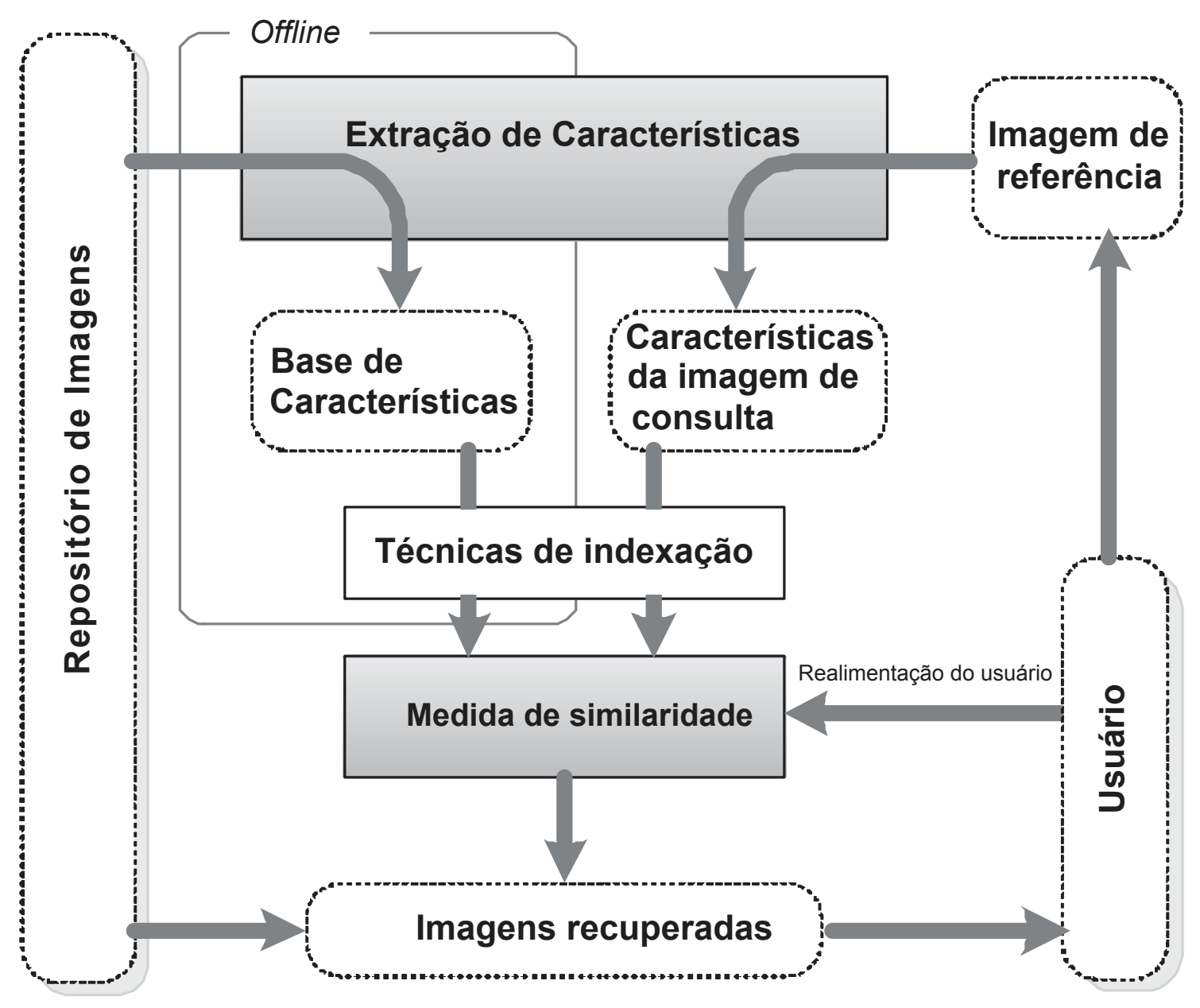

Figura 2.1: Visão geral de um sistema CBIR.

Desde o início das pesquisas em CBIR, diversos sistemas comerciais e acadêmicos foram propostos e desenvolvidos. Um dos pioneiros e mais conhecidos nesta área é o sistema QBIC $^{1}[33,34]$ ( Query by Content) da IBM. Outros sistemas comerciais que alcançaram popularidade são o Virage ${ }^{2}[35,36]$, que é utilizado pela rede de TV americana CNN, e o sistema AMORE [37] da NEC. Entre os principais sistemas desenvolvidos no meio acadêmico estão o

\footnotetext{
${ }^{1}$ http://wwwqbic.almaden.ibm.com/

${ }^{2}$ http://www.virage.com/
} 
Candid [38], Photobook [39] e o Netra [40], que utilizam características simples de cor e textura para descrever as imagens. O sistema Blobworld [41, 42] é outro sistema acadêmico que introduziu a utilização de informação de mais alto nível da imagem, incluindo características extraídas com auxílio de segmentação da imagem. Um sistema CBIR que também merece destaque é o GIFT ${ }^{3}$ ( GNU Image Finding Tool), por ser um sistema inteiramente de domínio público. Entre os sistemas desenvolvidos mais recentemente estão o CLUE (CLUster-based rEtrieval) [43] e o SIMPLIcity (Semantics-sensitive Integrated Region Matching for Picture LIbraries) $[44,45]$.

\subsection{Extração de características}

Em CBIR, uma "característica" é uma medida numérica que captura determinada propriedade visual da imagem, podendo ser de escopo global (para toda imagem) ou local (para pequenas regiões da imagem). As características mais comuns empregadas em sistemas CBIR são, de fato, as características definidas como primitivas [26], ou seja, aquelas que descrevem cor, textura e forma. Estas características serão discutidas brevemente nas seções a seguir. A vantagem da extração de características de escopo global está ligada à baixa complexidade tanto na composição do vetor de características quanto na computação do valor de similaridade. Entretanto, as características globais geralmente fornecem uma representação muito rígida da imagem, não considerando a diversidade de objetos que ela possa conter. As características de escopo local, por outro lado, providenciam uma descrição mais flexível e realista da imagem, embora possam resultar em um vetor de características maior e mais complexo.

\section{Cor}

$\mathrm{Na}$ literatura são encontrados diversos métodos de recuperação de imagens baseados em característica de cor, ou brilho, sendo que quase todos eles compartilham a mesma idéia de utilizar os histogramas na representação da imagem. Esta representação varia de acordo com o espaço de cores que define o valor dos pixels da imagem. O RGB (Red, Green and Blue), por exemplo, é o espaço de cores mais comum para imagens. Entretanto, outros espaços como o HSV (Hue, Saturation and Value) [46], o CIE Lab [34] e o Luv [47] são mais adequados à percepção humana de cor, e por isso, são mais utilizados na representação da imagem por histograma.

Para imagens em escala de cinza a representação da imagem é definida como o histograma de brilho, ou histograma de níveis de cinza da imagem. Neste caso o tamanho do vetor de características é definido como o nível de cinza máximo de acordo com a quantização da imagem. Uma evolução interessante do uso de histogramas de brilho são os histogramas métricos $[48,49]$, que são bem mais compactos e podem representar as imagens independen-

\footnotetext{
${ }^{3} \mathrm{http}: / /$ www.gnu.org/software/gift
} 
temente dos níveis globais de brilho e contraste.

\section{Textura}

Embora bem conhecida e implicitamente intuitiva, a definição da característica de textura não possui uma versão formal bem estabelecida. Muitos autores a descrevem com suas próprias palavras, como os exemplos a seguir:

- "Textura se refere à repetição de elementos básicos da imagem chamados textels. A distribuição dos textels pode ser periódica ou aleatória. Texturas naturais geralmente possuem um comportamento aleatório, sendo que as artificiais possuem um comportamento periódico e determinístico." [50].

- "Padrões que caracterizam objetos em uma cena são chamados texturas." [51].

As medidas de textura capturam essencialmente a granularidade e padrões repetitivos na distribuição dos pixels. Por exemplo, vidro, tijolos, grama, madeira, papel, diferem entre si tanto pela suavidade da textura quanto pela repetição de padrões.

Algumas das mais conhecidas técnicas de extração de características de textura são as wavelets [52] e os filtros de Gabor [46], sendo que os filtros de Gabor são considerados mais adequados para corresponder às propriedades de percepção do sistema de visão humano [53]. Estas medidas de textura procuram capturar as variações de intensidade dos pixels em diversas direções e em diversas escalas, sendo mais úteis para regiões ou imagens com texturas homogêneas.

Outras medidas mais tradicionais são baseadas nas "matrizes de co-ocorrência" [54], nas "matrizes Run-Lengths" [55] e na transformada bi-dimensional de Fourier [56]. A partir dessas técnicas é possível computar medidas de periodicidade, granularidade, direcionalidade e regularidade das regiões texturizadas da imagem. Um dos primeiros trabalhos a aplicar informação de textura em CBIR foi desenvolvido por Manjunath e Ma [57], em 1996.

\section{Forma}

O formato, ou forma, de um determinado objeto da imagem pode ser considerado o atributo de maior relevância para a abordagem de recuperação de imagens por conteúdo baseada em características primitivas. As diversas evidências de que objetos reais são identificados pelo sistema de visão humana primordialmente pela forma podem ser a justificativa para isto $[58,59,60]$.

Para extração de características de forma de uma imagem é essencialmente necessário que esta imagem seja previamente segmentada, o que significa encontrar e delimitar os elementos (objetos) da imagem para os quais se desejam computar as propriedades de forma. Após ter a imagem segmentada, não só características de forma podem ser computadas das regiões que correspondem aos objetos da imagem, mas também medidas de cor e textura que podem ser combinadas para caracterizar melhor as regiões. A esta abordagem, que combina 
segmentação de imagens com extração de características é dado o nome RBIR, do termo em inglês (Region-Based Image Retrieval) [21, 61, 62]. Esta categoria de métodos será discutida logo mais adiante.

Uma propriedade desejável do conjunto de características de forma é que ele se mostre invariante para objetos de mesma natureza que estejam em posição, rotação e escala diferentes (invariância às transformações geométricas), e, além disso, possa descrever adequadamente a forma do objeto mesmo quando a imagem contém ruídos. Quanto à classificação dos métodos de extração de características de forma, a mais comum e geral delas leva em consideração se o método analisa apenas os contornos dos objetos ou analisa o objeto como um todo, levando em consideração também os pontos de seu interior. Sendo assim, desta classificação são derivadas duas classes de métodos: os métodos baseados em contornos e os baseados em região.

Os descritores de Fourier [63] são um exemplo tradicional de caracterização de forma baseada em contornos. Entre os métodos baseados em região estão os populares e eficientes momentos de Zernike [64, 65]. Mesmo sendo de uma complexidade computacional relativamente alta, estes dois métodos adquiriram popularidade e estão entre os mais citados e utilizados em sistemas CBIR devido às suas propriedades inerentes de invariância às transformações geométricas. Outras técnicas mais recentes de caracterização de forma incluem a transformada imagem-Floresta [66, 67] e os contextos de forma (shape contexts) [68].

O Capítulo 3 apresenta uma revisão mais detalhada de algumas das principais técnicas de extração de características de imagens aqui citadas, incluindo os descritores de Fourier, os momentos de Zernike, a análise das transformadas bi-dimensionais de Fourier e de Wavelets, e as matrizes de co-ocorrências.

\section{Gap semântico}

Um problema bem conhecido em CBIR, e citado por muitos autores, diz respeito à incapacidade das características de baixo nível em descrever o conhecimento semântico embutido nas imagens. A representação matemática da imagem na qual os sistemas CBIR são baseados está bem mais relacionada à estrutura matricial da imagem do que à representação perceptual que uma pessoa faz daquela imagem, incluindo o significado dos objetos e a complexa rede de relacionamentos que pode existir entre eles. A esta discrepância de representações da imagem é dado o nome de gap semântico, que, embora seja abordado em diversos trabalhos ainda continua sendo um problema em aberto e o maior desafio em CBIR. No trabalho de revisão desenvolvido por Liu et al. [21], por exemplo, são propostas cinco abordagens para suprimir o problema do gap semântico nas características de baixo nível, incluindo a utilização de técnicas de aprendizado de máquinas e segmentação de imagens, a utilização de realimentação de relevância por parte do usuário, e a definição de padrões semânticos para classificação das imagens. É também coerente pensar que, o aumento da especialização de um sistema CBIR com relação ao domínio de imagens considerado causa o estreitamento do 
gap semântico, porque possibilita o aproveitamento de conhecimento prévio do domínio [69].

\subsection{RBIR - Recuperação de imagens baseada em região}

Conforme mencionado anteriormente, em uma técnica RBIR a extração de características é feita para regiões específicas da imagem, após a segmentação ter sido feita por um algoritmo adequado. Uma série de características são extraídas para cada região e o conjunto de todas as características é utilizado para representação da imagem.

Uma segmentação confiável é um requisito importante para as técnicas RBIR, pois sem isso as características de formato das regiões, por exemplo, podem agregar pouco ou nenhum significado. O artigo de revisão em CBIR de Datta et al. [25] afirma que há dúvidas de que o processo de segmentação é o passo mais importante para a compreensão e caracterização da imagem. Entretanto, a segmentação ainda é um problema complexo e parece estar longe de ser resolvido por completo.

Assim como o gap semântico, a segmentação se beneficia do fato de se ter um domínio mais específico para as imagens. As imagens médicas, por exemplo, constituem um domínio muito interessante para o estudo e aplicação de técnicas de segmentação, devido a algumas propriedades que incluem, principalmente, a padronização no processo de aquisição. Assim, é possível adaptar técnicas existentes e também desenvolver métodos dedicados para alcançar maior precisão e confiabilidade na delimitação de tecidos, estruturas ou anomalias. De modo geral, as imagens provenientes de experimentos científicos também são um domínio adequado para se explorar a extração de características baseada em segmentação.

Neste trabalho em específico, métodos adaptativos de segmentação são propostos e aplicados em domínios diferentes de imagens, possibilitando a extração de características para representação sucinta e eficiente da imagem. Os domínios considerados são: imagens clínicas 2D de ressonância magnética (Capítulo 5), imagens de padrões espaciais de expressão genética (Capítulo 6) e imagens 3D do cérebro (Capítulo 7).

\subsection{Avaliação de similaridade}

A tarefa de avaliação de similaridade entre elementos de um repositório de imagens é realizada mediante a escolha adequada de uma função de distância. Para esta função ser considerada uma "função de distância métrica" é preciso que ela obedeça quatro propriedades. Considerando $p_{1}, p_{2}$ e $p_{3}$ como pontos em um espaço de características, as propriedades que tal função deve obedecer são as seguintes:

1. Simetria: $d\left(p_{1}, p_{2}\right)=d\left(p_{2}, p_{1}\right)$

2. Não negatividade: $d\left(p_{1}, p_{2}\right) \geq 0$

3. Identidade: $d\left(p_{1}, p_{2}\right)=0$ se e somente se $p_{1}=p_{2}$ 
4. Desigualdade triangular: $d\left(p_{1}, p_{2}\right) \leq d\left(p_{1}, p_{3}\right)+d\left(p_{3}, p_{2}\right)$

Uma função de distância métrica deve ser estabelecida de modo a refletir, o melhor possível, a percepção humana de similaridade entre duas imagens, dado o conjunto de características extraídas. Diversas funções têm sido exploradas em CBIR destacando-se entre elas a família de distâncias de Minkowski (família $L_{p}$ ) [70, 71], a função de distância Cosseno [70], a função de distância intersecção de histograma [72, 70], a função de distância quadrática [71] e a função de distância Mahalanobis [73, 70]. A seguir são apresentadas tais funções.

\subsubsection{Funções de distâncias de Minkowski (família $L_{p}$ )}

A família de distâncias proposta por Minkowski é comumente conhecida como família de distâncias $L_{p}$ e assume a seguinte forma:

$$
L_{p}(R, S)=\left(\sum_{i=0}^{N-1}\left(R_{i}-S_{i}\right)^{p}\right)^{\frac{1}{p}}
$$

onde $R=\left[R_{0}, R_{1}, \ldots, R_{N-1}\right]$ e $S=\left[S_{0}, S_{1}, \ldots, S_{N-1}\right]$ são vetores de $N$ características.

Três funções de distância conhecidas fazem parte da família $L_{p}$. A distância $L_{1}$ corresponde à distância Manhattan, ou "city block distance":

$$
L_{1}(R, S)=\sum_{i=0}^{N-1}\left|R_{i}-S_{i}\right|
$$

A bem conhecida "distância Euclidiana", corresponde à distância $L_{2}$ :

$$
L_{2}(R, S)=\left(\sum_{i=0}^{N-1}\left(R_{i}-S_{i}\right)^{2}\right)^{\frac{1}{2}}
$$

Fazendo $p \rightarrow \infty$ tem-se a distância $L_{\infty}$ ou $L_{\text {infinity }}$ definida como:

$$
L_{\infty}(R, S)=\max _{0 \leq i<N}\left[\left|R_{i}-S_{i}\right|\right]
$$

A Figura 2.2 ilustra as configurações de um conjunto de pontos eqüidistantes considerando as distâncias $L_{1}, L_{2}$ e $L_{\text {infinity }}$ em um espaço bi-dimensional.

\subsubsection{Função de distância Cosseno}

A função de distância Cosseno leva em consideração apenas o ângulo $\theta$ entre dois vetores $R$ e $S$, dispensando a informação de magnitude dos mesmos. Sua definição parte do produto escalar de dois vetores dado por: 


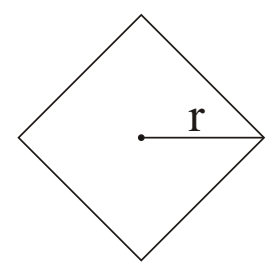

$L_{1}$

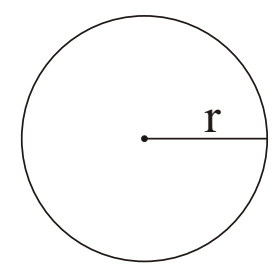

$L_{2}$

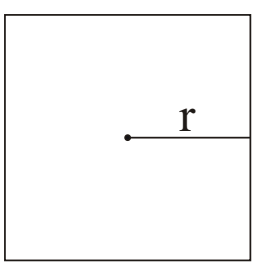

$L_{\text {infinity }}$

Figura 2.2: Configurações de um conjunto de pontos eqüidistantes para as distâncias $L_{1}, L_{2}$ e $L_{\text {infinity }}$ em um espaço bi-dimensional.

$$
R \cdot S=R^{t} S=|R||S| \cos \theta
$$

A função de distância Cosseno é definida como [74]:

$$
d_{c o s}(R, S)=\cos \theta=\frac{R^{t} S}{|R||S|}
$$

\subsubsection{Intersecção de histograma}

A intersecção de histogramas foi proposta por Swain e Ballard [72] com o objetivo de medir a similaridade de imagens representadas pelo seu histograma de cores ou brilho. Dado os histogramas $R$ e $S$ de duas imagens, a função intersecção de histogramas é definida como:

$$
d_{\cap}(R, S)=\sum_{i=0}^{N-1} \min \left(R_{i}, S_{i}\right)
$$

Para duas imagens, quanto maior o valor da função $d_{\bigcap}(R, S)$, maior é considerada a similaridade entre elas.

\subsubsection{Distância quadrática}

A função de distância quadrática leva em consideração não apenas a correspondência existente entre características (dimensões) de mesmo índice no vetor. Também são levadas em consideração informações sobre a similaridade de elementos de índices diferentes. A distância quadrática entre dois vetores $R$ e $S$, ambos de dimensão $N$, é definida como:

$$
d_{\text {quad }}(R, S)=\sqrt{(R-S)^{T} A(R-S)}
$$

Onde $A$ é uma matriz de dimensão $N \times N$ de elementos $a_{i, j}$ que correspondem ao coeficiente de afinidade entre os elementos de índices $i$ e $j$. O valor de $a_{i, j}$ é dado por:

$$
a_{i, j}=1-\frac{d_{i, j}}{\max \left[d_{i, j}\right]} \quad \text { onde } \quad d_{i, j}=\left|R_{i}-S_{j}\right|
$$




\subsubsection{Distância Mahalanobis}

A distância Mahalanobis é um caso especial da distância quadrática onde a matriz de transformação $A$ corresponde à matriz inversa da matriz de covariância, obtida a partir de um conjunto de treinamento de vetores de características. Para se alcançar a definição desta função é preciso considerar um vetor de variáveis aleatórias $X=\left[X_{0}, X_{1}, \ldots, X_{N-1}\right]$ que assume os valores de características dos vetores que constituem um conjunto de treinamento estabelecido. A matriz de covariância $V$ é dada por $V=\left[\sigma_{i, j}^{2}\right]$ onde $\sigma_{i, j}^{2}=E\left[X_{i} X_{j}\right]-E\left[X_{i}\right] E\left[X_{j}\right]$. Assim, a distância Mahalanobis entre dois vetores $R$ e $S$ é definida como:

$$
d_{m a h}=\sqrt{(R-S)^{T} V^{-1}(R-S)}
$$

No caso especial onde as variáveis $X_{0}, X_{1}, \ldots, X_{N-1}$ são estatisticamente independentes, a matriz de covariância $V$ é a matriz diagonal

$$
V=\left[\begin{array}{cccc}
\sigma_{0}^{2} & 0 & \cdots & 0 \\
0 & \sigma_{1}^{2} & \cdots & 0 \\
\vdots & \vdots & \ddots & \vdots \\
0 & 0 & \cdots & \sigma_{N-1}^{2}
\end{array}\right]
$$

Neste caso a distância Mahalanobis fica reduzida à seguinte forma:

$$
d_{m a h-i}(R, S)=\sum_{i=0}^{N-1} \frac{\left(R_{i}-S_{i}\right)^{2}}{\sigma_{i}^{2}}
$$

Esta última, corresponde a uma função de distância $L_{2}$ ponderada pela variância. Para as características que possuem pequena variância dentro do conjunto de treinamento é atribuído um peso maior, ao passo que para características de maior variância o peso é menor.

\subsection{Consultas por similaridade em espaços vetoriais}

As consultas por similaridade em CBIR procuram responder à seguinte requisição: dada uma imagem qualquer, recupere o conjunto de imagens mais similares a ela, visto que essas imagens estão representadas em um espaço vetorial de características.

Essencialmente, existem duas abordagens comuns para se responder a esta requisição. Uma é conhecida como "consulta por raio de abrangência" (range queries) e a outra é denominada "consultas aos $k$ vizinhos mais próximos" (k-nearest neighbor queries). Nas seções a seguir são apresentados esses dois tipos de consultas.

\subsubsection{Consulta por raio de abrangência (range query)}

Para este tipo de consulta são fornecidos um objeto de referência $O$ e um raio de cobertura $r$. O conjunto resposta $R_{r q}$ inclui todos os elementos $S$ da base que se encontram a uma distância menor ou igual a $r$ do elemento $O$. Ou seja: 


$$
R_{r q}=\{S \mid d(S, O) \leq r\}
$$

A Figura 2.3 ilustra um exemplo de consulta por raio de abrangência no domínio bidimensional, onde o conjunto resposta contém sete elementos. A função de distância utilizada neste caso é a função euclidiana $\left(L_{2}\right)$.

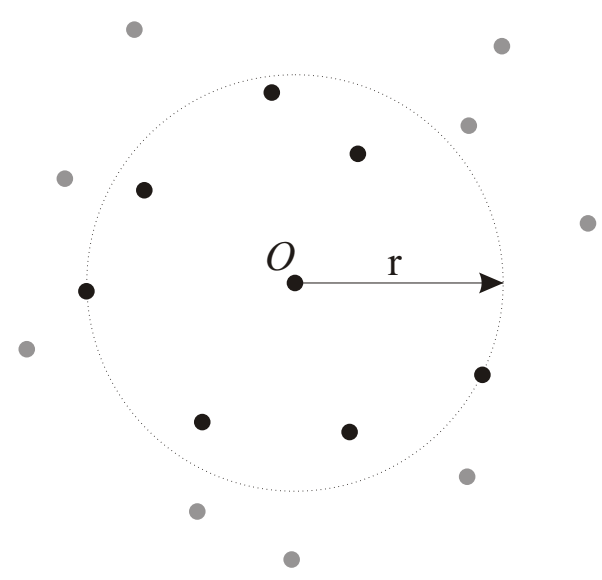

Figura 2.3: Exemplo de uma consulta por raio de abrangência onde o conjunto resposta contém 7 elementos sendo que $O$ não faz parte do resultado.

Vale mencionar que, dependendo da implementação, o elemento de busca também pode estar contido no conjunto resposta.

\subsubsection{Consulta aos $\mathbf{k}$ vizinhos mais próximos ( $k N N$ query)}

Neste tipo de consulta são fornecidos um objeto de referência $O$ e um número inteiro $k$ referente ao número de elementos mais próximos do elemento $O$ que se deseja obter como conjunto resposta $R_{k N N}$. Formalmente tem-se:

$$
R_{k N N}=\left\{S\left|\forall P \in\left\{\Omega-R_{k N N}\right\}, d(O, S) \leq d(O, P),\right| R_{k N N} \mid=K\right\}
$$

onde $\Omega$ representa o conjunto de todos os elementos.

A Figura 2.4 ilustra um exemplo de consulta do tipo kNN no domínio bi-dimensional, onde o conjunto resposta contém cinco elementos. Dependendo da implementação, o elemento de busca $O$ pode também fazer parte do conjunto resposta, sendo contabilizado como um dos $k$ elementos.

\subsection{Avaliação de eficiência}

Para se ter uma estimativa da qualidade do resultado obtido em uma operação de consulta em CBIR é necessário utilizar métodos adequados de avaliação de desempenho. A visualização gráfica do par de medidas denominadas precisão (precision) e revocação (recall) [1] constitui 


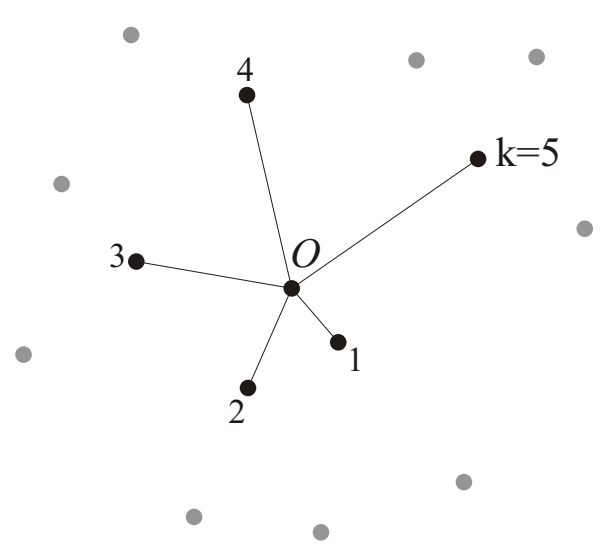

Figura 2.4: Exemplo de uma consulta do tipo kNN onde o conjunto resposta contém 5 elementos sem contar o elemento de busca $O$.

a estratégia mais conhecida e utilizada para se avaliar a eficácia de sistemas de busca. A seguir são apresentados detalhes da construção de tais gráficos.

\subsubsection{Gráficos de Precisão versus Revocação}

Considere que para uma determina requisição de informação $I$ existe um conjunto $R$ de elementos relevantes. Um determinado sistema de busca processa a requisição $I$ retornando um conjunto $A$. A intersecção dos conjuntos $R$ e $A$ compreende os elementos relevantes à requisição $I$ que foram recuperados na operação de busca realizada. Vamos denotar a cardinalidade dos conjuntos $R, A$ e $R \cap A$ como sendo, respectivamente, $|R|,|A|$ e, $|R a|$. A Figura 2.5 ilustra tais conjuntos. As medidas precisão e revocação são definidas da seguinte maneira:

- Revocação é a porção do conjunto de elementos relevantes $(R)$ que foram recuperados pela operação de busca.

$$
\operatorname{Rev}=\frac{|R a|}{|R|}
$$

- Precisão é a porção do conjunto de elementos recuperados $(A)$ que são relevantes à requisição $I$.

$$
\operatorname{Prec}=\frac{|R a|}{|A|}
$$

A avaliação das medidas é realizada construindo-se o gráfico de precisão versus revocação para vários pares de medidas. O primeiro passo para a obtenção desse conjunto de pares consiste em ordenar elementos do conjunto $A$ (elementos recuperados) de acordo com seu grau de relevância. Cada elemento de $A$ que é relevante à consulta é então examinado, e as medidas precisão e revocação vão sendo computadas a partir desta verificação.

Como um exemplo prático [1], considere que para uma determinada operação $q$ de consulta na base existe um conjunto $R q$ de 10 elementos relevantes, composto da seguinte maneira: 


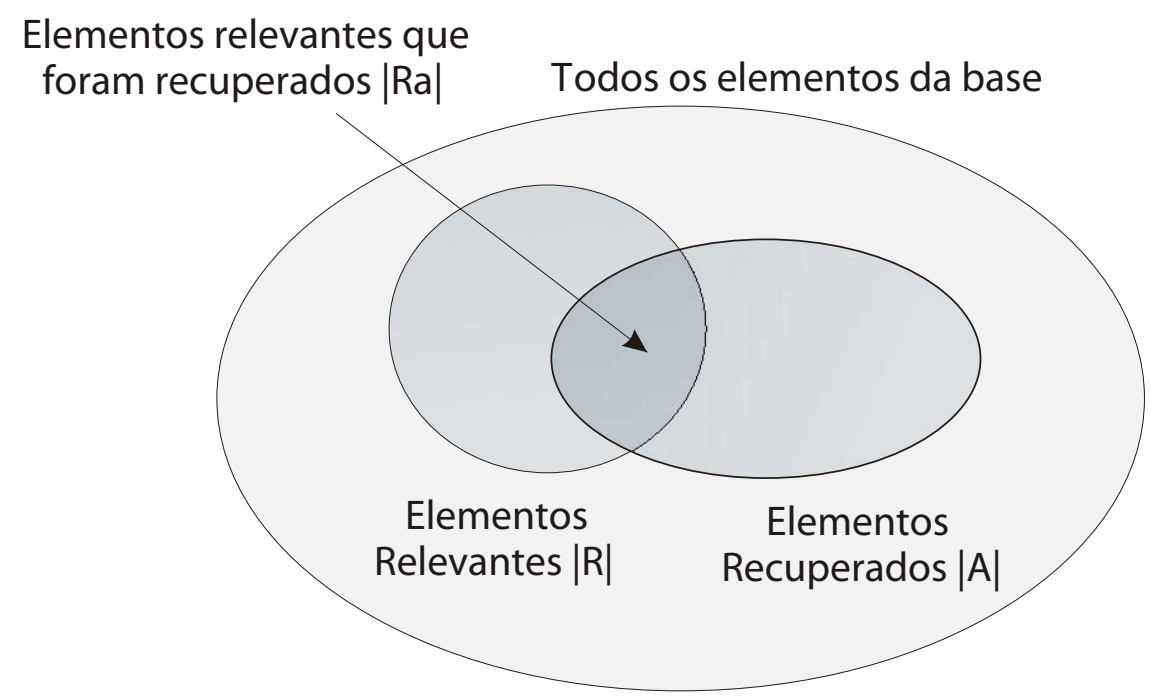

Figura 2.5: Conjuntos referentes às medidas de precisão e revocação para uma determinada operação de busca.

$$
R q=e_{5}, e_{13}, e_{17}, e_{20}, e_{31}, e_{36}, e_{42}, e_{47}, e_{55}, e_{61}
$$

É importante mencionar que o conjunto de elementos relevantes a uma consulta deve ser previamente estabelecido com a ajuda de um ou mais especialistas do domínio de imagens.

Considere agora que um algoritmo de busca tenha retornado um conjunto de elementos $A q$, referente à consulta $q$, cujos elementos e sua respectiva classificação são dados por:

$\begin{array}{ll}\text { 1. } e_{42} \bullet & \text { 2. } e_{54} \\ \text { 3. } e_{17} \bullet & \text { 4. } e_{15} \\ \text { 5. } e_{2} & \text { 6. } e_{5} \bullet \\ \text { 7. } e_{25} & \text { 8. } e_{27} \\ \text { 9. } e_{13} \bullet & \text { 10. } e_{54} \\ \text { 11. } e_{55} \bullet & \text { 12. } e_{67}\end{array}$

Os elementos que são relevantes à consulta $q$ estão marcados com • Examinando o conjunto $A q$ dos elementos recuperados, verifica-se que o primeiro elemento $\left(e_{42}\right)$ é um dos elementos relevantes à consulta. Neste caso, o valor de precisão é de 100\%, pois de todos os elementos analisados (apenas o primeiro até aqui), todos são relevantes à consulta. Neste ponto, o valor de revocação é $10 \%$ pois um elemento relevante, dentro de um conjunto de dez elementos, foi recuperado até esse ponto. O próximo elemento relevante da lista é o terceiro elemento $\left(e_{17}\right)$. Para este elemento o valor de precisão é de aproximadamente $66 \%$ (dois elementos relevantes em três verificados) e o valor de revocação é de $20 \%$ (dois entre dez elementos relevantes já verificados). A análise prossegue desta maneira até que todos os elementos relevantes sejam verificados. Os valores de precisão e revocação são então visualizados graficamente, conforme o exemplo ilustrado na Figura 2.6.

Para uma avaliação confiável dos resultados obtidos por um determinado sistema de recuperação, é necessário que diversas operações de consultas sejam realizadas e consideradas 


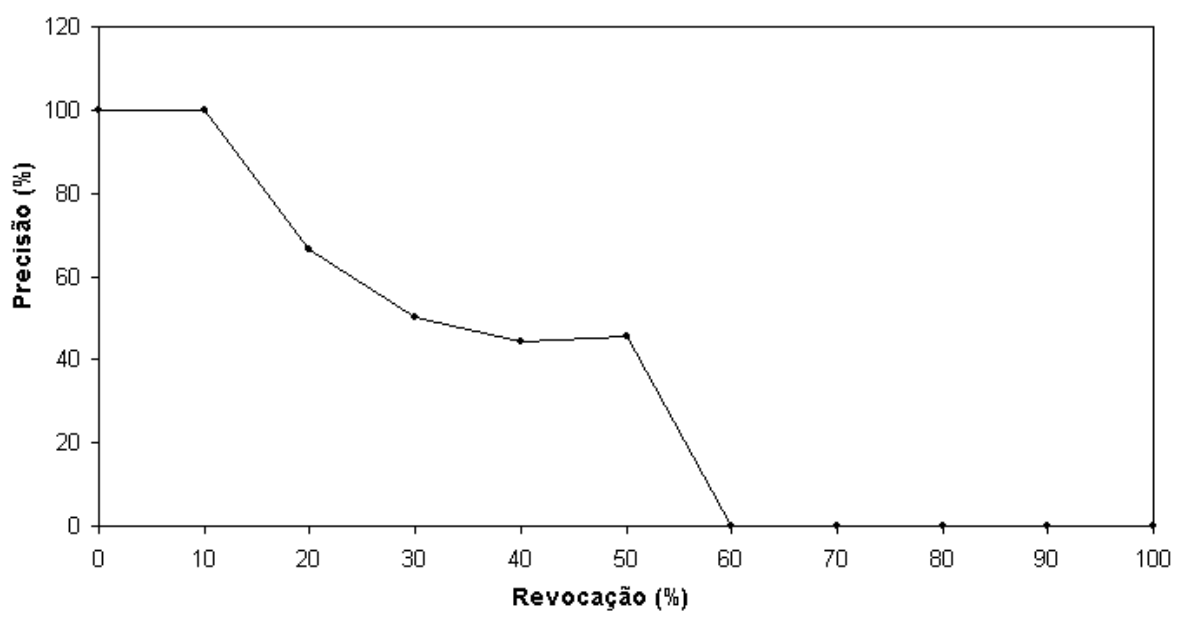

Figura 2.6: Exemplo de um gráfico de medidas Precisão versus Revocação para uma operação de busca [1].

na avaliação. Para isso, é preciso construir uma curva de precisão e revocação que represente a média dos desempenhos das diversas consultas realizadas. Isto é feito, geralmente, calculando-se valores de precisão para escalas determinadas de revocação, como por exemplo, nas dezenas. Calcula-se então, para os diversos valores de precisão obtidos em cada escala de revocação, a média aritmética dos mesmos.

A avaliação do desempenho é realizada de maneira prática, verificando-se o formato da curva obtida. Quanto mais próxima do topo do gráfico a curva estiver melhor será o resultado da operação de busca. Sendo assim, a curva de um resultado de consulta ideal apresenta $100 \%$ de precisão para todos os valores de revocação.

\subsection{Considerações finais}

Este Capítulo apresentou um panorama da área de recuperação de imagens baseada em conteúdo (CBIR). O grande número de pesquisas publicadas nesta área, especialmente nos últimos anos, revela que ela constitui um campo de estudo relevante e com grandes desafios, que tem atraído a atenção de um número crescente de pesquisadores de diversos ramos da ciência. Os métodos CBIR podem ser empregados em diversas aplicações e a uma ampla variedade de domínios de imagens. Algumas áreas de aplicação incluem bibliotecas, publicidade, medicina, engenharia, biologia, genética, entretenimento, vendas, entre outras.

Um dos maiores desafios em CBIR está diretamente ligado à tarefa de extração de características das imagens. Como representar matematicamente duas imagens em um espaço de características para que seja possível inferir o nível de semelhança visual entre elas? Quais características são as mais adequadas para um determinado domínio de imagens?

Estas e outras questões constituem a base de motivação do trabalho apresentado nesta tese. A idéia principal que sustentamos é que a segmentação é um processo importante rumo ao objetivo de caracterização eficiente da imagem. Além disso, a especificação do domínio 
da imagem permite desenvolver algoritmos de segmentação adaptativos, ou dedicados, que oferecem resultados mais precisos na delimitação de regiões de interesse na imagem. Essas idéias foram elaboradas e ao longo deste trabalho sustentaram o desenvolvimento de novas técnicas de extração de características e segmentação de imagens que produzem resultados excelentes e superam diversas outras técnicas reconhecidas por sua eficiência. O desenvolvimento desses novos métodos é apresentado nos Capítulos 5, 6 e 7. Os próximos Capítulos, 3 e 4 apresentam algumas das principais técnicas de extração de características e segmentação de imagens que estão mais estreitamente ligadas ao trabalho desenvolvido nesta tese. 



\section{Técnicas de extração de características de imagens}

Este Capítulo apresenta uma revisão de alguns dos principais métodos de extração de características de imagens baseados em textura e forma, que estão mais relacionados ao projeto desenvolvido e apresentado nesta tese.

\subsection{Assinaturas de forma}

As assinaturas de forma (shape signatures) são funções unidimensionais discretas que representam o contorno de um objeto da imagem. Usualmente é dito que uma assinatura de forma descreve de maneira unívoca a forma do objeto ao qual ela está associada. Deste modo, elas podem ser utilizadas como forma de caracterização do conteúdo de imagens onde um ou mais objetos relevantes são especificados.

Para se obter tal função é preciso, primeiramente, que a borda ou contorno do objeto da imagem que se deseja descrever tenha sido previamente determinado em uma etapa de segmentação, gerando um vetor de coordenadas discretas $(x(t), y(t))$, onde $t=0,1, \ldots, N-1$, e $N$ representa o número total de amostras deste contorno. A seguir são descritas duas das principais assinaturas de formas: a função distância do centróide e a função de posição (ou coordenadas complexas).

\subsubsection{Função distância do centróide}

A função distância do centróide $r(t)$ é expressa pela distância entre os pontos que correspondem às amostras do contorno do objeto $(x(t), y(t))$ ao centróide (ou centro de massa) do objeto $\left(x_{c}, y_{c}\right)$ :

$$
r(t)=\sqrt{\left(x(t)-x_{c}\right)^{2}+\left(y(t)-y_{c}\right)^{2}}
$$


onde

$$
x_{c}=\frac{1}{N} \sum_{t=0}^{N-1} x(t) \quad y_{c}=\frac{1}{N} \sum_{t=0}^{N-1} y(t)
$$

A função $r(t)$ é inerentemente invariante à translação do objeto. Uma operação de rotação do objeto causa em $r(t)$ um deslocamento circular, e uma transformação de escala altera $r(t)$ linearmente.

\subsubsection{Função posição}

A função de posição $z(t)$, ou coordenadas complexas, corresponde simplesmente ao número complexo gerado a partir das coordenadas de contorno do objeto:

$$
z(t)=\left(x(t)-x_{c}\right)+i\left(y(t)-y_{c}\right)
$$

A função $z(t)$ é uma representação direta do contorno representado por $(x(t), y(t))$ e, assim como a função distância do centróide, também apresenta invariância à translação. Uma rotação do objeto também causa um deslocamento circular em $z(t)$, e uma operação de escalonamento também apenas a modifica linearmente.

\subsection{Descritores de Fourier}

De maneira geral os descritores de Fourier são obtidos aplicando-se a transformada de Fourier sobre a função assinatura de forma de algum objeto da imagem. Diversas assinaturas de forma têm sido exploradas para se obter descritores de Fourier. Dentre elas, as mais conhecidas e utilizadas são a função de posição (ou coordenadas complexas), a função distância do centróide, a função de curvatura e a função angular cumulativa. Como foi comprovado no artigo de Zhang [75], os descritores de Fourier obtidos a partir da função distância do centróide, superam os descritores obtidos a partir das demais assinaturas de forma em termos de desempenho em geral. A seguir é apresentada uma visão geral da transformada de Fourier e uma descrição detalhada dos descritores.

\subsubsection{Transformada de Fourier}

A transformada de Fourier é uma das ferramentas mais utilizadas para se transformar funções ou seqüências de dados ( $n$-dimensionais) definidas no que é denominado "domínio do espaço" para o "domínio da freqüência".

Uma função contínua pode ser representada em um determinado intervalo por uma combinação linear de funções senoidais com freqüências e fases variadas. A transformada de 
Fourier de uma função determina a contribuição (ou amplitude) de uma componente senoidal de freqüência $w$ para a combinação linear que representa aquela função. Uma descrição mais detalhada e didática sobre a formulação desta transformada pode ser obtida no relatório técnico de Hagit Shatkay [76].

A transformada de Fourier de uma função contínua e integrável $f(t)$ é definida da seguinte maneira:

$$
F(w)=\int_{-\infty}^{\infty} f(t) e^{-2 \pi i w t} d t
$$

sendo que a "transformada inversa de Fourier" fornece uma maneira de descrever a função como uma combinação linear de funções senoidais,

$$
f(t)=\int_{-\infty}^{\infty} F(w) e^{2 \pi i w t} d w
$$

Vale lembrar que pela fórmula de Euler:

$$
e^{-2 \pi i w t}=\cos (2 \pi w t)-i \operatorname{sen}(2 \pi w t)
$$

Para o caso discreto, define-se a transformada de Fourier, e sua respectiva transformada inversa, da seguinte maneira:

$$
F[w]=\frac{1}{N} \sum_{t=0}^{N-1} f[t] e^{-2 \pi i w t / N} \quad 0 \leq w \leq N-1
$$

$\mathrm{e}$

$$
f[t]=\frac{1}{N} \sum_{w=0}^{N-1} F[w] e^{2 \pi i w t / N} \quad 0 \leq t \leq N-1
$$

A transformada de Fourier pode ser uma função complexa ou não dependendo do tipo da função $f(t)$. A Tabela 3.1 apresenta a relação que existe entre os tipos de $f(t)$ e os tipos da respectiva transformada de Fourier $F(w)$.

\begin{tabular}{|c|c|}
\hline $\mathbf{f}(\mathbf{t})$ & $\mathbf{F}(\mathbf{w})$ \\
\hline \hline real e par & real e par \\
\hline real e ímpar & complexa e ímpar \\
\hline complexa e par & complexa e par \\
\hline complexa e ímpar & real e ímpar \\
\hline
\end{tabular}

Tabela 3.1: Relação entre os tipos de função e respectivas transformadas de Fourier 
Caso a transformada $F(w)$ seja uma função complexa então $F(w)=R(w)+i I(w)$, onde $R(w)$ e $I(w)$ são respectivamente, as componentes reais e imaginárias de $F(w)$. Também é comum expressar a transformada da seguinte forma:

$$
F(w)=|F(w)| e^{i \phi(w)}
$$

onde

$$
|F(w)|=\sqrt{R^{2}(w)+I^{2}(w)}
$$

e

$$
\phi(w)=\arctan \left(\frac{I(w)}{R(w)}\right)
$$

onde a magnitude $|F(w)|$ é chamada "espectro de Fourier" da função $f(t)$ e a função $\phi(w)$, é denominada "ângulo de fase". O quadrado do espectro de Fourier $\left(P(w)=|F(w)|^{2}\right)$ é conhecido como "espectro de energia" ou "densidade espectral". As principais propriedades da transformada de Fourier são descritas na Tabela 3.2.

\begin{tabular}{|l|l|l|}
\hline Propriedade & $f(t)$ & $F(w)$ \\
\hline \hline Linearidade & $a f_{1}(t)+b f_{2}(t)$ & $a F_{1}(w)+b F_{2}(w)$ \\
\hline Deslocamento de tempo & $f\left(t-t_{0}\right)$ & $F(w) e^{-2 \pi i w t_{0}}$ \\
\hline Deslocamento de freqüência & $f(t) e^{2 \pi i w_{0} t}$ & $F\left(w-w_{0}\right)$ \\
\hline Escalonamento & $f(a t)$ & $|a|^{-1} F(w / a)$ \\
\hline
\end{tabular}

Tabela 3.2: Propriedades da transformada de Fourier

\subsubsection{Obtenção do descritores}

Para uma determinada função assinatura de forma $u(t)$, aplica-se a transformada discreta de Fourier da seguinte maneira:

$$
a_{n}=\frac{1}{N} \sum_{t=0}^{N-1} u(t) e^{-2 \pi i n t / N}
$$

Os coeficientes $a_{n}, n=0,1, \ldots, N-1$, constituem a base dos descritores de Fourier de um determinado objeto. Tais coeficientes possuem invariância à translação se a função assinatura de forma utilizada for baseada no centróide do objeto. Para se obter descritores invariantes à rotação, a informação de fase dos coeficientes $a_{n}$ é ignorada, utilizando-se apenas a magnitude dos mesmos $\left(\left|a_{n}\right|\right)$. A invariância à escala é obtida dividindo as magnitudes pela maior magnitude do conjunto de coeficientes, ou seja, $\left|a_{0}\right|$. Caso a função $u(t)$ seja real, somente metade dos coeficientes $a_{n}$ são necessários para se obter os descritores do objeto, devido 
à propriedade de periodicidade e simetria conjugada da transformada de Fourier [77]. Finalmente, o conjunto $D F$ de descritores de Fourier é o seguinte:

$$
D F=\left[\frac{\left|a_{1}\right|}{\left|a_{0}\right|}, \frac{\left|a_{2}\right|}{\left|a_{0}\right|}, \ldots, \frac{\left|a_{N / 2}\right|}{\left|a_{0}\right|}\right]
$$

Com os descritores de Fourier, características mais gerais da forma dos objetos são capturados por coeficientes de baixa ordem, enquanto que características mais específicas (detalhes) são obtidos por coeficientes de ordem maior. Ruídos e pequenas irregularidades não constituem um problema visto que elas somente aparecem em altas freqüências. Utilizando-se um número reduzido e fixo de descritores de ordem mais baixa, é possível armazenar as características de forma mais relevantes do objeto sem levar em consideração detalhes e imperfeições do mesmo, o que torna o conjunto de descritores uma representação compacta e eficiente.

\subsection{Momentos de Zernike}

Em 1934, Zernike [64] apresentou um conjunto de polinômios complexos que formam uma base ortogonal completa definida no interior de um disco unitário, isto é, $x^{2}+y^{2} \leq 1$. Tais polinômios são denotados por $V_{n, m}(x, y)$, e podem ser expressos em coordenadas polares da seguinte maneira:

$$
V_{n, m}(x, y)=V_{n, m}(\rho \cos (\theta), \rho \sin (\theta))=R_{n, m}(\rho) e^{i m \theta}
$$

onde $n$ é um valor inteiro, maior ou igual a zero, que define a ordem do polinômio; e $m$, também inteiro (negativo ou positivo), descreve a dependência angular, ou rotação, do polinômio.

O mapeamento das coordenadas cartesianas $(x, y)$ para o sistema polar é dado por: $\rho=\sqrt{x^{2}+y^{2}}$ e $\theta=\arctan \left(\frac{y}{x}\right)$, onde $\rho$ representa a distância do ponto $(x, y)$ à origem, e $\theta$, o ângulo formado entre o vetor de tamanho $\rho$ e o eixo $x$, na direção anti-horária. Para os pares de valores $n$ e $m$ as seguintes restrições são estabelecidas:

$$
n-|m| \text { deve ser par; } \quad \text { e } \quad-n \leq m \leq n
$$

A função $R_{n, m}(\rho)$ é denominada polinômio radial e é definida conforme a seguir:

$$
R_{n, m}(\rho)=\sum_{s=0}^{\frac{n-|m|}{2}}(-1)^{s} \frac{(n-s) !}{s !\left(\frac{n+|m|}{2}-s\right) !\left(\frac{n-|m|}{2}-s\right) !} \rho^{n-2 s}
$$

Nota-se que $R_{n, m}(\rho)=R_{n,-m}(\rho)$. Caso as condições definidas em 3.1 não sejam verificadas, 
então o polinômio $R_{n, m}(\rho)$ é nulo. Os seis primeiros polinômios radiais são:

$$
\begin{array}{ll}
R_{0,0}(\rho)=1 & R_{1,1}(\rho)=\rho \\
R_{2,0}(\rho)=2 \rho^{2}-1 & R_{2,2}(\rho)=\rho^{2} \\
R_{3,1}(\rho)=3 \rho^{3}-3 \rho & R_{3,3}(\rho)=\rho^{3}
\end{array}
$$

Em 1980, Michael Reed Teague [78] combinou a formulação dos polinômios ortogonais de Zernike com a teoria geral dos momentos para se gerar um conjunto de momentos ortogonais, os quais foram nomeados "momentos de Zernike".

A grande vantagem de se utilizar um conjunto de momentos ortogonais consiste no fato de que tais momentos possuem redundância praticamente nula de informação. Assim, pode-se dizer que cada momento armazena uma característica distinta da imagem, sendo necessário um menor número de momentos para se armazenar a mesma quantidade de informação em relação aos momentos não ortogonais.

A teoria dos momentos de Zernike é similar à idéia da transformada de Fourier que tem como objetivo expandir o sinal (ou imagem) em séries de bases ortogonais. Mais especificamente, os momentos de Zernike constituem uma projeção da imagem $f(x, y)$ sobre a base ortogonal formada pelos polinômios $V_{n, m}(x, y)$. O momento de Zernike $Z_{n, m}$ de ordem $n$ e repetição (ou dependência angular) $m$ é calculado da seguinte maneira:

$$
Z_{n, m}=\frac{n+1}{\pi} \iint_{x^{2}+y^{2} \leq 1} f(x, y) V_{n, m}^{*}(x, y) d x d y
$$

onde $V_{n, m}^{*}$ denota o conjugado do valor complexo de $V_{n, m}$.

Para uma imagem digital as integrais são substituídas por somatórios:

$$
Z_{n, m}=\frac{n+1}{\pi} \sum_{x} \sum_{y} f(x, y) V_{n, m}^{*}(x, y), \quad x^{2}+y^{2} \leq 1
$$

Devido às restrições já mencionadas para os polinômios de Zernike $(n-|m|$ deve ser par e $-n \leq m \leq n)$, para cada ordem $n$ existem $\frac{n}{2}$ momentos com repetição, ou dependência angular $m$, distintos. Sendo assim, existem $(n+1)(n-1) / 2$ momentos de ordem inferior ou igual a $n$. Vale também citar a seguinte relação entre os momentos de ordem $n: Z_{n, m}^{*}=$ $Z_{n,-m}$.

Uma das principais características dos momentos de Zernike consiste no fato de que a magnitude do valor complexo $Z_{n, m}$ não se altera devido a uma rotação na imagem. Desta forma, é possível obter um conjunto de momentos invariantes à rotação.

Nenhuma propriedade intrínseca dos momentos de Zernike garante que os momentos calculados para uma determinada imagem não se alterem caso esta imagem seja transladada ou escalonada. É possível, porém, realizar uma normalização da imagem, utilizando os primeiros momentos cartesianos [79] e obter descritores que sejam invariantes a ambas as transformações. 
Para se obter os momentos de Zernike de uma determinada imagem é necessário, primeiramente, realizar o mapeamento da imagem do domínio cartesiano para o domínio dos polinômios de Zernike, ou seja, o disco de raio unitário. Os pixels da imagem mapeados para fora do disco não são utilizados no cálculo dos momentos. A invariância à translação pode ser obtida, simplesmente, fazendo com que a origem do disco coincida com o centro de massa da imagem na ocasião no mapeamento. Seguindo esta idéia, a invariância à escala é obtida escalonando-se a imagem de modo que a sua massa $\left(m_{0,0}\right)$ passe a assumir um valor $\beta$ definido a priori. Isto pode ser alcançado a partir da seguinte função:

$$
h(x, y)=f\left(\frac{x}{a}+x c, \frac{y}{a}+y c\right) \quad \text { onde } \quad a=\sqrt{\frac{\beta}{m_{0,0}}}
$$

Os momentos de Zernike invariantes às três transformações da imagem (rotação, translação e escala), correspondem então à magnitude dos momentos computados a partir da função $h(x, y)$.

\subsection{Matrizes de co-ocorrência}

As matrizes de co-ocorrência, também denominadas matrizes SGLD (Spatial Gray Level Dependence) [80], são uma das mais populares fontes de características de textura para imagens [55].

Dado uma imagem $f$ com um conjunto discreto de tons de cinza I, define-se a matriz de co-ocorrência $P_{d, \phi}(i, j)$, onde cada elemento $(i, j)$ corresponde a um número inteiro que indica quantas vezes um pixel $p_{1}$ de nível de cinza $i$ aparece distante de um pixel $p_{2}$ de intensidade $j$ por uma distância $d$ e um ângulo $\phi$ ou, de maneira formal, quantas vezes ocorre $p_{1}=p_{2}+(d \cos \phi, d \sin \phi)$, onde $f\left(p_{1}\right)=i$ e $f\left(p_{2}\right)=j$. A Figura 3.1 ilustra um exemplo de duas matrizes de co-ocorrência para a imagem em tons de cinza representada na Figura 3.1a. As matrizes de co-ocorrência são matrizes quadradas e simétricas em relação à diagonal principal, ou seja, $P_{d, \phi}(i, j)=P_{d, \phi}(j, i)$.

$$
\begin{aligned}
& \begin{array}{|l|l|l|l|}
\hline 0 & 0 & 1 & 1 \\
\hline 0 & 0 & 1 & 1 \\
\hline 0 & 2 & 2 & 2 \\
\hline 2 & 2 & 3 & 3 \\
\hline
\end{array} \\
& P_{1,0^{\circ}}=\left[\begin{array}{cccc}
4 & 2 & 1 & 0 \\
2 & 4 & 0 & 0 \\
1 & 0 & 6 & 1 \\
0 & 0 & 1 & 2
\end{array}\right] \quad P_{1,135^{\circ}}=\left[\begin{array}{cccc}
2 & 1 & 3 & 0 \\
1 & 2 & 1 & 0 \\
3 & 1 & 0 & 2 \\
0 & 0 & 2 & 0
\end{array}\right]
\end{aligned}
$$

Figura 3.1: Exemplo de matrizes de co-ocorrência. (a) imagem em tons de cinza; (b) matriz de co-ocorrência para ângulo 0 e $d=1$; (c) matriz de co-ocorrência para ângulo $135^{\circ}$ e $d=$ 1. 
Diversas medidas podem ser extraídas de uma matriz de co-ocorrência. Haralick [80] propõe 14 , porém as mais comuns e utilizadas na literatura são quatro:

- Energia:

$$
\sum_{i, j} P_{d, \phi}^{2}(i, j)
$$

- Entropia:

$$
-\sum_{i, j} P_{d, \phi}(i, j) \log \left(P_{d, \phi}(i, j)\right)
$$

- Contraste:

$$
\sum_{i, j}(i-j)^{2} P_{d, \phi}(i, j)
$$

- Homogeneidade:

$$
\sum_{i, j} \frac{P_{d, \phi}(i, j)}{1+(i-j)^{2}}
$$

As duas primeiras medidas (energia e entropia) dão uma indicação do comportamento da textura em relação à sua uniformidade e periodicidade. A medida de contraste analisa os valores da matriz com ênfase nos elementos mais distantes da diagonal, ou seja, os pontos cujos níveis de cinza possuem maior distinção entre si, o que vale, de fato, como um indicador do nível de contraste da textura. A homogeneidade possui a mesma tendência, porém, com sentido inverso.

A dimensão da matriz $P_{d, \phi}$ é estritamente definida pelo número de tons de cinza distintos na imagem. Deste modo, uma prática comum consiste na utilização de algoritmos de quantização sobre a imagem que se está trabalhando para se reduzir a quantidade de tons de cinza, proporcionando assim, a obtenção de matrizes de dimensões reduzidas.

Para se obter um conjunto de medidas que apresente maior poder de caracterização, é necessário computar um número razoável de matrizes para diferentes ângulos $\phi$ e distâncias d. Caso exista informações a priori das texturas a serem caracterizadas é possível tirar proveito disto. Por exemplo, para texturas mais refinadas é melhor que sejam computadas matrizes com parâmetros $d$ de pequenos valores, geralmente 1 ou 2. Por outro lado, para texturas mais grosseiras é aconselhável a utilização de valores maiores para $d$.

Procura-se também, a utilização de ângulos múltiplos de $\pi / 4$, já que a natureza espacial da imagem induz ao cálculo mais simplificado nas direções vertical, horizontal e nas diagonais. Vale notar que a seguinte relação é válida: $P_{d, \phi}=P_{d, \phi+\pi}$.

A grande desvantagem da utilização das matrizes de co-ocorrência na extração de características da textura está relacionada com seu alto custo computacional. Computar várias matrizes de grandes dimensões nem sempre é uma alternativa factível. Também, a escolha 
adequada dos parâmetros $d$ e $\phi$ depende muitas vezes de um conhecimento prévio acerca da qualidade das imagens, o que nem sempre é possível, ou desejável, em determinadas aplicações.

\subsection{Análise da transformada de Fourier}

A transformada de Fourier descreve uma imagem através de suas freqüências espaciais. A partir de uma análise sistemática do resultado desta função (no espaço das freqüências) é possível também extrair características tais como a espessura e a direcionalidade da textura. A idéia é calcular a energia da transformada bi-dimensional da imagem [76] em regiões pré-definidas, como por exemplo, ao longo de cunhas ou anéis, conforme ilustrado na Figura 3.2 , e utilizar estes valores como características.

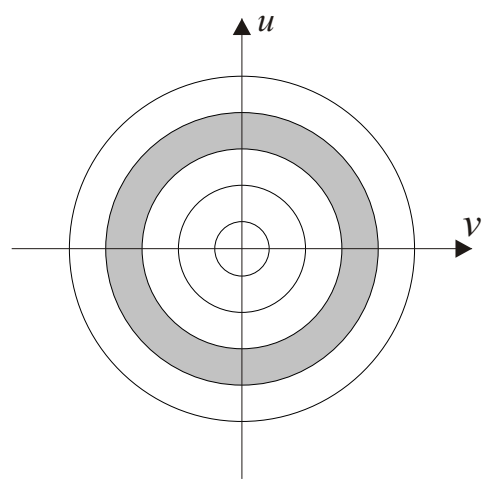

(a)

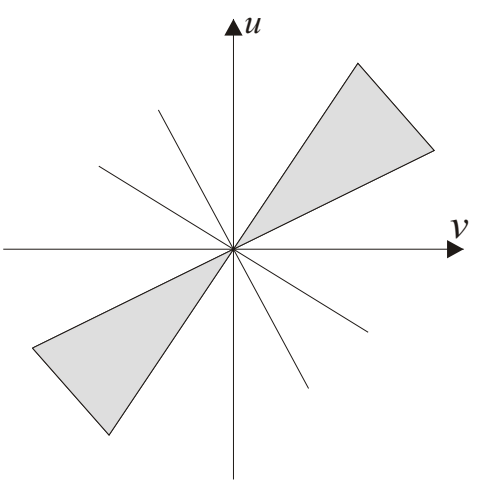

(b)

Figura 3.2: Extração de características a partir da transformada de Fourier (espaço das freqüências.) (a) energia ao longo de anéis; (b) energia ao longo de cunhas [2].

Características avaliadas a partir de anéis (Figura 3.2a) refletem a espessura da textura. Energia alta em anéis de raio grande é característico de texturas mais refinadas (presença de altas freqüências), enquanto que energia alta em anéis de raio pequeno é característico de texturas grosseiras e esparsas (presença de baixas freqüências). As características provenientes da análise de regiões tipo cunha (Figura 3.2b) dão uma idéia da direcionalidade da textura. Caso esta possua um comportamento direcional com ângulo $\phi$, será observado na transformada uma alta energia na cunha de direção $\phi+\pi / 2$.

\subsection{Análise da transformada de Wavelet}

As wavelets $[81,82]$ são um conjunto de funções especiais utilizadas para prover a representação espectral de uma determinada função em vários níveis de resolução da mesma. Assim como as funções seno e cosseno são as funções base para a transformada de Fourier, as wavelets são funções de base para a transformada de wavelet. Uma família de funções wavelet é gerada a partir de uma função $\psi(x)$, denominada "wavelet mãe" definida em um intervalo finito. "As wavelets filhas" $\psi_{a, b}(x)$ são obtidas a partir da contração e da translação 
da wavelet mãe, regidas respectivamente pelos índices $a$ e $b$. As famílias mais conhecidas de funções wavelets são as wavelets de Haar e as wavelets de Daubechies.

As wavelets de Haar foram as primeiras wavelets, propostas em 1909 por Alfred Haar. Elas constituem o conjunto mais simples de wavelets e são geradas a partir da seguinte wavelet mãe:

$$
\psi(x)=\left\{\begin{aligned}
1, & \text { se } 0 \leq x \leq 1 / 2 \\
-1, & \text { se } 1 / 2 \leq x \leq 1 \\
0, & \text { se } \quad \text { em nenhum dos casos }
\end{aligned}\right.
$$

As demais wavelets $\psi_{j, k}(x)$ são obtidas da seguinte forma:

$$
\psi_{j, k}(x)=\psi\left(2^{j} x-k\right)
$$

Sendo assim, as primeiras wavelets de Haar são:
1. $\psi_{0,0}=\psi(x)$
2. $\psi_{1,0}=\psi(2 x)$
3. $\psi_{1,1}=\psi(2 x-1)$
4. $\psi_{2,0}=\psi(4 x)$
5. $\psi_{2,1}=\psi(4 x-1)$
6. $\psi_{2,2}=\psi(4 x-2)$
7. $\psi_{2,3}=\psi(4 x-3)$

A Figura 3.3 ilustra os gráficos de tais funções.

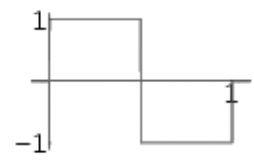

1

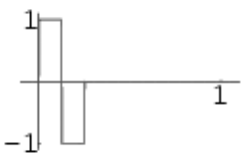

4

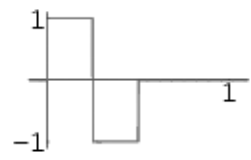

2

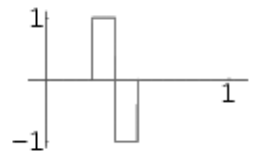

5

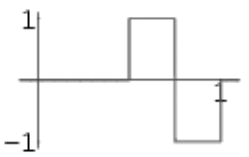

3

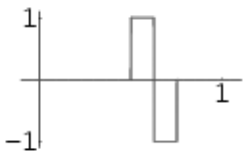

5

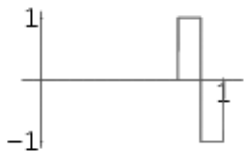

7

Figura 3.3: As primeiras sete wavelets de Haar.

Uma função $f(x)$ pode ser escrita como uma expansão em série da seguinte maneira:

$$
f(x)=c_{0}+\sum_{j=0}^{\infty} \sum_{k=0}^{2^{j}-1} c_{j, k} \psi_{j, k}(x)
$$

O conjunto de coeficientes $\left[c_{0}, c_{j, k}\right]$ constitui a transformada de wavelet da função $f(x)$ tendo como base as wavelets de Haar.

Uma das principais propriedades das wavelets de Haar, que não é observada em todas as famílias, é a ortogonalidade, ou seja, todas as funções base $\psi_{j, k}(s)$ são ortogonais duas a duas. 


\subsubsection{Transformada de Wavelet}

A transformada de wavelet de uma função $f(x)$ é definida da seguinte forma:

$$
W T_{f}(j, k)=\int_{-\infty}^{\infty} f(x) \psi_{j, k}(x) d x
$$

No caso contínuo $j$ e $k$ são valores reais e, para o caso discreto, são valores inteiros. Obter os coeficientes de wavelet para o caso contínuo requer um enorme esforço computacional. Devido a este fato, na transformada discreta de wavelet escolhe-se um subconjunto de valores $j$ e $k$ sobre os quais são obtidos os coeficientes da transformada. Existem duas abordagens comumente consideradas para a implementação transformada discreta de wavelet, que são: a utilização de sistemas redundantes discretos (frames), e a análise multi-resolução desenvolvida por Mallat [83].

A transformada wavelet sob a abordagem multi-resolução pode ser considerada uma decomposição do sinal (função), onde os coeficientes da transformada são obtidos a partir de filtros passa-baixa e passa-alta. Nessa abordagem, a função wavelet $\psi(x)$ atua como um filtro passa-alta, produzindo os coeficientes de detalhes da decomposição. Outra função $\phi(x)$ atua como um filtro passa-baixa. A função $\phi(x)$ é denominada função de escalonamento $\phi(x)$ (scaling function) e está associada aos coeficientes de aproximação da decomposição.

$\mathrm{Na}$ abordagem multi-resolução, a transformada de wavelet de uma imagem é baseada na decomposição progressiva de suas linhas e colunas. A Figura 3.4 apresenta o diagrama deste processo. Inicialmente, aplica-se a transformada de wavelet unidimensional para cada linha da imagem. Este processo é equivalente à aplicação de um filtro passa-baixa (LPF) e outro passa-alta $(\mathrm{HPF})$ para cada linha da imagem, gerando duas novas linhas para cada linha original. Em seguida, para cada nova linha obtida no processo de filtragem, é realizada uma operação de decimação, que consiste na diminuição do número de elementos. Neste caso, cada linha perde metade de seus pixels ficando com a metade do comprimento original. As linhas resultantes são então concatenadas duas a duas, produzindo uma linha onde a primeira metade é constituída pelos elementos de baixa freqüência e, a segunda metade, contém elementos de alta freqüência, ambos relacionados com a linha original correspondente. $\mathrm{Na}$ seqüência, aplica-se o mesmo processo para as colunas da imagem gerada na etapa anterior. Obtêm-se então quatro regiões distintas na imagem. A região inferior esquerda $\left(\mathrm{Hx}_{1}\right)$ corresponde aos elementos de alta freqüência na direção horizontal e baixa freqüência na direção vertical. De maneira oposta, a região superior direita $\left(\mathrm{Hy}_{1}\right)$ contém elementos de alta freqüência na direção vertical e baixa freqüência na direção horizontal. Os demais quadrantes, superior esquerdo $\left(\mathrm{Lxy}_{1}\right)$ e inferior direito $\left(\mathrm{Hxy}_{1}\right)$, correspondem respectivamente aos elementos de baixa freqüência em ambas as direções e aos de alta freqüência, também em ambas as direções. Este processo consiste em uma etapa completa da decomposição. Na próxima etapa, é realizada a mesma operação de decomposição para a imagem do quadrante superior esquerdo, originando assim outros novos quadrantes: $\mathrm{Lxy}_{2}, \mathrm{Hxy}_{2}, \mathrm{Hx}_{2}$ e $\mathrm{Hy}_{2}$. A 
decomposição se repete por um número determinado de etapas $P$, ou enquanto a região a ser decomposta tiver mais de uma linha e mais de uma coluna.

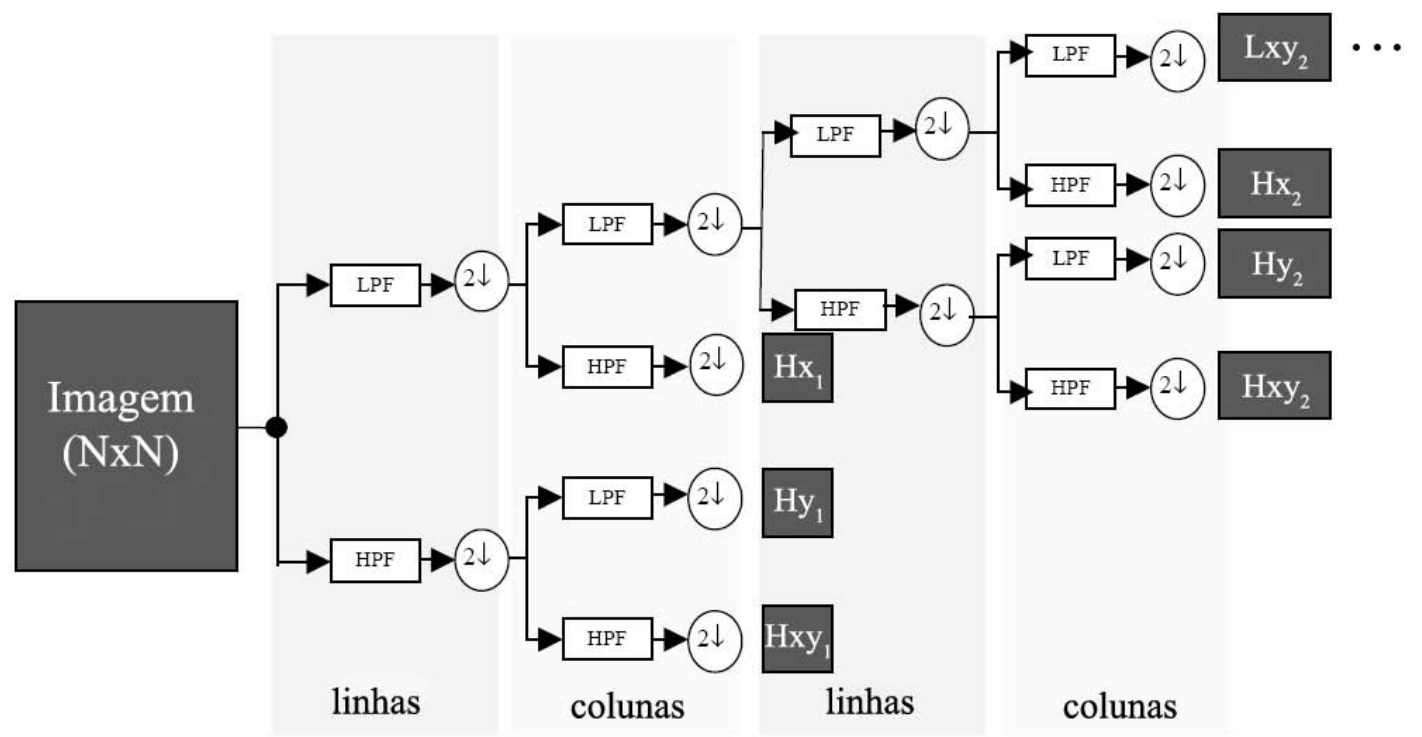

Figura 3.4: Decomposição progressiva das linhas e colunas da imagem [3].

A Figura 3.5 ilustra um exemplo de decomposição de imagem e apresenta a configuração das regiões após esse processo.

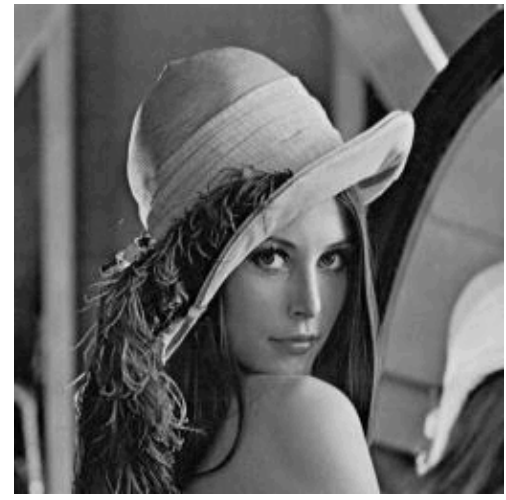

(a)

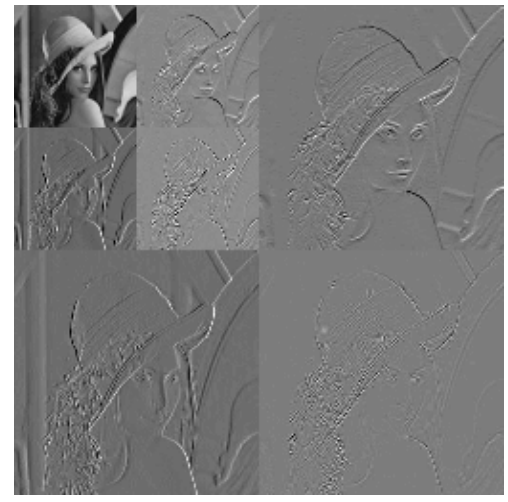

(b)

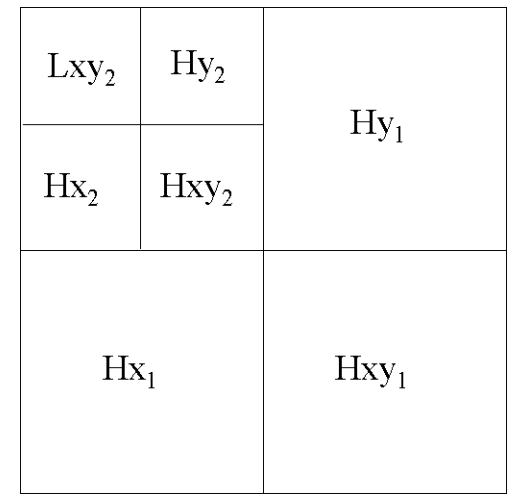

(c)

Figura 3.5: Exemplo de decomposição wavelet. (a) imagem original; (b) imagem decomposta em duas etapas a partir das wavelets de Haar; (c) configuração das regiões após a decomposição.

\subsubsection{Medidas da transformada de Wavelet}

Uma observação cuidadosa do resultado da decomposição wavelet (Figura 3.5) indica que existe uma relação hierárquica entre os distintos subespaços gerados. É formada uma estrutura piramidal de sub-imagens com várias resoluções correspondentes às diferentes etapas da decomposição. Por exemplo, o subespaço $\mathrm{Hx}_{1}$ tem informação similar ao subespaço $\mathrm{Hx}_{2}$, porque ambos os subespaços expressam elementos de alta freqüência na direção horizontal, mas em escalas distintas da imagem. 
O cálculo dos vetores de características está baseado em medidas dos subespaços da decomposição wavelet. Diversas medidas podem ser obtidas desses espaços. Na maioria dos estudos que utilizam a transformada de wavelet para extração de características da imagem, calcula-se o valor de energia para cada subespaço da transformada, obtendo-se um vetor de características com $N$ medidas correspondentes a cada subespaço [84, 85, 3]. Também é possível considerar outras medidas, também para cada subespaço, tais como os primeiros momentos estatísticos (média, variância, inclinação, curtose), e entropia.

Assim como as medidas da transformada bi-dimensional de Fourier, as medidas da transformada de wavelet podem ser consideradas características de textura da imagem. Por exemplo, valores altos de energia nos subespaços de altas freqüências nas direções horizontal e vertical, separadamente, exprimem características de direcionalidade da textura enquanto as medidas dos subespaços de altas freqüências em ambas as direções representam a noção de espessura.

\subsection{Considerações finais}

Neste Capítulo foi apresentada uma revisão de alguns dos principais métodos de extração de características de imagens baseados em textura e forma, que estão mais relacionados ao trabalho desenvolvido e apresentado nesta tese.

Em especial, as propriedades de ortogonalidade e invariância às transformações geométricas dos momentos de Zernike fazem deles uma técnica robusta de caracterização da imagem, que é empregada em muitos trabalhos de CBIR [86, 87, 88, 89]. Por esse motivo essa técnica foi escolhida para fazer parte de um estudo comparativo envolvendo a nova técnica de extração de características de imagens médicas desenvolvida e apresentada no Capítulo 5. 



\section{Segmentação de imagens}

A segmentação é um processo que consiste na subdivisão de uma imagem em regiões distintas, levando-se em consideração duas propriedades básicas das imagens: descontinuidade e homogeneidade. A segmentação é a principal etapa para a análise automática de imagens. A partir dela são delimitados objetos que podem ser utilizados em processos subseqüentes, tal como classificação, descrição, contagem, reconhecimento, entre outros.

O princípio da segmentação foi introduzido no início do século XX por alguns psicólogos alemães (Khler, Wertheimer e Kofftka) [90]. Eles mostraram que o sistema de visão humana realiza agrupamentos baseados na proximidade, similaridade e continuidade das imagens captadas. Tais agrupamentos são utilizados na classificação e análise semântica dos objetos percebidos. Esta idéia foi estendida para o contexto computacional e deu origem aos primeiros algoritmos de segmentação de imagens.

O ideal da segmentação é que cada região obtida no resultado esteja diretamente relacionada com um objeto real contido na imagem, como por exemplo um automóvel ou uma pessoa; e que também se possa fazer distinção do plano de fundo (background) da mesma.

Existem na literatura diversas taxonomias para classificação dos métodos de segmentação de imagem. Neste Capítulo será considerada a mesma taxonomia adotada por Gonzales [77] que classifica os métodos de segmentação em três categorias básicas: limiarização (thresholding); segmentação baseada em bordas; e segmentação baseada em regiões. Recentemente várias outras categorias são levadas em consideração.

Dentre elas estão os métodos baseados em cores [91, 92, 93], os que utilizam técnica de classificação e de agrupamento de dados [94, 95, 96] e algoritmos genéticos [97, 98, 99, 100, $101]$.

Neste Capítulo são apresentados alguns dos principais métodos de segmentação de imagens encontrados na literatura, incluindo os métodos cujos conceitos são utilizados diretamente na realização deste trabalho, em especial a segmentação pela transformada de watershed e o método EM/MPM baseado nos modelos de Markov. 


\subsection{Limiarização (Thresholding)}

A limiarização é o método mais simples e intuitivo de segmentação de imagens. Basicamente, todos os pixels que estão dentro de uma faixa de intensidade são classificados como pertencentes a uma mesma região. Em sua forma mais geral a limiarização pode ser descrita matematicamente como:

$$
S(i, j)=k \quad \text { se } \quad T_{k-1} \leq f(i, j)<T_{k} \quad \text { para } \quad k=1,2, \ldots, m
$$

onde $S(i, j)$ é a função resultante, $f(i, j)$ é a função original (imagem), $T_{0}, \ldots, T_{m}$ são os valores de limiarização (thresholding) e $m$ é o número de classes distintas a serem aplicadas à imagem.

Se $m=2$, o método de limiarização é denominado limiarização binária. Para $m>2 \mathrm{o}$ método é descrito como limiarização multi-modal.

A limiarização é geralmente aplicada a imagens que possuem áreas homogêneas sobre um plano de fundo uniforme. Uma aplicação comum para a limiarização binária é a extração de texto da imagem digitalizada de uma página.

Existem várias técnicas para se determinar os valores de corte $T_{0}, \ldots, T_{m}$. Uma delas é a própria seleção manual, baseada no melhor resultado obtido após o teste com vários valores por parte do usuário. Dentre as técnicas automáticas, a mais tradicional, e também a mais intuitiva, baseia-se na detecção dos pontos de mínimo do histograma da imagem (vales) [102]. O histograma é uma função que indica o nível de ocorrência de um determinado nível de cinza dentro da imagem ou, para imagens coloridas, o nível de ocorrência de cada cor. É coerente pensar que nas regiões de mínimo local do histograma, há uma barreira que separa objetos. Sendo assim, os valores e limiar $T_{0}, \ldots, T_{m}$ serão os pontos de mínimo do histograma. Um problema desta técnica está no fato de que muitas vezes os vales são longos e planos, tornando a escolha do limiar uma busca arbitrária. Também, é possível que os vales assumam valores muito baixos, o que proporciona ao método uma sensibilidade maior aos ruídos.

A Figura 4.1 ilustra um típico histograma bimodal (histograma que possui apenas um ponto de mínimo local e dois picos). O limiar $T_{1}$ foi selecionado a partir do único ponto de mínimo da função. $T_{0}$ e $T_{2}$ correspondem, respectivamente, à mínima e à máxima intensidade do histograma.

A maioria das técnicas automáticas para escolha dos níveis de corte se baseiam no histograma. A tradicional técnica de Otsu [77], por exemplo, é reconhecida por ser bem eficiente. Ela se baseia na escolha do valor de corte que maximiza a medida de variância entre duas partes do histograma, ou seja, o objetivo é encontrar $T$ que minimize a função:

$$
u(T)=q_{1}(T) \sigma_{1}^{2}(T)+q_{2}(T) \sigma_{2}^{2}(T)
$$

onde:

- $q_{1}(T)$ é o número de pixels cuja intensidade é menor que $T$; 
- $q_{2}(T)$ o número de pixels com intensidade superior a $T$;

- $\sigma_{1}^{2}(T)$ variância dos pixels cuja intensidade é menor que $T$;

- $\sigma_{2}^{2}(T)$ variância dos pixels cuja intensidade é maior que $T$.

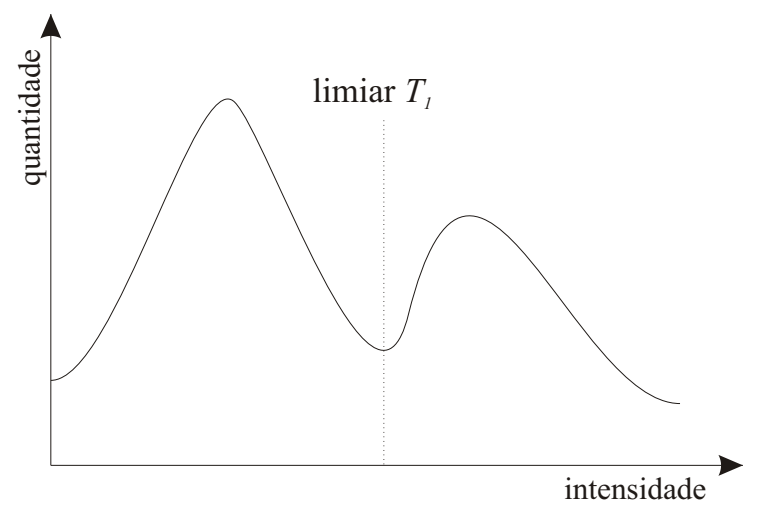

Figura 4.1: Seleção do limiar (threshold) ótimo para um histograma bimodal.

\subsection{Métodos baseados na detecção de bordas}

Os métodos de segmentação baseados na detecção de bordas envolvem, basicamente, a localização de regiões da imagem onde a variação dos tons de cinza ocorre de maneira relativamente abrupta. As descontinuidades, como são chamadas, podem ocorrer na forma de pontos isolados, linhas, segmentos ou curvas e, a partir delas, são formados os contornos, ou bordas, dos objetos contidos na imagem.

Após a detecção das descontinuidades segue-se, geralmente, a aplicação de algum método capaz de conectar tais fragmentos e gerar contornos que estejam associados com os contornos reais dos objetos. Estes métodos são denominados algoritmos de enlace (edge linking algorithms) e na maioria das vezes eles fazem uso das técnicas de percurso em grafos.

A detecção de descontinuidades é geralmente realizada a partir da aplicação de um operador de derivação local sobre uma imagem $f$, tal como a função gradiente $G(f)$ e o Laplaciano $L(f)$, que são operadores de derivação de primeira e segunda ordem, respectivamente.

A Figura 4.2 ilustra o comportamento da primeira e da segunda derivada para dois tipos de linhas verticais: uma linha branca em um fundo escuro e uma linha escura em um fundo branco. Embora a Figura ilustre apenas uma amostra unidimensional da função é fácil estender o exemplo para duas dimensões.

Para uma função bi-dimensional $f(x, y)$, uma imagem por exemplo, o gradiente é definido da seguinte maneira:

$$
\nabla f(x, y)=G[f(x, y)]=\left[\begin{array}{c}
G_{x} \\
G_{y}
\end{array}\right]=\left[\begin{array}{c}
\frac{\partial f}{\partial x} \\
\frac{\partial f}{\partial y}
\end{array}\right]
$$




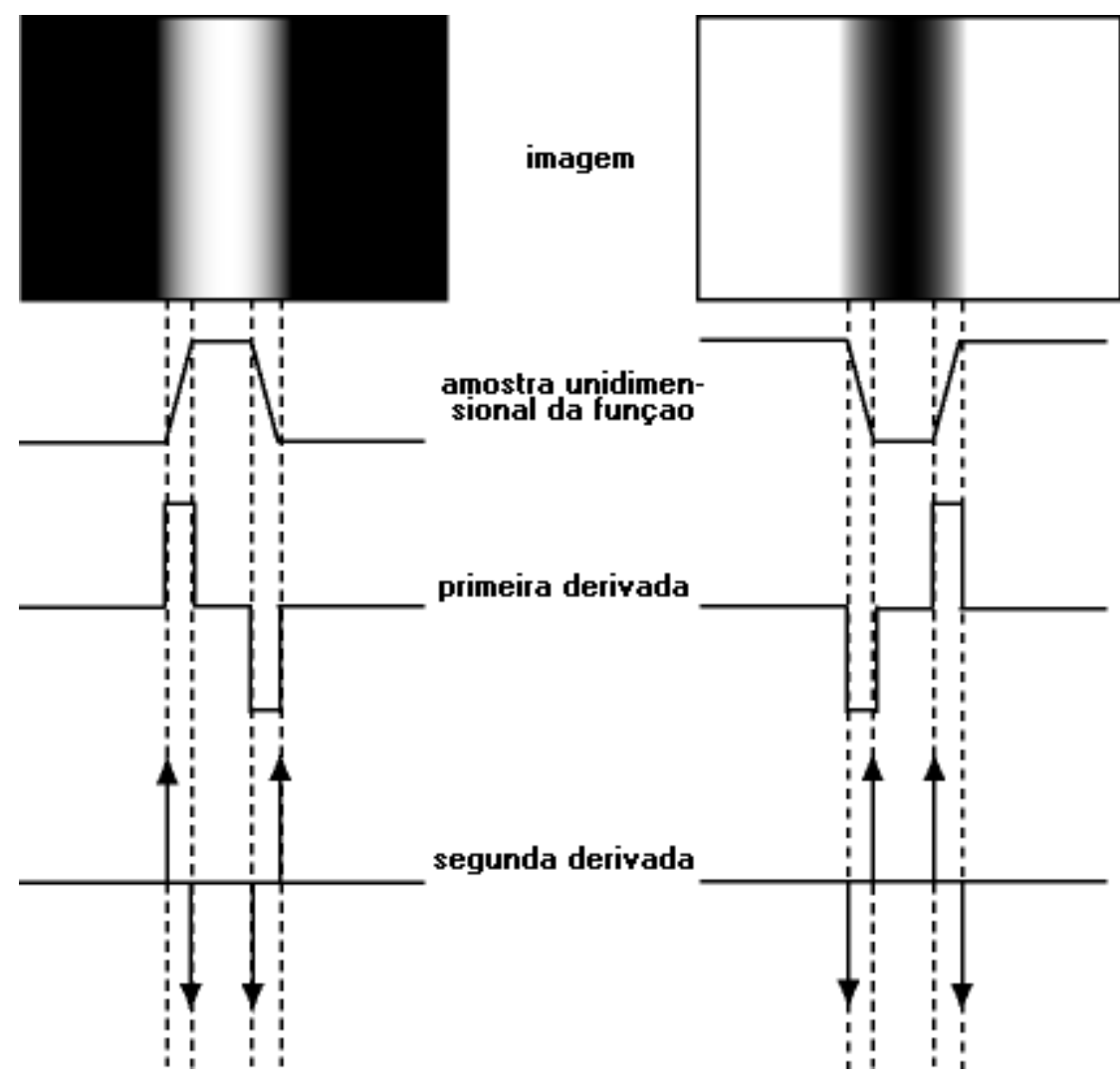

Figura 4.2: Primeira e segunda derivada de uma amostra unidimensional de uma imagem.

A tarefa de detecção de contornos requer apenas a informação da magnitude do vetor gradiente que, por conveniência, é simplesmente referenciada como o gradiente da imagem:

$$
|G[f(x, y)]|=\sqrt{G_{x}^{2}+G_{y}^{2}}
$$

Outra informação importante é a direção do gradiente em um ponto qualquer da imagem $(\theta(x, y))$. Ela é utilizada para conectar os contornos obtidos através do gradiente e é definida da seguinte maneira:

$$
\theta(x, y)=\arctan \left(\frac{G_{y}}{G_{x}}\right)
$$

onde o ângulo $\theta$ é medido com relação ao eixo $x$.

No domínio espacial, os gradientes parciais $G_{x}$ e $G_{y}$ de uma imagem são calculados a partir da operação de convolução de máscaras. Os operadores de Sobel [77], por exemplo, são máscaras 3x3 comumente utilizadas nesta tarefa. Tais operadores estão ilustrados na Figura 4.3. A Figura 4.4 ilustra um exemplo da aplicação destas máscaras.

\subsubsection{Algoritmos de Enlace (Edge Linking)}

Os algoritmos de enlace produzem contornos vetoriais a partir da imagem de bordas realçadas. No entanto, esta pode não ser uma tarefa das mais simples devido aos ruídos que geram descontinuidades nas bordas dos objetos. Os métodos mais conhecidos são os de análise local, análise baseada na transformada de Hough e percurso em grafos [77]. 


\begin{tabular}{|c|c|c|}
\hline 1 & 2 & 1 \\
\hline 0 & 0 & 0 \\
\hline-1 & -2 & -1 \\
\hline
\end{tabular}

(a)

\begin{tabular}{|l|l|l|}
\hline-1 & 0 & 1 \\
\hline-2 & 0 & 2 \\
\hline-1 & 0 & 1 \\
\hline \multicolumn{3}{|c|}{ (b) }
\end{tabular}

(b)

Figura 4.3: Operadores de Sobel (a) máscara usada para computar $G_{y}$; (b) máscara usada para computar $G_{x}$.

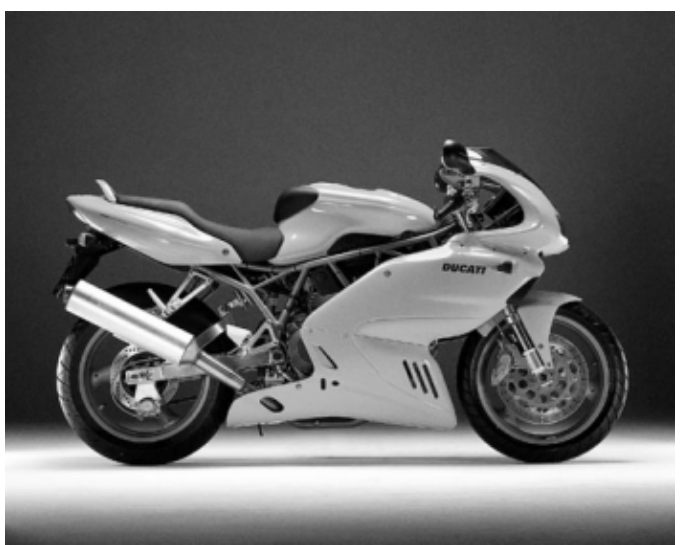

(a)

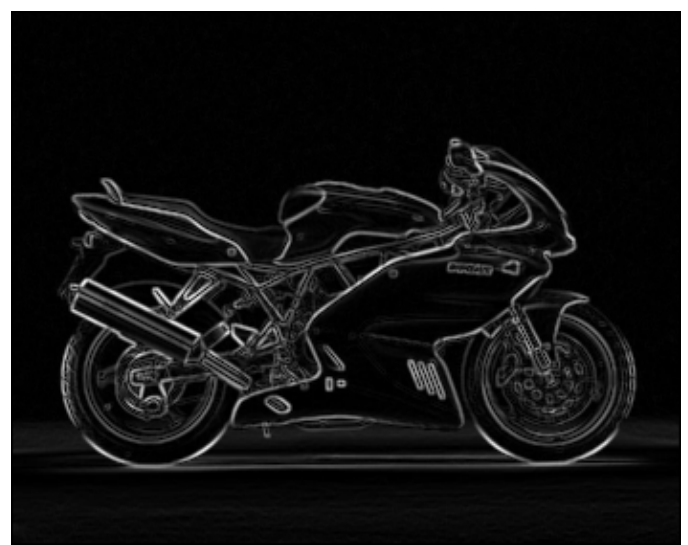

(b)

Figura 4.4: Exemplo da utilização dos operadores de Sobel. (a) imagem original; (b) imagem gradiente $\sqrt{G_{x}^{2}+G_{y}^{2}}$.

A análise local é a mais simples de todas. Ela consiste em analisar as características de todos os pixels da imagem dentro de uma vizinhança pequena, geralmente $3 \times 3$ ou $5 \times 5$. Todos os pontos que possuem características similares são conectados, formando uma fronteira de pixels que compartilham características em comum.

Neste método, as características principais de análise são a intensidade e a direção do gradiente da imagem. Como já foi dito na seção anterior, a intensidade do gradiente é dada por $|G[f(x, y)]|$. Para se dizer que dois pixels vizinhos são similares na intensidade dos seus gradientes, basta verificar se $|G[f(x, y)]|-\left|G\left[f\left(x^{\prime}, y^{\prime}\right)\right]\right| \leq T$, onde $T$ é um limiar pré-estabelecido. Analogamente diz-se que dois pixels são similares nas direções de seus gradientes se $\left|\theta(x, y)-\theta\left(x^{\prime}, y^{\prime}\right)\right| \leq A$, onde $A$ é o ângulo limite.

O método baseado na transformada de Hough é utilizado para encontrar curvas específicas dentro da imagem, tais como retas, circunferências ou elipses. A idéia é transferir a imagem original do espaço cartesiano para o espaço dos parâmetros da curva procurada. O resultado desta operação irá mapear em um único ponto $p$, no espaço dos parâmetros, todos os pontos da imagem original pertencentes à curva cujos parâmetros são as coordenadas de $p$. Deste modo, para se detectar curvas específicas, basta procurar no espaço dos parâmetros os pontos de maior evidência.

Os métodos de percurso em grafos são, em geral, bem mais complicados, porém possuem a vantagem de fornecer resultados satisfatórios em presença de ruídos [90]. Esta é uma técnica de análise global que consiste em representar segmentos de reta na forma de uma estrutura em grafo e, a partir desta estrutura, encontrar caminhos de menor custo, que representam 
contornos significativos na imagem. Facon [90] e Gonzales [77] apresentam um estudo mais elaborado desta técnica.

\subsubsection{Modelos de contorno ativo - Snakes}

Os modelos de contorno ativo (ou snakes) foram desenvolvidos por Kass, Witkin e Terzopoulos [103] com o objetivo principal de ajustar curvas suaves às bordas de regiões de interesse de uma imagem. As snakes, ou contornos ativos, são curvas definidas no domínio da imagem que podem se mover sob a influência de "forças" intrínsecas à geometria da própria curva (internas) e "forças" provenientes da imagem (externas). Tais forças, internas e externas, são definidas de tal maneira que a forma inicial do contorno ativo seja atraída para as bordas de objetos da imagem adaptando/modelando-se em torno dos mesmos em um processo de convergência. De fato, a principal aplicação dos modelos ativos é a tarefa de encalço de movimento (motion tracking) [104, 105, 106].

As principais limitações encontradas na formulação original das snakes são as seguintes:

- posição e forma iniciais da snake devem ser bem próximas da borda do objeto ao qual de deseja que a curva se adapte;

- dificuldade de adaptação em concavidades do objeto e;

- não são previstas alterações topológicas para que uma snake possa se dividir em duas, por exemplo.

Tendo em vista tais limitações, diversos estudos têm sido apresentados no sentido de apresentar melhorias à formulação original [107, 108, 4, 109, 110, 111, 112, 113, 114].

\section{Modelo matemático original}

Uma snake é definida como uma curva parametrizada $v(s)=(x(s), y(s)), s \in[0,1]$ que possui uma configuração inicial (posição e formato) geralmente definida pelo usuário.

Define-se uma função de energia potencial associada à snake, de modo que essa energia seja mínima quando a snake se encontrar sobre o contorno de algum objeto da imagem. Dessa maneira, o problema de detecção de bordas é convertido em um problema de otimização. Neste caso, o problema de otimização a ser resolvido é o de encontrar uma configuração da snake que minimize o seguinte funcional de energia:

$$
E_{\text {snake }}=\int_{0}^{1} \frac{1}{2}\left(\alpha(s)\left|v^{\prime}(s)\right|^{2}+\beta(s)\left|v^{\prime \prime}(s)\right|^{2}\right)+E_{\text {ext }}(s) d s
$$

A primeira parcela da integral corresponde à energia interna da snake e controla as características de rigidez e elasticidade da curva. O termo de primeira ordem $v^{\prime}(s)$ faz com que a snake atue como uma membrana elástica, com tendência a esticar-se ou contrair-se dependendo do valor de ponderação $\alpha(s)$. 
O termo de segunda ordem $v^{\prime \prime}(s)$ controla a capacidade de flexão da curva, segundo o parâmetro de ponderação $\beta(s)$. Se este parâmetro fosse nulo, por exemplo, a curva poderia desenvolver uma descontinuidade de segunda ordem, ou seja, uma quina. Por outro lado, quanto maior o valor de $\beta$ mais resistente à flexão se torna a curva.

A segunda parcela da integral $\left(E_{\text {ext }}(s)\right)$ corresponde à energia externa sob a qual a curva está submetida. Ela é responsável por atrair a snake para regiões de interesse na imagem, como as bordas de determinados objetos. Na formulação original proposta por Kass et al., são apresentadas três opções de função de energia externa sendo que a mais comum corresponde ao módulo do gradiente da imagem. Neste caso, a snake será atraída para regiões da imagem onde o gradiente é alto, ou seja, para as bordas dos objetos.

Outro funcional de energia externa, proposto no artigo de Chenyang Xu e Jerry L. Prince [4] tem a vantagem de aumentar consideravelmente a intensidade do campo de atração ao qual a snake está submetida com a vantagem de não comprometer a adaptação correta da curva ao contorno do objeto. O mapa de fluxo do vetor gradiente (Gradient Vector Flow), como é denominado, consiste em um campo vetorial $\mathrm{v}(x, y)=[u(x, y), v(x, y)]$ que minimiza outro funcional de energia pré-definido. Ocorre, porém, que a obtenção deste campo é mais custosa comparada com os demais funcionais, já que este é proveniente de um processo iterativo.

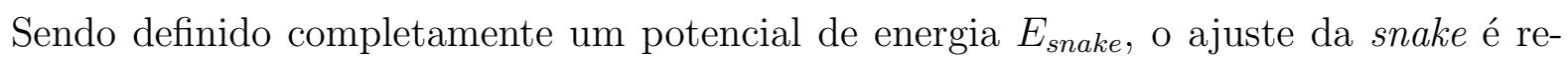
alizada por métodos numéricos que procuram encontrar uma configuração da curva que minimize o potencial $E_{\text {snake }}$. Diversos métodos são propostos para minimizar o potencial de energia da snake. Os principais encontrados na literatura incluem a solução do sistema de equações de Euler-Lagrange associado à função de energia [103, 115, 4], programação dinâmica [116] e abordagem Greedy [117].

A Figura 4.5 ilustra um exemplo de segmentação da cavidade do ventrículo esquerdo de um coração humano. A Figura 4.5d apresenta as etapas de deformação da snake até encontrar a sua posição de equilíbrio. Neste exemplo, foi utilizado um mapa de fluxo do vetor gradiente (Gradient Vector Flow) como funcional de energia externa da snake (Figura 4.5c). Também se encontra ilustrado na Figura $4.5 \mathrm{~b}$ o funcional de energia $\left|\nabla\left[\mathcal{G}_{\sigma}(x, y) * I(x, y)\right]\right|^{2}$ $\operatorname{com} \sigma=2.5$.

\subsection{Métodos baseados em regiões}

Enquanto os métodos de limiarização e os métodos baseados em bordas delimitam objetos na imagem encontrando diferenças nas tonalidades dos pixels ou conjunto de pixels, os métodos baseados em regiões abordam a procura de similaridades entre os mesmos. As técnicas mais tradicionais desta categoria são o Crescimento de Região (Region Growing) [118, 119, 120] e Divisão e Fusão (Split and Merge) [121, 122, 123]. Nesta seção, entretanto, vamos apenas apresentar o método baseado em watersheds cujos conceitos principais foram empregados no trabalho desenvolvido e apresentado no Capítulo 6. 


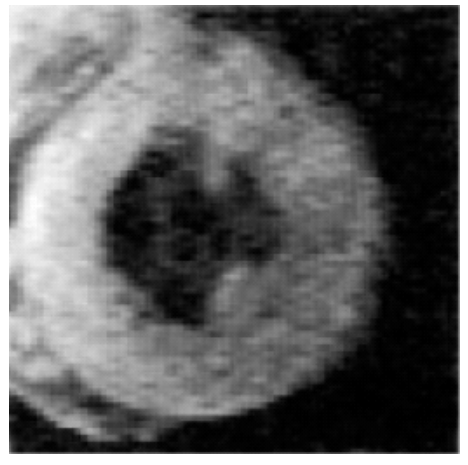

(a)

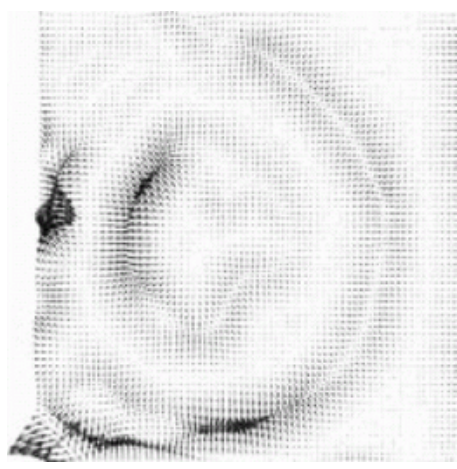

(b)

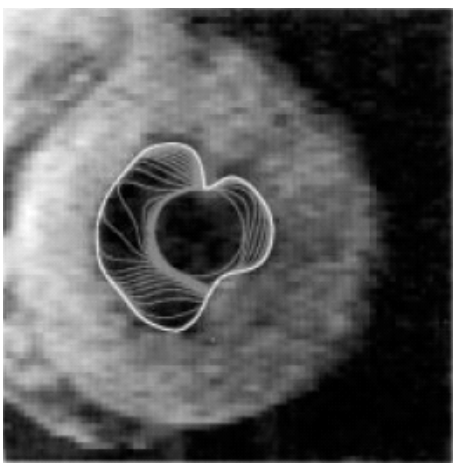

(c)

Figura 4.5: Exemplo de segmentação utilizando snakes (a) imagem de ressonância magnética do ventrículo esquerdo de um coração humano; (b) mapa de fluxo do vetor gradiente ( $\mathrm{Gra-}$ dient Vector Flow); (c) etapas de ajuste da snake até a posição de equilíbrio [4].

\subsubsection{Watersheds}

A transformada de watershed [124] é uma técnica de segmentação de imagens pertencente ao campo da morfologia matemática $[2,125]$, que pode ser considerada como um tipo de segmentação por região.

O conceito da transformada de watershed foi originalmente proposto por Digabel e Lantuéjoul [126] e posteriormente elaborado por Beucher e Lantuéjoul [127]. A idéia básica desta técnica consiste em observar uma imagem digital em tons de cinza como se ela fosse uma superfície montanhosa, sendo que a altitude de cada ponto está diretamente relacionada ao nível de cinza do pixel correspondente. Uma gota de água que cair sobre esta superfície irá percorrer o caminho mais íngreme até chegar em uma região de mínimo. O conjunto de todos os pontos (pixels) para os quais uma gota de água cai e converge para a mesma região de mínimo é chamado represa (catchment basin). Porém, para alguns pontos não é possível se determinar para onde irá escorrer a gota de água que ali cair. O conjunto desses pixels constitui as fronteiras das represas e são denominados divisores de água (watersheds). A Figura 4.6 ilustra tais conjuntos.
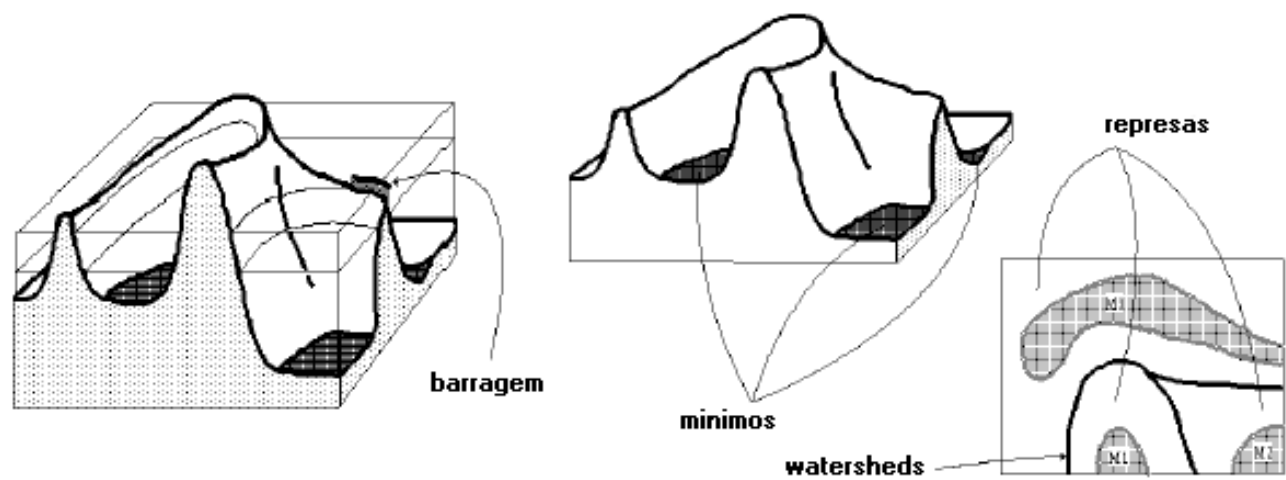

Figura 4.6: Ilustração dos divisores de água (watersheds) e represas (catchment basins). Visões sob perspectiva e "visão aérea" [5].

Existem diversas definições matemáticas para este conceito informal da transformada de 
watershed, porém, na maioria dos casos, as diferenças entre elas são muito sutis.

Em geral, a transformada de watershed é aplicada sobre o gradiente de uma imagem (ver Figura 4.4). Isto porque os contornos da imagem estão realçados após a aplicação do gradiente, tornando mais fácil o processo de segmentação.

\section{Algoritmo clássico de alagamento, ou imersão}

Uma definição algorítmica da transformada de watershed foi proposta por Vincent e Soille [128]. Seja $f$ uma imagem digital em tons de cinza com $h_{\min }$ e $h_{\max }$ sendo, respectivamente, os valores mínimo e máximo que um pixel da imagem pode assumir. Define-se uma recursão com o nível de cinza $h$ aumentando de $h_{\min }$ a $h_{\max }$, na qual as represas associadas com regiões de mínimo de $f$ são sucessivamente expandidas. Seja $X_{h}$ a união de todas as represas computadas no nível $h$. Um componente conexo do conjunto $T_{h+1}$ (pixels com nível de cinza menor ou igual a $h+1$ ) pode tanto ser uma nova região de mínimo quanto uma extensão de alguma represa pertencente a $X_{h}$. No segundo caso, é computada a zona de influência geodésica [124] de $X_{h}$ com relação ao conjunto $T_{h+1}\left(I Z_{T_{h+1}}\left(X_{h}\right)\right)$, resultando na atualização $X_{h+1}$. A transformada de watershed de $f$ é o complemento de $X_{h_{\max }}$ sob o domínio $D$ da imagem, ou seja:

$$
\operatorname{wshed}(f)=D \backslash X_{h_{\max }}
$$

Para um exemplo prático desta recorrência observe a Figura 4.7. Neste exemplo, A e B são utilizados para denotar represas (regiões) distintas, e W para denotar as linhas divisórias (watersheds). A Figura 4.7a ilustra a imagem original em tons de cinza. A recursão ocorre do nível $h_{\text {min }}=0$ ao nível $h_{\max }=3$ considerando uma vizinhança 4-conectada. Para $h=0, X_{h}$ é a união de todas as regiões conexas com intensidade igual a zero $\left(T_{h_{\text {min }}}\right)$. Observa-se então a criação de duas regiões distintas $\mathbf{A}$ e $\mathbf{B}$. No segundo passo $(h=1)$, a zona de influência geodésica é calculada para os subconjuntos $\mathbf{A}$ e $\mathbf{B}$ sob o conjunto $T_{h+1}=T_{2}$ (conjunto de todos os pontos com intensidade menor ou igual a dois). Alguns pontos estão eqüidistastes de $\mathbf{A}$ e de $\mathbf{B}$, portanto são demarcados provisoriamente como W. Os demais são agregados à região mais próxima, como é o caso do pixel logo acima de $\mathbf{B}$ na Figura 4.7b. O resultado deste passo é a Figura 4.7c. No passo seguinte, novamente calcula-se $I Z_{T_{h+1}}\left(X_{h}\right)$ para $h=2$, resultando na Figura 4.7d. Nota-se que o pixel central da imagem, que no passo anterior fora denominado $\mathrm{W}$, passa a fazer parte da região $\mathbf{B}$ sendo conectado pela vizinhança definida. Por fim, a Figura 4.7e ilustra o resultado final da segmentação. Os pontos das regiões A e B formam o conjunto $\left(X_{h_{\max }}\right)$. A transformada de watershed, conforme mencionado, é o complemento deste conjunto sob o domínio da imagem, ou seja, todos os pontos da imagem rotulados W. 


\begin{tabular}{|l|l|l|}
\hline 3 & 2 & 2 \\
\hline 3 & 1 & 1 \\
\hline 0 & 1 & 0 \\
\hline \multicolumn{3}{|c|}{ (a) } \\
\end{tabular}

\begin{tabular}{|l|l|l|}
\hline 3 & 2 & 2 \\
\hline 3 & 1 & 1 \\
\hline $\mathbf{A}$ & 1 & $\mathbf{B}$ \\
\hline \multicolumn{3}{|c|}{ (b) $\mathrm{h}=0$} \\
\hline
\end{tabular}

\begin{tabular}{|c|c|c|}
\hline 3 & 2 & 2 \\
\hline 3 & $\mathrm{~W}$ & $\mathbf{B}$ \\
\hline A & $\mathrm{W}$ & $\mathbf{B}$ \\
\hline \multicolumn{3}{|c|}{ (c) $\mathrm{h}=1$} \\
\hline
\end{tabular}

\begin{tabular}{|c|c|c|}
\hline 3 & B & B \\
\hline 3 & B & B \\
\hline A & W & B \\
\hline \multicolumn{3}{|c}{ (d) $\mathrm{h}=2$} \\
\end{tabular}

\begin{tabular}{|c|c|c|}
\hline B & B & B \\
\hline $\mathrm{W}$ & $\mathbf{B}$ & $\mathbf{B}$ \\
\hline $\mathbf{A}$ & $\mathrm{W}$ & $\mathbf{B}$ \\
\hline \multicolumn{2}{|c}{$\mathrm{e}) \mathrm{h}=3$} \\
\hline
\end{tabular}

Figura 4.7: Ilustração do algoritmo de alagamento utilizando uma vizinhança 4-conectada (a) imagem original; (b-e) etapas da rotulação.

\section{Super-Segmentação (Over-Segmentation)}

A transformada de watershed possui propriedades interessantes que a torna útil para a segmentação de diversas categorias de imagens: ela é simples, intuitiva e o seu processo pode ser paralelizado. Entretanto alguns problemas existem nesta abordagem, sendo o principal deles a "super-segmentação" (over-segmentation). Isto ocorre geralmente quando a transformada é aplicada sobre imagens complexas ou ruidosas, produzindo um resultado carregado de muitas regiões e detalhes indesejáveis. Um exemplo de super-segmentação é ilustrado na Figura 4.8.

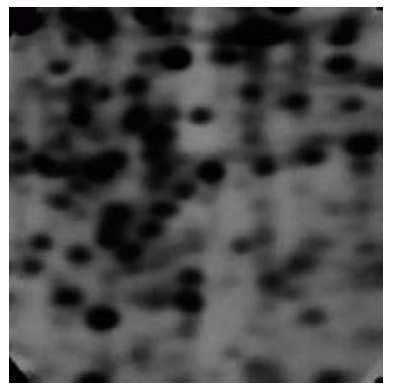

(a)

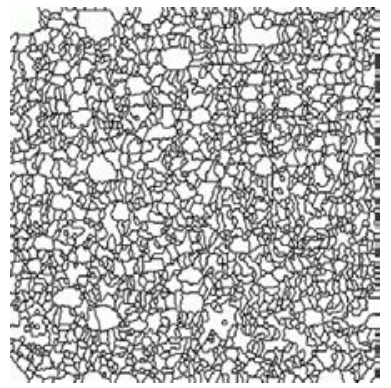

(b)

Figura 4.8: Exemplo de super-segmentação. (a) imagem original (gel de electroforese); (b) imagem super-segmentada [5].

Para suprimir este problema, existe uma variação da transformada que utiliza um esquema de marcadores. As represas iniciais são somente as regiões que contém os marcadores e não mais todas as regiões de mínimo. Ver Figura 4.9.

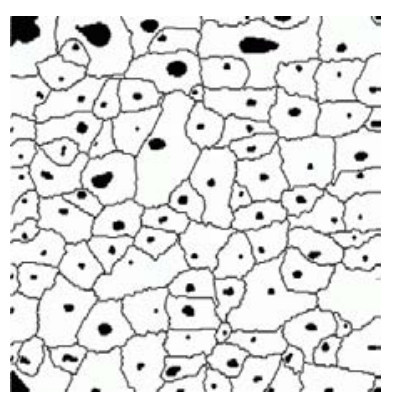

(a)

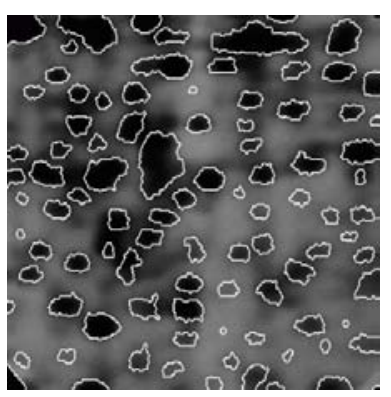

(b)

Figura 4.9: Transformada de watershed a partir de marcadores. (a) marcadores da imagem da Figura 4.8a; (b) resultado da transformada de watershed [5].

Em alguns casos a determinação dos marcadores pode ser feita por intermédio do usuário. 
Porém, muitas aplicações necessitam de um processo automático para esta tarefa. Basicamente, a determinação automática dos marcadores é feita a partir da extração dos pontos de máximo da transformada de distância da imagem binarizada. A transformada de distância, por sua vez, é uma nova imagem que indica para cada ponto do primeiro plano da imagem binarizada (foreground), qual a menor distância deste ponto até o fundo (background) desta mesma imagem.

Um exemplo desta transformada de distância é ilustrado na Figura 4.10. Quanto maior a distância de um pixel do primeiro plano ao background da imagem binarizada, maior a intensidade deste pixel na transformada de distância.

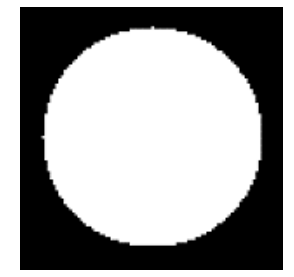

(a)

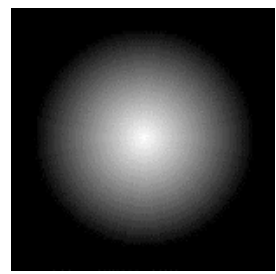

(b)

Figura 4.10: Exemplo de transformada de distância para uma imagem binarizada. (a)imagem original; (b) transformada de distância.

Uma nova e eficiente abordagem para seleção automática de marcadores foi desenvolvida no decorrer deste trabalho e é apresentada no Capítulo 6.

\section{Separação de partículas sobrepostas}

A separação de partículas sobrepostas em uma imagem binária é uma outra aplicação interessante para a transformada de watershed. Trata-se de uma operação bem comum que se destina a separar objetos (geralmente circulares) em uma imagem, visando a contabilização dos mesmos. Por exemplo, realizar a contagem de um conjunto de moedas em uma mesa (na imagem binarizada várias moedas poderão estar sobrepostas) ou realizar a contagem de células do sangue. Basicamente, o esquema de separação de partículas segue a seguinte ordem:

- binarização da imagem (thresholding);

- cálculo da transformada de distância;

- determinação dos marcadores;

- criação do negativo da transformada de distância; ${ }^{1}$

- aplicação da transformada de watershed sobre a imagem negativa.

A Figura 4.11 ilustra um exemplo da separação de partículas sobrepostas.

\footnotetext{
${ }^{1}$ Seja $I_{\text {max }}$ o maior nível de cinza em uma imagem $f(x, y)$. Define-se o negativo de $f(x, y)$ como sendo: $g(x, y)=I_{\max }-f(x, y)$.
} 


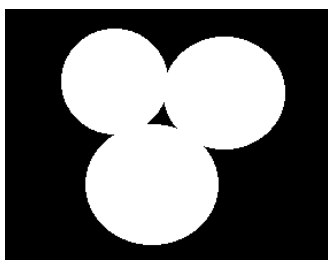

(a)

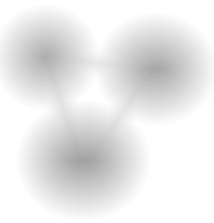

(b)

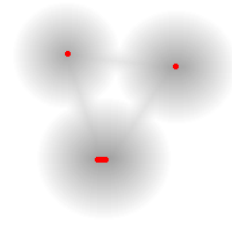

(c)

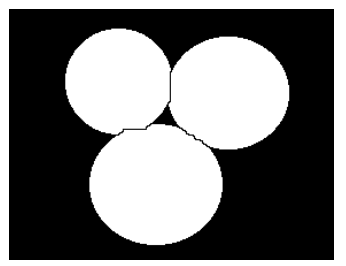

(d)

Figura 4.11: Exemplo de separação de partículas circulares parcialmente sobrepostas. (a) imagem binária das partículas; (b) negativo do mapa de distância euclidiano; (c) marcadores sobrepostos no mapa de distâncias (neste caso os marcadores são pontos de máximo local); (d) resultado da transformada de watershed.

\subsection{Métodos baseados em Textura}

Conforme Van Gool e Todd R. Reed [129, 55], os métodos de segmentação baseada em textura são classificados como:

- Métodos estatísticos;

- Métodos baseados em modelos e;

- Métodos estruturais

Os métodos estatísticos, também conhecidos como métodos baseados em características, seguem uma abordagem em etapas, que são geralmente três: a) extração de características locais de textura, por exemplo, utilizando técnicas discutidas no Capítulo 3 ; b) seleção ou redução do número de características caso haja um número muito grande delas e; c) utilização de algoritmos de aprendizado de máquina para classificação dos pixels. A grande desvantagem destes métodos está relacionada com a etapa de extração de características. Geralmente esta etapa demanda grande quantidade de processamento e grande quantidade de memória para armazenar as estruturas utilizadas [2].

A abordagem estrutural é empregada na classificação e segmentação de imagens que possuem texturas de comportamento bem definido, ou seja, determinísticos. Neste caso elas são compostas por um arranjo repetitivo de elementos estruturais denominados textels. Alguns exemplos deste tipo de textura estão ilustrados na Figura 4.12a-d. Visto que a maioria das texturas encontradas na natureza não possuem este tipo de comportamento (Figuras 4.12e-h), a utilização dos métodos estruturais abrange um conjunto limitado de problemas.

Os métodos baseados na utilização de modelos constituem uma categoria cuja utilização se estende a praticamente qualquer tipo de textura. Existem basicamente dois tipos de modelos utilizados nesta abordagem: os modelos Fractais e os modelos Estocásticos [55]. A utilização de métodos estocásticos para modelagem de imagens em algoritmos de segmentação é uma área importante e de rápido crescimento. Isto é refletido pelo grande número de aplicações que atualmente fazem uso desta técnica. 


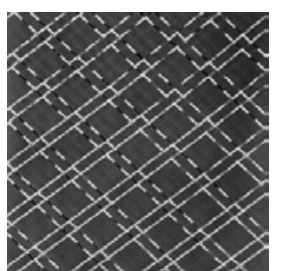

(a)

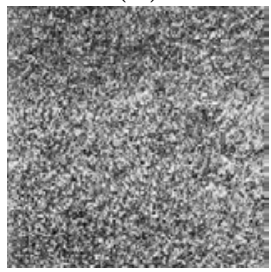

(e)

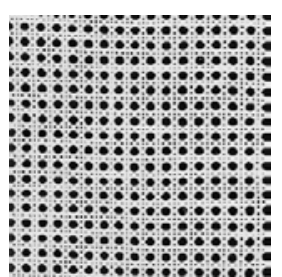

(b)

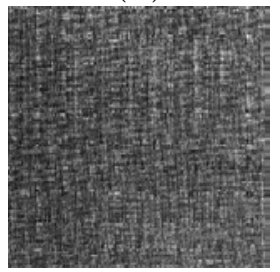

(f)

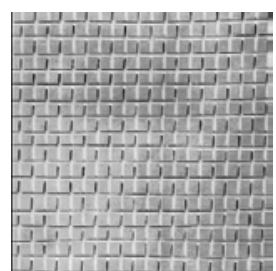

(c)

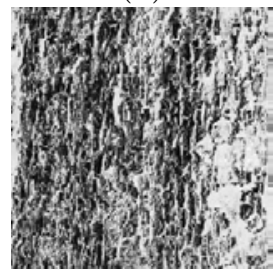

(g)

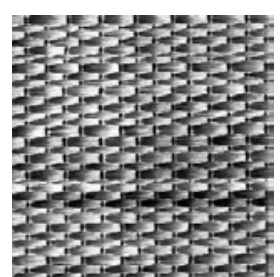

(d)

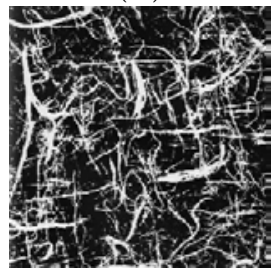

(h)

Figura 4.12: Exemplos de texturas extraídas do álbum de Brodatz [6] (a)-(d) texturas de comportamento determinístico; (e)-(h) texturas de comportamento aleatório.

Os Campos Aleatórios de Markov (Markov Random Fields - MRFs) constituem um modelo estocástico muito utilizado na segmentação de imagens baseada em texturas de comportamento não determinístico [130]. A idéia desse modelo é representar uma imagem através da captura de características locais, determinando para cada pixel a dependência de sua intensidade em relação às intensidades de seus vizinhos.

Nesta próxima seção é apresentado em detalhes o método de segmentação denominado EM/MPM [94, 131] que combina o bem conhecido algoritmo EM com o paradigma de classificação Bayesiano, utilizando os Campos Aleatórios de Markov. A metodologia do EM/MPM é empregada diretamente no trabalho desenvolvido e apresentado no Capítulo 5.

\subsection{Método de segmentação EM/MPM}

O EM/MPM é um método não-supervionado de segmentação de imagens. Nesta técnica são utilizados dois modelos: um Modelo de Mistura de Gaussianas (GMM) referente a imagem observada (em tons de cinza); e um campo aleatório de Markov (MRF) para o mapa de classificação dos pixels (futuro resultado da segmentação). O objetivo do algoritmo é, alternadamente, estimar os parâmetros do modelo GMM, por meio do método EM, e minimizar o número estimado de pixels classificados erroneamente no mapa de classes por meio de classificação Bayesiana [132].

Mais precisamente, a abordagem Bayesiana para este caso consiste, inicialmente, em eleger uma função densidade de probabilidade para o mapa de classes até então desconhecido. Tal função é denominada probabilidade prévia (prior probability), pois ela não é baseada em dados existentes. A partir desta distribuição deseja-se obter uma nova função, denominada probabilidade posterior (posterior probability). A probabilidade posterior, neste caso, é uma função de custo que indica o quão correto está o mapa de classes atual em relação ao resultado esperado, em vista da imagem observada. 
O tão conhecido teorema de Bayes postula que a probabilidade posterior é proporcional à probabilidade prévia vezes uma outra função denominada função de verossimilhança (likelihood function). Um bom esclarecimento a respeito desta função pode ser encontrado em [133]. Tanto ela quanto o teorema de Bayes serão abordados ao longo desta seção.

Algumas notações serão utilizadas a seguir para a descrição do método EM/MPM e dos modelos empregados. São elas:

- $X$ - mapa de classes (ou campo de rótulos);

- $Y$ - imagem observada;

- $S$ - espaço 2D onde $X$ e $Y$ estão definidos;

- $N$ - número de pixels em $S$;

- $x=\left(x_{1}, x_{2}, \ldots, x_{N}\right)$ - instância de $X=\left(X_{1}, X_{2}, \ldots, X_{N}\right)$;

- $y=\left(y_{1}, y_{2}, \ldots, y_{N}\right)$ - instância de $Y=\left(Y_{1}, Y_{2}, \ldots, Y_{N}\right)$

- $\Omega_{x}$ - espaço das possíveis instâncias de $X$;

- $\Omega_{y}$ - espaço das possíveis instâncias de $Y$;

- $L$ - número de classes para segmentação.

\subsubsection{Modelos das Imagens}

Conforme mencionado, no método EM/MPM é utilizado um campo aleatório de Markov para modelar o mapa de classes $X$. Um campo aleatório é basicamente uma malha 2D formada por variáveis aleatórias (variáveis que podem assumir qualquer valor e possuem uma função densidade de probabilidade associada). Neste caso as variáveis aleatórias são $\left(X_{1}, X_{2}, \ldots, X_{N}\right)$ e os valores que elas podem assumir são os valores associados a cada classe $\{1,2, \ldots, L\}$. Um campo aleatório de Markov é um campo aleatório onde a probabilidade de alguma variável aleatória assumir um valor qualquer, dado o conjunto de valores de todas as variáveis do campo, é igual à probabilidade desta mesma variável assumir um valor qualquer dado apenas os valores das variáveis definidas dentro de um sistema de vizinhança. Formalizando:

$$
P\left(X_{i}=x_{i} \mid x_{j}, j \in S\right)=P\left(X_{i}=x_{i} \mid x_{j}, j \in \eta_{i}\right)
$$

onde $\eta_{i}$ é o conjunto de pixels vizinhos de $i$, dado um sistema de vizinhança pré-estabelecido.

O esquema de vizinhanças para os campos de Markov segue o esquema da Tabela ilustrada na Figura 4.13. A vizinhança 4-conectada, em relação ao pixel "x", é obtida tomando-se apenas os valores "1" da Tabela e, neste caso, o campo é denominado de primeira ordem. 
Para um campo de ordem dois, os pixels enumerados "1" e "2" são escolhidos, e assim por diante. Para o método EM/MPM em particular é utilizado um campo de ordem um, mas nada impede que alguns testes sejam feitos para ordens maiores.

\begin{tabular}{|l|l|l|l|l|}
\hline 5 & 4 & 3 & 4 & 5 \\
\hline 4 & 2 & 1 & 2 & 4 \\
\hline 3 & 1 & $\mathrm{x}$ & 1 & 3 \\
\hline 4 & 2 & 1 & 2 & 4 \\
\hline 5 & 4 & 3 & 4 & 5 \\
\hline
\end{tabular}

Figura 4.13: Estruturas de vizinhanças para os campos aleatórios de Markov, considerando o elemento central $\mathrm{x}$.

Um conceito importante, ainda relacionado com a vizinhança utilizada no campo, é o conceito de cliques. Um clique é um conjunto de um ou mais pixels onde cada pixel é vizinho de todos os demais do conjunto (dado um sistema de vizinhança). Por exemplo, para a vizinhança de quatro pixels (ordem um) os cliques possíveis são o conjunto de todos os pixels individuais mais o conjunto das duplas de pixels adjacentes na vertical mais o conjunto de duplas adjacentes na horizontal, conforme ilustrado na Figura 4.14. O conjunto de todos os possíveis cliques de uma imagem é representado por $\mathcal{C}$ e a notação $\mathcal{G}_{s}$ será utilizada para referenciar o conjunto de pixels vizinhos do pixel $s$, dada a vizinhança estabelecida.

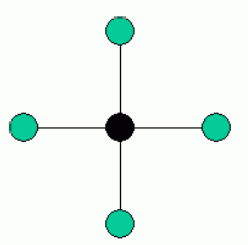

(a)
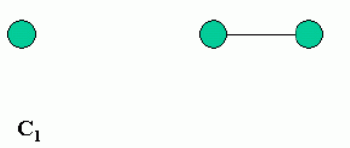

$\mathrm{C}_{2}$

Figura 4.14: Conjunto de cliques. (a) vizinhança de primeira ordem; (b) cliques correspondentes.

O conceito fundamental a respeito dos campos aleatórios de Markov está no teorema de Hammersley-Clifford [134] que diz que a probabilidade conjunta $p\left(X_{1}=x_{1}, X_{2}=\right.$ $\left.x_{2}, \ldots, X_{N}=x_{N}\right)$ de um campo de Markov, ou simplesmente $p(x)$, é equivalente a uma distribuição de Gibbs, ou seja:

$$
p(x)=\frac{\exp (-U(x))}{z}
$$

onde $z$ é uma constante de normalização e $U(x)$ é o somatório de alguma função potencial $V_{c}(x)$ dependente dos cliques da imagem, ou seja:

$$
U(x)=-\sum_{c \in \mathcal{C}} V_{c}(x)
$$


Esta fórmula assume um papel importante dentro do método de segmentação, pois ela representa a probabilidade prévia (prior probability) a ser utilizada dentro do paradigma Bayesiano. O modelo proposto por Mary L. Comer e Edward Delp [94], assim como outros modelos empregados em estudos anteriores sobre segmentação de imagens [135, 136, 137], utilizam a seguinte função $U(x)$ :

$$
U(x)=-\sum_{\{r, s\} \in \mathcal{C}} \beta t\left(x_{r}, x_{s}\right)+\sum_{\{r\} \in \mathcal{C}} \gamma_{x_{r}}
$$

onde

$$
t\left(x_{r}, x_{s}\right)= \begin{cases}0, & \text { se } x_{r}=x_{s} \\ 1, & \text { se } x_{r} \neq x_{s}\end{cases}
$$

O parâmetro $\beta$ constitui uma constante experimental que ajusta a correlação existente entre pixels vizinhos do modelo e por isso é denominada parâmetro de interação espacial. O conjunto de valores $\left\{\gamma_{k}\right\}$ corresponde aos parâmetros que regem a utilização dos cliques formados por um único pixel. $\mathrm{O}$ parâmetro $\gamma_{k}$ pode ser visto como uma estimativa de custo associada à classe $k$. Quanto maior for o valor de $\gamma_{k}$, menor será a probabilidade de ocorrência de regiões daquela classe.

Utilizando a função $U(x)$ definida em 4.5, a probabilidade prévia, que é probabilidade conjunta do campo aleatório de Markov, corresponde a:

$$
p(x)=\frac{\exp \left(\sum_{\{r, s\} \in \mathcal{C}} \beta t\left(x_{r}, x_{s}\right)-\sum_{\{r\} \in \mathcal{C}} \gamma_{x_{r}}\right)}{z}
$$

O objetivo desta seção, que descreve os modelos para o método de segmentação EM/MPM, é encontrar uma fórmula para a probabilidade posterior que é a chave da abordagem de classificação Bayesiana. Para isto é necessário também assumir um modelo para a imagem observada $Y$. Do mesmo modo, este modelo será uma malha 2D de variáveis aleatórias $\left(Y_{1}, Y_{2}, \ldots, Y_{N}\right)$.

O Modelo de Mistura de Gaussianas considera que as variáveis aleatórias $\left(Y_{1}, Y_{2}, \ldots, Y_{N}\right)$ são independentes, e associadas a uma função densidade de probabilidade do tipo $f\left(Y_{r}=\right.$ $\left.y_{r} \mid X_{r}=x_{r}, \theta_{x_{r}}\right)$, que indica a probabilidade de um pixel $r$ ter intensidade $y_{r}$, dado que este pixel pertence à classe $x_{r}$ no mapa de classes. Neste modelo também é considerado que $f\left(Y_{r}=y_{r} \mid X_{r}=x_{r}, \theta_{x_{r}}\right)$ é uma curva gaussiana, ou seja:

$$
f\left(Y_{r}=y_{r} \mid X_{r}=x_{r}, \theta_{x_{r}}\right)=\frac{1}{\sqrt{2 \pi \sigma_{x_{r}}^{2}}} \exp \left(-\frac{\left(y_{r}-\mu_{x_{r}}\right)^{2}}{2 \sigma_{x_{r}}^{2}}\right)
$$


onde $\theta_{x_{r}}$ são os parâmetros desconhecidos das gaussianas que compõem o modelo GMM.

Conforme dito anteriormente, a probabilidade posterior é proporcional à probabilidade prévia vezes a função de verossimilhança (likelihood function). Dado um conjunto de variáveis aleatórias independentes (uma malha 2D, por exemplo), a função de verossimilhança é a probabilidade conjunta do sistema, obtida através do produtório das probabilidades das variáveis [133]. No caso da imagem observada $Y=\left(Y_{1}, Y_{2}, \ldots, Y_{N}\right)$, a função de verossimilhança $L(\theta \mid X, Y)=f(y \mid x, \theta)$ é definida como:

$$
\begin{gathered}
L(\theta \mid X, Y)=\prod_{r=1}^{N} f\left(Y_{r}=y_{r} \mid X_{r}=x_{r}, \theta_{x_{r}}\right)= \\
=\prod_{r=1}^{N} \frac{1}{\sqrt{2 \pi \sigma_{x_{r}}^{2}}} \exp \left(-\frac{\left(y_{r}-\mu_{x_{r}}\right)^{2}}{2 \sigma_{x_{r}}^{2}}\right)
\end{gathered}
$$

Como já foi dito, $\theta$ é o vetor de parâmetros desconhecidos para gaussianas que compõem o modelo GMM. Ele possui $L$ posições da seguinte forma: $\theta=\left[\mu_{1}, \sigma_{1}^{2} ; \ldots ; \mu_{L}, \sigma_{L}^{2}\right]$. O objetivo do método EM é estimar iterativamente estes valores.

Neste ponto, com base no teorema de Bayes e utilizando as equações 4.8 e 4.6, é possível encontrar uma fórmula para a distribuição posterior $p(x \mid y, \theta)$. Ela tem a seguinte forma:

$$
\begin{aligned}
& p(x \mid y, \theta) \cong f(y \mid x, \theta) p(x)=\prod_{r=1}^{N} f\left(y_{r} \mid x_{r}, \theta_{x_{r}}\right) \exp \left(\sum_{c \in \mathcal{C}} V_{c}(x)\right) \frac{1}{z}= \\
= & {\left[\prod_{r=1}^{N} \frac{1}{\sqrt{2 \pi \sigma_{x_{r}}^{2}}} \exp \left(-\frac{\left(y_{r}-\mu_{x_{r}}\right)^{2}}{2 \sigma_{x_{r}}^{2}}\right)\right] \exp \left(\sum_{\{r, s\} \in \mathcal{C}} \beta t\left(x_{r}, x_{s}\right)-\sum_{\{r\} \in \mathcal{C}} \gamma_{x_{r}}\right) \frac{1}{z}=} \\
= & \frac{1}{z}\left[\prod_{r=1}^{N} \frac{1}{\sqrt{2 \pi \sigma_{x_{r}}^{2}}}\right] \exp \left(-\sum_{r=1}^{N} \frac{\left(y_{r}-\mu_{x_{r}}\right)^{2}}{2 \sigma_{x_{r}}^{2}}+\sum_{\{r, s\} \in \mathcal{C}} \beta t\left(x_{r}, x_{s}\right)-\sum_{\{r\} \in \mathcal{C}} \gamma_{x_{r}}\right)
\end{aligned}
$$

Maximizar o valor da distribuição posterior significa encontrar o mapa de classes $X$ (ou imagem segmentada) mais provável, dada a imagem a ser segmentada $Y$, o que, em outras palavras, significa minimizar o número de pixels mal classificados em $X$. A maximização direta de distribuição posterior é uma abordagem conhecida por MAP (Maximum A Posterior). Outra abordagem conhecida é a maximização das densidades marginais da distribuição posterior, ou MPM, do inglês MPM (Maximization of the Posterior Marginals).

A abordagem MAP associa um custo constante para todas as segmentações incorretas sem levar em conta o número de pixels mal classificados, ou seja, os pixels cuja classificação diferem da segmentação verdadeira esperada. Já a abordagem MPM associa um determinado 
custo para cada segmentação incorreta, considerando o número de pixels mal classificados da mesma [130]. Deste modo, a abordagem MPM é considerada mais indicada para a tarefa de segmentação.

Infelizmente, tanto para o método MAP quanto para o MPM, não é possível gerar uma amostra direta de $X$ a partir da probabilidade posterior $p(x \mid y, \theta)$, mas é possível que ela seja aproximada iterativamente utilizando, por exemplo, o método Gibbs Sampler [138], que é empregado no método EM/MPM e discutido nas próximas seções.

\subsubsection{Abordagem MPM}

Vamos assumir inicialmente que os parâmetros do vetor $\theta$ já são conhecidos. A abordagem MPM é utilizada para realizar a segmentação da imagem baseada no paradigma Bayesiano, maximizando a distribuição marginal $p\left(X_{s}=k \mid Y=y, \theta\right)$ para todo $k \in\{1,2, \ldots, L\}$ e para todo $s \in S[139]$.

Portanto, para encontrar uma estimação MPM de $X$ é necessário encontrar para cada $s \in S$ o valor de $k$ que maximize:

$$
p\left(X_{s}=k \mid Y=y\right)=\sum_{x \in \Omega_{k, s}} p(x \mid y, \theta)
$$

onde $\Omega_{k, s}=\left\{x: x_{s}=k\right\}$.

É possível perceber que a computação exata desta distribuição é computacionalmente inviável. Se fixarmos o pixel $s$ como sendo da classe $k$ e variarmos todos os pixels restantes, obteremos inúmeras combinações para o mapa $X$, correspondente ao espaço $\Omega_{k, s}$. É por isso que a abordagem MPM utiliza técnicas iterativas para obter a maximização das distribuições marginais. No método EM/MPM, em especial, é utilizado o algoritmo Gibbs sampler.

Basicamente, a idéia é aproximar a probabilidade $p\left(X_{s}=k \mid Y=y\right)$ para cada $s \in S$ e $k \in 1,2, \ldots, L$ da seguinte maneira:

- utilizar o Gibbs sampler para gerar uma cadeia de Markov $X(t)$, discreta no tempo, que convirja em distribuição para um campo aleatório com probabilidade $p(x \mid y, \theta)$;

- aproximar a densidade marginal $p\left(X_{s}=k \mid Y=y, \theta\right)$, que deve ser maximizada, como sendo a fração de tempo em que a cadeia de Markov passa no estado $k$ no pixel $s$, para cada $s$ e $k$.

Para uma cadeia de Markov $X(t)$, gerada utilizando-se o Gibbs sampler, há um total de $L^{N}$ estados possíveis (correspondentes aos elementos de $\Omega_{x}$ ). A cada passo do Gibbs sampler somente um pixel é visitado de modo que $X(t-1)$ e $X(t)$ diferem apenas pela localização de um pixel. Em uma posição de tempo qualquer $t$, o estado de $X(t)$ em um pixel $s$ corresponde à variável aleatória $X_{s}(t)$. Considere $q_{t} \in S$ como sendo o pixel visitado no tempo $t$. O estado de $X_{q_{t}}(t)$ é determinado gerando-se um valor aleatório com distribuição de probabilidade $p\left(X_{q_{t}}=k \mid Y=y, x_{r}(t-1), r \in \mathcal{G}_{q t}, \theta\right)$. 
Se a seqüência $\{q 1, q 2,, q 3, \ldots\}$ contém cada pixel $s \in S$ com freqüência tendendo ao infinito, então para uma configuração $x(0) \in \Omega_{X}$ :

$$
\lim _{t \rightarrow \infty} p(X(t)=x \mid Y=y, x(0))=p(x \mid y, \theta)
$$

para cada $x \in \Omega$. Deste modo, a cadeia de Markov converge em distribuição a um campo aleatório com probabilidade $p(x \mid y, \theta)$, ou seja, $p(x \mid y, \theta)$ é a distribuição limite para a cadeia de Markov.

Para formalizar a aproximação da densidade marginal $p\left(X_{s}=k \mid Y=y, \theta\right)$ considere primeiramente a seguinte função:

$$
\alpha_{k, s}(t)= \begin{cases}1, & \text { se } X_{s}(t)=k \\ 0, & \text { se } X_{s}(t) \neq k\end{cases}
$$

Sendo assim, se $T_{s}$ é o número de visitas ao pixel $s$ realizadas pelo Gibbs sampler então a aproximação ocorre da seguinte maneira:

$$
p\left(X_{s}=k \mid Y=y, \theta\right) \approx \frac{1}{T_{s}} \sum_{t=1}^{T_{s}} \alpha_{k, s}(t) \quad \forall k, s
$$

\subsubsection{Algoritmo EM}

O algoritmo EM [139, 140, 141, 142] é um método de estimação de parâmetros que se encaixa no esquema geral de estimação por máxima-verossimilhança e é aplicado em problemas onde parte dos dados não é conhecida, ou seja, em problemas de dados incompletos.

No EM/MPM, o objetivo do método EM é estimar o vetor de parâmetros $\theta$, do Modelo de Misturas de Gaussianas definido para $Y$. Conforme foi visto, estes parâmetros são importantes no processo de otimização realizado pelo algoritmo MPM.

Os métodos de estimação baseados no esquema de máxima-verossimilhança procuram, como o próprio nome diz, maximizar a função de verossimilhança [133]. Como esta função é definida a partir de um produtório, a tarefa de otimização da mesma se torna mais simples utilizando-se o seu logaritmo. Isto ocorre porque o logaritmo de um produtório é equivalente a um somatório de logaritmos.

Para um problema comum, que não possui dados ausentes, bastaria simplesmente que a função de verossimilhança fosse maximizada. Porém, com a existência de dados ausentes, o que se procura é a maximização do valor esperado desta função [139]. Vale ressaltar que os dados ausentes, nesse caso, são as classes dos pixels.

O método EM é essencialmente um algoritmo iterativo de otimização que converge para um máximo local da função de verossimilhança. Em cada iteração são realizados dois passos: 
determinação do valor esperado e maximização.

Seja $\theta(p)$ o conjunto de parâmetros estimados na iteração $p$, então o primeiro passo do algoritmo é computar a seguinte função:

$$
Q(\theta, \theta(p-1))=E[\log f(y \mid x, \theta) \mid Y=y, \theta(p-1)]
$$

A estimação $\theta(p)$ é obtida no passo seguinte como sendo o valor $\theta$ que maximize $Q(\theta, \theta(p-1))$, ou seja, que satisfaça:

$$
Q(\theta(p), \theta(p-1)) \geq Q(\theta, \theta(p-1)) \quad \forall \theta \in \Omega_{\theta}
$$

Substituindo (4.8) em (4.14), diferenciando, igualando a zero e resolvendo para $\theta(p)=$ $\left[\mu_{1}(p), \sigma_{1}^{2}(p) ; \ldots ; \mu_{L}(p), \sigma_{L}^{2}(p)\right]$ obtém-se:

$$
\mu_{k}(p)=\frac{1}{N_{k}(p)} \sum_{s=1}^{N} y_{s} p\left(X_{s}=k \mid Y=y, \theta(p-1)\right)
$$

e

$$
\sigma_{k}^{2}(p)=\frac{1}{N_{k}(p)} \sum_{s=1}^{N}\left(y_{s}-\mu_{k}(p)\right)^{2} p\left(X_{s}=k \mid Y=y, \theta(p-1)\right)
$$

onde

$$
N_{k}(p)=\sum_{s=1}^{N} p\left(X_{s}=k \mid Y=y, \theta(p-1)\right)
$$

para $k=1, \ldots, L$.

Estas equações são utilizadas para se obter iterativamente as atualizações dos parâmetros contidos no vetor $\theta$ (média e variância para cada classe).

\subsubsection{Algoritmo EM/MPM}

O algoritmo EM/MPM combina alternadamente as técnicas descritas nas seções 4.5.2 e 4.5.3. A Figura 4.15 ilustra, de forma simplificada, o diagrama em blocos do processo completo de segmentação.

Para o detalhamento do processo, considere inicialmente um vetor $\theta$ escolhido arbitrariamente e denominado $\hat{\theta}(0)$. A partir de $\hat{\theta}(0)$ o algoritmo Gibbs sampler é executado pela primeira vez, fornecendo a estimação para a densidade marginal $p\left(X_{s}=k \mid Y=y, \hat{\theta}(0)\right)$, conforme especificado em (4.13). Este valor estimado da marginal é utilizado nas equações (4.16) e (4.17) para se obter a primeira estimação do vetor $\theta$, ou seja, $\hat{\theta}(1)$. Esta nova estimação 


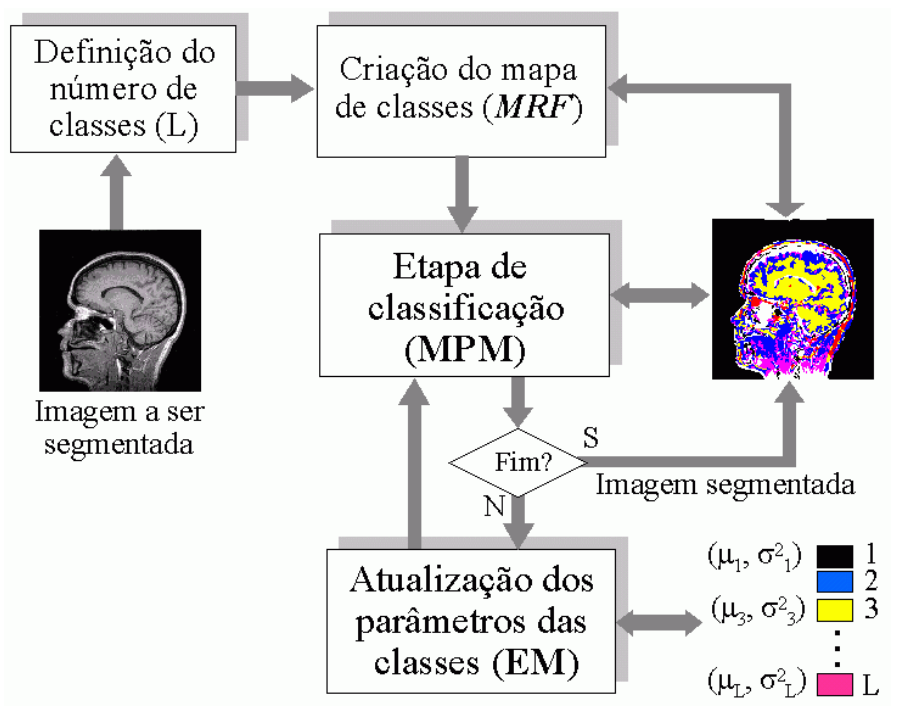

Figura 4.15: Diagrama simplificado do processo de segmentação EM/MPM.

é então utilizada na nova etapa MPM para se obter a estimação de $p\left(X_{s}=k \mid Y=y, \hat{\theta}(1)\right)$, que por sua vez é utilizada na obtenção de $\hat{\theta}(2)$. Este processo continua até que um número determinado de iterações (estágios) seja atingido.

Em cada execução do algoritmo Gibbs sampler é gerada uma cadeia de Markov $X(t)$ que converge em distribuição para um campo aleatório com probabilidade $p(x \mid y, \theta)$. Os elementos desta cadeia são os mapas $X(0), X(1), \ldots, X(T)$ e, conforme mencionado na seção 4.5.2, estes elementos se diferem apenas pela classificação de um pixel. Ao longo do processo EM/MPM, várias destas cadeias são geradas, formando o conjunto $X(1, t), \ldots, X(P+1, t)$, para algum $P>=1$. A geração da cadeia $X(p, t)$ corresponde então à execução do estágio $p$ do algoritmo EM/MPM.

Por fim, o algoritmo EM/MPM pode ser resumido da seguinte maneira:

1. Escolher valores para o vetor de parâmetros inicial $\hat{\theta}(0)$ e para o mapa de classes inicial $X(1,0)$;

2. Realizar $T$ iterações do algoritmo Gibbs sampler utilizando $\hat{\theta}(p-1)$ como o valor de $\theta$;

3. Utilizar as equações (4.16) e (4.17) do método EM para obter $\hat{\theta}(p)$;

4. Se a variação dos valores em $\hat{\theta}(p)$ for menor que um limiar pré-definido $\mathcal{E}$, parar o processo: o método convergiu;

5. Repetir os ítens 2, 3 e 4 para $P$ estágios.

A segmentação final é obtida executando o algoritmo MPM pela última vez com a estimação de $\theta$ obtida no estágio $P$, ou seja, $\hat{\theta}(P)$. A execução desta etapa final irá produzir a cadeia de Markov $X(P+1, t)$ sendo que a imagem segmentada corresponde ao último elemento desta cadeia: $X(P+1, T)$. 
Um estudo detalhado sobre a convergência do método EM/MPM pode ser encontrado no artigo escrito por Mary L. Comer e Edward Delp [94]. Esse estudo garante, a partir de teoremas e formulações matemáticas, a convergência tanto do algoritmo EM quanto do algoritmo Gibbs sampler para a abordagem MPM.

\subsection{Considerações finais}

Este Capítulo apresentou uma revisão dos principais métodos de segmentação de imagens encontrados na literatura, em especial aqueles cujos conceitos são aplicados diretamente no desenvolvimento deste trabalho. O processo de segmentação constitui uma etapa inicial para a maioria das aplicações de reconhecimento de padrões e análise de cenas. Em CBIR, os métodos que aplicam segmentação para extrair características de imagens são denominados RBIR (Region-Based Image Retrieval) [21, 61, 62]. Um dos pioneiros e principais sistemas a adotar a abordagem RBIR foi o Blobworld [41, 42], que utiliza informação de cor para segmentar as imagens.

A partir de uma imagem segmentada de maneira adequada é possível extrair automaticamente características de mais alto nível da imagem. Por exemplo, a quantidade de objetos encontrados na imagem e a disposição dos mesmos pode sugerir a ocorrência de uma determinada cena ou evento e até revelar uma anomalia específica em um órgão ou tecido nas imagens médicas. O recente artigo de revisão em CBIR de Datta et al. [25], por exemplo, afirma que não há dúvidas de que o processo de segmentação é o passo mais importante para a compreensão e caracterização eficiente da imagem. É também coerente dizer que a utilização da segmentação em CBIR constitui um dos caminhos que levam ao estreitamento do tão conhecido gap semântico (Capítulo 2).

Neste trabalho, especialmente, a segmentação também é considerada um ponto chave para caracterização da imagem. No trabalho desenvolvido e apresentado nesta tese foram abordados três domínios de imagens onde o tema da segmentação constitui um elemento fundamental. 


\section{Extração de características de imagens médicas 2D de ressonância magnética}

Neste Capítulo é apresentado um novo método de extração de características de imagens médicas provenientes de exames de ressonância magnética. No desenvolver deste trabalho procuramos responder à seguinte questão: Dado um repositório de imagens médicas de ressonância magnética de diversos pacientes e diversas partes do corpo, como representar essas imagens em um espaço vetorial de características de modo a possibilitar a realização de consultas de imagem por similaridade?

O exame clínico de ressonância magnética se baseia nas propriedades de relaxamento do núcleo de moléculas de hidrogênio presentes na água e gordura, elementos que constituem a maior parte do corpo humano. Por isso, este exame possibilita diferenciar um número relativamente grande de tecidos com relação aos outros tipos de exame, como a tomografia computadorizada.

A disposição dos diferentes tecidos nas imagens de ressonância magnética, e o formato que eles apresentam, possibilitam a um observador caracterizar o conteúdo do exame e, deste modo, inferir sobre a semelhança de duas ou mais imagens. É exatamente este ponto que exploramos no desenvolvimento de um novo extrator de características que se baseia na segmentação da imagem. O objetivo neste método é estabelecer uma diferenciação adequada dos tecidos da imagem, para que a disposição e o formato dos mesmos possam ser analisados. Em outras palavras, a imagem é inicialmente segmentada por um algoritmo adequado às imagens de ressonância magnética e, posteriormente, um conjunto de características representando a disposição e forma dos tecidos encontrados é computado.

Diversos descritores de forma estão presentes na literatura, incluindo os descritores de Fourier [143] e a transformada imagem-Floresta [67, 66]. Neste trabalho, entretanto, uma combinação de medidas simples se mostrou extremamente eficiente na tarefa de caracterização das imagens. Uma dessas medidas, em especial, é a Dimensão Fractal das regiões 
da imagem segmentada. O uso dessa medida possibilita, com apenas um valor numérico, distinguir regiões de formato linear, puntiforme ou planares.

O método de segmentação empregado é uma variação do método EM/MPM, descrito no capitulo anterior, que combina o algoritmo EM (Estimation and Maximization) para ajuste de um Modelo de Mistura Gaussiano (Gaussian Mixture Model) no histograma da imagem, com um classificador baseado nos Campos Aleatórios de Markov que, essencialmente, incorpora o conceito de coerência espacial entre os pixels. Este método de segmentação é perfeitamente adequado para as imagens de ressonância magnética, pois o modelo de mistura gaussiano está diretamente ligado ao fato de que, em tais imagens, os diferentes tecidos do corpo humano tendem a ser representados por níveis de cinza diferentes. Porém, as perturbações inerentes ao processo de aquisição da imagem, como por exemplo o ruído gaussiano, são responsáveis por estender o nível de cinza de cada tecido para uma faixa de níveis adjacentes, determinando assim a presença de curvas gaussianas no histograma da imagem. A utilização do modelo de Markov, por sua vez, minimiza a classificação errônea dos pixels devido à sobreposição das curvas gaussianas no histograma.

Nas próximas seções o método proposto é apresentado em detalhes. Uma parte dos conceitos utilizados neste trabalho, incluindo a teoria dos fractais, são apresentados no Apêndice A. Os experimentos realizados e os resultados obtidos são apresentados na seção 5.2.

\subsection{Método proposto}

Neste Capítulo é apresentada uma nova abordagem para extração de características e recuperação de imagens médicas por conteúdo. O método proposto é baseado na segmentação da imagem que é realizada por uma variação eficiente de EM/MPM, apresentado em detalhes no Capítulo 4. Primeiramente, é importante lembrar as notações mais importantes utilizas na descrição do método:

- $X$ - mapa de classificação ou imagem segmentada;

- $Y$ - imagem a ser segmentada;

- L - número de classes para segmentação;

- $p$ - estágio do método EM/MPM;

- $\beta$ - parâmetro de interação espacial do modelo de Markov.

\subsubsection{Segmentação de imagens}

O método que desenvolvemos para segmentação das imagens é baseado no EM/MPM, porém incorpora uma técnica interessante que acelera a convergência do processo, conforme apresentamos a seguir. 


\section{Variação do método EM/MPM}

O ajuste do parâmetro $\beta$ no EM/MPM corresponde ao ajuste mais crítico do processo. Valores muito baixos para este parâmetro não são adequados, visto que eles diminuem a correlação existente entre pixels vizinhos, ocasionando a geração de um resultado ruidoso, ou seja, uma imagem composta por vários pixels isolados classificados de maneira errada. Valores mais elevados exercem uma influencia negativa no início da segmentação. Isto ocorre porque nesta ocasião, a maioria dos pixels se encontra classificada erroneamente, ou seja, o resultado encontra-se ainda distante da segmentação verdadeira. Se a correlação entre pixels vizinhos for relativamente alta, em conseqüência do valor alto de $\beta$, as regiões maiores irão suprimir o surgimento de regiões menores, que, eventualmente fazem parte da segmentação real, levando o processo a convergir para a geração de um resultado completamente incorreto.

Uma alternativa interessante que incorporamos ao EM/MPM, consiste em desconsiderar a utilização de um valor fixo para $\beta$, realizando variações sistemáticas deste valor ao longo do processo. Esta técnica é conhecida na literatura com o nome de Annealing, que significa enrijecimento, ou o ato de temperar um determinado tipo de metal através de uma variação brusca de temperatura, o que proporciona um rearranjo estrutural de suas moléculas de modo a torná-lo mais rígido. O motivo desta denominação provém do fato de que, comumente, aplicações que utilizam o modelo de Markov, referem-se ao parâmetro de iteração espacial $\beta$ através de um valor que corresponde ao inverso do mesmo, ou seja, $\beta=\frac{1}{T}$, onde $T$ significa "temperatura" [144].

A técnica de Annealing aplicada ao algoritmo de segmentação EM/MPM foi implementada de forma a aumentar gradativamente o valor de $\beta$ durante a segmentação de uma imagem. Assim, foram definidos dois novos parâmetros: valor inicial do parâmetro de interação espacial $\beta_{I}$ e; uma constante de incremento $\beta_{\nabla}$. Inicialmente, é atribuído a $\beta$ o valor inicial $\beta_{I}$. Ao longo do processo, em cada estágio $p$, é adicionado a $\beta$ o valor constante $\beta_{\nabla}$

Um valor pequeno de $\beta_{I}$ faz com que a classificação dos pixels ocorra de maneira mais dinâmica, proporcionando maior velocidade na convergência do método. Isto ocorre pois na fase inicial, os pixels encontram-se pouco correlacionados, constituindo um mapa de classes ruidoso e inconstante, que pode ser comparado a uma chapa metálica em alta temperatura, cujas moléculas se encontram em intensa movimentação. O aumento gradual do parâmetro de iteração espacial causa um "resfriamento" no mapa de classes, tornando-o mais estável e constante, proporcionando assim um resultado sem ruídos.

Nas demais seções, o termo EM/MPM será utilizado para referenciar o método de segmentação desenvolvido, incluindo a incorporação da técnica de Annealing, conforme descrito nesta seção.

\section{Segmentação das imagens médicas}

Na etapa de segmentação o objetivo é classificar corretamente a maioria dos pixels com relação aos diferentes tecidos da imagem. Naturalmente, um método de segmentação não 
supervisionado como o que empregamos, poderá atribuir a mesma classe para pixels de tecidos diferentes, principalmente nos tecidos que possuem nível de cinza similares, como é o caso de muitos deles. A idéia, porém, do método proposto para caracterização das imagens médicas, é capturar a essência da distribuição espacial dos tecidos na imagem e, para isto, uma alta precisão na segmentação não é necessária.

Por outro lado, o número $L$ de classes, utilizado para segmentar as imagens é um parâmetro importante e deve ser escolhido cuidadosamente. Esse valor deve ser o mais próximo possível do número médio de tecidos que o exame de ressonância magnética é capaz de diferenciar a partir do contraste de níveis de cinza na imagem. Em nossos experimentos, diversos valores de $L$ foram testados. O valor ideal encontrado será apresentado e discutido mais adiante, na seção 5.2.1.

A imagem segmentada é um mapa de classificação dos pixels, onde cada pixel é classificado com um valor de classe $k \in[1, L]$. Os pixels classificados com a mesma classe $c$ formam agrupamentos conexos, que são grupos onde todos os pixels estão direta ou indiretamente conectados uns aos outros por um determinado critério de vizinhança. A Figura 5.1 apresenta um exemplo de imagem do cérebro segmentada com o método EM/MPM. A imagem original é um corte axial de um exame com ponderação em T1 (Figura 5.1a), que foi segmentada utilizando $L=5$, incluindo a classe de pixels do plano de fundo. A primeira classe (Figura 5.1c) está principalmente relacionada com o fluido cérebro-espinhal e outros tecidos com nível de cinza também escuros em T1, assim como a pele e a membrana da meninge. A segunda e a terceira classe, Figuras 5.1d,e, representam principalmente os tecidos de massa cinzenta e massa branca, respectivamente. Por fim, a quarta classe representa os tecidos que são apresentados em níveis de cinza mais claros, como a gordura, a medula óssea, e a dura. Uma segmentação mais precisa dos tecidos do cérebro só poderia ser realizada por métodos dedicados para esta categoria de imagem, como veremos no Capítulo 7. A Figura 5.3 apresenta outro exemplo de segmentação realizada pelo método EM/MPM com $L=5$.

\subsubsection{Caracterização da imagem}

Na abordagem proposta de extração de características, após a segmentação da imagem, um conjunto compacto de características é computado considerando-se a imagem original $Y$ e o resultado da segmentação $X$.

Observe, por exemplo, que na Figura 5.1e, a região referente à massa branca apresenta dois grandes componentes conexos. Uma opção intuitiva para representação da imagem seria analisar os componentes conexos da imagem segmentada e extrair medidas dos mesmos para compor um vetor de características. Entretanto, um problema desta abordagem consiste no fato de que o número de componentes conexos pode variar bastante entre diferentes imagens e, conseqüentemente, os vetores de características teriam tamanhos variados. Neste caso, seria necessário desenvolver uma função de distância complexa para poder comparar dois vetores. 


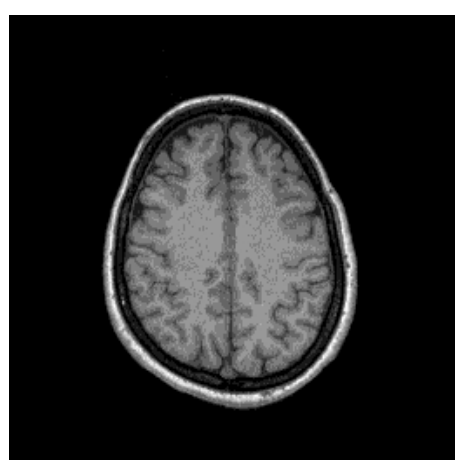

(a)

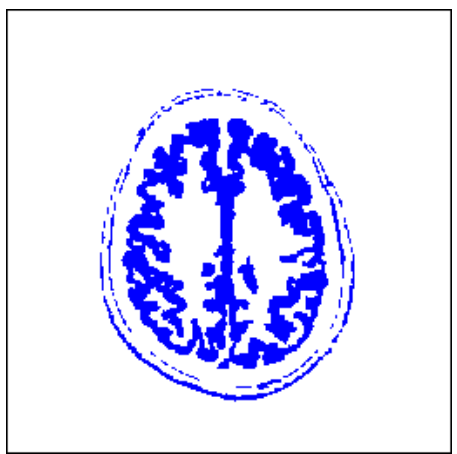

(d)

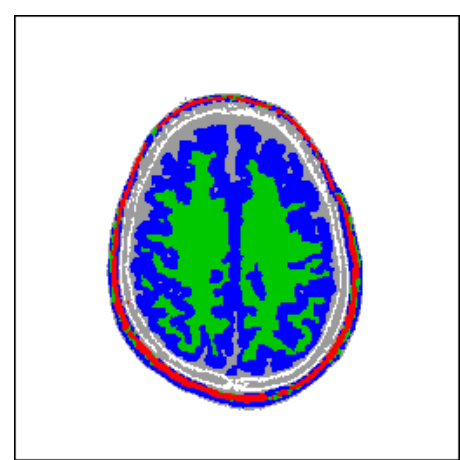

(b)

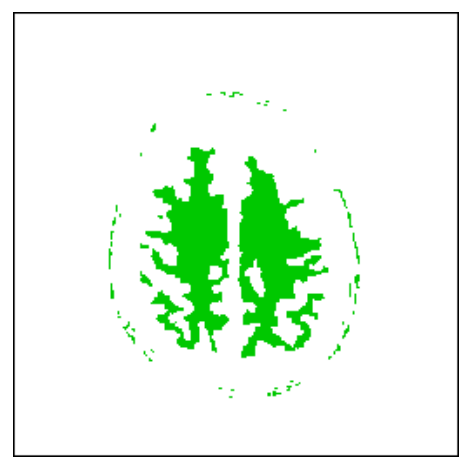

(e)

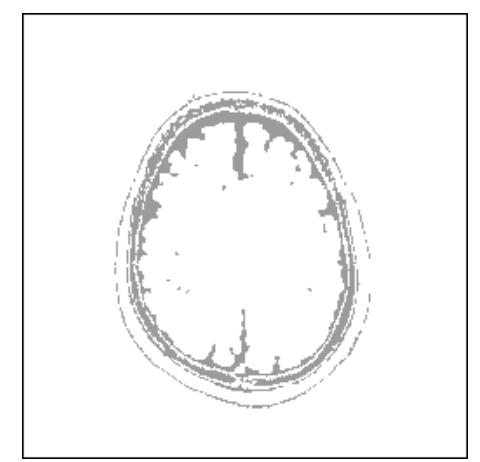

(c)

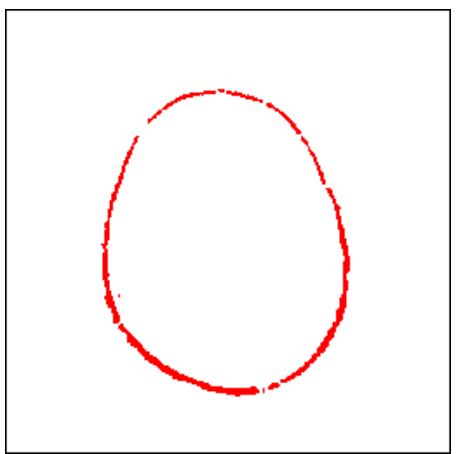

(f)

Figura 5.1: Exemplo de segmentação realizada pelo método EM/MPM. (a) imagem original; (b) imagem segmentada com $L=5$; (c) região de classe 1 (fluido cérebro-espinhal); (d) região de classe 2 (massa cinzenta); (e) região de classe 3 (massa branca); (f) região de classe 4 (dura, medula óssea, gordura).

Ao invés de analisar separadamente cada componente conexo, consideramos que todos os pixels da mesma classe formam uma única região composta, de onde um número $N C$ fixo de características são extraídas. Na nossa abordagem, todas as imagens da base são segmentadas com o mesmo parâmetro $L$ de número de classes para que ao final da segmentação todas as imagens tenham o mesmo número $L$ de regiões compostas. Assim, o tamanho do vetor de características das imagens é fixo e determinado por $L \times N C$. Algumas imagens de ressonância magnética, entretanto, podem apresentam um nível de contraste muito baixo entre os diferentes tecidos e, neste caso, o método de segmentação pode retornar uma classificação dos pixels com menos de $L$ classes. Isto pode acontecer, por exemplo, devido à presença de fortes gradientes de brilho na imagem ou em imagens de densidade de prótons. O sistema que propomos não considera a utilização dessas imagens. Uma imagem segmentada apresentando menos que $L$ classes deve ser automaticamente descartada da base. Na próxima seção o vetor de características proposto é apresentado em detalhes.

\section{Extração de características}

As características consideradas para representar cada região composta da imagem segmentada são simples e demandam um esforço computacional mínimo para serem calculadas. O vetor de características composto representa um panorama da distribuição das regiões com 
especificação do tamanho e formato das mesmas. O nível de cinza médio das regiões também é uma informação importante, pois nas imagens de ressonância magnética ele está diretamente relacionado com os diferentes tecidos. Assim, as características que descrevem cada região, são as seguintes:

- a massa, ou tamanho;

- o centro de massa, ou centróide;

- o nível de cinza médio;

- a dimensão fractal (dimensão de correlação).

As primeiras duas características, massa e centro de massa, são calculadas diretamente do mapa de classificação dos pixels, ao passo que o nível de cinza médio é calculado a partir da imagem original usando a região correspondente como uma máscara. Vamos considerar aqui as notações apresentadas no início desta seção: $\mathbf{Y}$ para a imagem original e $\mathbf{X}$ para o mapa de classificação. Vamos também considerar que o par $(r, s)$ representa uma localização espacial de um pixel no espaço retangular discreto de tamanho $W \times H$ onde $\mathbf{X}$ e $\mathbf{Y}$ estão definidos. A massa $m_{c}$ da região rotulada pela classe $c$ é definida por:

$$
m_{c}=\frac{\sum_{r, s} h_{c}(r, s)}{W H}
$$

onde

$$
h_{c}=\left\{\begin{array}{lll}
1 & \text { se } & \mathbf{X}_{r, s}=c \\
0 & \text { se } & \mathbf{X}_{r, s} \neq c
\end{array}\right.
$$

O centro de massa $o_{c}$ da região rotulada por $c$ é formado pelas coordenadas $y o_{c}$ e $x o_{c}$, onde:

$$
x o_{c}=\frac{\sum_{r, s} r h_{c}(r, s)}{W} \quad e \quad y o_{c}=\frac{\sum_{r, s} s h_{c}(r, s)}{H}
$$

O nível de cinza médio $\mu_{c}$ da região rotulada por $c$ é definida como:

$$
\mu_{c}=\frac{\sum_{r, s} \mathbf{Y}_{r, s} h_{c}(r, s)}{m_{c} l_{\max }}
$$

onde $l_{\max }$ é o nível de cinza máximo que um pixel pode assumir de acordo com a quantização da imagem $Y$.

Como é possível de ser observado, a utilização do centróide das regiões, definido no espaço retangular das imagens, impede que o conjunto de características seja invariante às transformações geométricas de translação e rotação. Porém, a padronização do exame de ressonância magnética com relação ao posicionamento do paciente na máquina proporciona 
um alinhamento razoável das imagens, o que torna dispensável a propriedade de invariância das características. Além disso, técnicas de co-registro de imagens podem ser utilizadas precedendo o esquema proposto de extração de características. Entretanto, o estudo de tais técnicas foge do escopo deste trabalho.

\section{Dimensão fractal}

O conceito de dimensão fractal é utilizado em nosso vetor de características com o objetivo de descrever de modo elementar o formato de cada uma das $L$ regiões compostas presentes no mapa de classificação. Por exemplo, regiões com formato de linha terão dimensão fractal próximo a um, enquanto que regiões largas planares terão dimensão fractal próximo de dois, e regiões formadas por pequenos fragmentos espalhados pela imagem terão dimensão próximo a zero. Estes formatos estão diretamente ligados com a dimensão intrínseca das regiões, consideradas como conjuntos de pontos imersos no espaço bi-dimensional da imagem.

A dimensão fractal é adequada para este caso porque ela é um meio simples e bem conhecido de se estimar a dimensão intrínseca de conjuntos de pontos. Dentre os diversos formalismos que existem para o conceito de dimensão fractal, escolhemos o mais adequado para conjuntos relativamente pequenos imersos em uma dimensão também pequena. A dimensão de correlação, como é conhecida, envolve conceitos simples e é um dos métodos mais rápidos e diretos para o cálculo da dimensão fractal. Os principais conceitos envolvendo a teoria dos fractais e a dimensão de correlação são apresentados no Apêndice A.

Assim como no cálculo das demais características apresentadas na seção anterior, cada região de pixels rotulados pela classe $c$ é submetida ao cálculo da dimensão de correlação, de acordo com a Definição A.1. Para cada região, os seguintes passos são seguidos:

- A integral de correlação é calculada para o conjunto de pontos, para todos os valores de distância $r$ tal que $r_{\min } \leq r \leq r_{\max }$, onde $r_{\min }$ representa a distância de pontos adjacentes (mínima), e $r_{\max }$ a distância entre os dois pontos mais distantes do conjunto (máxima). Para isto, a métrica de distância $L_{1}$, ou Manhattan, é utilizada;

- O gráfico $\log C(r)$ vs. $\log r$ é desenhado e uma rápida análise da curva resultante é realizada para separar pontos da mesma que possuem comportamento linear;

- Um reta é ajustada aos pontos da curva do gráfico $\log C(r)$ vs. $\log r$ que apresentam comportamento linear, utilizando-se o método dos mínimos quadrados. A dimensão de correlação $D_{2}$ é então calculada como o coeficiente angular (inclinação) da reta ajustada [145].

A Figura 5.2 apresenta os gráficos $\log C(r)$ vs. $\log r$ das quatro regiões da imagem segmentada apresentada na Figura 5.1. Para cada gráfico, a reta ajustada com o método dos mínimos quadrados encontra-se sobreposta. O coeficiente angular de cada reta define a dimensão fractal da região correspondente. Observe, por exemplo, que a região da Figura 5.1 
rotulada com a classe 4 assemelha-se com uma linha em formato circular, e por isso, sua dimensão fractal é relativamente baixa, próximo de 1. Por outro lado, as regiões rotuladas com as classes 2 e 3, correspondentes aos tecidos de massa cinzenta e massa branca, são mais amplas e assemelham-se mais a um objeto planar, assim eles apresentam uma dimensão fractal mais alta. A Figura 5.3 apresenta outro exemplo de segmentação realizada pelo método $\mathrm{EM} / \mathrm{MPM}$ com $L=5$, e os respectivos gráficos $\log C(r)$ vs. $\log r$ que definem a dimensão fractal das regiões.
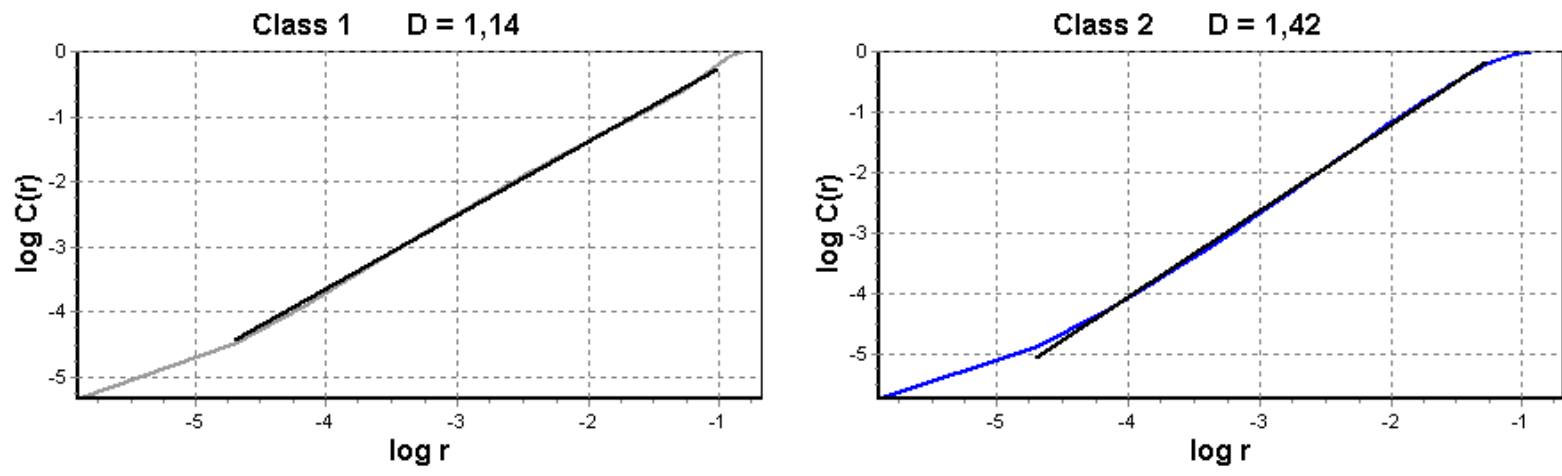

Class $3 \quad D=1,44$

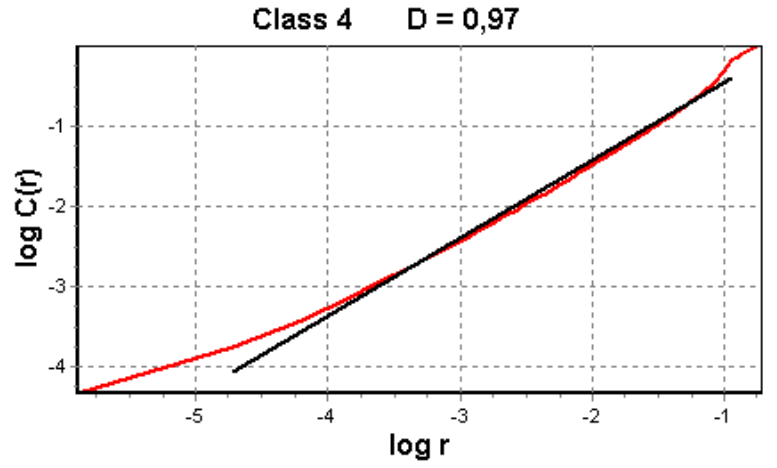

Figura 5.2: Cálculo da dimensão fractal das regiões da Figura 5.1

\section{Composição do vetor de características}

Ao todo, são quatro medidas que utilizamos para representação de cada região da imagem: (1) a dimensão fractal $D_{2}$; (2) o centro de massa xo e yo; (3) a massa $m$; e o nível de cinza médio $(\mu)$. Todas as medidas são valores reais e, sendo que o centróide da região é dado por duas coordenadas, cada região é representada por cinco valores reais. Como a região de plano de fundo (background) da imagem segmentada não é considerada na caracterização da imagem o tamanho fixo do vetor de características proposto é definido por $5(L-1)$ valores reais. As características são agrupadas por região no vetor e dispostas conforme ilustrado na Figura 5.4.

Uma propriedade importante do vetor de características diz respeito à ordem dos grupos de características de cada região. Na maioria dos casos, o método EM/MPM retorna um mapa de classificação onde as regiões estão ordenadas pelo nível de cinza médio, isto é, a região de classe 1 possui um nível de cinza médio mais escuro, ou menor, que a região de 


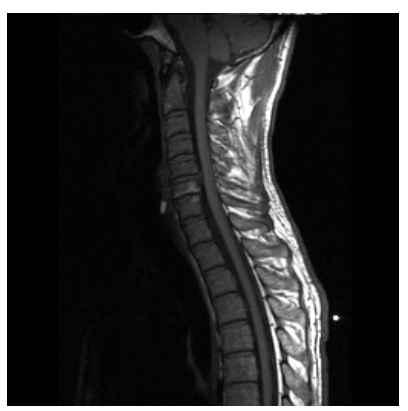

(a)

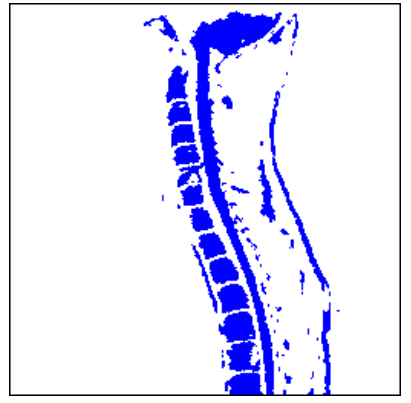

(d)

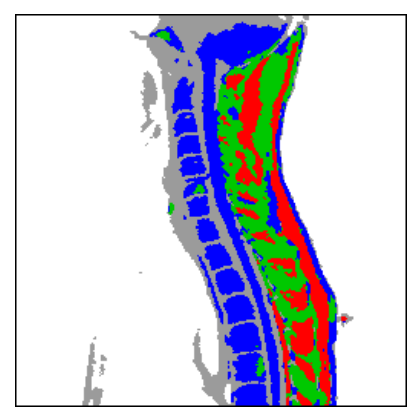

(b)

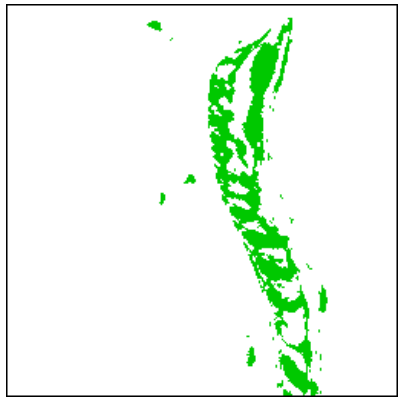

(e)

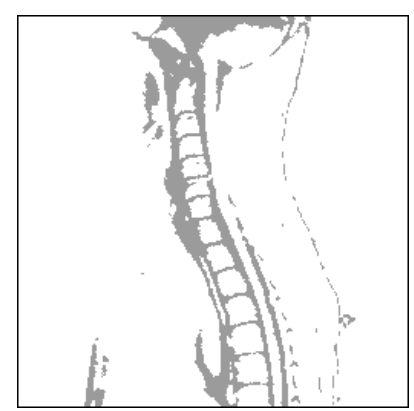

(c)

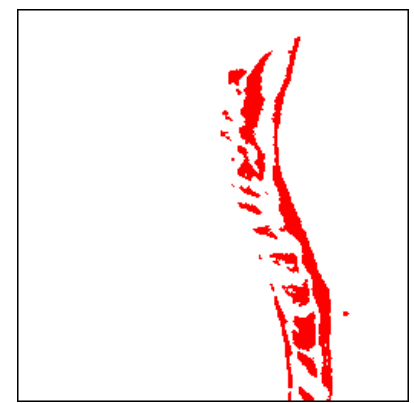

(f)
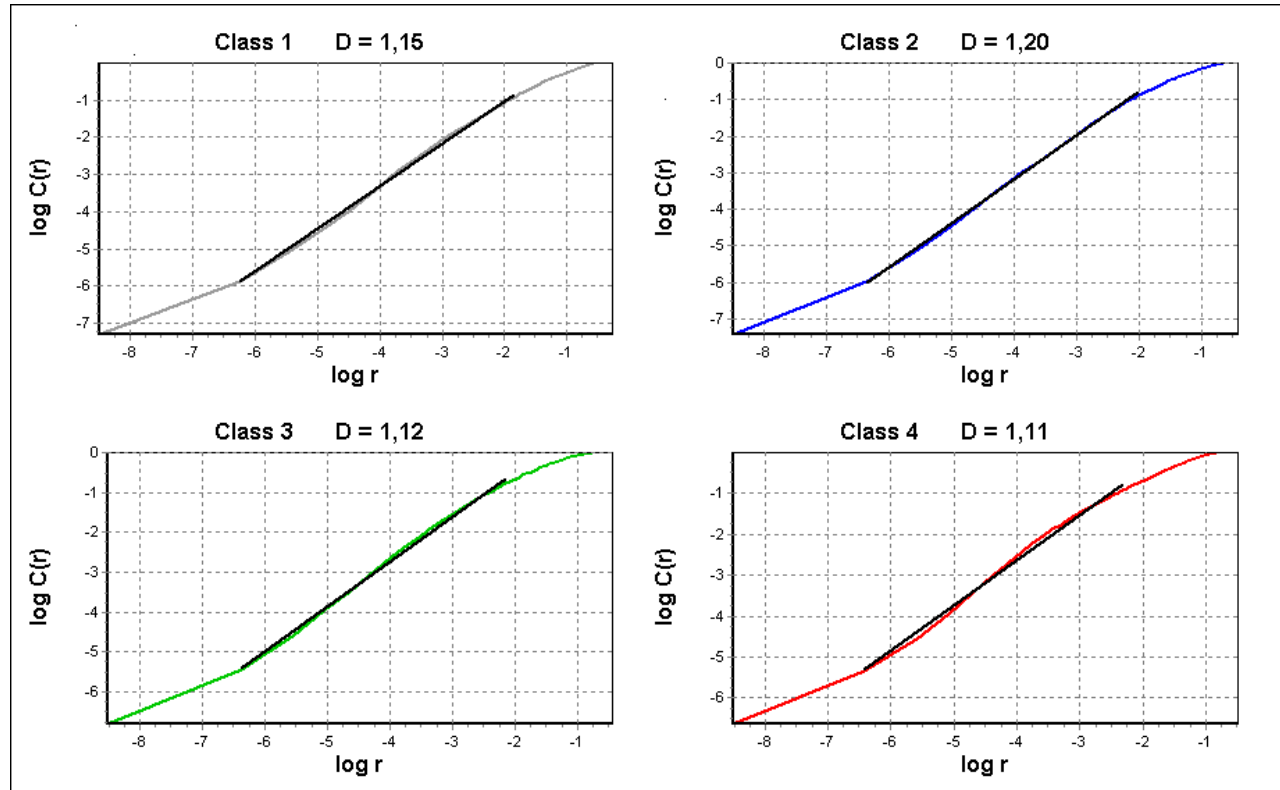

(g)

Figura 5.3: Exemplo de imagem da espinha segmentada pelo método EM/MPM. (a) imagem original; (b) imagem segmentada com $L=5$; (c) região de classe 1; (d) região de classe 2; (e) região de classe 3; (f) região de classe 4; (g) gráficos de correlação das regiões e respectivas dimensões fractais.

\begin{tabular}{|l|l|l|l|l|l|l|l|l|l|l|}
\hline$D_{2}$ & xo & yo & $m$ & $\mu$ & $\ldots$ & $\underbrace{D_{2}}_{\text {Região Classe } 1}$ & xo & yo & $m$ & $\mu$ \\
$\underbrace{}_{\text {Região Classe } L-1}$
\end{tabular}

Figura 5.4: Vetor de características das imagens - $5(L-1)$ valores reais. 
classe 2, e assim por diante. Entretanto, isto pode vir a não acontecer em alguns casos, devido às propriedades estocásticas do algoritmo. Assim, uma ordenação auxiliar é sempre realizada para garantir que os grupos de características de cada classe estejam ordenados pela característica de nível de cinza médio $\mu$. Ou seja, o primeiro grupo de cinco características no vetor está associado à classe de nível de cinza mais escuro, enquanto os demais grupos estão ordenados de maneira crescente de acordo com o nível médio de cinza correspondente. Esta ordenação é importante porque o nível de cinza médio em imagens de ressonância magnética, conforme já mencionado, está ligado à própria identificação dos tecidos na imagem. Assim, a ordenação dos grupos proporciona a correspondência das características com relação ao tecido que elas representam. Ainda que esta correspondência dos tecidos não ocorra entre imagens de categorias diferentes, cérebro e espinha, por exemplo, ela ainda é importante para manter o agrupamento no espaço vetorial das imagens similares de mesma categoria.

\subsubsection{Função de distância}

Em CBIR, a similaridade entre duas imagens é definida pela distância entre seus respectivos vetores de características, dada uma métrica, ou função de distância adequada. Como mencionado anteriormente, a vantagem de ter vetores de características de tamanho fixo, possibilita a utilização de métricas simples tais como as métricas da família $L_{p}$, incluindo a métrica euclidiana $L_{2}$ e a de Manhattan $L_{1}$. Diversas métricas foram experimentadas, todas elas discutidas no Capítulo 2. Os melhores resultados em nossos experimentos, entretanto, foram obtidos com a utilização de uma versão da distância Manhattan ponderada pela variância dos atributos da base de imagem. Esta função atribui maior relevância aos atributos que possuem menor variância sobre todo o conjunto de imagens da base e menor relevância para os atributos com alta variância de valores. A idéia vem da função de distância Mahalanobis, onde os atributos são considerados correlacionados de alguma maneira e a matriz de covariância dos mesmos é utilizada para expressar e modelar essa correlação. No nosso caso, consideramos todas as características estatisticamente independentes, assim a matriz de covariância é uma matriz diagonal preenchida somente com a variância de cada atributo. Por isso, a função de distância que utilizamos é considerada um caso especial da distância Mahalanobis. Acreditamos que a vantagem de se ponderar os atributos pela variância vem do fato de que a influência das características é equalizada, evitando que somente um subconjunto das mesmas seja responsável por controlar a medida de distância. Assim, os resultados que apresentamos na seção de experimentos são obtidos usando esta função que denominamos $d_{W}$, definida para dois vetores de características $R$ e $S$ de tamanho $5(L-1)$. Formalmente, $d_{W}$ é definida por:

$$
d_{W}(R, S)=\sum_{i=1}^{5(L-1)} \frac{R_{i}-S_{i}}{\sigma_{i}^{2}}
$$

onde $\sigma_{i}^{2}$ é a variância da coluna de atributos $i$, para todo o conjunto de vetores de carac- 
terísticas da base de imagens.

\section{$5.2 \quad$ Experimentos e resultados}

Um protótipo experimental foi desenvolvido para conter a implementação do método de extração de características proposto, incluindo o método de segmentação EM/MPM, e possibilitar a partir de sua interface a realização de consultas por imagens similares dado uma imagem chave de consulta. Uma demonstração inicial do protótipo desenvolvido encontra-se na Figura 5.5 onde é apresentada uma operação de consulta kNN tendo como chave de busca um corte radial da parte superior da coluna vertebral. O sistema é projetado para calcular e apresentar automaticamente o gráfico de precisão vs. revocação da consulta caso as imagens da base tenham sido previamente classificadas como relevantes ou não relevantes à imagem de busca da consulta.

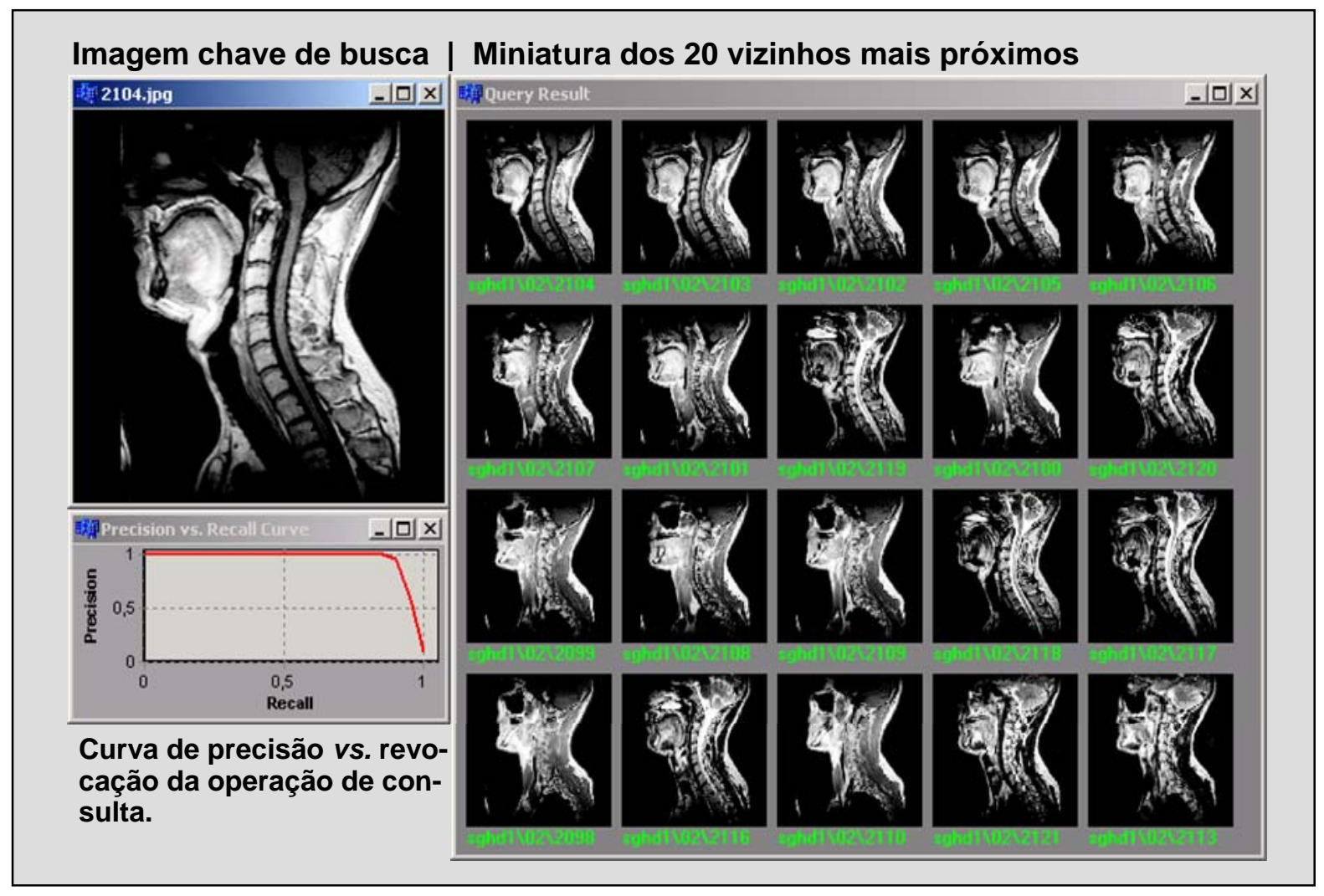

Figura 5.5: Exemplo de consulta aos 20 vizinhos mais próximos realizada pelo sistema desenvolvido sobre uma base de 704 imagens de variadas categorias.

Para avaliar e validar a eficiência na tarefa de recuperação de imagens do sistema desenvolvido foram consideradas imagens de ressonância magnética ponderadas em T1 e T2 de diversas partes do corpo, adquiridas nas três orientações: axial, coronal e sagital. Um conjunto de 704 imagens foi preparado para ser a base de tal avaliação e as curvas de precisão versus revocação foram utilizadas para fornecer uma medida adequada de eficácia visto que elas são bem conhecidas e constituem a abordagem mais comum para avaliar a recuperação de informação. A Tabela 5.1 apresenta a distribuição de imagens da base experimental. 
Todas as imagens desta base são de 8 bits (256 níveis de cinza) com tamanho de $256 \times 256$ pixels.

Tabela 5.1: Configuração da base de imagens preparada para experimentação.

\begin{tabular}{|l|c|}
\hline Categoria & \# de imagens \\
\hline \hline Angiograma RM & 36 \\
\hline Pélvis Axial & 86 \\
\hline Cabeça Axial & 155 \\
\hline Cabeça Sagital & 258 \\
\hline Abdômen Coronal & 23 \\
\hline Espinha Sagital & 59 \\
\hline Abdômen Axial & 51 \\
\hline Cabeça Coronal & 36 \\
\hline Total & $\mathbf{7 0 4}$ \\
\hline
\end{tabular}

Para avaliação dos resultados das consultas por meio das curvas de precisão vs revocação foram criados subgrupos de imagem similares dentro de cada uma das categorias listadas na Tabela 5.1. Basicamente, os subgrupos comportam imagens similares com relação à parte do corpo examinada, orientação (axial, radial, coronal), altura do corte, e ponderação (T1, T2). O tamanho dos grupos pode variar de 15 a 40 imagens, sendo que a maioria deles contém imagens de diferentes pacientes e exames. Em nossos experimentos, dada uma imagem chave de busca, as imagens consideradas relevantes para a consulta são todas aquelas pertencentes ao mesmo subgrupo de imagens similares. Assim, o gráfico de precisão e revocação da consulta pode ser computado automaticamente pelo sistema desenvolvido. Alguns exemplos de subgrupos de imagens similares são apresentados na Tabela 5.2. A última linha da Tabela indica o número total de imagens em cada grupo.

Todas as imagens da base experimental foram segmentadas com o método EM/MPM e tiveram seus vetores de características computados de acordo com a seção 5.1.2 (Figura 5.4). Três valores de $L$ foram utilizados: $L=3, L=5$ e $L=8$. Assim, cada imagem possui três vetores de características que são armazenados, cada um, em uma base de vetores distinta. Vale lembrar que o tamanho dos vetores de características é dado por $5(L-1)$. Assim, como veremos a seguir, a influência do parâmetro $L$ nas operações de consulta será analisada.

\subsubsection{Avaliação quantitativa}

Para um estudo comparativo do vetor de características proposto foram escolhidas duas técnicas bem conhecidas e importantes de representação de conteúdo de imagens: os momentos de Zernike e os histogramas de brilho ou níveis de cinza. Os momentos de Zernike são reconhecidos pela sua excelente capacidade de representação das imagens devido às características de ortogonalidade de sua base de polinômios. Além disso, os momentos de Zernike também apresentam naturalmente a propriedade de invariância à rotação, o que os torna bastante comum em aplicações de classificações de padrões e recuperação de imagens por conteúdo. Os histogramas de brilho, por outro lado, também são muito utilizados em 
Tabela 5.2: Exemplos de subgrupos de imagens similares

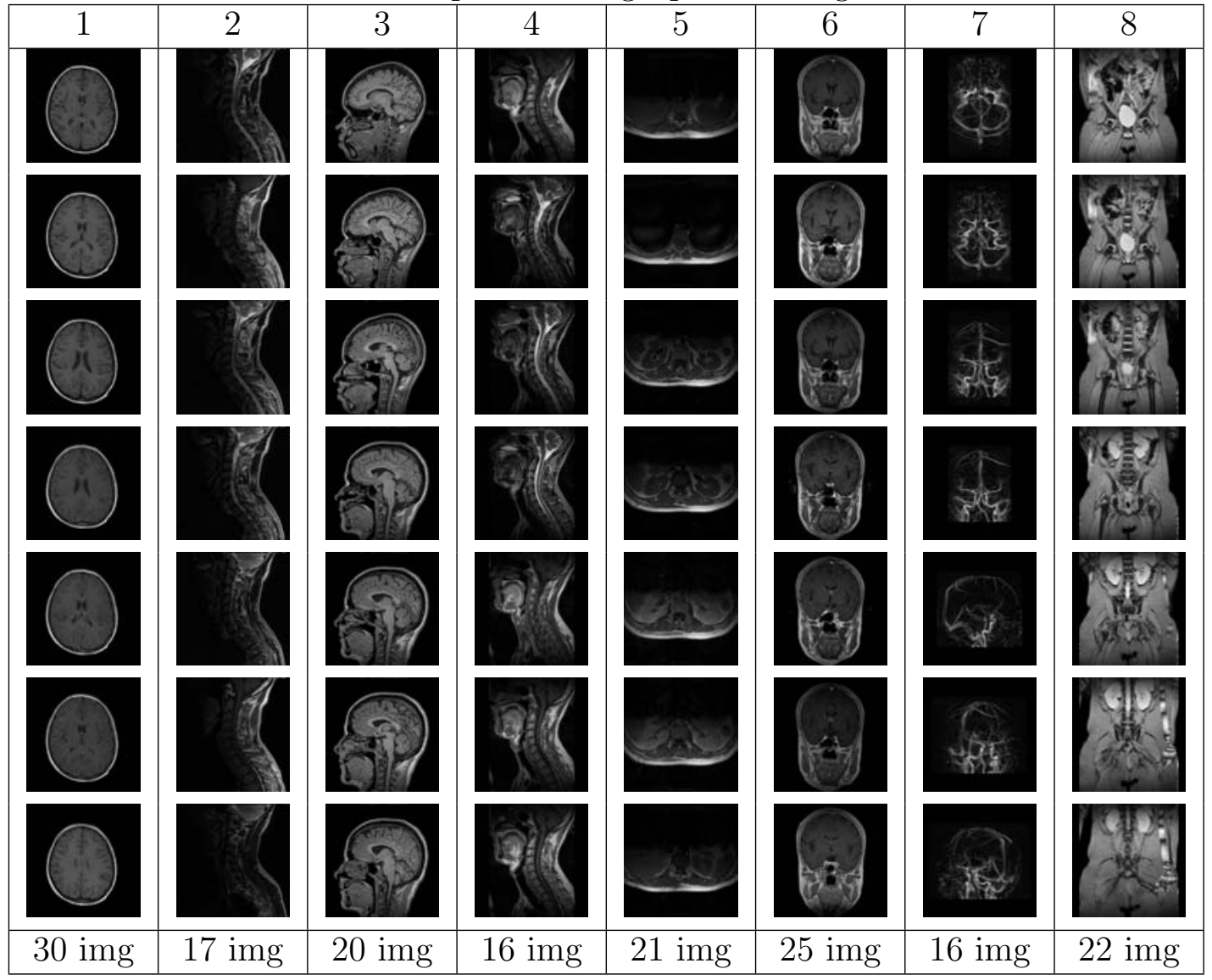

CBIR, especialmente no GBDI-ICMC-USP [49, 146], devido à facilidade e rapidez com que eles podem ser computados.

Os trinta primeiros momentos de Zernike foram computados para cada uma das 704 imagens da base experimental, resultando em vetores de características de 256 valores reais. Os histogramas normalizados de brilho também foram computados para as mesmas imagens resultando em vetores de características de 256 valores reais. Nesta comparação utilizamos nossa base de vetores de características obtida com $L=5$, assim, cada vetor possui 20 valores reais. O gráfico da Figura 5.6 apresenta as curvas médias de precisão vs revocação obtidas pelas técnicas comparadas. Para cada técnica, todas as imagens da base foram submetidas a uma operação de consulta kNN, de onde uma curva de precisão vs. revocação foi computada automaticamente. As curvas do gráfico da Figura 5.6 representam uma média aritmética de todas as curvas obtidas nas operações de consultas para cada uma das técnicas. Para se ter uma idéia do pior caso em recuperação de imagens, também é apresentada uma curva média de precisão e revocação para vetores de características contendo valores reais aleatórios.

Uma breve avaliação visual das curvas da Figura 5.6 revela que o vetor de características proposto se sobressai com larga vantagem em relação às duas técnicas comparadas. Para uma avaliação em números, a Tabela apresenta a área, em porcentagem, sob as curvas PR da Figura 5.6. O valor 100\% indica a área sob a curva PR ideal, ou seja, precisão máxima para todos os valores de revocação. Vale salientar que, com apenas 20 valores reais o nosso vetor 


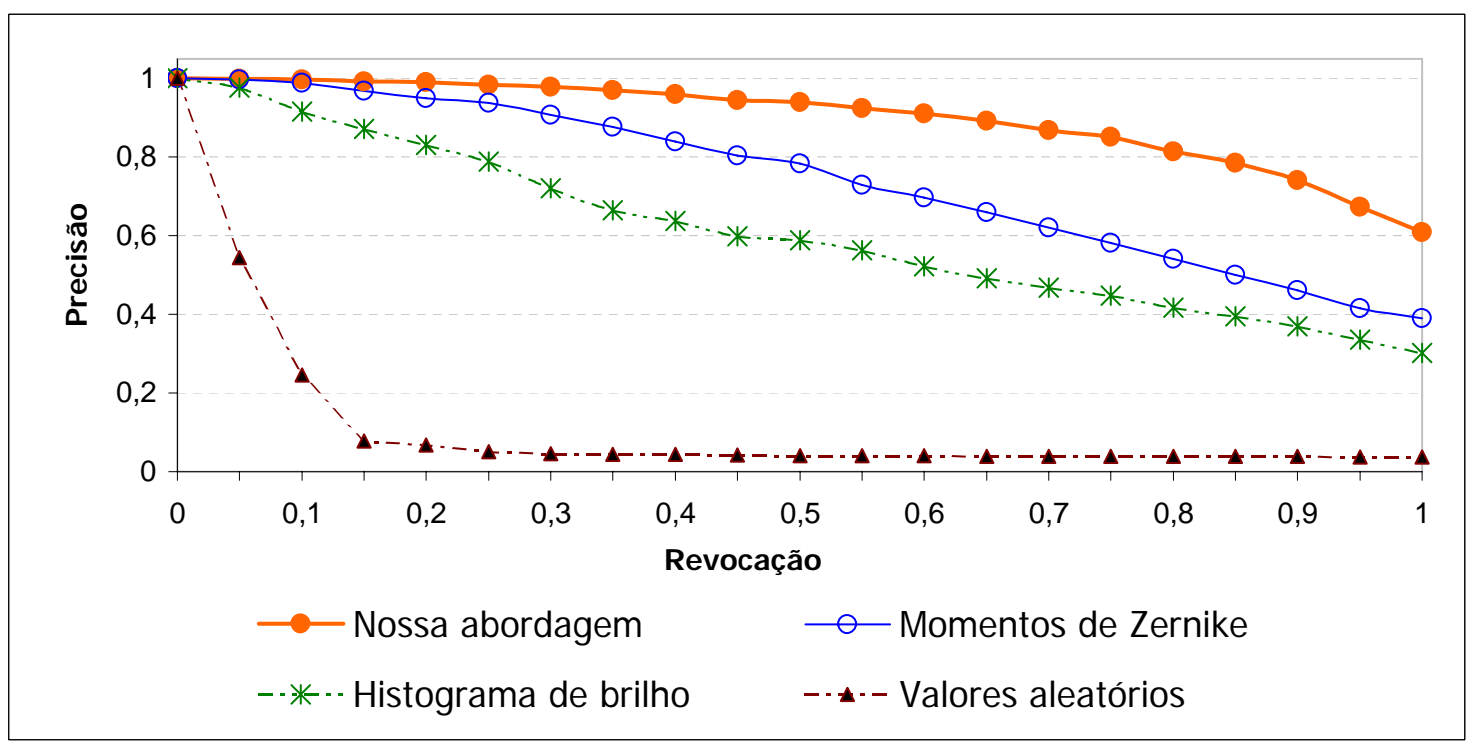

Figura 5.6: Curvas médias de precisão vs. revocação ilustrando o comportamento na recuperação de imagens de diversos vetores de características, incluindo nossa abordagem, os momentos de Zernike e histogramas de brilho da imagem.

de características apresenta resultados bem melhores do que os momentos de Zernike, que são descritos na literatura como ótimos descritores de imagens. Com relação aos práticos e comuns histogramas de brilho, nossa técnica possui uma vantagem ainda mais considerável.

Tabela 5.3: Área sob as curvas de precisão vs. revocação do gráfico da Figura 5.6.

\begin{tabular}{|l|c|}
\hline Abordagem & Área (\%) \\
\hline \hline Nossa abordagem & 90.14 \\
\hline Momentos de Zernike & 74.78 \\
\hline Histogramas de brilho & 61.25 \\
\hline Valores aleatórios & 10.38 \\
\hline
\end{tabular}

A Figura 5.7 apresenta a comparação do nosso vetor de características obtido com os três valores do parâmetro $L$ citados anteriormente: $L=3, L=5$ e $L=8$. Vale lembrar que $L$ é o número de classes para segmentação da imagem que está diretamente relacionado com o tamanho do vetor de características gerado $\left(5^{*}(\mathrm{~L}-1)\right)$. O gráfico da Figura 5.7 contém curvas médias de precisão e revocação computadas da mesma maneira que as curvas da Figura 5.6. A curva de $L=5$ na Figura 5.7 é a mesma curva que representa nossa abordagem no gráfico da Figura 5.6. Observe que essa curva se sobressai razoavelmente com relação às curvas de $L=3$ e $L=4$. Isto nos faz concluir que cinco é um número de classes bem adequado para segmentar imagens de ressonância magnética de diversas partes do corpo. Nas imagens de cabeça, por exemplo, as cinco classes representam: (1) a massa branca; (2) a massa cinzenta; (3) o fluido cérebro-espinhal; (4) a medula óssea, dura e gordura, e; (5) o plano de fundo da imagem. Outro exemplo são imagens da pélvis onde as cinco classes representam: (1) tecido do fígado; (2) tecido do baço; (3) músculo; (4) medula óssea, gordura, e; (5) plano de fundo da imagem. Assim, um valor de $L$ inferior a cinco tende a simplificar demais as imagens 
segmentadas confundindo diversos tecidos. Por outro lado, um valor maior de $L$ tende a criar fragmentos de regiões e deixa o método de segmentação muito sensível aos gradientes de brilho na imagem.

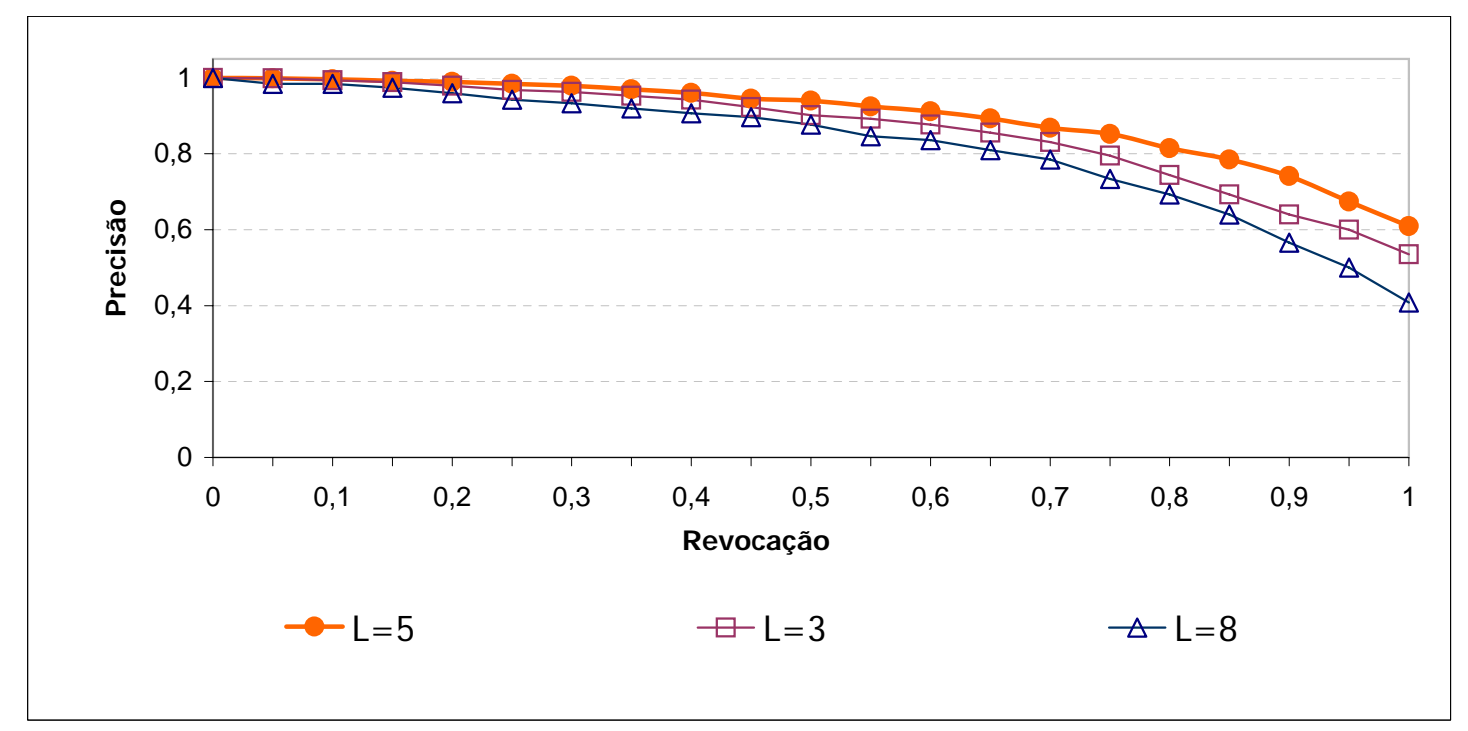

Figura 5.7: Comparação do vetor de características proposto para diferentes valores do parâmetro $L$ - o número de classes para segmentação da imagem.

A Figura 5.8 apresenta as curvas médias de precisão obtidas separadamente para cada categoria de imagens da base experimental, conforme descrito na Tabela 5.1. O objetivo é ilustrar o comportamento do vetor de características proposto, com $L=5$, para diferentes tipos de imagens. Observe que para a maioria das categorias o valor de precisão é acima de $80 \%$ para valores de revocação até $70 \%$. A curva com menor precisão é a curva relacionada com as imagens de cabeça de corte coronal. O principal motivo disto é que muitas imagens de cabeça de corte axial são bem parecidas com as imagens de corte coronal, assim, ambas as categorias se misturam no resultado de várias operações de consulta por similaridade. Como o número de imagens de cabeça com corte coronal é bem menor do que as imagens de corte axial, a queda na precisão das consultas é mais acentuada para esta categoria.

\subsubsection{Avaliação qualitativa}

Alguns exemplos de consultas realizadas pelo sistema desenvolvido são apresentados nas Figuras 5.9 e 5.10, para uma avaliação visual qualitativa do vetor de características proposto. A interface do sistema é projetada para marcar as imagens como relevantes ou não relevantes na janela onde se encontram as miniaturas das imagens retornadas. As imagens relevantes têm o nome do arquivo logo abaixo da miniatura, escritos na cor verde; enquanto as imagens não relevantes têm o nome do arquivo escrito na cor laranja. É possível observar na maioria dos resultados de consultas que, embora as imagens marcadas como não relevantes não pertençam ao mesmo subgrupo de imagens similares à imagem chave de busca, elas ainda pertencem à mesma categoria, ou seja, exibem a mesma parte do corpo. 


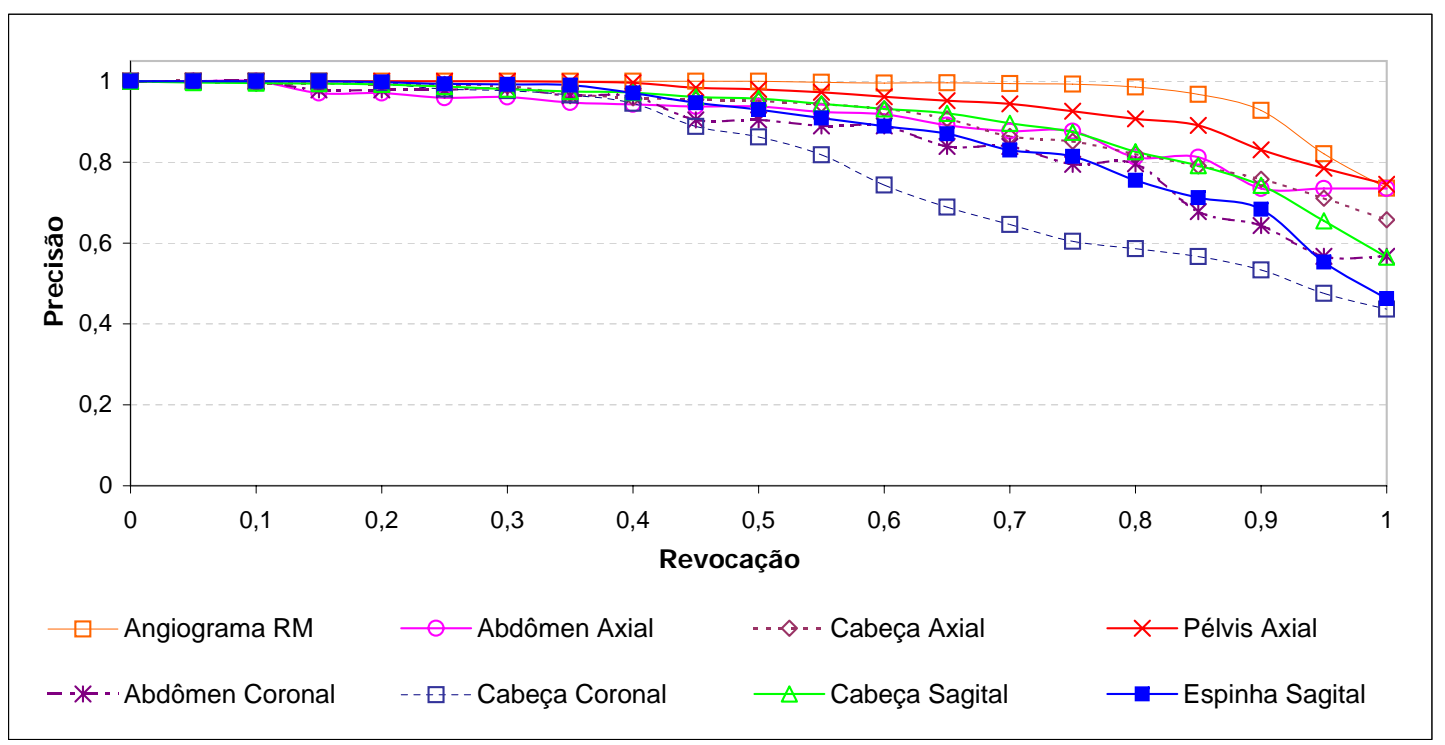

Figura 5.8: Curvas médias de precisão e revocação para cada categoria de imagens da base experimental descrita na Tabela 5.1.
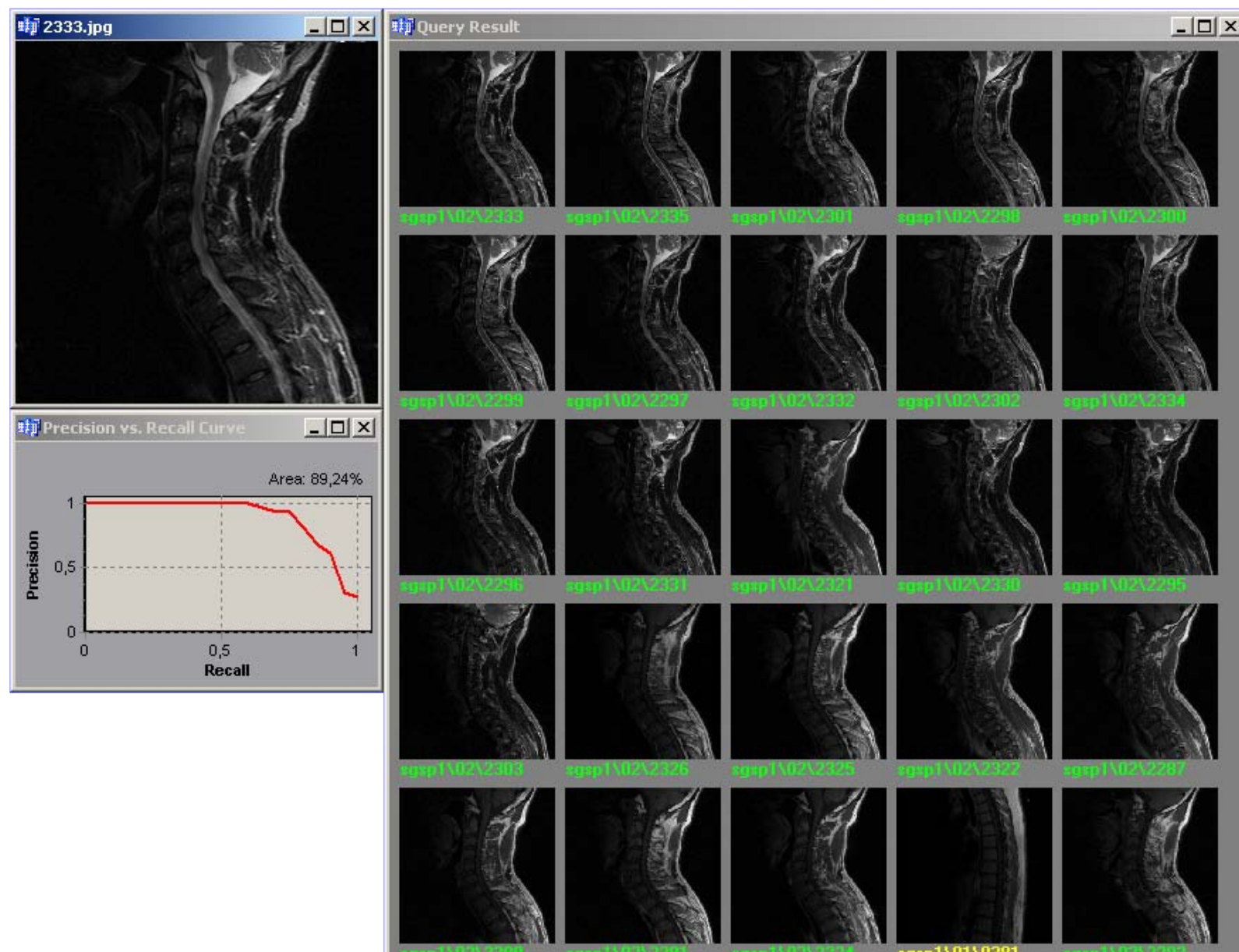

sgsp 110110381

Figura 5.9: Exemplo de consulta kNN $(k=25)$. Número total de imagens relevantes: 37.

\subsection{Tempo de processamento}

As tarefas mais custosas na determinação do vetor de características proposto são a segmentação da imagem e o cálculo da dimensão fractal por meio da integral de correlação 


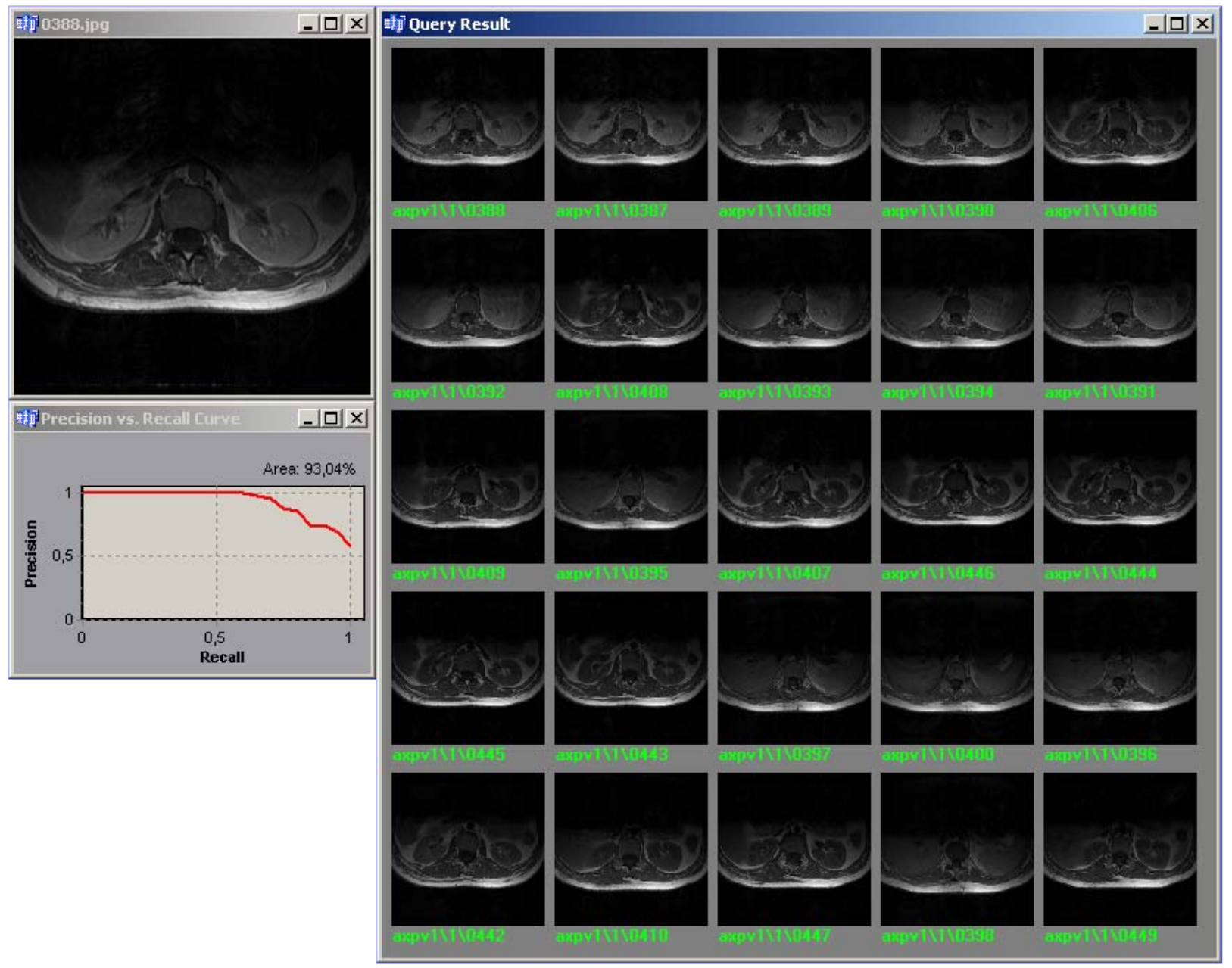

Figura 5.10: Exemplo de consulta kNN $(k=25)$. Número total de imagens relevantes: 58 .

definida na Equação A.1. Para obter uma estimativa da complexidade do método em tempo de execução foram medidos os tempos médios de segmentação da imagem e computação do vetor de características para todas as imagens da base experimental. Vale lembrar que essas imagens são de 8 bits (256 níveis de cinza) e de tamanho $256 \times 256$ pixels. Todos os algoritmos foram implementados na linguagem $\mathrm{C}++$, utilizando o sistema Builder da Borland. Para os testes foi utilizado um computador PC com processador principal de $3.4 \mathrm{GHz}$ e $1 \mathrm{~Gb}$ de memória RAM a $800 \mathrm{MHz}$ de freqüência de barramento. O tempo médio de segmentação em 5 classes $(L=5)$ foi de 3 segundos para cada imagem, sendo que a convergência do método EM/MPM ocorreu, na média, em 250 estágios, conforme o algoritmo descrito na seção 4.5.4. O cálculo da dimensões fractais para cada imagem segmentada em $L=5$ é de 2.5 segundos. Assim, em média, cada imagem tem seu vetor de características computado em 5.5 segundos.

\subsection{Considerações Finais}

Neste Capítulo foi apresentada uma nova abordagem de extração de características de imagens médicas para realização de consultas por similaridade em sistemas CBIR. O ponto 
principal desta abordagem é a proposta de um vetor de características compacto, de tamanho fixo e altamente eficaz em consultas por similaridade de imagens. Uma técnica de segmentação de imagens não supervisionada baseada nos Campos Aleatórios de Markov é utilizada para classificar os pixels com relação aos principais tecidos observados em imagens de ressonância magnética, que são essencialmente caracterizados por faixas de níveis de cinza. Cada região referente a um determinado tecido é considerada uma região composta, da qual é extraído um conjunto de medidas que caracterizam o seu formato e posicionamento na imagem. A dimensão fractal é utilizada como um descritor elementar das regiões, que possibilita com apenas um valor numérico distinguir regiões de formato linear, puntiforme ou planares. As medidas extraídas de diversas regiões compostas são combinadas e compõem o vetor de características proposto que, em outras palavras, procura capturar a essência da distribuição espacial dos tecidos em imagens médicas.

Em nossos experimentos foram consideradas imagens de diversos exames clínicos, incluindo exames de cabeça, espinha, abdômen, pélvis e angiogramas. A capacidade de recuperação de imagens similares foi estimada com a utilização de curvas de precisão vs. revocação e os resultados obtidos mostram que a nossa técnica apresenta grande vantagem de precisão sobre os bem conhecidos momentos de Zernike e os tradicionais histogramas de brilho da imagem. Além disso, o vetor de características proposto é bem mais compacto contendo apenas 20 valores reais que representam características intuitivas e de fácil interpretação. Isto favorece fortemente o sucesso das estruturas de indexação vetorial que dependem essencialmente do tamanho dos vetores e da simplicidade da função de distância utilizada. Um artigo [12] resumindo este trabalho foi apresentado no CBMS'2005 (18th IEEE Symposium on Computer-Based Medical Systems). 


\section{Sistema FEMine - CBIR para padrões de expressão genética}

A Genética é uma ciência relativamente nova que desperta um enorme interesse na comunidade científica por abordar temas diretamente relacionados à vida e aos diversos elementos da mesma, tais como evolução, reprodução, hereditariedade, melhoramento, entre outros. As décadas de 80 e 90 foram marcantes para o campo da Genética com o surgimento dos "Projetos Genoma", que tinham como objetivo descobrir e mapear todo o conjunto de genes de uma determinada espécie, em especial a do ser humano. A utilidade mais saliente e imediata para tais projetos era a de permitir conhecer a origem e causa de diversas doenças, envolvendo com isso a busca pela melhoria e simplificação dos métodos de diagnósticos, tratamentos, cura e prevenção das mesmas.

O Projeto Genoma Humano (PGH) foi proposto em 1990 com o objetivo de mapear e ordenar o genoma humano, sendo que sua finalização ocorreu em 2003. Entretanto, a finalização do PGH, e de outros tantos projetos genoma, marcou apenas o início de outra longa e extensiva tarefa: a análise dos dados obtidos. Um dos temas principais desta análise consiste em estudar e interpretar o papel de cada gene incluindo a complicada relação que existe entre eles durante a vida do respectivo organismo.

Neste Capítulo é apresentado o desenvolvimento de um sistema denominado FEMine, do inglês Fly Embryo Miner, capaz de processar imagens de expressão genética, extrair características das mesmas e possibilitar a realização de consultas por similaridade levando em consideração a semelhança entre seus padrões de expressão genética. Neste sistema, a extração de características da imagem é baseada na Análise dos Componentes Principais de um grande conjunto de imagens, técnica conhecida com PCA. O método proposto de processamento das imagens possibilita preparar automaticamente, e com eficiência, grandes volumes de imagens para extração de características. O Apêndice B apresenta uma revisão dos principais conceitos de genética e dos métodos utilizados para obter as imagens de 
padrões de expressão genética que são o foco desta etapa de trabalho.

\subsection{Motivação}

Atualmente, os padrões de expressão genética, especialmente da Drosophila Melanogaster, popularmente conhecida como "mosca da fruta", têm atraído o interesse de muitos pesquisadores da área de biologia e computação. O maior exemplo disso é a base de dados FlyBase ${ }^{1}$ [147, 148] mantida por um consórcio fundado pelo Instituto Nacional de Saúde dos Estados Unidos e pelo Conselho de Pesquisa Médica de Londres, envolvendo pesquisadores de diversas universidades, incluindo Harvard, Cambridge, Indiana, California e Berkeley. Dentre as mais diversas categorias de informação sobre a mosca da fruta, a FlyBase mantém atualmente, sob coordenação do BDGP (Berkeley Drosophila Genome Project) uma base com mais de 56.000 imagens digitais de expressão genética de mais de 3.000 genes, obtidas pela análise de hibridização in situ (ISH - In Situ Hybridization - ver Apêndice B). As imagens da Figura B.1 são exemplos de imagens dessa base que, pelo fato de estar em pleno crescimento e ter acesso público, constitui um interessante objeto de pesquisa para pesquisadores da área de computação e, mais especificamente, da área de processamento de imagens. Algoritmos sofisticados de reconhecimento de padrões, medidas de similaridade, análise de séries temporais, entre outros, fazem-se necessários para manter e desenvolver a recuperação e mineração de informações nesta base.

Dentro deste contexto, o objetivo deste trabalho é desenvolver um framework para realização de consultas relativas aos padrões de expressão genética das imagens da Drosophila, envolvendo a informação espacial 2D e, possivelmente, como trabalho futuro, a informação das séries temporais 3D. Tal mecanismo deve auxiliar os usuários da base de imagens possibilitando que eles descubram informações importantes no contexto biológico, como por exemplo, quais são os genes que expressam correlação espaço-temporal durante os estágios de 6 a 12 da embriogênese da Drosophila. Mais especificamente, os objetivos do projeto, sob perspectiva de mais baixo nível, são focados em torno de questões do seguinte tipo:

- Dado duas imagens de expressão genética de ISH, qual a similaridade entre elas? Quais as características que expressam de forma sucinta e eficiente os padrões contidos nas imagens? Quais funções de distância podem ser utilizadas?

- Como podemos descobrir e agrupar genes que apresentam padrões similares?

- Dado uma imagem de busca, quais as imagens similares da base?

\footnotetext{
${ }^{1}$ http://www.fruitfly.org/
} 


\subsection{Descrição do sistema}

Neste Capítulo apresentamos o desenvolvimento do sistema modular denominado FEMine, do inglês Fly Embryo Miner, capaz de processar imagens de expressão genética, extrair características das mesmas e possibilitar a realização de consultas por similaridade levando em consideração a semelhança dos padrões de expressão genética. Os principais componentes do sistema FEMine são responsáveis pelas seguintes tarefas.

- Pré-processamento e segmentação das imagens - o primeiro módulo de processamento das imagens tem como objetivo identificar a região dos embriões, separando-as da região de fundo. Esta é uma tarefa relativamente simples, pois os embriões possuem uma textura característica bem diferente da solução aquosa à qual estão imersos. Para isso é proposta uma combinação de filtros e operadores morfológicos. Este módulo é detalhado na seção 6.4.1;

- Isolamento do embrião principal - menos de um terço das imagens da FlyBase contém um único embrião envolto por solução aquosa. Muitas imagens possuem mais que um embrião e, na maioria desses casos, eles se encontram encostados ou muito próximos uns aos outros. Para isolar o embrião principal dos demais embriões é proposto um novo método que particiona recursivamente a imagem utilizando a transformada de watershed e, para que as partições sejam feitas corretamente, também é proposto um novo método iterativo para determinação automática de marcadores para o algoritmo de alagamento descrito no Capítulo 4. A seção 6.4.2 apresenta com detalhes os métodos propostos para este módulo;

- Registro das imagens segmentadas - os embriões estão dispostos dentro das imagens em diferentes posições, escalas e direção. O processo de extração de características deve buscar caracterizar apenas os padrões de expressão genética contidos nos embriões, independente de sua orientação, escala, posição e até mesmo de sua forma. Para que isso ocorra de maneira eficaz é necessário que os embriões passem primeiro por um processo de alinhamento que é comumente conhecido como "registro de imagens". Para este módulo é proposta a utilização de um algoritmo eficiente de registro desenvolvido por Thévenaz, Ruttimann e Unser [149] que segue uma abordagem multi-resolução. Uma discussão sobre esta etapa é apresentada na seção 6.4.3;

- Extração de características - o objetivo do módulo extrator de características, conforme já mencionado, é extrair medidas das imagens que representem apenas os padrões de expressão genética contidos nos embriões. A proposta de abordagem deste problema inclui a utilização da técnica de Análise dos Componentes Principais - PCA (Principal Component Analysis), como o algoritmo base para se capturar a essência dos padrões espaciais. A descrição detalhada deste módulo é apresentada na seção 6.5 
- Indexação - a indexação das características tem como objetivo agilizar as operações de consultas. Porém, não é escopo deste trabalho estudar ou desenvolver técnicas eficientes de indexação;

- Interface para consultas - o usuário do sistema FEMine deve ser capaz de realizar consultas envolvendo um raio de abrangência range query ou a busca pelos $k$ vizinhos mais próximos $k N N$ query. Os resultados devem ser apresentados em janelas contendo as miniaturas das imagens recuperadas e o nome de seus respectivos genes. Informações adicionais, tais como as partes do organismo que apresentam determinados níveis de expressão, também serão disponibilizadas para avaliação.

A Figura 6.1 apresenta uma visão geral do sistema FEMine envolvendo a relação existente os módulos descritos.

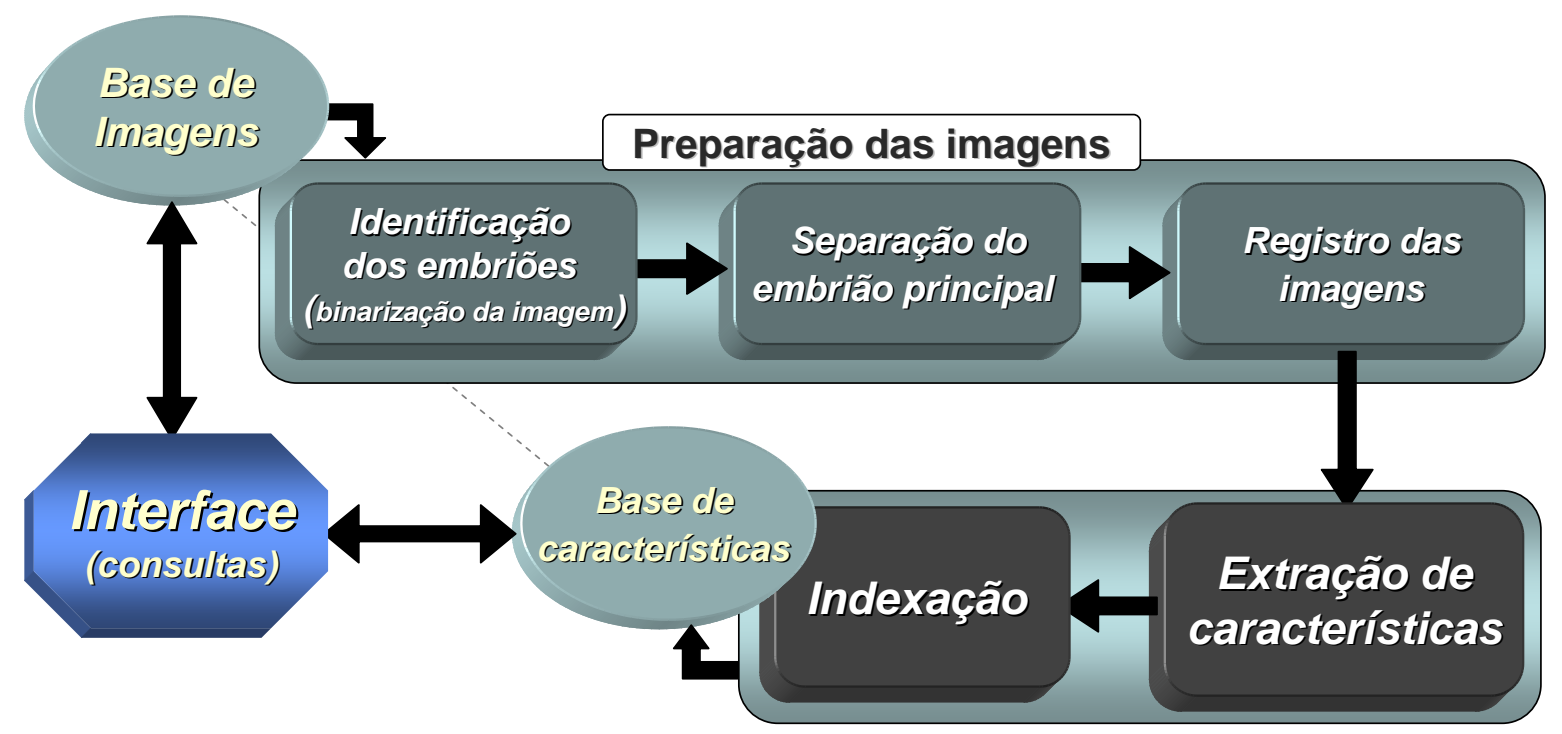

Figura 6.1: Diagrama de módulos do sistema FEMine.

\subsection{Trabalhos correlatos e contribuição do projeto}

Os principais trabalhos relacionados com a análise de imagens de ISH da mosca da fruta são relativamente recentes e pouco numerosos. Gurunathan et al. [150] e Jayaraman et al. [151], por exemplo, propõem uma abordagem semelhante baseada na extração de momentos invariantes das imagens binarizadas dos embriões. Já o sistema BEST proposto por Kumar et al. [152] realiza uma comparação pixel a pixel das imagens binarizadas, utilizando a intersecção das regiões em primeiro plano como medida de similaridade dos padrões de expressão. Outra abordagem bastante direta seria a utilização de histogramas de nível de cinza das imagens como forma de caracterização dos padrões, porém, neste caso a informação espacial seria desconsiderada e os resultados seriam os mesmos daqueles obtidos pela análise de microarray de DNA. 
A técnica apresentada no trabalho de Peng e Myers [153] é mais robusta e combina medidas de similaridade em nível local e global. Na análise global, a imagens são quantizadas utilizando-se um modelo de mistura Gaussiano (GMM), e comparadas com base na medida de "informação mútua" [154]. Na análise de nível local, as imagens quantizadas são divididas em regiões de intensidade homogêneas, denominadas "blobs", e a comparação entre duas imagens é feita medindo-se a intersecção de suas respectivas regiões.

As imagens da base de dados FlyBase constituem a base de experimento para a maioria das pesquisas do gênero, contendo a documentação de mais de 3012 genes por meio de mais de 56000 imagens de expressão genética obtidas por ISH. Porém, os conjuntos de imagens que têm sido utilizados nos experimentos são limitados e contém apenas as "melhores" imagens da base que, no caso, são as imagens que contém apenas um embrião e possui contornos bem definidos tanto do organismo quanto das "manchas" que determinam os padrões de expressão. Considerando que menos de um terço das imagens da base apresentam essas características podemos afirmar que o caráter de aplicação prática dessas pesquisas fica comprometido. A maioria das imagens possui mais de um embrião que, na maior parte dos casos, encontra-se encostado com os embriões vizinhos. Assim, um tratamento especial é necessário para essas imagens, para que o embrião principal seja devidamente separado do plano de fundo e dos demais embriões. Para o sistema FEMine, é proposta a utilização da transformada de watershed, baseada no mapa de distância euclidiana da imagem binarizada. Para lidar com o problema de ruídos nas bordas da máscara do embrião, conforme veremos a seguir, propomos um novo método automático de seleção de marcadores.

Além disso, a comparação pixel a pixel dos embriões, que ocorre, por exemplo, quando se quantifica a intersecção de regiões para se comparar duas imagens [153, 152], requer que o alinhamento (registro) dos embriões comparados seja praticamente perfeito. Levandose em consideração que os embriões variam em seu formato de acordo com o seu estágio de desenvolvimento e mesmo com sua orientação dentro da imagem, esse tipo de alinhamento só seria alcançado por meio da utilização de um método de registro que levasse em consideração a deformação das regiões dos embriões, conforme proposto nos trabalhos recentes de Fowlkes et al. [155] e Sorzano et al. [156]. Observa-se, porém, que a aplicação de tais técnicas pode aumentar significativamente a complexidade do esquema de extração de características e, eventualmente, descaracterizar o padrão de expressão contido na imagem.

Outra característica bastante comum nos padrões de expressão é a ausência de uma delimitação clara das manchas. Nesses casos, muitas células que expressam o gene específico (pontos escuros) encontram-se misturadas com células que não expressam (pontos claros), formando regiões de textura específica para as quais os métodos baseados na binarização da imagem [150, 151, 152, 153] não são adequados.

A proposta deste projeto com relação à extração de características das imagens para comparação dos padrões de expressão genética é baseada na técnica de reconhecimento automático de faces humanas desenvolvida por Turk e Pentland [157], que utiliza a análise 
dos componentes principais (PCA) do conjunto de imagens para capturar suas variações mais significantes e codificá-las de modo que elas sejam usadas na comparação das imagens. A técnica ficou conhecida pela utilização de um espaço de características constituído pelas então denominadas "autofaces" (Eigen-Faces), uma referência direta da utilização de autovetores (eigenvetors) pra reconhecimento de faces. Nesse projeto é proposta a utilizarção da técnica de PCA nas imagens de ISH dos embriões da Drosophila Melanogaster, buscando com isso contornar os dois problemas mencionados: a comparação pixel a pixel dos embriões e a binarização (quantização) das imagens. Nas seções a seguir serão apresentados detalhes de todos os módulos previstos para este projeto, conforme descrito na seção 6.2 , assim como todo o trabalho já realizado até o presente momento.

\subsection{Processamento das imagens}

A etapa inicial do processamento das imagens de expressão genética consiste em contê-las para o formato de 8 bits/pixel com escala de níveis de cinza, visto que elas não apresentam informação importante de cor. Na seqüência, as imagens são redimensionadas para um tamanho cuja relação entre a quantidade de informação armazenada e demanda por processamento fique razoavelmente equilibrada. Neste caso, o novo tamanho determinado foi $400 \times 284$, mantendo a relação de aspecto das imagens da FlyBase. As seções seguintes descrevem as etapas do módulo de processamento das imagens convertidas e redimensionadas, incluindo os passos de identificação dos embriões, isolamento do embrião principal e alinhamento (registro).

\subsubsection{Identificação dos embriões}

A segmentação das imagens contendo os embriões, e seus respectivos padrões de expressão genética, tem como objetivo separar o embrião principal (o embrião mais ao centro da imagem) do plano de fundo (a solução aquosa ao qual o embrião está envolvido) e dos demais embriões que, eventualmente, possam estar na imagem, encostados ou não no embrião principal. Para isso, o primeiro passo é identificar e separar os embriões do plano de fundo, obtendo uma imagem binária.

Visto que a solução aquosa possui uma textura lisa com variações bem suaves e os embriões possuem uma textura rugosa tanto nas regiões de células que expressam o gene quanto nas regiões de células que não expressam, a utilização de um filtro baseado na medida de variância local dos pixels combinado com uma operação de limiarização é suficiente para definir a maioria deles como sendo do primeiro plano (embriões) ou do plano de fundo. $\mathrm{O}$ filtro de variância ressalta as regiões de alta rugosidade da imagem, atribuindo para cada pixel o valor correspondente à variância dos níveis de cinza em uma vizinhança pré-definida. Neste caso, consideramos uma vizinhança circular de 12 vizinhos conforme ilustrado na Figura 6.2. Sobre o resultado do filtro de variância é aplicada uma operação de limiarização da 


\begin{tabular}{|c|c|c|c|c|}
\hline & & $\mathrm{X}$ & & \\
\hline & $\mathrm{X}$ & $\mathrm{X}$ & $\mathrm{X}$ & \\
\hline $\mathrm{X}$ & $\mathrm{X}$ & $\mathrm{O}$ & $\mathrm{X}$ & $\mathrm{X}$ \\
\hline & $\mathrm{X}$ & $\mathrm{X}$ & $\mathrm{X}$ & \\
\hline & & $\mathrm{X}$ & & \\
\hline
\end{tabular}

Figura 6.2: Vizinhança circular de 12 vizinhos definida para o filtro de variância local.

imagem (threshold), utilizando-se para isso um valor de limiar baixo, igual a 5. O tamanho da vizinhança e o valor do limiar foram determinados empiricamente.

A Figura 6.3 ilustra um exemplo da aplicação do filtro de variância local (Fig. 6.3b) e posterior limiarização (Fig. 6.3c) para um exemplo de imagem típico da base de dados, onde um embrião sobressalente compartilha com o embrião principal uma pequena extensão de suas respectivas bordas (Fig. 6.3a). Essas duas operações juntas conseguem classificar corretamente a maioria dos pixels, principalmente a região das bordas dos embriões, onde os valores de variância local costumam ser os mais altos. Porém, é muito comum que ocorram regiões homogêneas de nível de cinza também no interior dos embriões, fazendo com que apareçam buracos na região de primeiro plano. Para lidar com essa situação é utilizado o operador de preenchimento de buracos (fill holes), definido na morfologia matemática binária [2]. A Figura 6.3d ilustra o resultado da aplicação desses operadores.

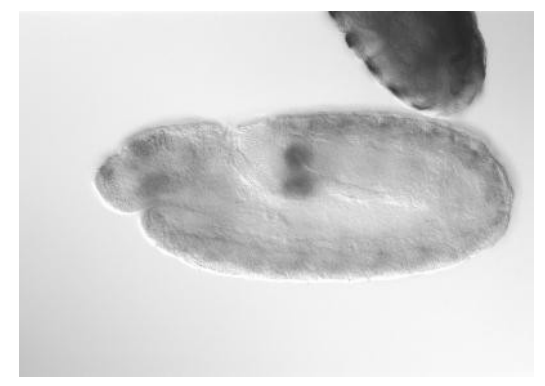

(a)

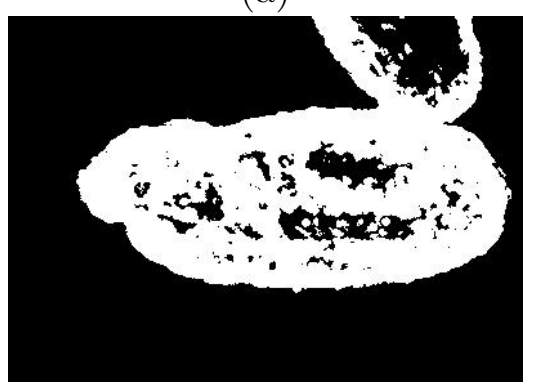

(c)

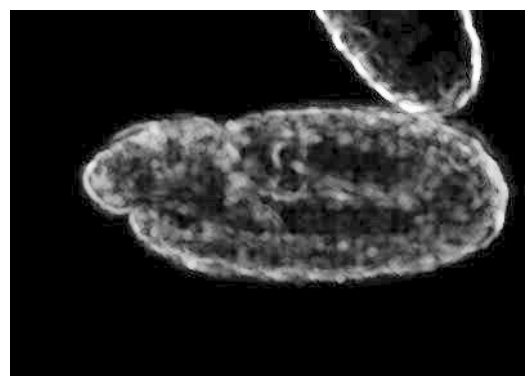

(b)

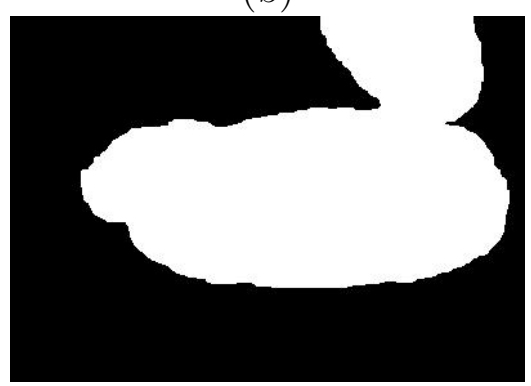

(d)

Figura 6.3: Identificação de embriões da Drosophila Melanogaster em imagem de ISH. (a) imagem original com o embrião principal ao centro e um embrião sobressalente interceptando parte de sua borda; (b) aplicação do filtro de variância local com uma vizinhança circular de 12 vizinhos (Fig. 6.2); (c) limiarização (threshold) do resultado do filtro de variância; (d) resultado da aplicação do operador morfológico binário de preenchimento de buracos (fill holes) e abertura binária.

Após a binarização da imagem e a aplicação dos operadores morfológicos, é comum 
que existam embriões sobressalentes em regiões isoladas da região do embrião principal. Considerando que nas imagens da base, o embrião principal é sempre aquele que está mais ao centro da imagem, uma operação é realizada para selecionar somente a região isolada mais ao centro e remover as demais regiões. Por último, para eliminar pequenos ruídos na borda da região central, também é aplicado o operador de abertura binário [2], utilizando um elemento estruturante simples de um pixel.

Para resumir os passos descritos, a Figura 6.4 apresenta o algoritmo do método proposto para identificação dos embriões. Na seção seguinte é apresentado o processo de isolamento do embrião principal.

Algoritmo 1: Identificação dos embriões na imagem original

- entrada: imagem original em níveis de cinza.

- saída: imagem binária contendo os embriões em primeiro plano.

1. Aplicar o filtro de variância local sobre a imagem, utilizando uma vizinhança circular de 12 vizinhos (ver Figura 6.2);

2. Binarizar o resultado do filtro de variância utilizando um limiar de nível de cinza igual a 5;

3. Aplicar sobre a imagem binária o operador morfológico de preenchimento de buracos (fill holes);

4. Se a imagem binária conter mais de uma região isolada de primeiro plano, manter somente a região mais ao centro, descartando as demais;

5. Aplicar o operador morfológico de abertura binária com elemento estruturante simples de um pixel.

Figura 6.4: Algoritmo de identificação dos embriões na imagem original.

\subsubsection{Isolando o embrião principal}

A necessidade de isolar o embrião principal da imagem vem do fato de que muitas imagens ISH possuem mais de um embrião que, normalmente, encontram-se encostados uns aos outros, conforme ilustrado na Figura 6.3a. Vale lembrar que o embrião principal é aquele mais ao centro da imagem.

Para realizar o isolamento do embrião principal na imagem binária, por exemplo, da Figura 6.3d, empregamos a abordagem de separação de partículas sobrepostas por meio da transformada de watershed, combinada com a técnica de marcadores, conforme apresentado em detalhes no Capítulo 4. O algoritmo tradicional de alagamento de Vincent e Soille [128], também apresentado no Capítulo, foi utilizado para obter a transformada de watershed.

Inicialmente, utilizamos como marcadores os pontos de máximo local do mapa de distância euclidiano, conforme o exemplo da Figura 4.11. Para a maioria das aplicações de análise de partículas essa abordagem é adequada. Células, grãos, peças industriais, entre outros, 
são elementos geralmente convexos. Entretanto, aplicando-se essa abordagem para separar partículas não convexas, implica na "quebra" das partículas em um número de pedaços proporcional ao número de marcadores, neste caso, os máximos locais correspondentes do mapa de distância, caracterizando assim o problema da super-segmentação (over-segmentation).

A super-segmentação foi a dificuldade encontrada quando tentamos separar as imagens binarizadas dos embriões da mosca da fruta. Os embriões sofrem transformações de seu formato ao longo do seu desenvolvimento tornado-se elementos não convexos. Além disso e, na maior parte dos casos, pequenas fissuras e imperfeições na borda das partículas fazem com que elas deixem de ser convexas e, conseqüentemente, a separação ocorra de forma incorreta. A Figura 6.5 ilustra exemplos da aplicação da transformada de watershed nas imagens binarizadas dos embriões utilizando como marcadores as regiões de máximo local no mapa de distâncias euclidianas. Na primeira imagem (Fig. 6.5a), por exemplo, há seis máximos locais no mapa de distância correspondente (Fig 6.5b) que dão origem a seis regiões separadas na transformação final (6.5c), quando o correto seria que houvesse apenas duas regiões.

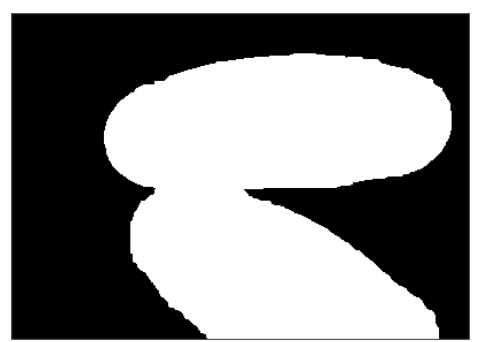

(a)

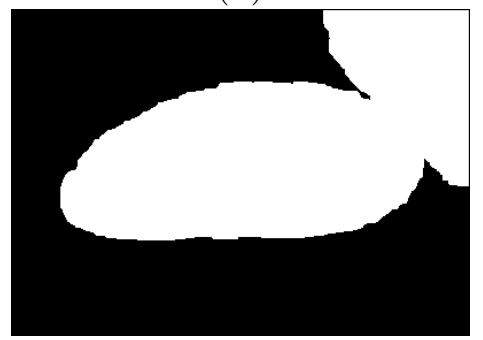

(d)

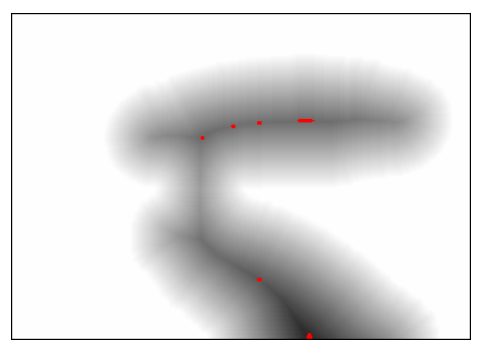

(b)

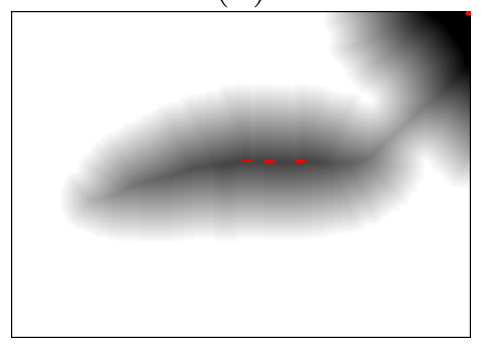

(e)

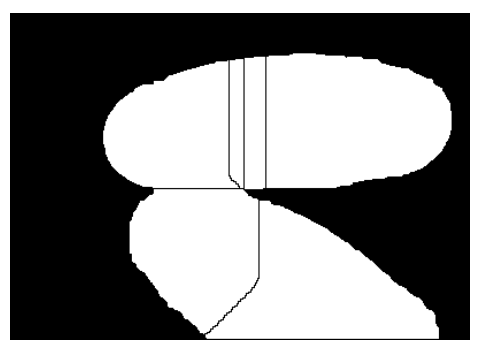

(c)

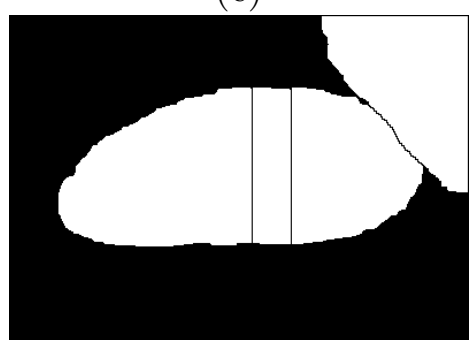

(f)

Figura 6.5: Exemplos da aplicação da transformada de watershed nas imagens binarizadas dos embriões. (a,d) imagens binárias dos embriões; (b,e) mapas de distâncias sobreposto com as respectivas regiões de máximo local; $(\mathrm{c}, \mathrm{f})$ resultados mal sucedidos na tentativa de separação dos embriões (as regiões dos embriões foram "quebradas").

Uma solução direta para esse problema seria filtrar a borda de toda região de primeiro plano, buscando eliminar as pequenas fissuras nas regiões dos embriões tornando-as convexas. Porém, determinar os parâmetros da filtragem seria uma tarefa de ajuste crítico que deveria ser considerada para cada imagem. Se a filtragem fosse excessiva, toda a região de primeiro plano da imagem se tornaria convexa, impossibilitando a separação das partículas. Por outro lado, se a filtragem fosse insuficiente, o problema da super-segmentação ocorreria novamente. 


\section{Um novo método proposto: Particionamento Recursivo}

Para resolver o problema da super-segmentação e separar os embriões da imagem corretamente foi desenvolvido um método de particionamento recursivo da região de primeiro plano combinando a transformada de watershed com um novo método de seleção automática de marcadores. Considere, por exemplo, uma das imagens binárias da Figura 6.5 (a ou d). A idéia consiste em encontrar somente dois marcadores no mapa de distâncias da imagem binária de modo que elas correspondam às duas partículas mais evidentes da imagem. Assim, aplicando-se o algoritmo de divisores de água, somente haverá duas regiões ao final do processo, sendo que a região mais distante do centro da imagem é descartada (o embrião principal é sempre aquele mais ao centro da imagem). Sobre a região que foi mantida é aplicado novamente este processo até que não existam mais partículas evidentes na imagem.

A seleção automática das represas referentes às partículas mais evidentes é um processo iterativo baseado na limiarização do mapa de distâncias. O valor do limiar (threshold) é variado de forma decrescente iniciando do valor mais alto. A cada iteração é realizada a binarização do mapa utilizando-se o valor atual de corte e, para a imagem resultante, é determinado o número de regiões isoladas. No valor mais alto do limiar o resultado da binarização é a própria imagem de entrada e existe apenas uma região isolada (o processo de identificação dos embriões descrito na seção 6.4.1 mantém apenas uma região, aquela mais ao centro da imagem). À medida que o valor de corte é decrementado essa região inicial vai sendo "desgastada" pelas bordas como se o operador morfológico de erosão estivesse sendo aplicado repetidamente sobre ela. Se a região inicial constituir uma forma não convexa, é garantido que, para algum valor do parâmetro de limiarização, a binarização da imagem resulte em mais de uma região isolada. Sendo assim, a iteração continua, decrementando o valor do limiar até que o resultado da binarização apresente mais de uma região isolada e, se neste ponto existir mais de duas regiões, as duas maiores são mantidas e as demais descartadas. A Figura 6.6 ilustra alguns passos desse processo para uma imagem com dois embriões encostados. O resultado dessa operação é uma imagem que contém duas regiões isoladas (Fig. 6.6e) que serão utilizadas como marcadores no algoritmo de alagamento. O algoritmo de seleção automática de represas é apresentado na Figura 6.7.

A Figura 6.8 apresenta a transformação de watershed para a imagem da Figura 6.6. O processo inicia a partir das represas inicias e do valor de limiar obtidos na etapa anterior. A iteração ocorre agora de maneira inversa, como se a imagem estivesse sendo reconstruída a partir das regiões iniciais. O valor do limiar é incrementado e os pixels que possuem o mesmo valor de nível de cinza são incorporados à região mais próxima dos mesmos. Os pixels cujas distâncias para uma e outra região são iguais formam os divisores de água que separam as regiões. A Figura, 6.8f ilustra o resultado final da operação. Verifique que, de fato, as partículas mais evidentes da imagem foram separadas.

Quando o algoritmo de seleção de regiões iniciais é aplicado para um região convexa, em nenhum valor de limiar para binarização do mapa de distâncias será encontrada mais de 


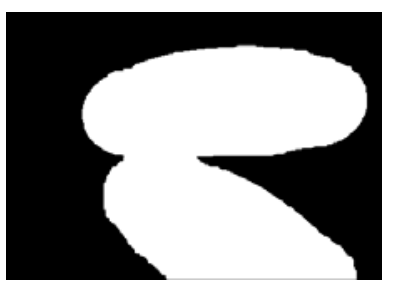

(a)

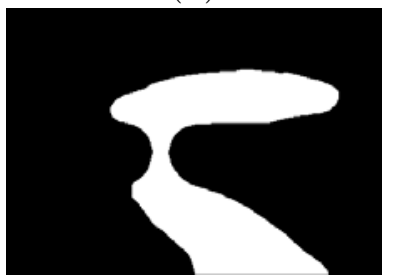

(d)

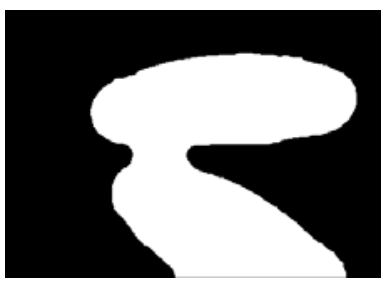

(b)

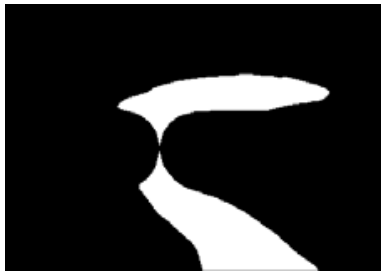

(e)

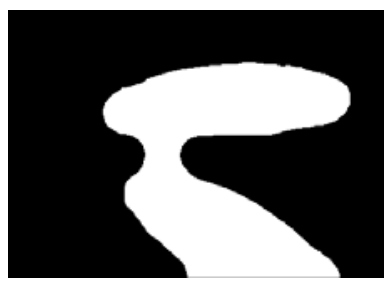

(c)

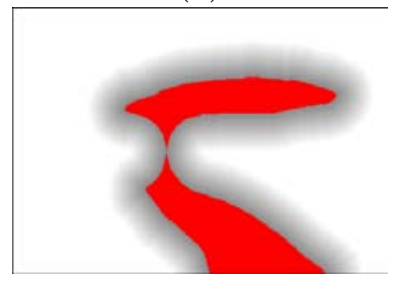

(f)

Figura 6.6: Processo iterativo de determinação de marcadores para aplicação da transformada de watershed. (a) imagem original (threshold=254); (b) threshold=244; (c) threshold $=234$; (d) threshold $=224$; (e) threshold $=215$ (duas regiões isoladas que serão os marcadores); (f) marcadores sobrepostas no mapa de distâncias euclidianas.

Algoritmo 2: Seleção de marcadores para a transformada de watershed

- entrada: mapa de distâncias euclidianas da imagem binária

- saída: imagem binária $r$ contendo as represas inicias, valor de corte $T$ final e valor mínimo $M I N$ do mapa de distâncias

1. Iniciar $T$ com o máximo valor do mapa de distâncias;

2. Gerar a imagem binária $r$ do mapa de distâncias utilizando $T$;

3. Determinar $N$, o número de regiões isoladas de $r$;

4. Decrementar $T$;

5. Se $T=M I N$ ou $N=2$ ir para o passo 8;

6 . Se $n>2$, manter apenas as duas maiores regiões em $r$ e ir para 8

7. Se $n=1$, voltar ao passo 2;

8. Finalizar o processo retornado $r, T$ e $M I N$.

Figura 6.7: Algoritmo de seleção de marcadores para a transformada de watershed

uma região. Assim, o limiar é decrementado do valor mais alto até o menor valor de nível de cinza no mapa de distâncias, percorrendo todos os valores possíveis. Neste caso então, a transformada de watershed não é aplicada.

$\mathrm{Na}$ verdade, o valor final do limiar após o processo de determinação dos marcadores constitui uma medida para se determinar quão "evidente" são as partículas da imagem a serem separadas. Se este valor final estiver próximo do valor máximo, as partículas são consideradas evidentes e, a transformada de watershed é aplicada. Caso contrário, se o valor final do limiar estiver próximo do valor mínimo, é considerado que não há partículas a serem separadas. Isso ocorre na maioria das vezes quando existem pequenas saliências nas bordas das regiões fazendo com que estas deixem de ser convexas. Conforme já mencionado, isso 


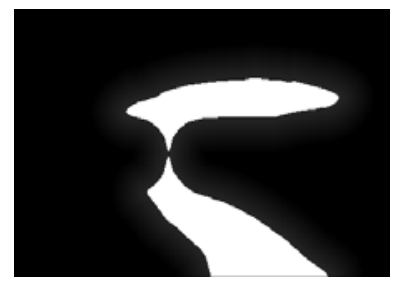

(a)

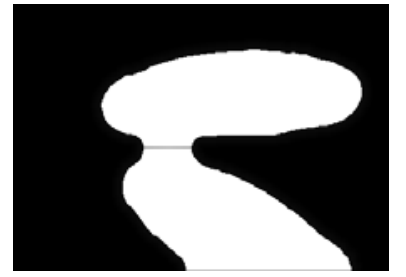

(d)

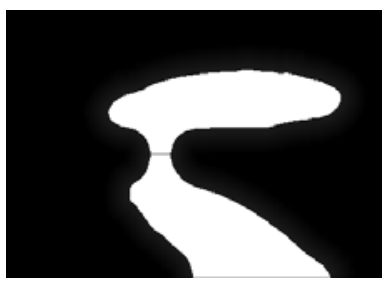

(b)

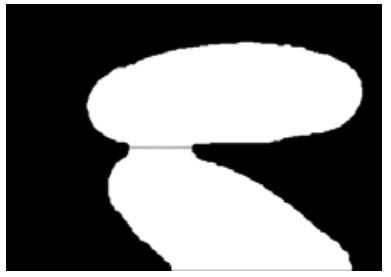

(e)

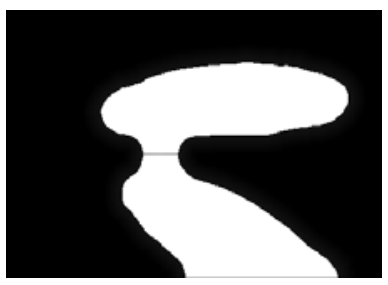

(c)

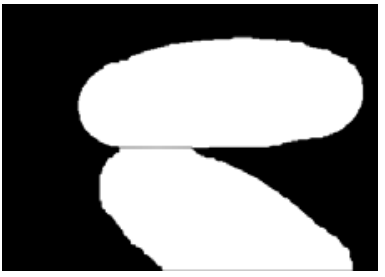

(f)

Figura 6.8: Passos do algoritmo de alagamento iniciado a partir dos marcadores da Figura 6.6.

é uma característica comum nas imagens dos embriões e, o método proposto neste trabalho pode lidar com essa situação separando corretamente os embriões sem que as saliências em suas bordas impliquem em "quebra" dos embriões, conforme ilustrado nos exemplos da Figura 6.5. O valor final de limiar é então utilizado para se determinar quando aplicar a transformada de watershed e, deste modo, funciona como critério de parada para o algoritmo de particionamento recursivo aqui proposto. Se este valor for próximo do valor mínimo o particionamento é encerrado, e, caso contrário, o particionamento é executado. Um valor constante é definido empiricamente para estabelecer a referida medida de proximidade.

A Figura 6.9 apresenta dois exemplos que ilustram como o valor final de corte pode ser usado pra interpretar se há evidências de partículas parcialmente sobrepostas ou não na imagem. No primeiro caso, uma pequena saliência foi criada na borda de uma elipse, tornando-a não convexa. O processo de determinação dos marcadores foi finalizado retornando um valor de limiar cuja diferença do valor mínimo no mapa de distâncias é apenas 5. Neste caso, a existência de partículas a serem separadas é desconsiderada, conforme esperado. No segundo exemplo, a necessidade de separação de duas partes é evidente, e isso é refletido pela diferença entre o limiar final e o limiar mínimo que, neste caso, é 94, um valor bem mais alto que o do primeiro exemplo.

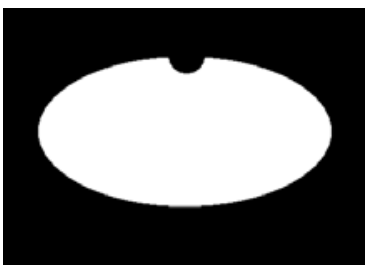

(a)

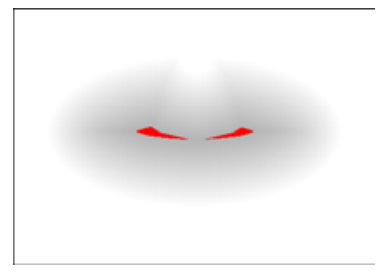

(b)

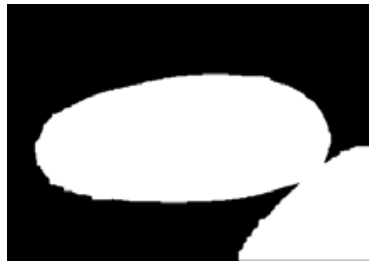

(c)

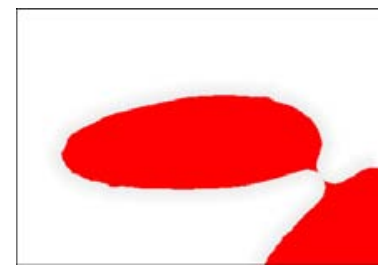

(d)

Figura 6.9: Exemplos de marcadores. (a) imagem com região não convexa, sem evidência de partículas conectadas; (b) marcadores (diferença do limiar final igual a 5); (c) imagem binária de embriões, com evidência de partículas a serem separadas; (d) marcadores (diferença do limiar final igual a 94). 
Para resumir a idéia do processo de particionamento recursivo aqui proposto, é apresentada na Figura 6.10 uma versão algoritmica do mesmo. As Figuras 6.11 e 6.12, por sua vez, apresentam exemplos da aplicação do algoritmo com imagens binárias contendo dois e três embriões, respectivamente.

Algoritmo 3: Particionamento recursivo de partículas binárias conectadas

- entrada: imagem binária com um ou mais embriões conectados

- saída: imagem binária contendo apenas o embrião principal

1. Aplicar à imagem de entrado o Algoritmo 1 (Figura 6.7) de determinação automática de represas iniciais, recebendo o valor final de limiarização $T$ (threshold), o valor mínimo $M I N$ de nível de cinza do mapa de distâncias, e uma imagem binária $r$ contendo os marcadores;

2. Se $(T-M I N)<\Delta$, o processo é terminado. ( $\Delta$ é determinado empiricamente);

3. Aplicar a transformada de watershed usando $T$ e $r$ como parâmetros de iniciais. 0 resultado são duas regiões isoladas correspondentes às duas partículas mais evidentes da imagem;

4. Manter somente a região mais ao centro da imagem, descartando a outra região;

5. Repetir o processo a partir do passo 1, para a imagem resultante do passo anterior.

Figura 6.10: Algoritmo de particionamento recursivo de partículas binárias conectadas
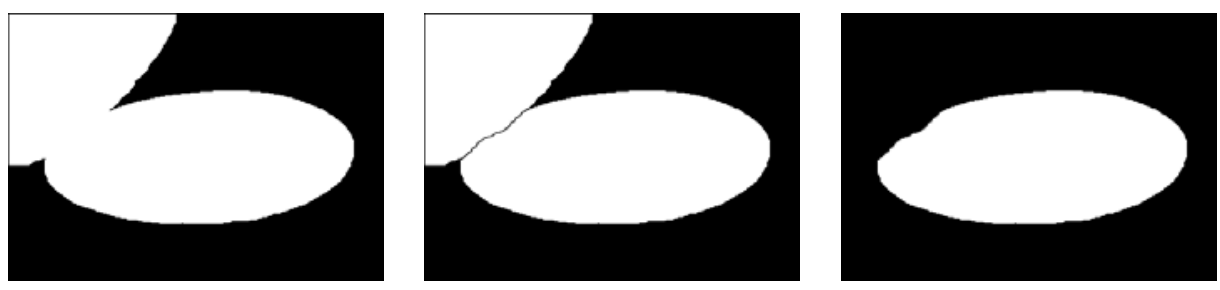

Figura 6.11: Exemplo da aplicação do algoritmo da particionamento recursivo para uma imagem binária com dois embriões.
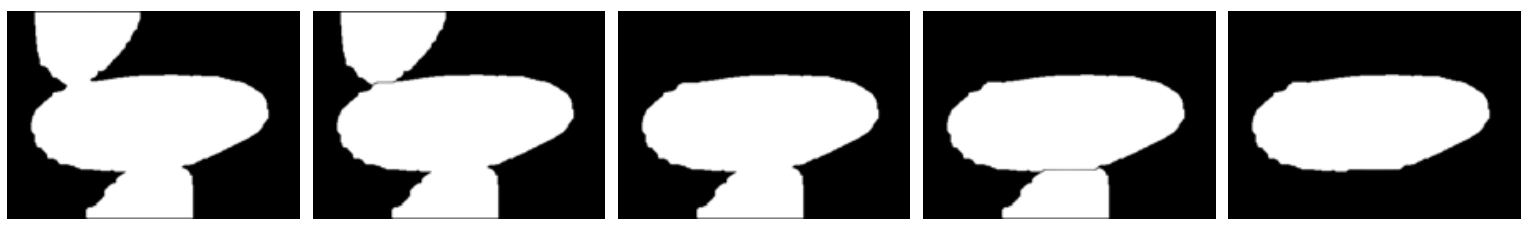

Figura 6.12: Particionamento recursivo de uma imagem binária com três embriões.

Utilizando o método proposto de particionamento recursivo nas imagens binarizadas dos embriões, incluindo a seleção automática de marcadores para a transformada de watershed, conseguimos aproveitar muitas imagens da FlyBase que até então eram desconsideradas nas 
pesquisas anteriores. Conforme mencionado anteriormente, menos de um terço das imagens da base possui o embrião principal isolado dos eventuais demais embriões da imagem. Com o novo algoritmo, foi possível aproveitar mais de dois terços da imagem da base, sendo que as restantes são consideradas muito pouco úteis por conter apenas uma região específica do embrião, estar fora de foco ou possuir iluminação que impossibilita até mesmo separar os embriões do plano de fundo. Assim, concluímos que este método além de realçar o caráter de aplicação prático do sistema proposto para indexação e recuperação das imagens, também pode ser considerado uma ferramenta importante para futuras pesquisas ou aplicações que venham a utilizar a mesma base de imagens ou imagens similares.

Após aplicação do método de particionamento recursivo nas imagens, é aplicado ainda um filtro gaussiano sobre as mesmas combinado com uma operação de limiarização para eliminar pequenos ruídos e suavizar as bordas da região correspondente ao embrião principal. A próxima etapa rumo à extração de características das imagens consiste no alinhamento (registro) das imagens segmentadas para que todos os embriões fiquem compatíveis em relação à escala, rotação e posição na imagem. A abordagem utilizada para essa operação é discutida na seção seguinte.

\subsubsection{Alinhamento (registro) das imagens}

O registro de imagens é uma operação importante em um sistema cujo objetivo é medir a similaridade de duas imagens desconsiderando aspectos espaciais e morfológicos das mesmas, tais como posição, orientação, escala e formato. Para estudar e comparar os padrões genéticos presentes nas imagens dos embriões é necessário, de fato, que estas sejam transformadas de modo que os embriões principais adquiram uma correspondência adequada entre si.

De acordo com o Instituto de Informação Científica (ISI), mais de 1000 artigos foram publicados sobre esse tópico somente nos últimos dez anos sendo que o artigo (survey) de Zitová e Flusser [158] resume e cita as técnicas mais importantes. Assim como na maioria dos processos computacionais, a qualidade e precisão no resultado do registro de duas imagens é diretamente proporcional à complexidade do método. Diversas transformações podem ser combinadas para que essas imagens sejam alinhadas incluindo desde as transformações geométricas elementares até transformações não lineares de deformação, envolvendo parâmetros de elasticidade e viscosidade. Verifica-se, porém, que a carga de processamento em algoritmos de registro de imagens cresce rapidamente com o aumento de complexidade das transformações empregadas, tornando infactível sua aplicação em sistemas que lidam com grandes conjuntos de dados.

Neste projeto é proposta a utilização de um método eficiente de registro que combine apenas transformações de translação, rotação e escala, buscando obter um alinhamento adequado dos embriões principais (já separados) sem, com isso, acrescentar uma sobrecarga no sistema de extração de características. Para isso, apenas a imagem binária, ou máscara, dos embriões principais será utilizada (segmentação descrita nas duas seções anteriores), não 
considerando, portanto, o interior dos mesmos. Considerando o formato elíptico dos embriões da base, a idéia é fazer com que suas respectivas máscaras sejam alinhadas a uma imagem alvo contendo ao centro uma elipse com eixo principal disposto horizontalmente e tamanho pré-definido (ver Figura 6.13a). Com isso, o algoritmo de alinhamento deve transformar a imagem binária buscando minimizar a diferença entre região do embrião e a elipse na imagem alvo conforme ilustrado na Figura 6.13. O resultado desse processo é uma máscara transformada (Fig. 6.13d) e o conjunto de transformações aplicadas sobre a mesma. Combinando esses dois elementos com a imagem original, obtém-se então uma imagem praticamente pronta para a extração de características.

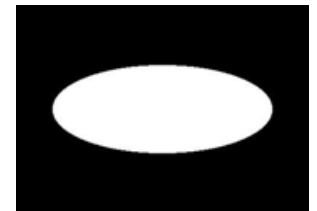

(a)

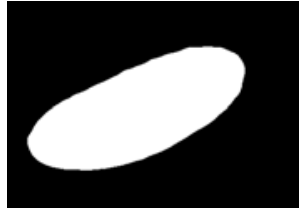

(b)

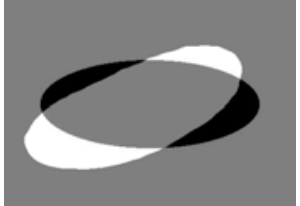

(c)

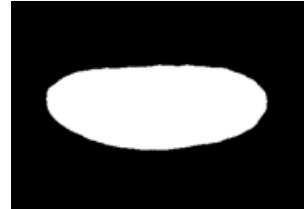

(d)

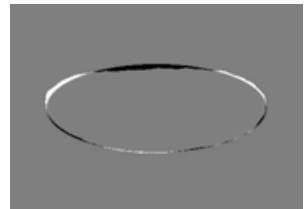

(e)

Figura 6.13: Registro da máscara do embrião principal utilizando uma imagem canônica. (a) imagem alvo contendo uma elipse; (b) imagem fonte (máscara de embrião a ser transformada); (c) diferença entre as imagens alvo e fonte antes do registro; (d) imagem fonte ao final do processo de registro; (e) diferença entre as imagens alvo e fonte depois do registro.

Dentre as diversas técnicas existentes, o algoritmo desenvolvido por Thévenaz, Ruttimann e Unser [149] foi escolhido para realizar o registro das imagens utilizando a imagem alvo da Figura 6.13a e combinando apenas operações de translação, rotação e escala. O objetivo do método é exatamente minimizar a soma das diferenças ao quadrado entre os pixels das imagens fonte (imagem a ser transformada) e alvo, utilizando para isso, uma variação mais eficiente do algoritmo de Marquardt-Levenberg para otimização não linear dos mínimos quadrados. Podendo ser aplicado em imagens binárias ou em tons de cinza, a grande vantagem desse método é a sua alta eficiência que se deve, principalmente, ao uso de um esquema multi-resolução com refinamento progressivo do resultado. Em outras palavras, o alinhamento da imagem ocorre primeiro em uma versão reduzida das imagens alvo e fonte. O resultado vai sendo então propagado para os passos seguintes onde é refinado com imagens gradativamente maiores, até se alcançar o tamanho original das mesmas. Além disso, o algoritmo também emprega um método preciso de interpolação baseado em splines cúbicas e, deste modo, as transformações de rotação e escala são realizadas acrescentando-se um erro mínimo ao resultado.

O registro dos embriões também é importante para o sistema FEMine, pois é justamente nesta etapa que as imagens "ruins" são descartadas. As imagens consideradas "ruins" são basicamente aquelas em que: (1) não há nenhum embrião inteiro dentro da imagem; (2) as bordas do embrião principal estão muito difusas com o plano de fundo, e (3) o embrião principal possui um formato muito diferente de uma elipse. Nestes casos, principalmente, as imagens fogem do padrão considerado ideal para o sistema FEMine, e não podem integrar 
a base de imagens para extração de características. O procedimento adotado para descartar essas imagens é realizado logo após a etapa de registro, verificando-se a diferença entre a imagem fonte (máscara do embrião) e a imagem alvo (máscara de modelo elíptico), conforme a Figura 6.13e. Para quantificar essa diferença foi utilizado o coeficiente de Jaccard [159], $J$, que é definido para duas máscaras $M_{A}$ e $M_{B}$ como

$$
J=\frac{\left|M_{A} \cap M_{B}\right|}{\left|M_{A} \cup M_{B}\right|}
$$

ou, em termos simples: o volume da intersecção dividido pelo volume da união das máscaras. $J=1$, portanto, indica que $M_{A}$ e $M_{B}$ são perfeitamente iguais. O coeficiente de Jaccard é computado para cada imagem ao final da operação de registro. As imagens que obtém $J<0.9$ são automaticamente descartadas pelo sistema. Nas seção de experimentos alguns exemplos de imagens consideradas "ruins" são apresentadas.

\subsubsection{Etapas finais na preparação de imagens}

A pequena variação de formatos dos embriões após o registro ainda constitui um fator negativo para a comparação dos padrões de expressão genética. Por exemplo, dois embriões com padrões similares mas com diferenças no formato podem ser considerados diferentes pelo sistema, o que não é desejável.

É possível observar que os embriões de um mesmo estágio de desenvolvimento apresentam apenas diferenças sutis de formato. A deformação (morphing) dos embriões poderia resolver esse problema, porém o custo computacional seria alto. Além disso, o formato das expressões genéticas também estaria sujeito a deformações. Sendo assim, consideramos uma abordagem mais simples e ainda eficiente para minimizar os efeitos negativos provenientes das diferenças de formato dos embriões:

- Após a operação de registro das imagens, a borda de cada embrião é levemente recortada com base no formato médio de todos os embriões daquele mesmo estágio de desenvolvimento;

- O formato médio é calculado contando o número de vezes que cada pixel da imagem aparece como sendo um pixel de primeiro plano (branco). Se o pixel aparece em mais de $90 \%$ das imagens como sendo de primeiro plano, assim também ele será na imagem de formato médio;

- O recorte das bordas é então obtido multiplicando-se a máscara de formato médio pelas imagens dos embriões já registradas.

Por fim, uma última operação de recorte da região central contendo o embrião também é realizada, eliminando assim o excesso da região de plano de fundo. O resultado da etapa de processamento são imagens em escala de cinza, de tamanho $352 \times 160$ pixels. 
Na Figura 6.14 são apresentados exemplos completos de preparação de imagens para a extração de características contendo os resultados da aplicação dos principais passos desta etapa, que são: (1) identificação dos embriões (Figuras 6.14b,g,l); (2) separação do embrião principal (Figuras 6.14c,h,m) e; (3) registro das imagens (Figuras 6.14d,i,n). As Figuras 6.14e,j,o apresentam o resultado final do processo de preparação. As próximas seções descrevem os métodos propostos de extração de características e indexação dos dados.

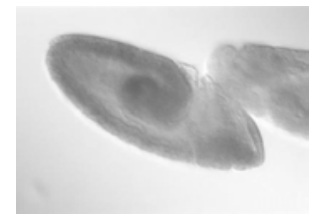

(a)

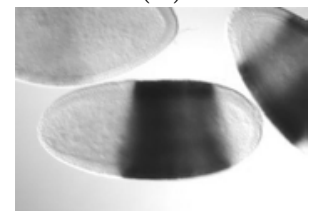

(f)

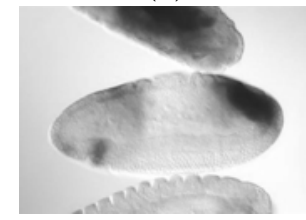

$(\mathrm{k})$

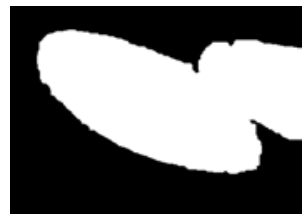

(b)

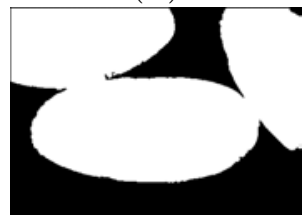

$(\mathrm{g})$

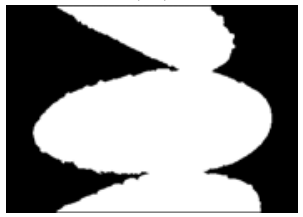

(l)

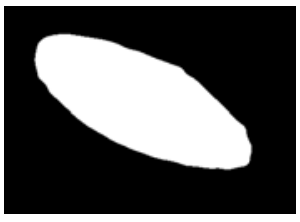

(c)

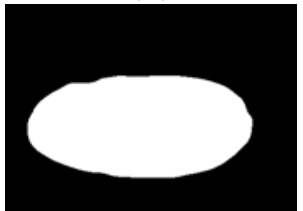

(h)

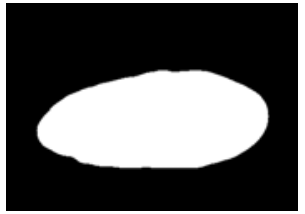

$(\mathrm{m})$

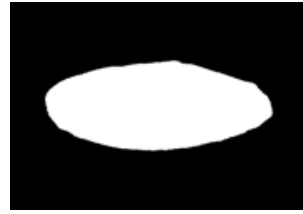

(d)

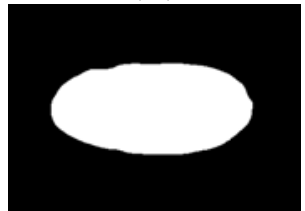

(i)

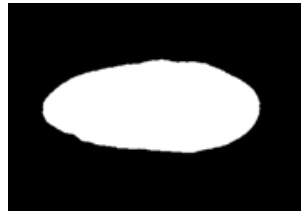

(n)

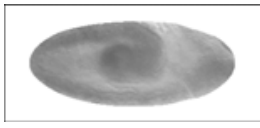

(e)

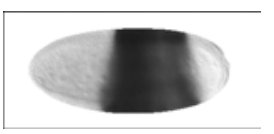

(j)

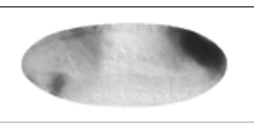

(o)

Figura 6.14: Preparação das imagens para extração de características. (a,f,k) imagens originais; (b,g,l) embriões identificados utilizando o método descrito na seção 6.4.1); (c,h,m) regiões dos embriões separadas utilizando o método proposto de particionamento recursivo (seção 6.4.2); (d,i,n) imagens registradas utilizando o método descrito na seção 6.4.3; (e,j,o) imagens prontas para a extração de características, com a borda dos embriões levemente recortada.

\subsection{Extração de características da imagem}

O objetivo principal deste trabalho é obter uma representação fiel e sucinta de imagens de ISH de embriões da Drosophila, visando capturar somente a essência dos padrões de expressão genética contidos nas mesmas. É desejável que tal representação seja o mais compacta possível e capaz de agrupar imagens com características visuais semelhantes. Para isso é proposta a utilização da técnica de PCA (Principal Component Analysis) sobre nossa base de imagens processadas. Utilizando PCA, temos como objetivo encontrar os melhores "representantes" do conjunto de imagens, para se tornarem um novo espaço de características para as imagens.

A seguir apresentamos os tópicos relacionados com a técnica de PCA aplicada ao nosso conjunto de dados, e o vetor de características proposto para representação das imagens. 


\subsubsection{Análise dos Componentes Principais - PCA}

A técnica de PCA busca encontrar uma nova base ortogonal para o conjunto para expressar as máximas variações presentes no espaço original. Basicamente, isto é feito calculando-se os autovetores da matriz de covariância do conjunto de dados. A partir daqui vamos considerar um subconjunto de imagens (ou conjunto de treinamento) $D=\left[I_{1}, \ldots, I_{M}\right]$ onde cada imagem $I$ possui $N=352 \times 160$ pixels e é um ponto no espaço $N$-dimensional. Vamos considerar também a imagem média $\Psi=\frac{1}{M} \sum_{j=1}^{M} I_{j}$. Os componentes principais do conjunto $D$ são os autovetores da matriz de covariância

$$
C=A A^{T}
$$

onde $A$ é uma matriz $N \times M$ cujas colunas são os vetores

$$
\Phi_{j}=\frac{I_{j}-\Psi}{\sqrt{M}}
$$

para $j=1, \ldots, M$.

Verifica-se, entretanto, que a determinação da matriz $C$, uma matriz $N \times N$, e posterior computação de seus autovetores, é uma tarefa impraticável do ponto de vista computacional.

Seguindo a mesma abordagem que Turk e Pentland [157] utilizaram, são computados os autovetores da matriz $L=A^{T} A$ que é consideravelmente menor, dado que $M<<N$. Assim, denotando o conjunto de autovetores da $L$ como sendo $\mathbf{v}_{\mathbf{i}}$, para $1 \leq i \leq M$, e seus respectivos autovalores $\mu_{i}$, devemos resolver o seguinte:

$$
A^{T} A \mathbf{v}_{\mathbf{i}}=\mu_{i} \mathbf{v}_{\mathbf{i}}
$$

para cada $i=1, \ldots, M$.

Tendo encontrado os $M$ autovetores $\mathbf{v}_{\mathbf{i}}$ da matriz $L$, um conjunto de $M$ autovetores da matriz $C$ é dado por $A \mathbf{v}_{\mathbf{i}}$. Podemos comprovar tal afirmação multiplicando ambos os lados da Equação 6.1 por $A$, conforme segue. Neste caso, verificamos que $A \mathbf{v}_{\mathbf{i}}$ são de fato autovetores da matriz $C$

$$
A A^{T} A \mathbf{v}_{\mathbf{i}}=\mu_{i} A \mathbf{v}_{\mathbf{i}}
$$

Os $M$ autovalores $A \mathbf{v}_{\mathbf{i}}$ formam uma base ortogonal de onde são selecionados apenas os $M^{\prime}$ vetores associados com os maiores autovalores. Para se determinar $M^{\prime}$ é usada uma regra prática: são selecionados os $M^{\prime}$ autovalores cuja soma dos respectivos autovalores é a mais próxima de $90 \%$ da soma total. Os autovetores selecionados são então divididos por suas respectivas normas para que a nova base seja ortonormal.

Visto que esses autovetores também são pontos do espaço $N$-dimensional e uma combinação linear dos elementos do conjunto $D=\left[I_{1}, \ldots, I_{M}\right]$, também é possível visualizá-los como imagens. Na verdade, eles podem revelar aspectos interessante dos padrões de expressão genética, conforme discutido mais adiante. Turk e Pentland utilizaram esta técnica 
para a tarefa de reconhecimento de faces e denominaram estes autovetores como EigenFaces. Em nosso trabalho estes vetores são denominados Eigen-Embryos. Na Figura 6.15 são apresentados 16 exemplos de Eigen-Embryos calculados a partir de um subconjunto de 2000 imagens de embriões preparadas para extração de características (ver seções 6.4.1, 6.4.2 e 6.4.3). Nesta Figura, a numeração das imagens indica em ordem decrescente a importância de cada (Eigen-Embryo) associada diretamente aos seus autovalores. A imagem de número 1 consiste no autovetor associado ao maior autovalor.

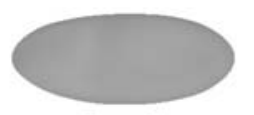

1

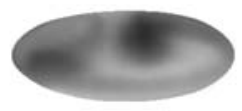

5

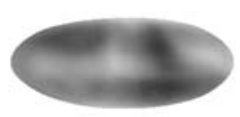

9

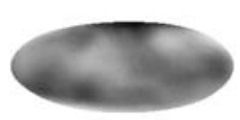

13

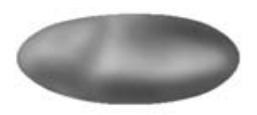

2

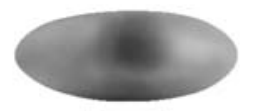

6

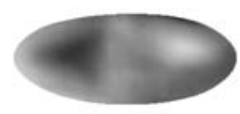

10

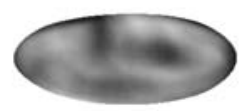

14

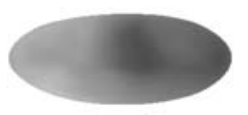

3

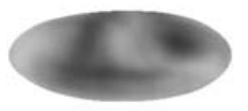

7

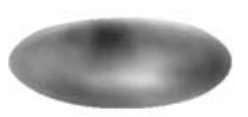

11

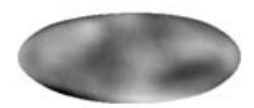

15

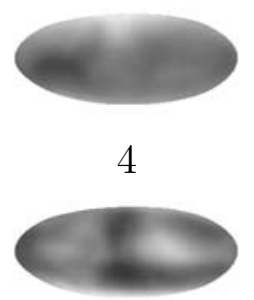

8

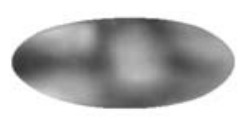

12

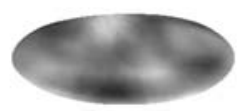

16

Figura 6.15: Eigen-Embryos mais significativos de um conjunto de 2000 imagens de embriões. A imagem de número 1 ilustra o autovetor associado ao maior autovalor. As demais imagens estão dispostas em ordem decrescente de seus respectivos autovalores.

Na Figura 6.16 é apresentado o algoritmo que resume os passos para a obtenção dos Eigen-Embryos descritos nesta seção.

\subsubsection{Vetor de características proposto}

Tendo determinado o conjunto de Eigen-Embryos, o vetor de características $P_{E}$ de uma imagem $I$ é calculado a partir da seguinte projeção:

$$
P_{E}=S(I-\Psi)
$$

onde $S$ é a matriz formada pelos Eigen-Embryos como vetores linhas e $\Psi$ é a imagem média calculada no algoritmo da Figura 6.16.

\subsection{Experimentos e Resultados}

A FlyBase, base de imagens ISH de embriões da Drosophila, contém exatamente 56.980 imagens divididas em diferentes estágios de desenvolvimento do embrião. Ao todo, são 16 
Algoritmo 4: Cálculo da base de Eigen-Embryos

- entrada: Conjunto $D=\left[I_{1}, \ldots, I_{M}\right]$ onde $I_{i}$ são imagens processadas pelo sistema FEMine

- saída: Matriz $S$ de Eigen-Embryos

1. Computar a imagem média $\Psi=\frac{1}{M} \sum_{j=1}^{M} I_{j}$;

2. Montar a matriz $N \times M A$, cujas colunas são os vetores $\Phi_{j}=\frac{I_{j}-\Psi}{\sqrt{M}}$ para $j=1, \ldots, M$;

3. Computar a matriz $M \times M L=A^{T} A$;

4. Computar $M$ autovetores $\mathbf{v}_{\mathbf{i}}$ da matriz $L$;

5. Computar $M$ Eigen-Embryos Avivi

6. Selecionar os $M^{\prime}$ Eigen-Embryos associados aos $M^{\prime}$ maiores autovalores, cuja soma represente $90 \%$ da soma de todos os $M$ autovalores;

7. Retornar a matriz $S$ de Eigen-Embryos, como vetores linha.

Figura 6.16: Algoritmo para o cálculo dos Eigen-Embryos.

estágios de desenvolvimento, porém as imagens são divididas em 6 grupos conforme a Tabela 6.1 .

Tabela 6.1: FlyBase - Base de imagens ISH da mosca Drosophila

\begin{tabular}{|c|c|}
\hline Estágio & \# de imagens \\
\hline $1-3$ & 4.105 \\
$4-6$ & 8.564 \\
$7-8$ & 4.968 \\
$9-10$ & 5.652 \\
$11-12$ & 13.556 \\
$13-16$ & 20.135 \\
\hline Total & $\mathbf{5 6 . 9 8 0}$ \\
\hline
\end{tabular}

Este conjunto contém imagens com qualidade bastante variável, muitas delas contendo múltiplos embriões ou embriões incompletos. Na Figura 6.17 são apresentados alguns exemplos de imagens para cada estágio de desenvolvimento do embrião.

\subsubsection{Processamento das imagens}

Todas as 56.980 imagens da FlyBase foram recolhidas e submetidas ao módulo de processamento de imagens proposto na seção 6.4, o qual inclui a extração, isolamento e registro dos embriões. O sistema FEMine descarta automaticamente as imagens consideradas "ruins", juntamente com a etapa de registro dos embriões. No total, foram processadas com sucesso 36.630 imagens, $64 \%$ do total da base. Isto representa um ganho significativo no aproveitamento das imagens com relação a trabalhos anteriores. O Dr. H.Peng [153] revelou em uma conversa pessoal que seu sistema de processamento não aproveita mais que $30 \%$ das imagens, pois não lida com imagens que contém mais de um embrião. Na maioria dos estágios de 


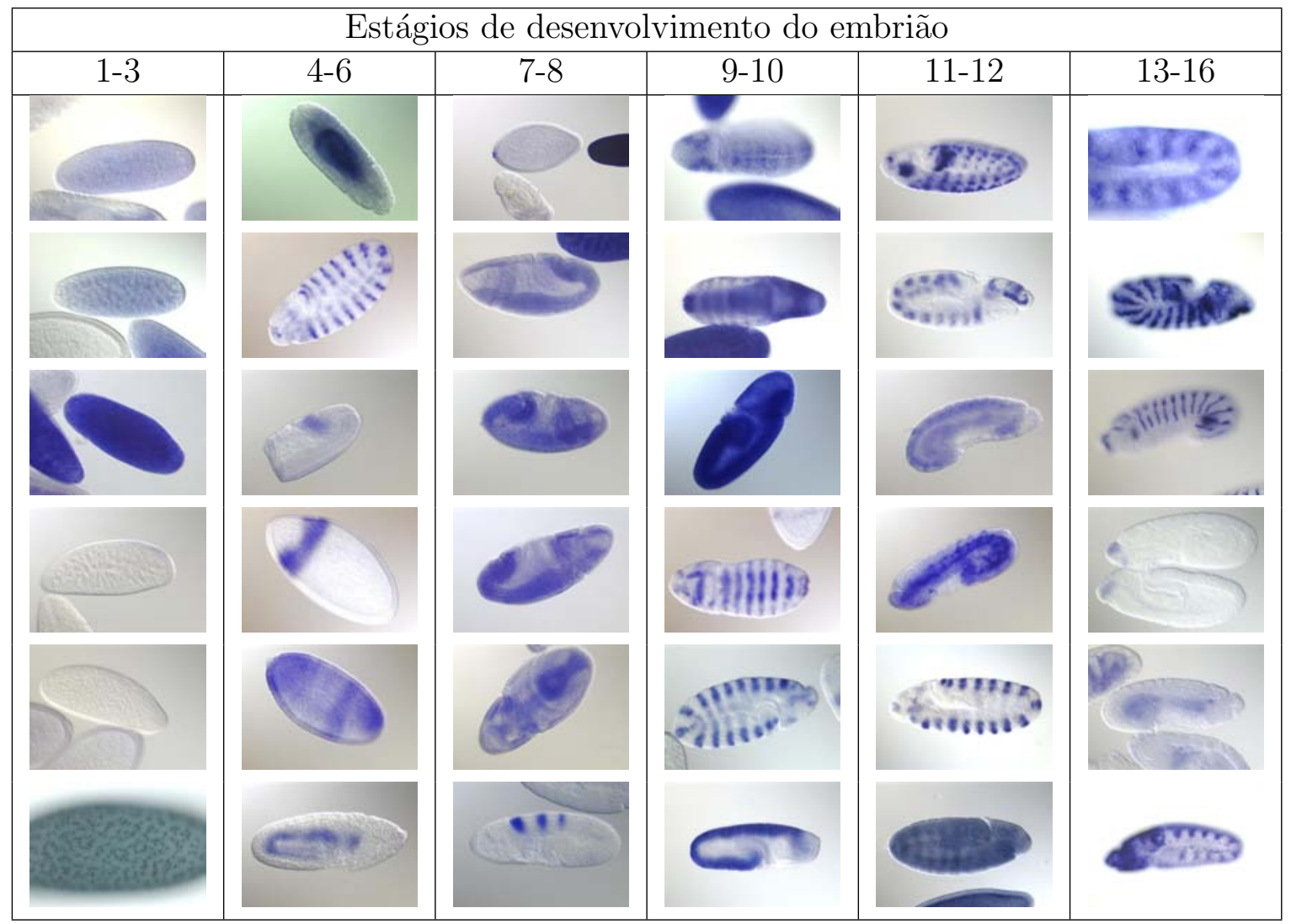

Figura 6.17: Exemplos de imagens da FlyBase.

desenvolvimento o aproveitamento das imagens com o módulo de processamento FEMine superou os 70\% conforme apresentado na Tabela 6.2. O menor aproveitamento nos estágios de desenvolvimento superiores está diretamente relacionado ao fato de que os embriões passam a perder o formato elíptico a medida que se desenvolvem, adquirindo o formato de feijão nos últimos estágios de embriogênese. A Figura 6.18 ilustra exemplos de imagens descartadas automaticamente pelo sistema FEMine.

Tabela 6.2: Relação de imagens processadas com sucesso pelo módulo de processamento de imagens FEMine

\begin{tabular}{|c|c|c|c|}
\hline Estágio & \# de imagens & \# de imagens processadas & relação de sucesso \\
\hline $1-3$ & 4.105 & 3.733 & $91 \%$ \\
$4-6$ & 8.564 & 6.278 & $73 \%$ \\
$7-8$ & 4.968 & 3.806 & $77 \%$ \\
$9-10$ & 5.652 & 4.183 & $74 \%$ \\
$11-12$ & 13.556 & 8.332 & $61 \%$ \\
$13-16$ & 20.135 & 10.298 & $51 \%$ \\
\hline Total & $\mathbf{5 6 . 9 8 0}$ & $\mathbf{3 6 . 6 3 0}$ & $64 \%$ \\
\hline
\end{tabular}

\subsubsection{Cálculo dos Eigen-Embryos}

O objetivo do sistema FEMine é interagir com os 6 grupos de imagens considerando-os bases de imagens distintas. A recuperação de padrões de expressão genética através de diferentes estágios de desenvolvimento é proposto como um trabalho de extensão. 


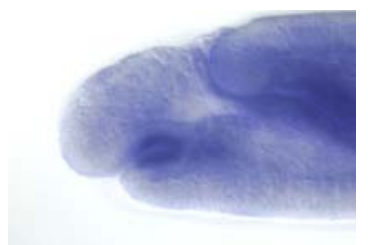

(a)

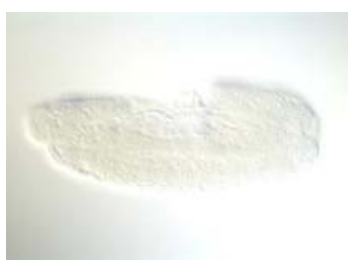

(b)

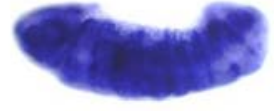

(c)

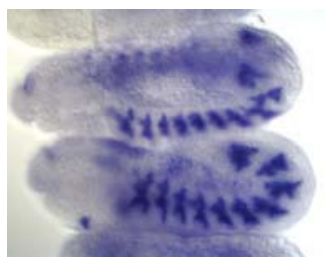

(d)

Figura 6.18: Exemplos de imagens "ruins", automaticamente descartadas pelo sistema FEMine. (a) imagem com embrião incompleto; (b) embrião muito difuso com o plano de fundo; (c) embrião com formato não elíptico; (d) imagem onde não se pode dizer qual o é embrião principal.

Após a etapa de processamento das imagens, a técnica de PCA foi aplicada aos 6 subconjuntos de imagens com o objetivo de gerar os Eigen-Embryos para cada um deles. Devido à alta complexidade do algoritmo que precisa manter todas as imagens em memória para o cálculo dos autovetores, uma significativa amostra de 2.000 imagens de cada conjunto foi utilizada para a determinação dos Eigen-Embryos. A amostragem é uniforme e não aleatória. O algoritmo descrito na Figura 6.16 foi aplicado para cada conjunto de amostras resultando em 6 bases distintas de Eigen-Embryos, cada uma com um número diferente de vetores. O número de Eigen-Embryos obtidos para as amostras de cada estágio de desenvolvimento é apresentado na Tabela 6.3.

Tabela 6.3: Número de Eigen-Embryos obtidos para cada amostra de 2.000 imagens de cada estágio de desenvolvimento.

\begin{tabular}{|c|c|}
\hline Estágio & \# de Eigen-Embryos \\
\hline $1-3$ & 1 \\
$4-6$ & 5 \\
$7-8$ & 16 \\
$9-10$ & 12 \\
$11-12$ & 17 \\
$13-16$ & 24 \\
\hline
\end{tabular}

De maneira muito interessante é possível observar que o número de vetores obtidos reflete a quantidade de padrões relevantes de expressão genética em cada conjunto de imagens. Do ponto de vista biológico, isto ocorre porque novos padrões de expressão genética são criados a medida que o embrião cresce e novas partes do seu organismo começam a se desenvolver. Isto pode ser observado nos exemplos de imagem da Figura 6.17. Nos primeiros estágios de desenvolvimento, por exemplo, é possível observar a presença de apenas 2 padrões relevantes: (1) todas as células do embrião expressam o gene, ou (2) nenhuma célula expressa o gene. Neste caso, uma base formada por um único Eigen-Embryo é capaz de distinguir entre esses dois padrões. Para ilustrar uma base de Eigen-Embryos, a Figura 6.15 apresenta os 16 vetores calculados para as imagens dos estágios 7-8. 


\subsubsection{Cálculo dos vetores de características}

Com as bases de Eigen-Embryos determinadas e as imagens processadas pelo sistema FEMine, o cálculo do vetor de características de uma imagem é basicamente uma operação de multiplicação conforme a Equação 6.2, que efetua uma operação de mudança de base. A grande vantagem das bases de Eigen-Embryos é que elas são bases ortonormais e, portanto, a operação de mudança de base não requer que a matriz da nova base seja invertida. Por isso, a complexidade de cálculo do vetor de características da imagem é sempre linear ao tamanho da imagem, ou seja, $\Theta\left(M^{\prime} N\right)$, onde $N$ é o número de pixels da imagem e $M^{\prime}$ o número de Eigen-Embryos da base.

Embora a operação de cálculo da base de Eigen-Embryos seja uma tarefa relativamente custosa, ela pode ser considerada uma operação de manutenção do sistema, que deve ser realizada apenas na ocorrência de mudanças significativas na base de imagens, quando se adiciona ou remove um número grande de imagens.

Foram computados os vetores de características para cada imagem de cada um dos 6 conjuntos. Os vetores de características do conjunto associado aos estágios 7-8, por exemplo, possui 16 valores reais. O tamanho do vetor para as imagens do estágio 11-12 é 17, e assim por diante, de acordo com o tamanho das bases de Eigen-Embryos descritas na Tabela 6.3.

\subsubsection{Recuperação de imagens por conteúdo}

A interface do sistema FEMine foi desenvolvida para possibilitar a realização de consultas por imagens de padrões de expressão genética semelhantes, dado uma imagem de busca. A imagem 6.19 ilustra esta funcionalidade do sistema sobre a base de imagens de estágio 11-12 (8.332 imagens). Trata-se de uma consulta kNN onde $K=20$. A função de distância utilizada neste caso é a função de distância euclidiana. Para cada consulta é retornada uma janela contendo as miniaturas das imagens mais similares. Esta janela também contém, logo abaixo das miniaturas:(1) o nome do arquivo da imagem; (2) a identificação do gene e; (3) as partes do corpo do embrião para as quais o gene está sendo expresso. Caso o usuário do sistema tenha pré-classificado as imagens como relevantes ou não-relevantes à imagem de busca, o sistema FEMine também calcula automaticamente, e apresenta em uma janela separada, o gráfico de precisão e revocação para aquela consulta e área sobre o gráfico. Na consulta da Figura 6.19, por exemplo, a área sobre o gráfico apresentado é de 94\%. Para identificar os ítens relevantes à consulta, o sistema escreve na cor laranja o nome de arquivo das imagens consideradas não relevantes. O nome de arquivo dos ítens relevantes é escrito em verde.

O sistema FEMine oferece ao usuário a opção de visualizar as imagens originais como resultado de consulta. Neste caso, é possível observar com maior clareza o desafio ao qual o sistema é submetido, lidando com as imagens de múltiplos embriões. Um exemplo de consulta deste tipo é apresentado na Figura 6.20, onde a própria imagem de busca contém dois embriões a mais que o embrião principal, sendo que um deles está praticamente encostado 


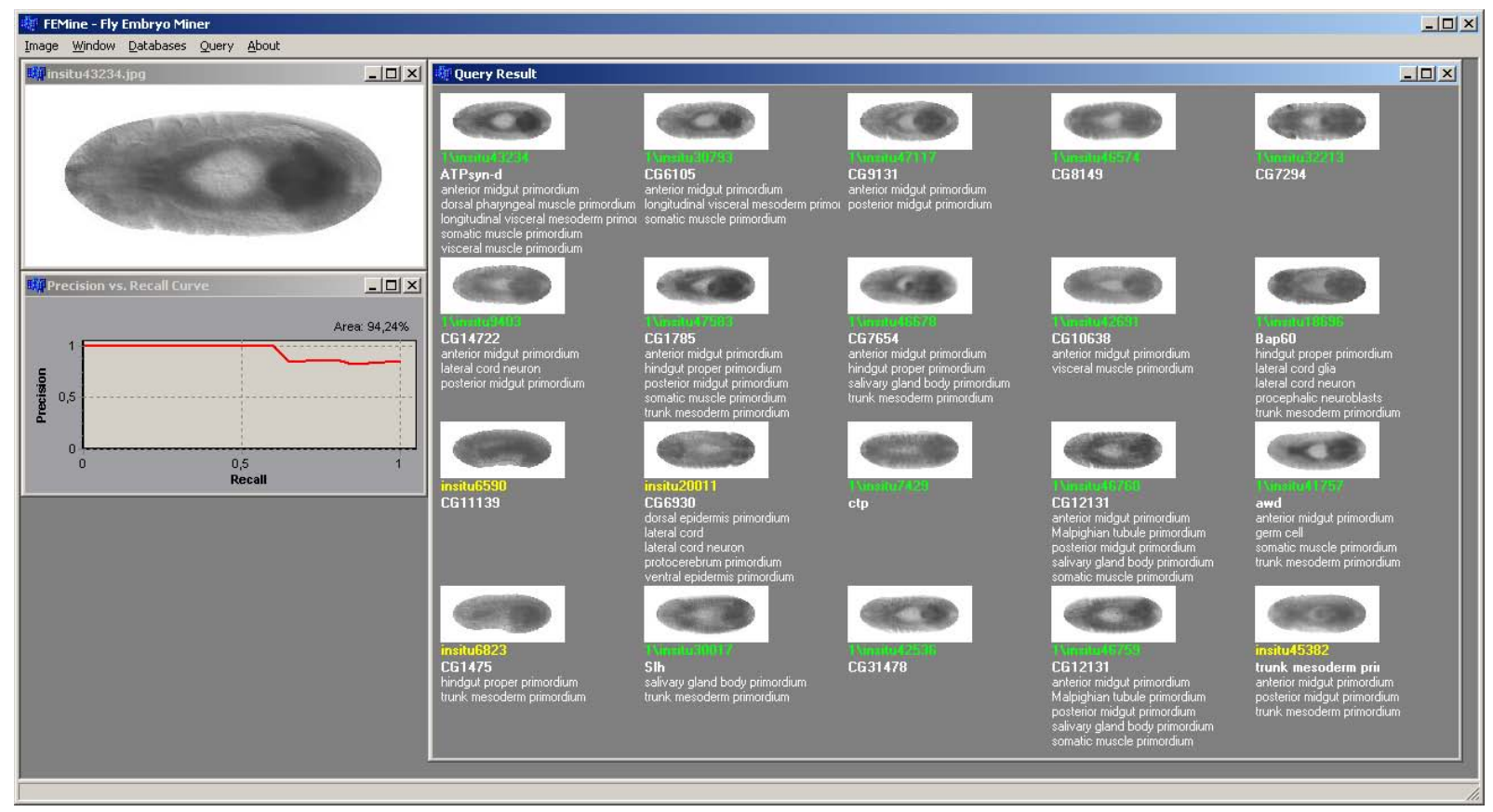

Figura 6.19: Exemplo de consulta por similaridade com o sistema FEMine.

no mesmo.

Nos exemplos da Figuras 6.19 e 6.20 é possível observar a semelhança de padrões existente entre a imagem de consulta e as imagens retornadas pelo sistema. Neste caso, as anotações das partes do corpo do embrião (listagem de termos logo abaixo das miniaturas), deveriam ser, em boa parte, coincidentes para as imagens retornadas. Entretanto, o resultado de consulta da Figura 6.20 é um exemplo de que muitas imagens da FlyBase ainda não possuem anotações deste tipo, as quais são realizadas manualmente pelos biólogos. Assim, observamos que o sistema FEMine também pode ser útil neste sentido, auxiliando os especialistas a preencher anotações em um grande número de imagens, a partir de consultas por similaridades.

\section{Avaliação quantitativa}

Para realizar uma avaliação quantitativa do sistema FEMine com relação às consultas por similaridade, selecionamos um conjunto de 20 imagens para constituir um conjunto de imagens de busca. As imagens foram selecionadas de todos os seis grupos de imagens de diferentes estágios de desenvolvimento do embrião, cada qual contendo um padrão distinto de expressão genética. Assistidos por um especialista da área de biologia, o professor Dr. Eric Xing, da universidade Carnegie Mellon, foi selecionado para cada imagem de busca um subconjunto de imagens consideradas relevantes para cada consulta. As imagens foram classificadas para permitir que o sistema FEMine gerasse automaticamente os gráficos de precisão e revocação. A Figura 6.21 ilustra alguns exemplos de imagens de busca (primeira linha) e imagens consideradas relevantes para as consultas (demais linhas da Tabela). O número exato de imagens relevantes para cada imagem de busca é indicado na última linha da Tabela. Observe que as 


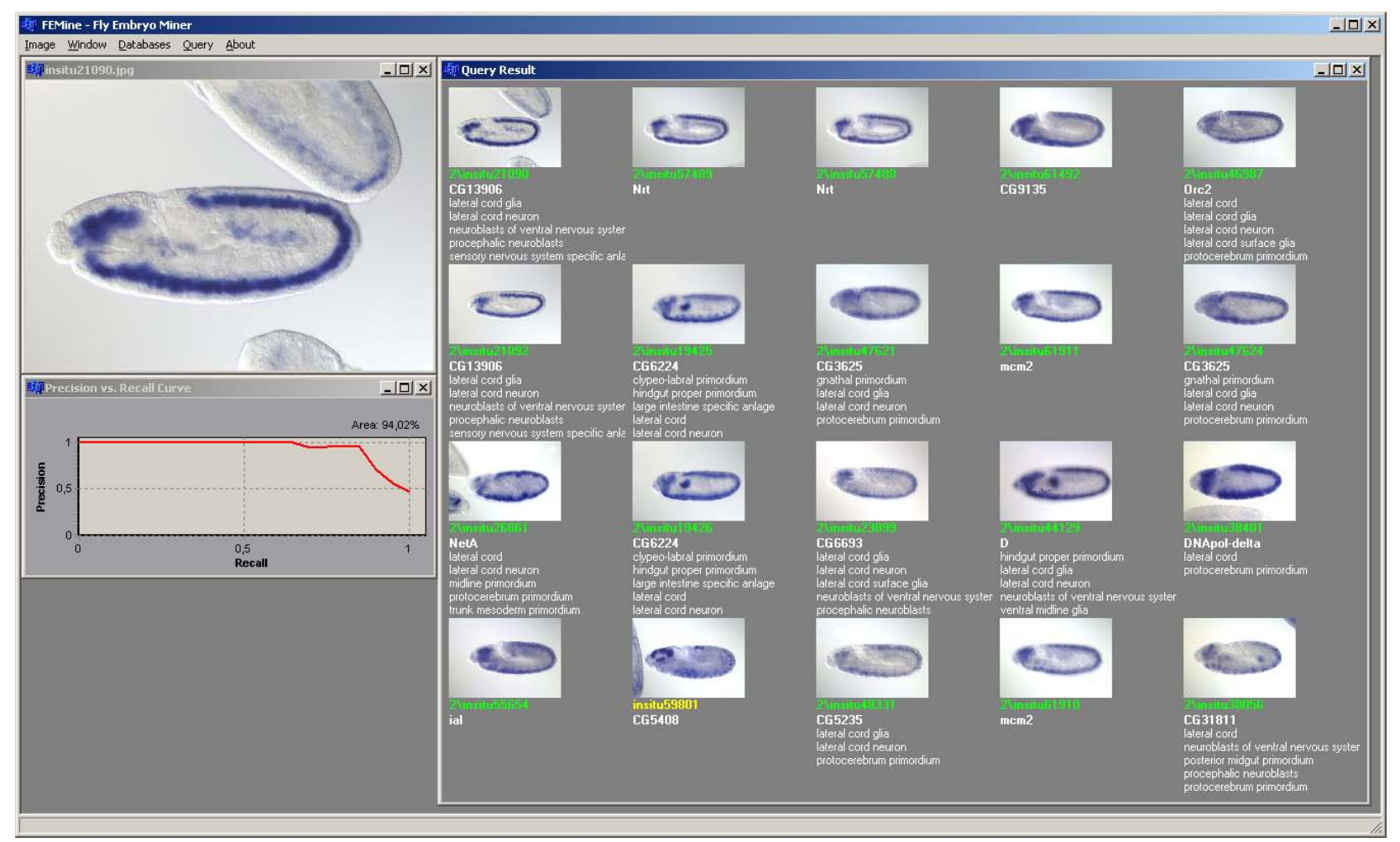

Figura 6.20: Exemplo de consulta por similaridade com o sistema FEMine.

imagens apresentam padrões similares, mais ainda preservam diferenças significativas entre os diferentes embriões.

\begin{tabular}{|c|c|c|c|c|c|c|}
\hline 1 & 2 & 3 & 4 & 5 & 6 & 7 \\
\hline 79 & & & ans: & $\Delta \rightarrow$ & cions & 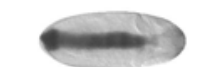 \\
\hline 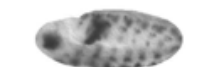 & & & $\operatorname{mong}$ & $\alpha=$ & & 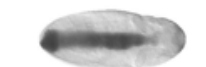 \\
\hline & & & santo & & & $\infty$ \\
\hline & & & (..... & 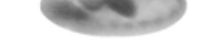 & 6 & 6 \\
\hline & & & $\ldots$ & & & Canas \\
\hline 3 & & & Caspas? & 6 & & 0 \\
\hline & & & & & & \\
\hline 14 imagens & 16 imagens & 18 imagens & 14 imagens & 18 imagens & 16 imagens & 15 imagens \\
\hline
\end{tabular}

Figura 6.21: Exemplos de grupos de consulta.

As 20 imagens de consultas foram submetidas ao sistema FEMine para realização de consultas kNN. Em cada consulta o sistema retornou automaticamente os curvas de precisão e revocação. A média aritmética das curvas obtidas é ilustrada no gráfico da Figura 6.22. A curva representa um ótimo estimador global de precisão nas operações de consulta por 


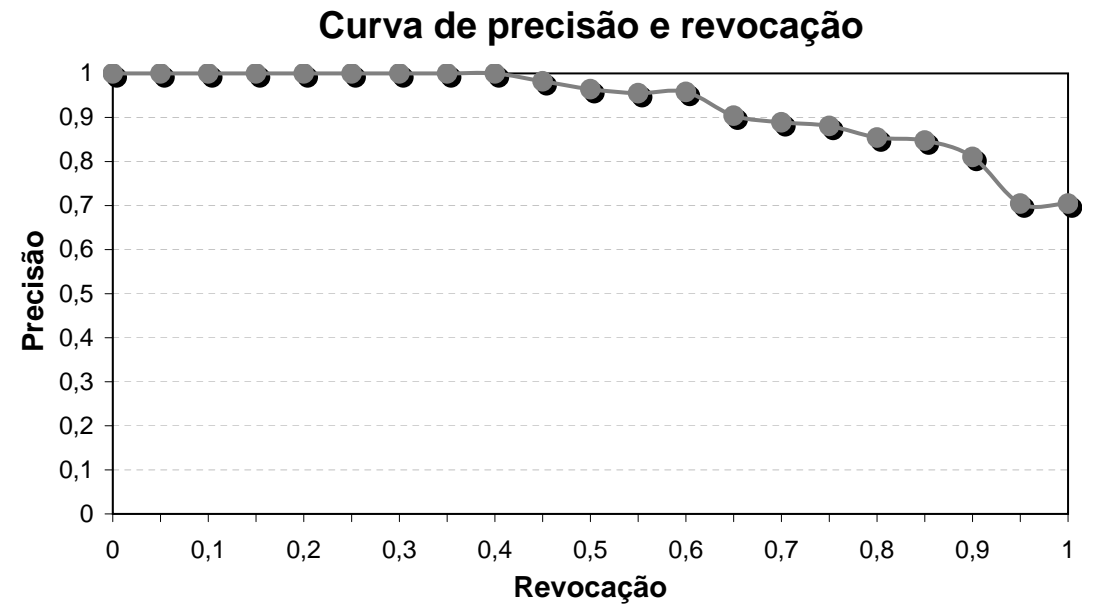

Figura 6.22: Média aritmética das curvas de precisão e revocação de 20 operações de consultas kNN realizadas pelo sistema FEMine.

similaridade, já que as 20 imagens de busca escolhidas compreendem os mais importantes e complexos padrões espaciais de expressão genética, escolhidos com a ajuda de um especialista nas imagens. Como podemos observar, os valores de precisão estão acima de $80 \%$ para valores de revocação até $90 \%$.

\subsection{Considerações finais}

Neste Capítulo é apresentado o desenvolvimento de um sistema automático de processamento e caracterização de imagens embrionárias contendo padrões espaciais de expressão genética, para realização de consultas por similaridade. O sistema, denominado FEMine (Fly Embryo Miner), possui como principal novidade a introdução e extração automática dos EigenEmbryos, um conjunto de vetores ortogonais que essencialmente definem um "espaço de padrões" onde imagens ISH de padrões complexos e variados podem ser sucintamente representadas. Um artigo [13] resumindo este trabalho foi apresentado no KDD'06 ("The Twelfth ACM SIGKDD International Conference on Knowledge Discovery and Data Mining").

Os diversos módulos do sistema FEMine realizam tarefas que vão desde a identificação, isolamento, alinhamento e recorte do embrião principal na imagem, passando pela determinação da base de Eigen-Embryos e determinação do vetor de características das imagens, até às funcionalidades de interface com usuário que incluem as consultas de imagens similares e a recuperação de informações textuais importantes no contexto biológico. Além de ser, como um todo, um framework inovador, os componentes individuais do sistema também merecem destaque, como é o caso do algoritmo de isolamento do embrião principal por particionamento recursivo e seleção de marcadores para a transformada watershed. O algoritmo foi desenvolvido desde o início buscando obter maior aproveitamento das imagens da FlyBase, da universidade de Berkeley, que possui muitas imagens contendo mais de um embrião. Os resultados superaram as expectativas e mais de $64 \%$ das 57.000 imagens puderam ser uti- 
lizadas nos experimentos. Em outro estudo relevante [153], por exemplo, o aproveitamento das imagens não alcança $30 \%$.

Acreditamos que o sistema FEMine constitui uma solução bastante adequada para análise de grandes bases de imagens ISH de embrião da Drosophila, podendo ser utilizado em aplicações que abordam diversos problemas de contexto científico, como a investigação de funções e mecanismos de regulação dos genes no interessante processo biológico da embriogênese. Além disso, todas as técnicas envolvidas são generalizáveis e podem ser estendidas para operar em imagens 3D ou até mesmo em imagens de outros organismos, como ratos e estrelas do mar. 



\section{Capítulo \\ 7 \\ Método HEAD - the Human Encephalon Automatic Delimiter}

A correta delimitação do encéfalo humano em imagens de ressonância magnética é a tarefa fundamental que possibilita um estudo refinado do cérebro e de sua respectiva patologia. Tarefas posteriores à delimitação incluem a classificação dos tecidos do cérebro, detecção de lesões, identificação de estruturas anatômicas, volumetria dos tecidos, etc. Todas estas tarefas têm sido empregadas no estudo de diversas doenças. A volumetria dos tecidos do cérebro, por exemplo, tem se mostrado útil no tratamento de doenças como o mal de Alzheimer [160], a epilepsia [161], a esquizofrenia [162] e a esclerose múltipla [163].

Com o número crescente de exames médicos realizados dia a dia nos hospitais e centros médicos do mundo inteiro, os métodos computacionais automáticos para a delimitação do encéfalo em imagens médicas se tornaram um relevante e popular assunto de pesquisa. Para tais métodos, é desejável que eles sejam rápidos e precisos no processamento, pois, conforme já mencionado, a delimitação é uma tarefa que precede diversas outras análises. É também importante que o método seja robusto à presença de ruídos e gradientes de brilho na imagem. A tarefa de delimitação do encéfalo em imagens digitais, é também conhecida como "segmentação do cérebro" ou o termo em inglês "skull-stripping".

Neste Capítulo é apresentado um método automático de delimitação do encéfalo humano em imagens provenientes de exames de ressonância magnética. O método, denominado HEAD - the Human Encephalon Automatic Delimiter, pertence à família dos métodos baseados em região e combina uma interessante análise do histograma da imagem com operações de morfologia matemática binária para obter uma máscara precisa do cérebro. A análise de histograma realizada pelo método HEAD é inovadora e eficiente, e se baseia no padrão morfológico do encéfalo para encontrar as faixas corretas de níveis de cinza dos tecidos do cérebro. Esta análise é composta por uma técnica de particionamento automático do histograma responsável por localizar concavidades, ou "vales", na curva. Esta técnica que 
desenvolvemos, apresenta vantagens sobre as mais conhecidas técnicas de particionamento automático de histograma, incluindo as técnicas de Otsu [164] e Rosenfeld [165].

\subsection{Visão geral do método HEAD}

Mais especificamente, o método HEAD foi desenvolvido para operar em imagens 3D de ressonância magnética, ponderadas em T1, independente da orientação (axial, coronal, sagital). O método é basicamente composto de dois passos: (1) remoção do plano de fundo da imagem (background), e; (2) delimitação do encéfalo. Na primeira etapa, o algoritmo de particionamento de histograma proposto é aplicado para delimitar a maior saliência (pico) do histograma que é relacionado com os voxels do plano de fundo da imagem, ou ar. Com o valor de corte encontrado a imagem é binarizada, gerando-se uma máscara que exclui o plano de fundo. Tal máscara é então refinada com operações de morfologia matemática binária. No segundo passo, o algoritmo de particionamento é empregado em duas etapas sobre o histograma da imagem já sem o plano de fundo. O objetivo é encontrar dois níveis de cinza que compreendam corretamente os níveis de cinza dos tecidos do cérebro, ou seja, a massa branca (MB) e a massa cinzenta (MB). Uma nova máscara binária é então gerada sendo que a maioria dos voxels do cérebro, e os voxels que o circundam, devem ter sido corretamente classificados. Então, para isolar completamente a região do encéfalo, uma nova série de operações da morfologia matemática binária é aplicada sobre a máscara.

Em nossos experimentos, o método HEAD foi aplicado e analisado em imagens provenientes do Hospital das Clínicas da Faculdade de Medicina de Ribeirão Preto - USP, e em um conjunto de imagens sintéticas. A precisão do método foi estimada comparando-se as imagens segmentadas automaticamente com imagens manualmente segmentadas com o auxílio de especialistas da área médica, e com a utilização de métricas conhecidas, tais como as de Jaccard e Dice [159]. O método HEAD foi comparado com o método BSE [166] um dos melhores métodos baseados em regiões [167]. O nosso método superou o BSE em todos os experimentos mostrando-se mais robusto para imagens com maiores níveis de ruído e gradientes de brilho.

Uma revisão dos principais trabalhos correlatos é apresentada na seção 7.2. A técnica proposta para particionamento automático de histograma é apresentada na seção 7.3.1. As seções 7.3.2 e 7.3.3 correspondem às duas principais etapas do método HEAD. Finalmente, as seções 7.4 e 7.5 descrevem os experimentos realizados e resultados obtidos e considerações finais.

\subsection{Trabalhos relacionados}

Diversos métodos foram propostos para automatizar a tarefa de delimitação do encéfalo. Uma taxonomia atual para tais métodos é definida por duas amplas categorias: métodos baseados em região e métodos baseados em bordas. Alguns métodos podem também pertencer 
à família dos meta-algoritmos, cujo resultado é uma combinação de resultados individuais provenientes de diferentes algoritmos que se prestam à mesma tarefa. Nesta seção é apresentada uma revisão dos principais métodos de cada categoria.

\subsubsection{Métodos baseados em região}

Os métodos baseados em região exploram diretamente o conceito de coerência espacial da imagem. Os tecidos de massa cinzenta e massa branca formam um bloco compacto no centro da imagem: o cérebro. Normalmente, nenhum outro bloco de tecidos na cabeça é maior que o cérebro. Os métodos baseados em região visam criar uma máscara binária inicial, onde a maioria dos voxels do cérebro é definida como classe de primeiro plano, e a maioria dos voxels que circundam o cérebro é definida como classe do plano de fundo. Para isso, geralmente é utilizado o método de limiarização, ou threshold, [168, 169, 170, 171, 172], e detecção de bordas [166]. Após a criação da máscara inicial, a região do cérebro é completamente separada utilizando operações de morfologia matemática.

Atkins e Mackiewich [169] apresentaram um método baseado em região que integra filtragem anisotrópica, limiarização, morfologia matemática binária, e contornos ativos (snakes) [173]. Neste método, um único nível de limiarização é determinado ajustando-se uma única curva gaussiana no histograma da imagem filtrada. Uma desvantagem evidente está no fato de que uma única curva gaussiana representa um modelo inadequado para o histograma de uma imagem de cabeça, que pode, normalmente conter mais de uma saliência associada aos tecidos de massa branca e massa cinzenta.

Lemieux et al. [168] apresentaram outro método de análise do histograma da imagem. Um nível inicial de limiarização é obtido com o método de Otsu [164]. Então, um nível mais refinado é determinado por um processo iterativo. A cada passo deste processo o nível inicial é incrementado e uma análise de componentes conexos em 3D é realizada. Evidentemente, a desvantagem deste método é a alta complexidade computacional, pois a análise de componentes conexos em 3D é uma operação custosa para ser executada várias vezes dentro de um processo iterativo. Outro método denominado MBRASE [171] utiliza uma abordagem iterativa similar, que também demanda um alto custo computacional. Os dois métodos se diferenciam apenas no critério de parada da iteração.

O algoritmo 3DIntracranial [170], que faz parte do sistema AFNI [174], realiza uma segmentação fatia por fatia da imagem 3D. Este método procura dois limites globais, inferior e superior, no histograma da imagem, tentando ajustar três curvas gaussianas: uma para a massa cinzenta, outra para massa branca e outra para o plano de fundo. Este ajuste é realizado utilizando o método SIMPLEX que encontra um ajuste para tal modelo baseado nos mínimos quadrados. Após o ajuste, o limite superior é definido como o centro da gaussiana associada à massa branca somado ao dobro do valor correspondente de desvio padrão. De forma similar, o limite inferior, é definido como o centro da gaussiana associada à massa cinzenta subtraído do dobro do valor correspondente de desvio padrão. Novamente, obser- 
vamos que o modelo sugerido para o ajuste no histograma é comumente inadequado, pois as saliências associadas aos tecidos de massa branca e cinzenta muitas vezes aparecem no histograma como uma única saliência. A grande diferença em tamanho entre saliência associada ao plano de fundo e as demais saliências no histograma também pode causar imprecisão no processo de ajuste do modelo. Além disso, o método SIMPLEX é um algoritmo iterativo que demanda, relativamente, um alto esforço computacional.

De forma alternativa, o bem conhecido Brain Surface Extractor - BSE [166, 175, 176, 177], parte do sistema BrainSuite, utiliza filtros de detecção de bordas para estabelecer uma máscara inicial para o cérebro. Por esse motivo, o método é comumente confundido com um método baseado em bordas. O BSE emprega uma pré-filtragem anisotrópica seguida por uma detecção de bordas realizada com o filtro de Marr-Hildreth para determinar uma máscara inicial ruidosa. Operações de morfologia matemática binária são então utilizadas para separar completamente a região do cérebro e filtrar adequadamente a máscara final. Em um estudo comparativo realizado por Fennema-Notestine [167], o método BSE se mostrou mais preciso e eficiente que diversos outros métodos bem conhecidos.

Outro método baseado em região é proposto por Hata et al. [172], que empregam lógica fuzzy e crescimento de regiões para alcançar uma máscara inicial para o cérebro. Huang et al. [178] apresentam uma abordagem híbrida, combinando o algoritmo EM e contornos geodésicos ativos.

\subsubsection{Métodos baseados em bordas}

Os métodos baseados em bordas procuram encontrar uma representação da superfície do cérebro utilizando diretamente modelos de superfície deformável combinados com forças de atração local. Um algoritmo bem conhecido desta classe é o BET (Brain Extraction Tool) [179], que faz parte de dois sistemas de domínio público: o software MRIcro e a biblioteca FSL. Tal método emprega um modelo deformável de superfície que se ajusta iterativamente ao encéfalo. Inicialmente, uma malha de triângulos esférica é estabelecida no centróide da imagem, sendo lentamente deformada. Em cada iteração os vértices da malha são movimentados com base em três forças de atração e ajuste: duas delas controlam o espaçamento dos vértices para garantir uma superfície suave, sem auto-intersecções. A outra força é baseada em um detector local de bordas, que procura atrair os vértices da malha para as bordas do cérebro.

Ségonne et al. [180] desenvolveram um método baseado no algoritmo de watershed e em um modelo de superfície deformável. O algoritmo de watershed cria uma estimativa inicial do volume do cérebro que é utilizada para iniciar o modelo deformável. Uma primeira etapa de deformação é realizada utilizando-se parâmetros globais das bordas do cérebro. Posteriormente, uma análise baseada em atlas verifica a correção da superfície resultante, modificando-a caso alguma parte importante do cérebro tenha sido desconsiderada. Finalmente, é realizada uma deformação mais refinada utilizando parâmetros de escopo local às 
bordas do cérebro. Este método de segmentação é denominado HWA (Hybrid Watershed Algorithm) e faz parte do sistema FreeSurfer.

O trabalho de Fennema-Notestine et al. [167] apresenta uma avaliação comparativa dos métodos HWA, BET, BSE e 3DIntracranial, testando-os em volumes de ressonância magnética de diversos grupos de diagnóstico. Eles principalmente concluíram que os métodos HWA e BSE são os mais robustos entre os diversos diagnósticos, e, com respeito à especificidade, o método BSE é o melhor para todos os grupos.

\section{Meta-algorithms}

O método BEMA, proposto por Rex et al. [181] é um exemplo de método que pertence à família de meta-algoritmos. Em particular, o método BEMA executa quatro diferentes métodos de delimitação do encéfalo, e combina as saídas individuais para obter um resultado aprimorado. Os algoritmos utilizados pelo BEMA são os previamente mencionados BSE, BET, HWA, e 3DIntracranial. Rehm et al. [182] propõem uma abordagem similar combinando o resultado de três técnicas incluindo o método BSE. A principal desvantagem dos meta-algoritmos é a alta complexidade computacional, o que os torna inadequados para o uso prático.

\subsection{O método HEAD}

Nesta seção nosso método HEAD, the Human Encephalon Automatic Delimiter, é apresentado em detalhes. Primeiramente, apresentamos o algoritmo de particionamento que é a base da nossa análise de histograma. Esta análise, por sua vez, é empregada nas duas principais tarefas que explicamos na seqüência: (1) remoção do plano de fundo da imagem, e; (2) delimitação do encéfalo.

\subsubsection{Algoritmo de particionamento de histograma}

Uma das novidades que compõem o método HEAD é uma eficiente técnica de particionamento automático de histogramas de imagens que demanda esforço computacional mínimo. O objetivo do algoritmo é procurar a concavidade, ou "vale", que é compreendido pelas maiores saliências, ou "colinas", da curva. Para isto, é desenhada uma curva auxiliar $\mathcal{P}(x)$ sobre o histograma $H(x)$, tendo como objetivo criar uma região de alto contraste entre as duas curvas ao longo das concavidades de $H(x)$ compreendidas por suas maiores saliências. A partir daí, o histograma é particionado em duas partes, selecionando-se o nível de cinza que indica a máxima diferença entre $\mathcal{P}(x)$ e $H(x)$. Intuitivamente, consideramos que a curva $\mathcal{P}(x)$ tem o formato de uma função distribuição de probabilidade gaussiana, com os parâmetros, média e variância, respectivamente correspondentes ao nível de cinza médio $\mu$ do histograma e sua variância correspondente $\sigma^{2}$. Também assumimos que $\mathcal{P}(x)$ e $H(x)$ têm 
a mesma área $\alpha$ sob suas curvas. Um exemplo visual das curvas $\mathcal{P}(x)$ e $H(x)$ é apresentado na Figura 7.1. Formalmente:

$$
\mathcal{P}(x)=\frac{\alpha}{z} G(x)
$$

onde:

$$
\begin{aligned}
G(x) & =\frac{1}{\sqrt{2 \pi \sigma^{2}}} \exp \left(\frac{-(x-\mu)^{2}}{2 \sigma^{2}}\right) ; \\
z & =\sum_{x=x_{\min }}^{x_{\max }} G(x) ; \\
\alpha & =\sum_{x=x_{\min }}^{x_{\max }} H(x) ; \\
\mu & =\frac{1}{\alpha} \sum_{x=x_{\min }}^{x_{\max }} x H(x) \quad ; \text { and } \\
\sigma^{2} & =\frac{1}{\alpha} \sum_{x=x_{\min }}^{x_{\max }}(x-\mu)^{2} H(x)
\end{aligned}
$$

A curva $\mathcal{P}(x)$ irá apresentar os maiores valores nas proximidades das saliências mais altas de $H(x)$. Se houver uma separação evidente dessas saliências, ela estará em contraste com os altos valores de $\mathcal{P}(x)$. Então, formalmente, o nível de particionamento $l$ é definido da seguinte forma:

$$
l=\underset{x}{\operatorname{argmax}}(\mathcal{P}(x)-H(x)), \quad x_{\min } \leq x \leq x_{\max }
$$

O quadro da Figura 7.10 inclui um resumo da técnica proposta de particionamento de histogramas. A Figura 7.1 exemplifica a técnica em um histograma típico com duas saliências. Esta técnica possui relação com a técnica de Rosenfeld [165] que procura concavidades na curva a partir do casco convexo da mesma. Entretanto, a vantagem da nossa técnica está no fato de que computar a curva $\mathcal{P}(x)$ é mais simples e requer menos esforço computacional do que computar o casco convexo do histograma. No melhor caso, a computação do casco convexo possui complexidade $O(n \log (n))[183,184]$. Por outro lado, a complexidade de cálculo da curva $\mathcal{P}(x)$ é sempre linear ao comprimento $n$ do histograma, ou seja, $\Theta(n)$. Além disso, a computação do casco convexo é naturalmente sensível a ruídos na curva, que ocorrem freqüentemente. Neste caso, a complexidade do método de Rosenfeld pode aumentar significativamente e até fazer com que o histograma seja particionado erroneamente.

Uma vantagem da nossa técnica sobre o popular método de Otsu [164, 185], está na habilidade de encontrar corretamente o nível de particionamento em histogramas cujas saliências apresentam diferenças significativas em seus tamanhos. O histograma apresentado na Figura 7.1 é também um típico exemplo deste caso, onde a primeira saliência possui, praticamente, 


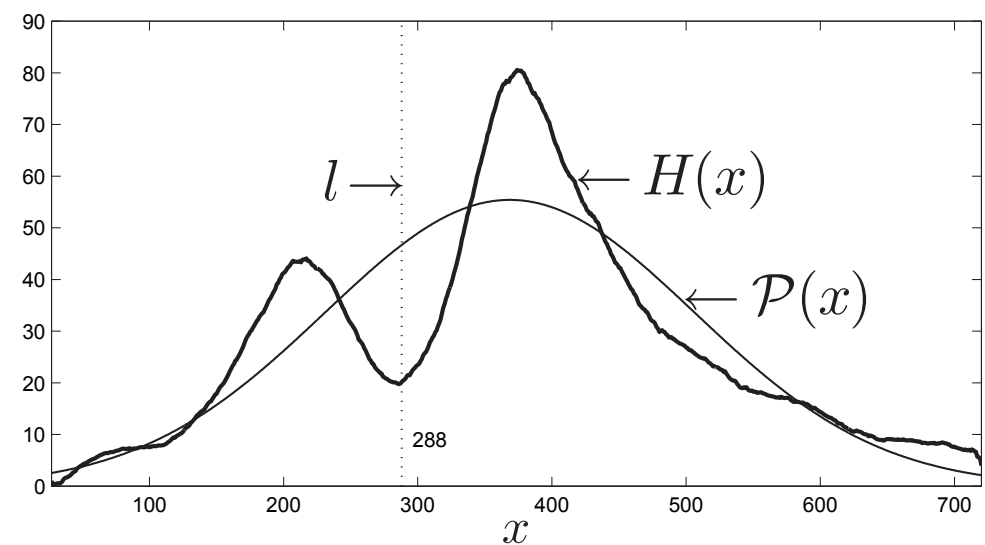

Figura 7.1: Exemplo de particionamento utilizando a técnica proposta (Eq. 7.2). l o nível de particionamento.

a metade do tamanho da segunda. Na Figura 7.2 são comparados os resultados obtidos com essas duas técnicas. Enquanto o nível de particionamento retornado por nossa técnica está corretamente localizado bem ao centro da concavidade mais evidente do histograma, o valor retornado pela técnica de Otsu está erroneamente deslocado em direção à maior saliência. Em exemplos posteriores, também será mostrado que nossa técnica pode, normalmente, processar com sucesso histogramas com mais de duas saliências, diferentemente da técnica de Otsu.

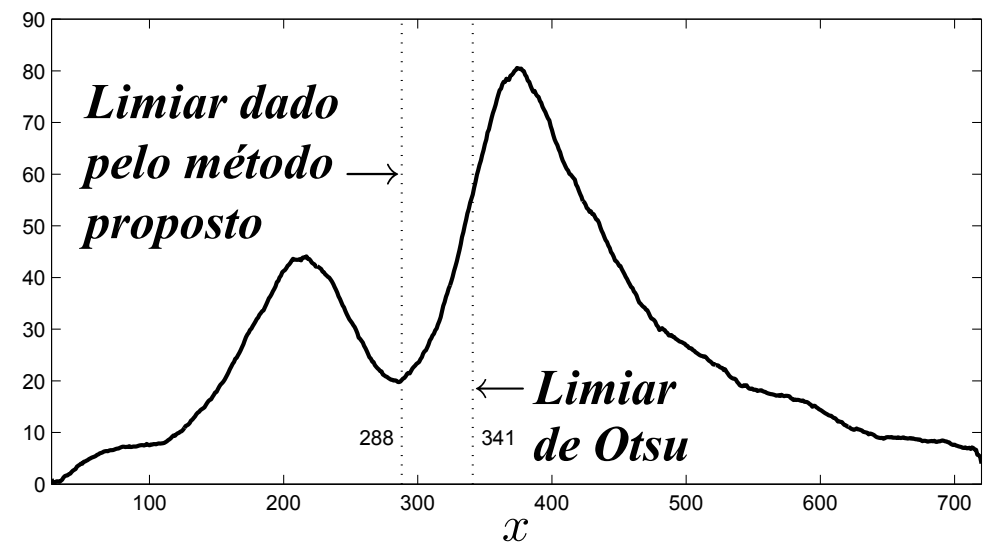

Figura 7.2: Uma comparação entre a técnica de particionamento de histogramas do método HEAD e a técnica de Otsu.

\subsubsection{Remoção do plano de fundo background}

O primeiro passo do método HEAD consiste na separação do plano de fundo da imagem, ou, em outras palavras, a criação de uma máscara binária para a região da cabeça do paciente. Devido à grande quantidade de ar circundando a cabeça, as imagens não recortadas de ressonância magnética apresentam um histograma com uma grande saliência próxima aos níveis de cinza mais escuros. O método de particionamento de histograma aqui apresentado é aplicado com o objetivo de encontrar os limites desta saliência, e classificar como plano de fundo a maioria dos voxels pertencentes ao espaço vazio (ar). Para simplificar esta 
tarefa, primeiramente é descartada a parte superior do histograma (níveis mais claros) que, definitivamente, não está relacionada com a região escura do plano de fundo. Na seqüência, e selecionada a parte inferior do histograma que soma $85 \%$ da área total sobre a curva e, sobre esta aplicamos o algoritmo de particionamento para encontrar o nível limite $l$.

A Figura 7.3 exemplifica a procura do limiar $l$ em uma imagem $3 \mathrm{D}$ de $256 \times 256 \times 154$ voxels ponderada em T1 (resolução de 1mm por fatia). Neste exemplo, a saliência relacionada ao espaço vazio é tão alta que fica difícil distinguir as demais. O nível de cinza médio $\mu$ da curva $\mathcal{P}(x)$ é atraída por esta saliência fazendo com que o maior contraste entre $\mathcal{P}(x)$ e $H(x)$ ocorra justamente na base da saliência, definindo $l$ corretamente.

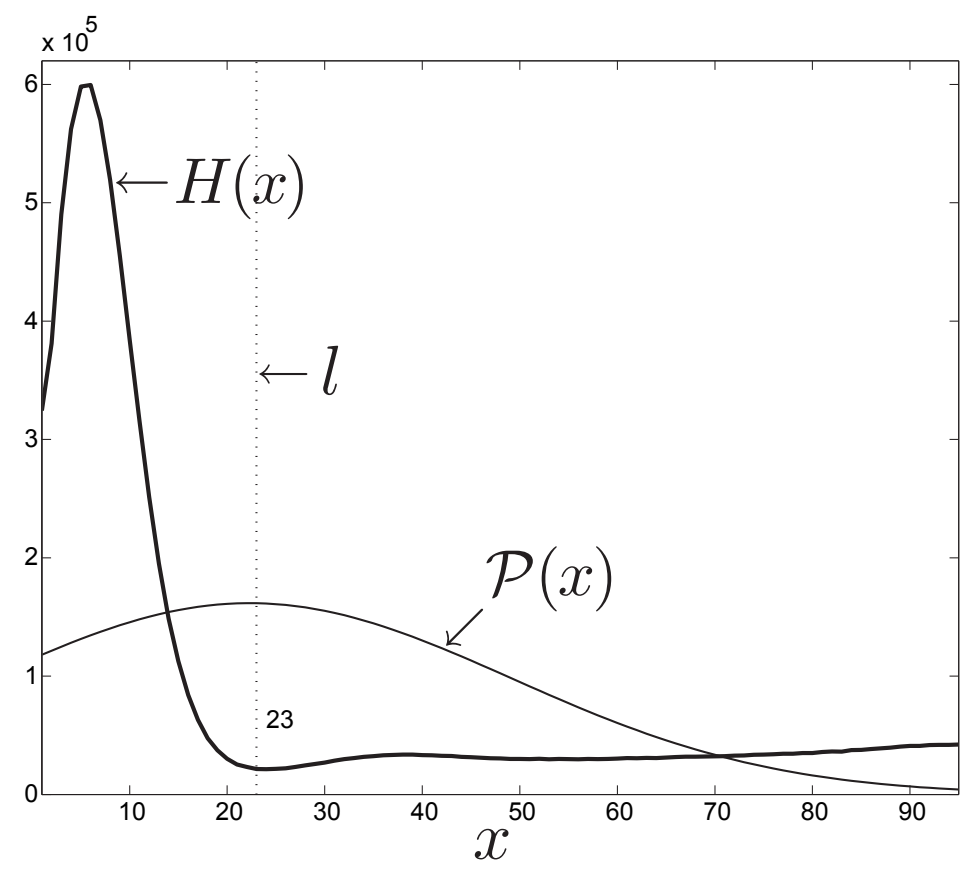

Figura 7.3: Determinação do limiar $l$ para remoção do plano de fundo da imagem.

A Figura 7.4a apresenta um corte sagital mediano da imagem 3D usada neste exemplo. Utilizando o limiar $l$ encontrado, a maioria dos voxels da imagem são corretamente classificados como voxels da região da cabeça (níveis de cinza maior que $l$ ), ou voxels do plano de fundo (níveis de cinza menor ou igual $l$ ). A Figura 7.4b ilustra o corte mediano da máscara gerada neste procedimento. O número de voxels classificados erroneamente é minimizado com a aplicação de duas operações de morfologia matemática binária sobre a máscara obtida, da seguinte maneira:

- Primeiramente, a máscara binária obtida é submetida a uma operação da morfologia matemática conhecida como "abertura de área" (area openning ) [125]. Esta operação elimina pequenos fragmentos da região de primeiro plano (branca) sem interferir no contorno das regiões maiores. Neste caso, a operação de abertura de área é aplicada para eliminar pequenos fragmentos brancos contendo menos de 200 voxels. Isto é feito, principalmente, para corrigir os voxels do plano de fundo que foram classificados erroneamente devido à presença de ruído na imagem 
- Na sequiência, a imagem resultante é submetida à operação de "preenchimento de buracos" [125], para corrigir os voxels da região da cabeça que foram classificados como plano de fundo (preto). Ambas as operações são realizadas considerando-se uma conectividade $3 \mathrm{D}$ de seis vizinhos, adjacentes às seis faces do voxel

Visto que o nosso interesse principal não é o contorno da cabeça, nenhuma operação é executada para suavizar a superfície da máscara. A Figura 7.4c apresenta o corte mediano da máscara final obtida neste exemplo, após aplicação das duas operações descritas. O quadro da Figura 7.10 inclui um resumo da etapa de remoção do plano de fundo.

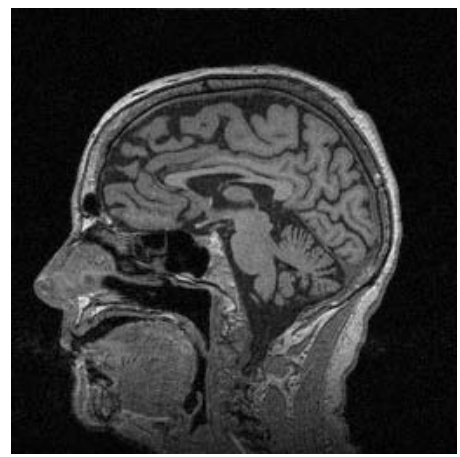

(a)

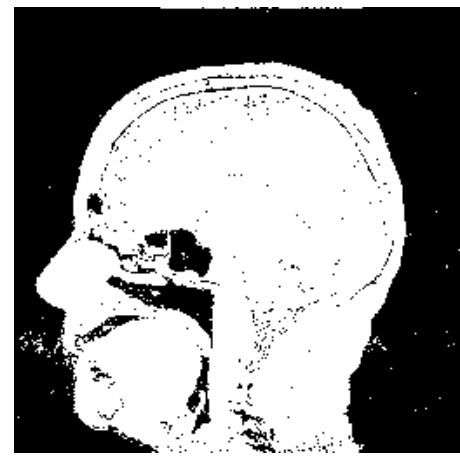

(b)

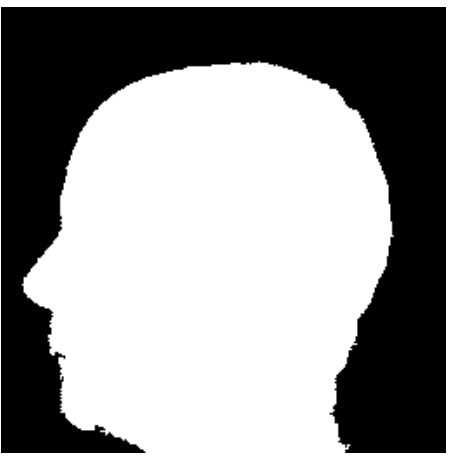

(c)

Figura 7.4: Remoção do plano de fundo da imagem. (a) Corte mediano da imagem original; (b) Classificação inicial obtida com o limiar $l$ (voxels com nível de cinza maior que $l$ são brancos); (c) Máscara final da cabeça.

\subsubsection{Delimitação do encéfalo}

Após a remoção do plano de fundo da imagem um novo histograma $H^{\prime}(x)$ da imagem é gerado, considerando apenas os voxels da região da cabeça. O algoritmo de particionamento de histograma proposto é empregado com o objetivo de estimar corretamente as faixas de níveis de cinza dos tecidos do cérebro: a massa branca (MB) e a massa cinzenta (MC). Em imagens de ressonância magnética ponderadas em T1, é comum que tecidos como osso e músculo sejam apresentados dentro da mesma faixa de nível de cinza do tecido de massa cinzenta. Assim, $H^{\prime}(x)$ é uma curva que deve apresentar uma grande saliência na faixa de níveis desses tecidos. A massa branca é apresentada em níveis de cinza mais claros e também está relacionada com uma saliência no histograma $H^{\prime}(x)$. A separação dessas duas saliências, entretanto, costuma ser muito sutil, sendo que na maioria das vezes elas aparecem como uma única saliência alta.

A Figura 7.5 apresenta dois exemplos de histogramas $H^{\prime}(x)$ onde as saliências para MB e MC estão destacadas em cinza. Deste ponto em diante essas duas saliências serão denominadas juntas por "saliência MB/MC". O primeiro histograma (7.5a) pertence a uma imagem real de $256 \times 256 \times 160$ voxels e nenhuma separação das saliências pode ser observada. A segunda curva (Fig. 7.5b), entretanto, pertence a uma imagem sintética proveniente do 
projeto Brain Web ${ }^{1}$ [186] do Instituto de Neurologia de Montreal (MNI). Tal imagem possui $181 \times 217 \times 182$ voxels e $3 \%$ de ruído gaussiano simulado. Diferentemente, neste caso a separação da saliência MB/MC é bastante evidente. Fatores que podem contribuir para este cenário estão principalmente relacionados ao processo de aquisição das imagens reais, incluindo o ajuste dos parâmetros (tempo de echo e tempo de repetição), a presença de ruídos mais fortes e gradientes de brilho causados por variações do campo magnético.

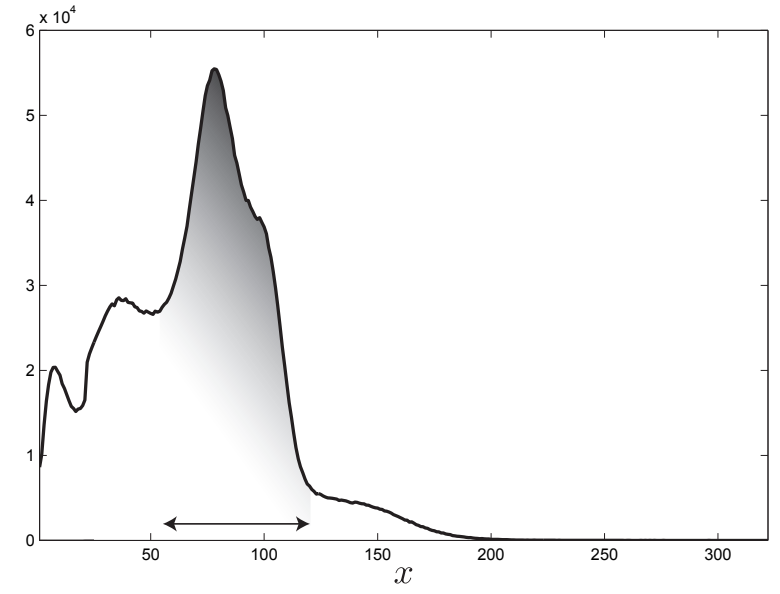

(a)

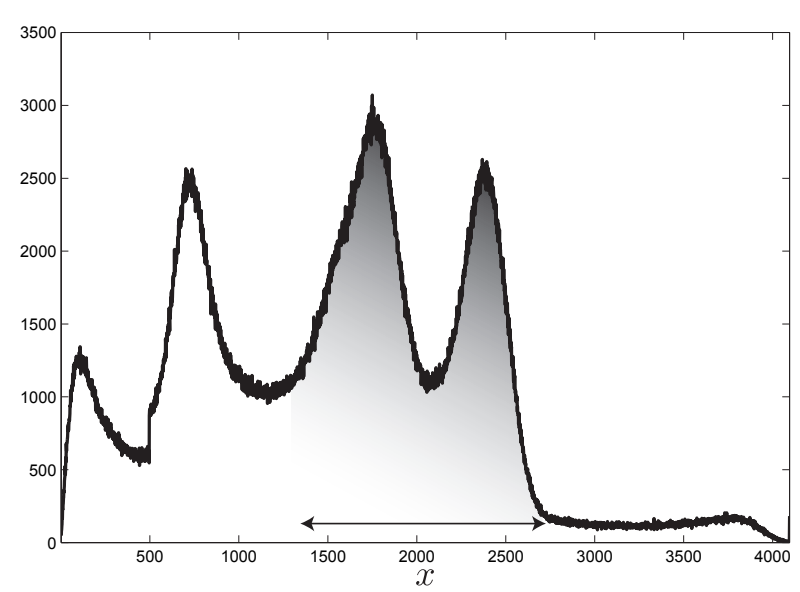

(b)

Figura 7.5: Exemplos de histogramas de nível de cinza de imagens de cabeça (com plano de fundo removido). (a) Histograma de uma imagem real de $256 \times 256 \times 160$ voxels; (b) Histograma de uma imagem sintética de $181 \times 217 \times 182$ voxels do projeto Brain Web (MNI).

Nosso objetivo é localizar corretamente os limites da saliência MB/MC sendo sua separação interna evidente ou não. Vamos denotar esses limites como sendo $l_{1}$ e $l_{2}$. Cada limite é determinado separadamente, sendo que cada um é procurado em uma parte distinta do histograma $H^{\prime}(x)$. Vamos considerar $x_{\min }^{\prime}$ e $x_{\max }^{\prime}$ os níveis de cinza mínimo e máximo de $H^{\prime}(x)$, respectivamente. Então:

- Para encontrar o nível limite $l_{1}$ a técnica de particionamento de histograma apresentada na seção 7.3.1 é aplicada sobre a parte inferior de $H^{\prime}(x)$ que soma $85 \%$ da área total, isto é, $H^{\prime}(x)$ para $x_{\text {min }}^{\prime} \leq x \leq x_{1}$, onde

$$
\frac{\sum_{x=x_{\min }^{\prime}}^{x_{1}} H^{\prime}(x)}{\sum_{x=x_{\min }^{\prime}}^{x_{\text {max }}^{\prime}} H^{\prime}(x)}=0.85
$$

- O nível limite $l_{2}$ é computado utilizando a técnica de particionamento de histograma sobre a parte superior de $H^{\prime}(x)$ que soma $25 \%$ da área total, isto é, $H^{\prime}(x)$ para $x_{2} \leq$ $x \leq x_{\text {max }}^{\prime}$, onde

$$
\frac{\sum_{x=x_{2}}^{x_{\max }^{\prime}} H^{\prime}(x)}{\sum_{x=x_{\min }^{\prime}}^{x_{\max }^{\prime}} H^{\prime}(x)}=0.25
$$

\footnotetext{
${ }^{1}$ http://www.bic.mni.mcgill.ca/brainweb/
} 
Essas porcentagens são escolhidas com base na morfologia geral do cérebro. Nas imagens de ressonância magnética ponderadas em T1, o fluido cérebro-espinhal, a pele, os olhos e o ar, são apresentados em níveis de cinza bem escuros e formam um volume consideravelmente grande na imagem. Por outro lado, tecidos que aparecem mais claros que a massa branca, como gordura, medula óssea, e dura, formam um volume consideravelmente menor. Deste modo, as partes escolhidas de $H^{\prime}(x)$, inferior e superior, deverão conter seguramente os limites $l_{1}$ e $l_{2}$, respectivamente. A técnica proposta de particionamento de histograma é então aplicada com o objetivo de encontrar a melhor estimativa dos limites dentro de cada banda do histograma.

As Figuras 7.6 e 7.7 exemplificam a determinação de $l_{1}$ e $l_{2}$ nos mesmos histogramas da Figura 7.5. Em cada gráfico, as computações de $l_{1}$ e $l_{2}$ (ver Equação 7.2) são apresentadas juntas para melhor visualização. A curva gaussiana utilizada para determinar $l_{1}$ é obtida pela Equação 7.1 utilizando $H^{\prime}(x)$ para $x_{\min }^{\prime} \leq x \leq x_{1}$. Da mesma forma, a curva gaussiana que determina $l_{2}$ é dada pela Equação 7.1 utilizando $H^{\prime}(x)$, para $x_{2} \leq x \leq x_{\text {max }}^{\prime}$. Tanto $x_{1}$ quanto $x_{2}$ são indicados nos gráficos. As partes das gaussianas desenhadas em cinza claro não são utilizadas na computação dos limites. Elas são apresentadas no gráfico apenas para oferecer uma visualização completa do formato das curvas. Em ambos os exemplos os níveis $l_{1}$ e $l_{2}$ obtidos representam corretamente os limites da saliência MB/MC.

Observamos aqui a habilidade do nosso algoritmo de particionamento de histogramas em tratar curvas com mais de duas saliências. Isto pode ser principalmente observado na computação de $l_{1}$, nas Figuras 7.6 e 7.7, onde as partes inferiores dos histogramas são bastante irregulares. Diferentemente, o popular método de Otsu é bem conhecido por não conseguir particionar corretamente histogramas com mais de duas saliências.

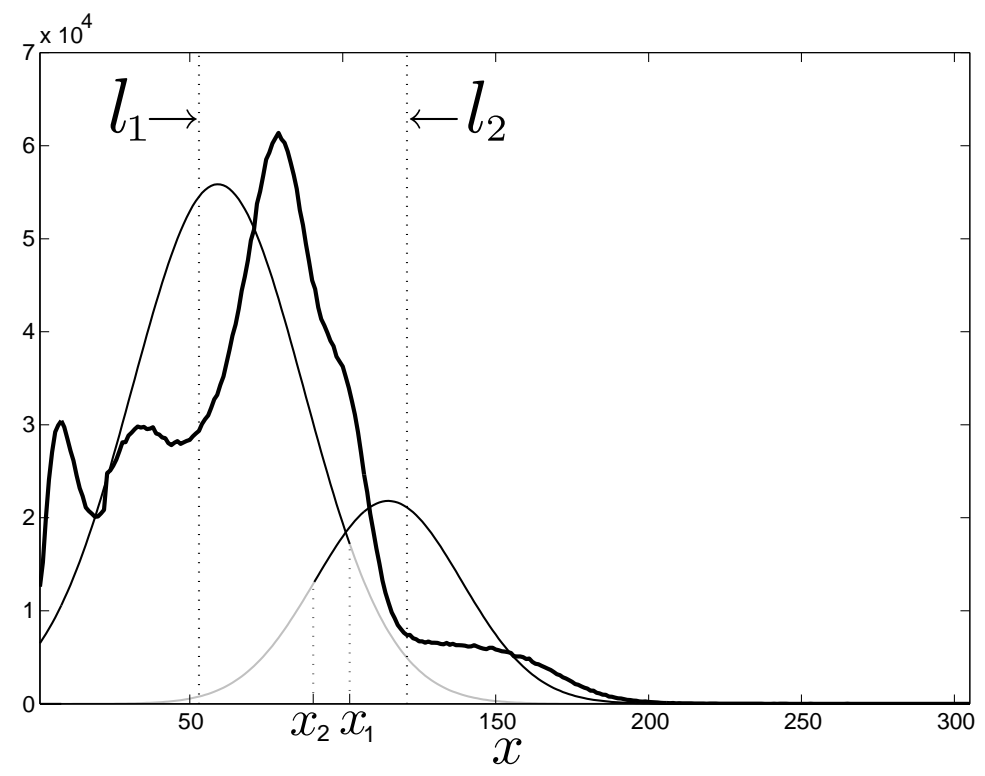

Figura 7.6: Determinação de $l_{1}$ e $l_{2}$, os limites da saliência MB/MC, em histograma de uma imagem MRI real de $256 \times 256 \times 160$ voxels.

Após determinar os limites $l_{1}$ e $l_{2}$ uma máscara binária inicial $M$ é gerada. Os voxels 


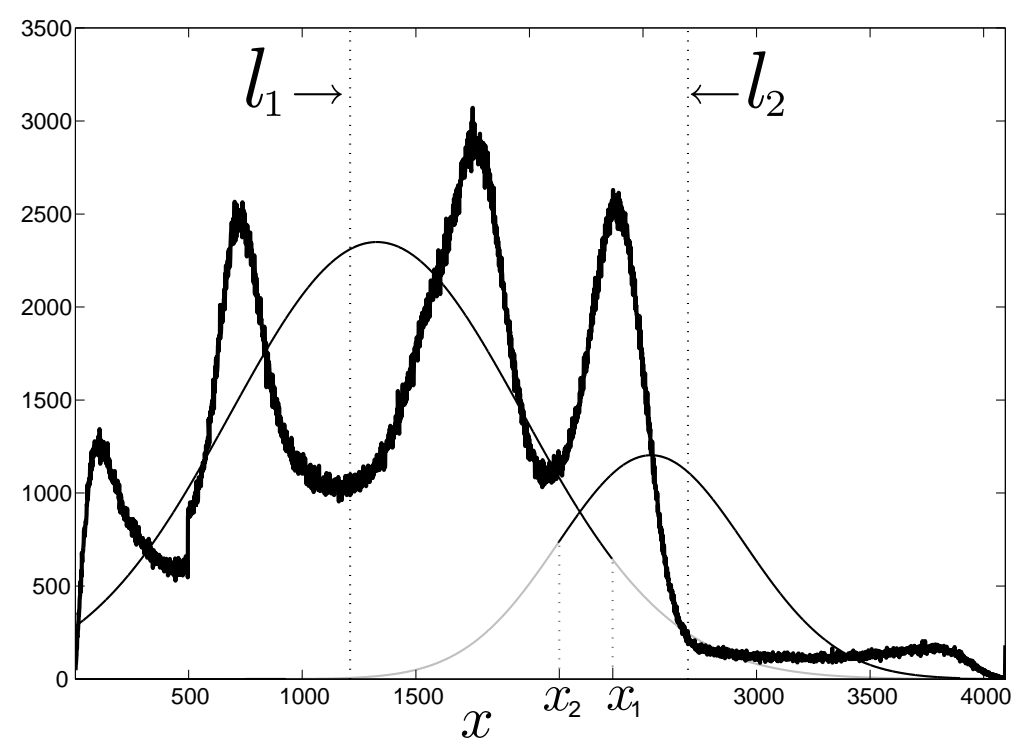

Figura 7.7: Computação de $l_{1}$ e $l_{2}$ no histograma de uma imagem sintética do projeto Brain Web $(\mathrm{MNI})$, de $181 \times 217 \times 182$ voxels.

cujos níveis de cinza estão entre $l_{1}$ e $l_{2}$ são classificados como primeiro plano (branco), e os demais são classificados como plano de fundo (preto). A Figura 7.8 apresenta exemplos de tal máscara mostrando os cortes medianos das imagens utilizadas nos exemplos anteriores. A imagens das Figuras 7.8a e 7.8b pertencem à imagem real 3D, cuja análise do histograma é apresentada na Figura 7.6. Já as imagens das Figuras 7.8c e 7.8d pertencem ao volume sintético cuja análise do histograma é apresentada na Figura 7.7. É possível observar em ambas as máscaras que a maioria dos voxels da região do encéfalo, e da região circundante ao mesmo, foram corretamente classificados. Esta é a condição ideal que permite obter a separação da região do cérebro com a utilização de operações de morfologia matemática binária. Na seqüência, é apresentado o conjunto de operações que o método HEAD emprega com este objetivo.

\section{Morfologia matemática binária}

Dada a máscara binária inicial $M$ gerada com a classificação dos voxels segundo os limiares $l_{1}$ e $l_{2}$, um conjunto de operadores da morfologia matemática binária é aplicado sobre $M$ com o intuito de isolar completamente a região do cérebro do restante da imagem. A seqüência de operadores é aplicada da seguinte maneira:

- Primeiramente, a máscara inicial $M$ é erodida com um elemento estruturante esférico de $2 \mathrm{~mm}$ de raio. Esta operação tem como objetivo remover estreitas conexões da região do cérebro com outras regiões de tecidos circundantes. Este tipo de conexão é bem comum e tende a ocorrer mais intensamente em imagens com maiores níveis de ruído;

- O maior bloco conexo de voxels do primeiro plano (branco) na máscara resultante é considerado a região do cérebro. Este bloco é selecionado com base em uma conectivi- 


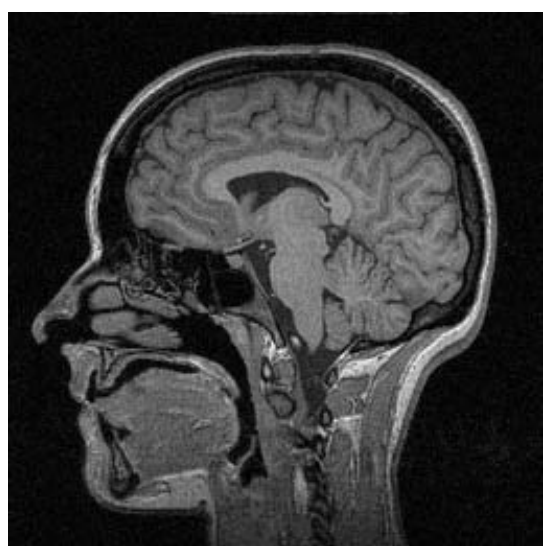

(a)

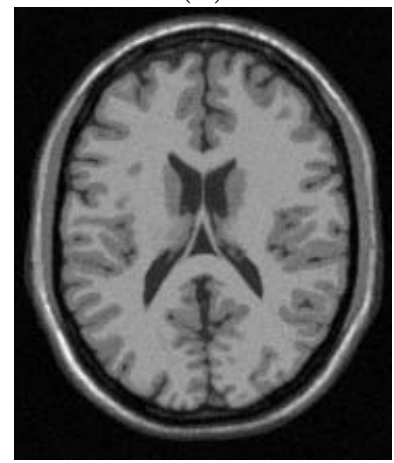

(c)

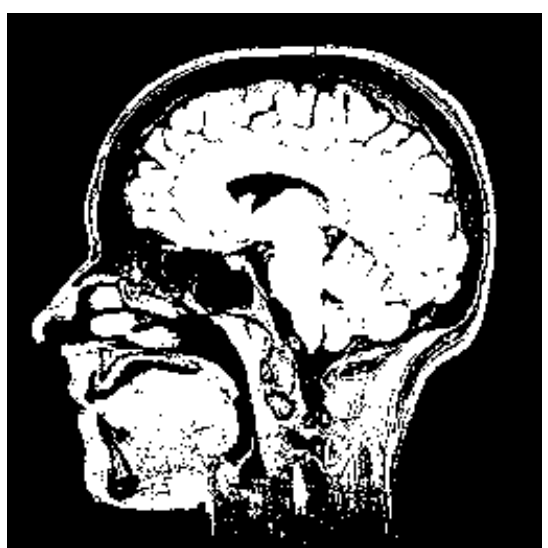

(b)

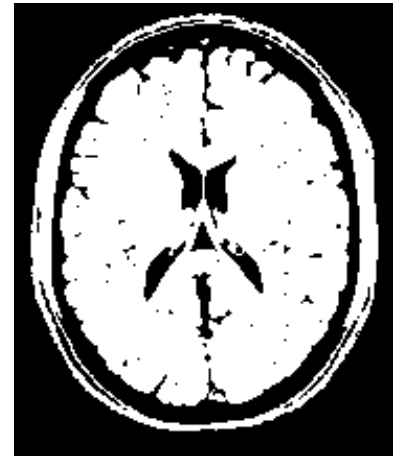

(d)

Figura 7.8: Classificações iniciais obtidas com os limiares $l_{1}$ e $l_{2}$. (a) Corte mediano original da imagem utilizada no exemplo da Figura 7.6; (b) Classificação binária correspondente; (c) Corte mediano original da imagem utilizada no exemplo da Figura 7.7, (d) Classificação binária correspondente.

dade 3D de seis vizinhos (um para cada face do voxel). Todo o restante da máscara é descartado;

- A máscara resultante é dilatada com elemento estruturante esférico de 3mm de raio;

- Um fechamento morfológico binário com elemento estruturante esférico de $4 \mathrm{~mm}$ de raio é aplicado sobre a máscara resultante;

- Finalmente, a operação de preenchimento de buracos é aplicada sobre o resultado anterior, gerando a máscara final do cérebro $M$.

Como é possível ser observado, o uso de operações morfológicas para filtragem binária não permite que o método alcance a representação mais refinada da superfície do cérebro, com detalhamento do sulco e giro. Isto, na verdade, não representa uma desvantagem do método, visto que em etapas posteriores de processamento, tais como, classificação dos tecidos, uma superfície mais refinada pode ser facilmente alcançada se necessário. A superfície suavizada é comumente denominada "envelope cortical". A Figura 7.9 exemplifica a aplicação da seqüência de operadores morfológicos descrita. O quadro da Figura 7.10 resume todos os passos do método HEAD, incluindo o algoritmo proposto de particionamento de histograma, a remoção do plano de fundo e a delimitação do encéfalo. 


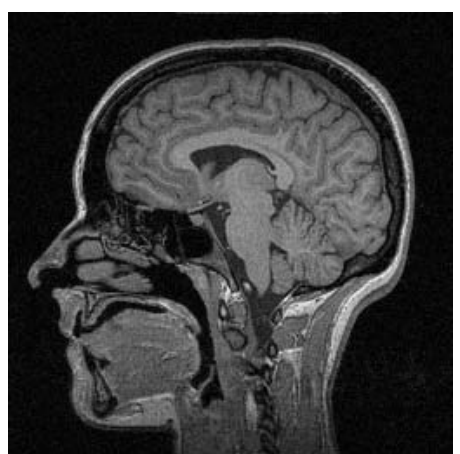

(a)

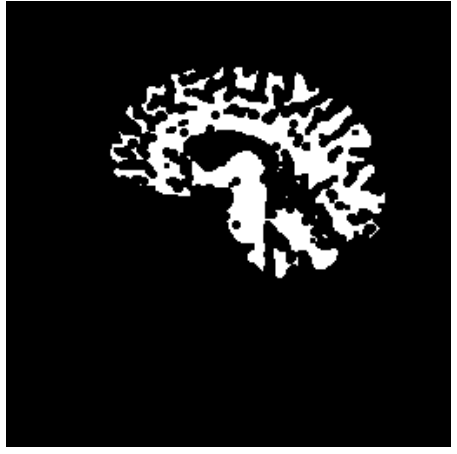

(d)

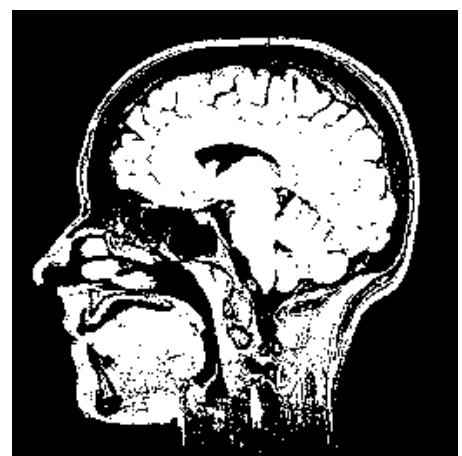

(b)

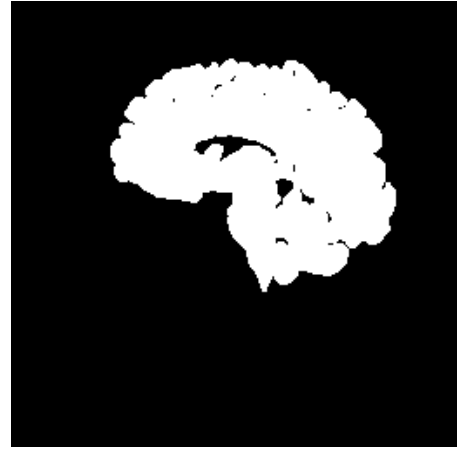

(e)

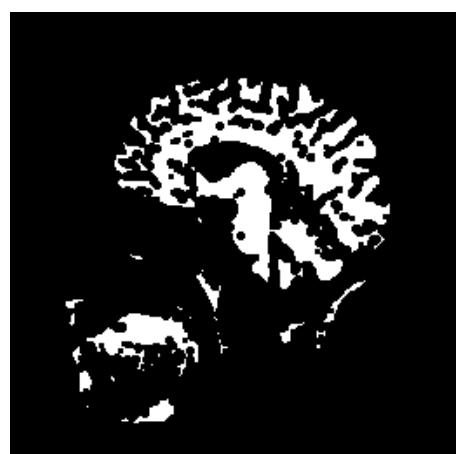

(c)

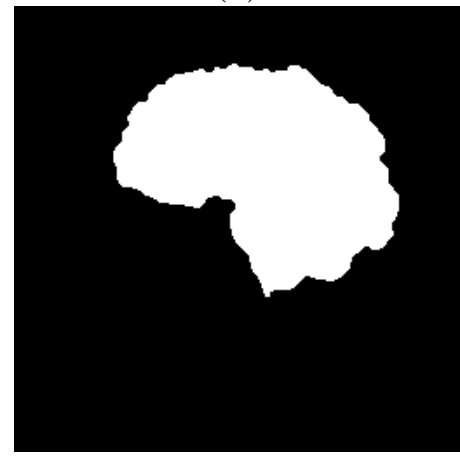

(f)

Figura 7.9: Seqüência de operadores morfológicos binários aplicados para se obter a máscara final do cérebro. (a) corte mediano da imagem original; (b) classificação binária inicial obtida com base nos limiares $l_{1}$ e $l_{2}$; (c) erosão binária; (d) seleção do maior componente conexo; (e) dilatação binária; (f) fechamento de buracos (máscara final do cérebro).

\subsection{Experimentos e resultados}

O método HEAD foi avaliado em 97 imagens MRI 3D, ponderadas em T1, de 62 pacientes do Hospital das Clínicas da Faculdade de Medicina de Ribeirão Preto - USP. Todas as imagens foram adquiridas por um scanner Siemens de 1.5 Tesla e possuem de 154 a 160 fatias sagitais. As taxas de ruídos e gradientes de brilho variam significativamente nestas imagens, o que as torna um conjunto experimental bastante adequado.

Em uma primeira demonstração, comparamos visualmente os resultados dos métodos HEAD e BSE na segmentação de uma imagem típica do nosso conjunto experimental. O método BSE foi escolhido porque ele é um dos melhores métodos baseados em região, e distribuído livremente, para segmentação do cérebro [167]. Para o BSE, os parâmetros padrões definidos no sistema BrainSuite2 foram utilizados.

Um especialista em radiologia segmentou manualmente a imagem selecionada, sem considerar o detalhamento do sulco e giro do cérebro. Dada esta máscara "verdadeira", diversos mapeamentos dos principais erros cometidos pelos dois métodos são apresentados na Figura 7.11, onde a coluna da esquerda corresponde ao método HEAD e a coluna da direita corresponde ao BSE. O objetivo é focalizar, principalmente, os pontos nas máscaras resultantes onde são descartadas regiões do cérebro compreendidas pela máscara verdadeira. Na primeira linha da Figura, é apresentada uma visão por baixo das máscaras 3D. As falhas nas 
Algoritmo de particionamento de histograma - (Sec. 7.3.1):

$l=\operatorname{particiona}\left(H(x), x_{i}, x_{f}\right)$

$H(x)$ : histograma de níveis de cinza

$x_{i}$ e $x_{f}$ : limites superior e inferior de $H(x)$

$l$ : nível de particionamento

Passos:

(1) Computar $\mathcal{P}(x)$ para $x_{i} \leq x \leq x_{f}$ (Eq. 7.1)

(2) Encontrar $l$ que maximize $\mathcal{P}(x)-H(x)$ (Eq. 7.2)

(3) Retornar $l$

Remoção do plano de fundo - (Sec. 7.3.2):

$M_{h}=$ remove_fundo $_{-}(I)$

I: Imagem 3D MRI ponderada em T1

$M_{h}$ : Máscara binária da cabeça

Passos:

(1) Computar o histograma $H(x)$ da imagem $I$

(2) $l=\operatorname{particiona}\left(H(x), x_{m i n}, x_{h}\right)$ onde

$$
\frac{\sum_{x=x_{\min }}^{x_{h}} H(x)}{\sum_{x=x_{\min }}^{x_{\max }} H(x)}=0.85
$$

(3) Criar a máscara $M_{h}$ a partir de $I$ e do limiar $l$

(4) Aplicar sobre $M_{h}$ o operador morfológico de abertura de área para eliminar fragmentos brancos com menos de 200 voxels (conectividade 3D de 6 vizinhos)

(5) Preencher os buracos dentro de $M_{h}$ (conectividade 3D de 6 vizinhos)

(6) Retornar $M_{h}$

Delimitação do cérebro - (Sec. 7.3.3):

$M=$ delimita_cerebro $(I)$

I: Imagem 3D MRI ponderada em T1

$M$ : Máscara binária do cérebro

Passos:

(1) $M_{h}=$ remove_fundo(I)

(2) Computar o histograma $H^{\prime}(x)$ de $I$ restrito a $M_{h}$

(3) $l_{1}=\operatorname{particiona}\left(H^{\prime}(x), x_{m i n}^{\prime}, x_{1}\right)$ onde

$$
\frac{\sum_{x=x_{\min }^{\prime}}^{x_{1}} H^{\prime}(x)}{\sum_{x=x_{\text {min }}}^{x_{\text {max }}^{\prime}} H^{\prime}(x)}=0.85
$$

(4) $l_{2}=\operatorname{particiona}\left(H^{\prime}(x), x_{2}, x_{\max }^{\prime}\right)$ onde

$$
\frac{\sum_{x=x_{2}}^{x_{\max }^{\prime}} H^{\prime}(x)}{\sum_{x=x_{\min }^{\prime}}^{x_{\max }^{\prime}} H^{\prime}(x)}=0.25
$$

(5) Criar uma máscara binária $M$ a partir de $I$ e dos limiares $l 1$ e $l_{2}$

(6) Erodir $M$ com um elemento estruturante esférico de $2 \mathrm{~mm}$ de raio

(7) Selecionar em $M$ o maior bloco conexo de voxels brancos e descartar o restante (conectividade 3D de 6 vizinhos)

(8) Dilatar $M$ com um elemento estruturante esférico de $3 \mathrm{~mm}$ de raio

(9) Fechar $M$ com um elemento estruturante esférico de $4 \mathrm{~mm}$ de raio

(10) Preencher os buracos de $M$ (conectividade 3D de 6 vizinhos)

(11) Retornar $M$

Figura 7.10: Resumo do método HEAD. 
máscaras são desenhadas na cor laranja. É possível observar que o método BSE falha em diversos pontos da superfície, enquanto o método HEAD apresenta pequenas falhas apenas na região do cerebelo. A segunda linha da Figura apresenta uma combinação de um corte da imagem original com as máscaras 3D resultantes, evidenciando uma falha significativa da máscara gerada pelo BSE na região do cerebelo. Finalmente, a terceira linha apresenta um corte mediano da imagem original aplicado às máscaras, onde outro erro significativo da máscara BSE é ressaltado.

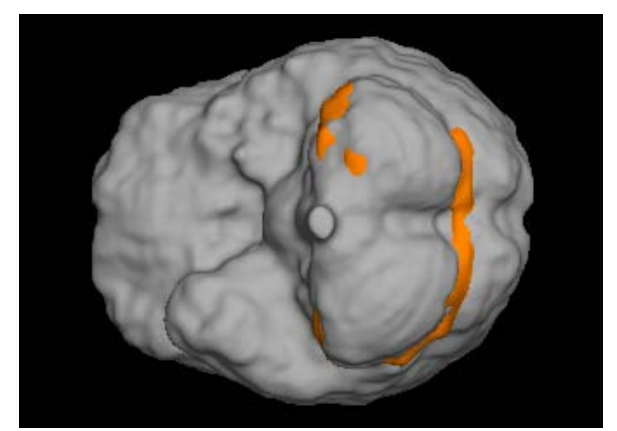

(a)

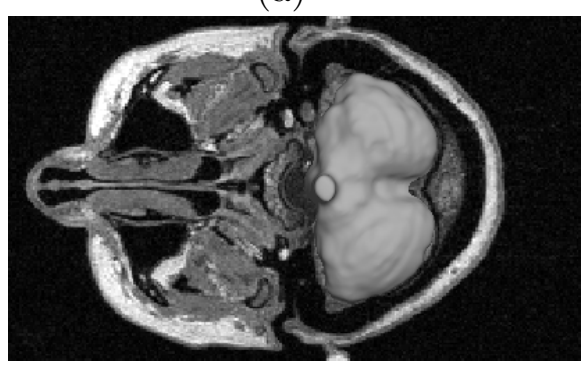

(c)

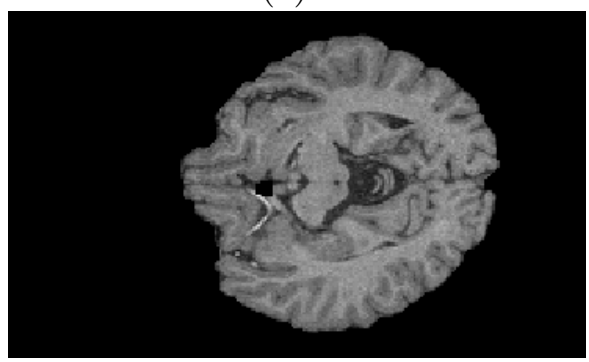

(e)

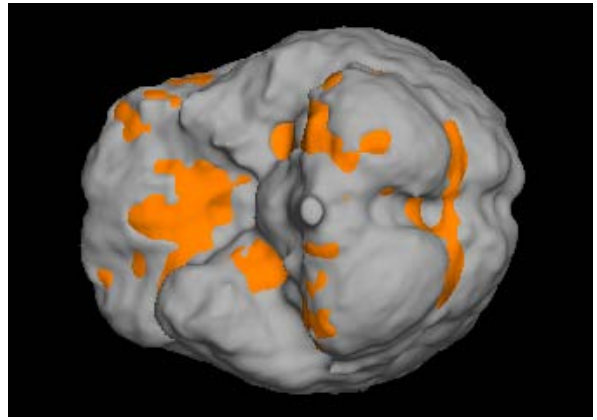

(b)

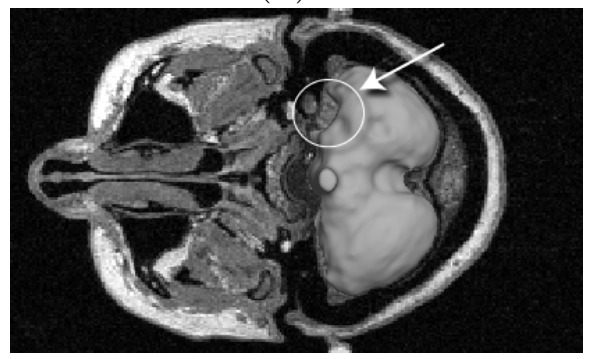

(d)

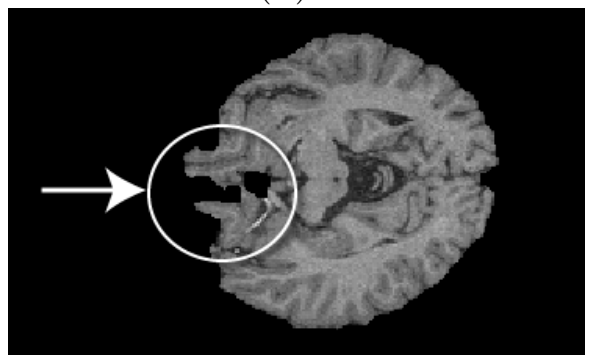

(f)

Figura 7.11: Uma comparação visual do método HEAD (coluna da esquerda) e o algoritmo BSE (coluna da direita). (a,b) Mapeamento 3D de erros nas máscaras resultantes (áreas em laranja indicam as falhas); (c,d) Corte da imagem original combinada com as máscaras resultantes; (e,f) Corte mediano da imagem original aplicado às máscaras resultantes.

No exemplo da Figura 7.11, o coeficiente Jaccard para a máscara gerada pelo método BSE é 0.959, enquanto a máscara gerada pelo método HEAD alcança 0.991. Vale lembrar que o coeficiente Jaccard [159] é o volume da intersecção sobre o volume da união das duas máscaras, conforme apresentado no Capítulo 6.

Em outro teste preliminar, selecionamos uma imagem com taxa de ruído relativamente alta, e comparamos os dois métodos com a máscara verdadeira correspondente, determinada por um especialista. Neste caso, o método HEAD superou o método BSE mais evidente- 
mente, obtendo um coeficiente Jaccard de 0.989 , contra 0.916 obtido pelo BSE. A Figura 7.12 apresenta uma visualização desta comparação onde as colunas esquerda e direita correspondem, respectivamente, ao HEAD e ao BSE. Na primeira linha, uma visão oblíqua das máscaras revela a diferença significativa entre elas, principalmente na região inferior do cérebro, próximo ao cerebelo. A segunda linha apresenta uma combinação da máscara verdadeira, na cor laranja, que nos permite observar as maiores falhas nas máscaras resultantes. Finalmente, um corte de altura mediana da imagem original aplicada às mascaras de saída é apresentado na terceira linha. Neste exemplo é possível observar o método BSE descartando uma parte significativa do cérebro, ao passo que o método HEAD oferece um resultado consideravelmente melhor.

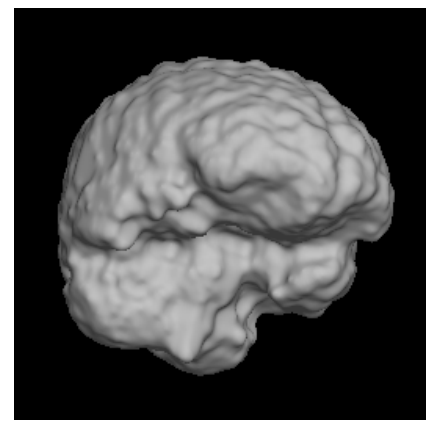

(a)

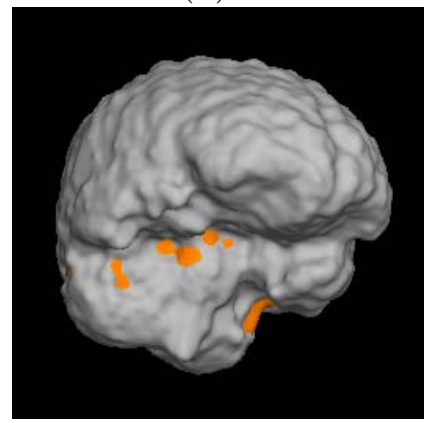

(c)

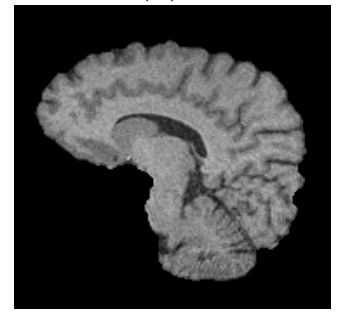

(e)

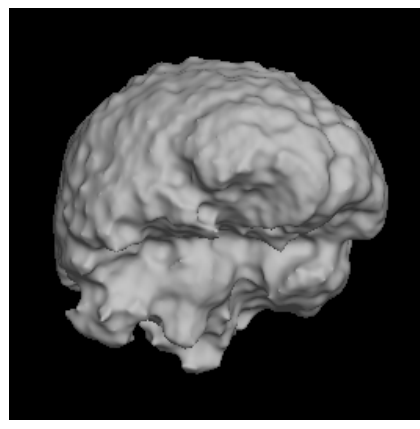

(b)

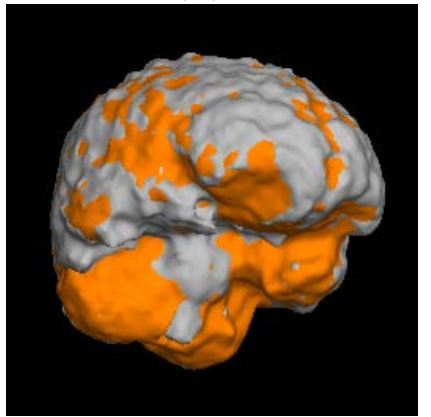

(d)

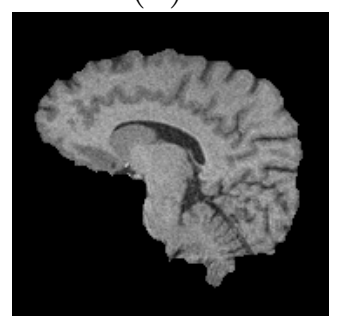

(f)

Figura 7.12: Comparação visual do método HEAD (coluna da esquerda) e do algoritmo BSE (coluna da direita), para uma imagem ruidosa do conjunto experimental. (a,b) Visão oblíqua das máscaras; (c,d) Mapeamento 3D dos erros mais salientes (desenhados na cor laranja) dada a segmentação manual de um especialista; (e,f) Corte de altura aleatória da imagem original aplicada às mascaras de saída. 


\subsubsection{Avaliação quantitativa}

Assistidos por um especialista na área de radiologia, foram segmentadas manualmente 40 imagens selecionadas da maneira aleatória do nosso conjunto experimental, para avaliação do método HEAD e comparação com o método BSE. Para uma comparação justa, o caule cerebral de todas as máscaras utilizadas na avaliação foram igualmente removidos, visto que não existe um consenso entre os métodos quanto à sua eliminação automática na máscara final.

O coeficiente Jaccard foi computado para cada máscara resultante de ambos os métodos. A medida final de avaliação para cada método, consiste na média aritmética de todos os coeficientes Jaccard que cada um obteve. O coeficiente Dice $D$ é outra medida comumente citada, definida como

$$
D=\frac{2\left|M_{A} \cap M_{B}\right|}{\left(\left|M_{A}\right|+\left|M_{B}\right|\right)}
$$

O coeficiente de Dice se relaciona com o coeficiente de Jaccard da seguinte maneira: $D=$ $2 J /(J+1)$. Quando $D=1$ as máscaras $M_{A}$ e $M_{B}$ são idênticas. Na Tabela 7.1 são apresentados os coeficientes médios, de Dice e Jaccard, que cada método obteve nesta avaliação.

Tabela 7.1: Precisão na segmentação de imagens clínicas reais

\begin{tabular}{c|cc}
\hline \multirow{2}{*}{ Métrica } & HEAD & MSÉtodo \\
\cline { 2 - 3 } Jaccard & $\mathbf{0 . 9 8 7 8}( \pm 0.022)$ & $0.9474( \pm 0.030)$ \\
Dice & $\mathbf{0 . 9 9 3 7}( \pm 0.011)$ & $0.9728( \pm 0.017)$
\end{tabular}

Observamos que a superioridade do método HEAD sobre o BSE ocorre principalmente porque o BSE costuma "cortar" partes importantes do cérebro nas proximidades das bordas. Acreditamos que este problema está relacionado com a alta sensibilidade da etapa de detecção de bordas no BSE. Na maioria dos casos, um ajuste manual dos parâmetros pode melhorar a qualidade da máscara resultante. Porém, isto compromete o caráter de automação do método. Além disso, o BSE é muito sensível até a pequenas modificações nos parâmetros, o que os torna difíceis de serem ajustados.

O método HEAD, por outro lado, alcança ótimos resultados mesmo não utilizando nenhuma etapa de pré-processamento da imagem. Os parâmetros que podem eventualmente ser ajustados são as porcentagens que determinam as bandas do histograma submetidas ao algoritmo de particionamento, e o tamanho dos elementos estruturantes utilizados nas operações de morfologia matemática binária. Os valores de parâmetros que utilizamos, entretanto, mostraram-se adequados para um amplo e diversificado conjunto de imagens. A maior parte dos erros observados nas máscaras geradas pelo método HEAD consiste em incluir pequenos fragmentos que circundam o cérebro, onde é possível observar pouca ou nenhuma separação entre eles. Isto, porém, é menos grave do que descartar partes do cérebro. A Figura 7.13 
lista uma série de exemplos que ilustram o comportamento geral dos métodos HEAD e BSE em nossos experimentos. As máscaras verdadeiras criadas manualmente também são apresentadas para avaliação visual. É possível observar em vários exemplos que o método BSE descarta, de fato, diversas partes do encéfalo, enquanto o método HEAD alcança resultados bem próximos daqueles produzidos manualmente por um especialista.
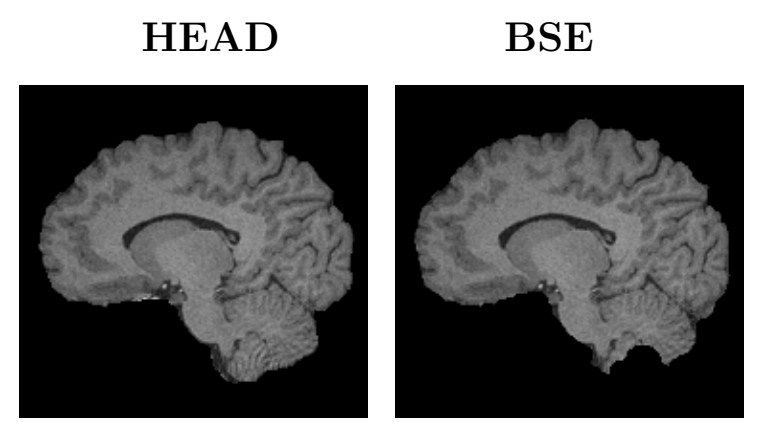

Máscara real
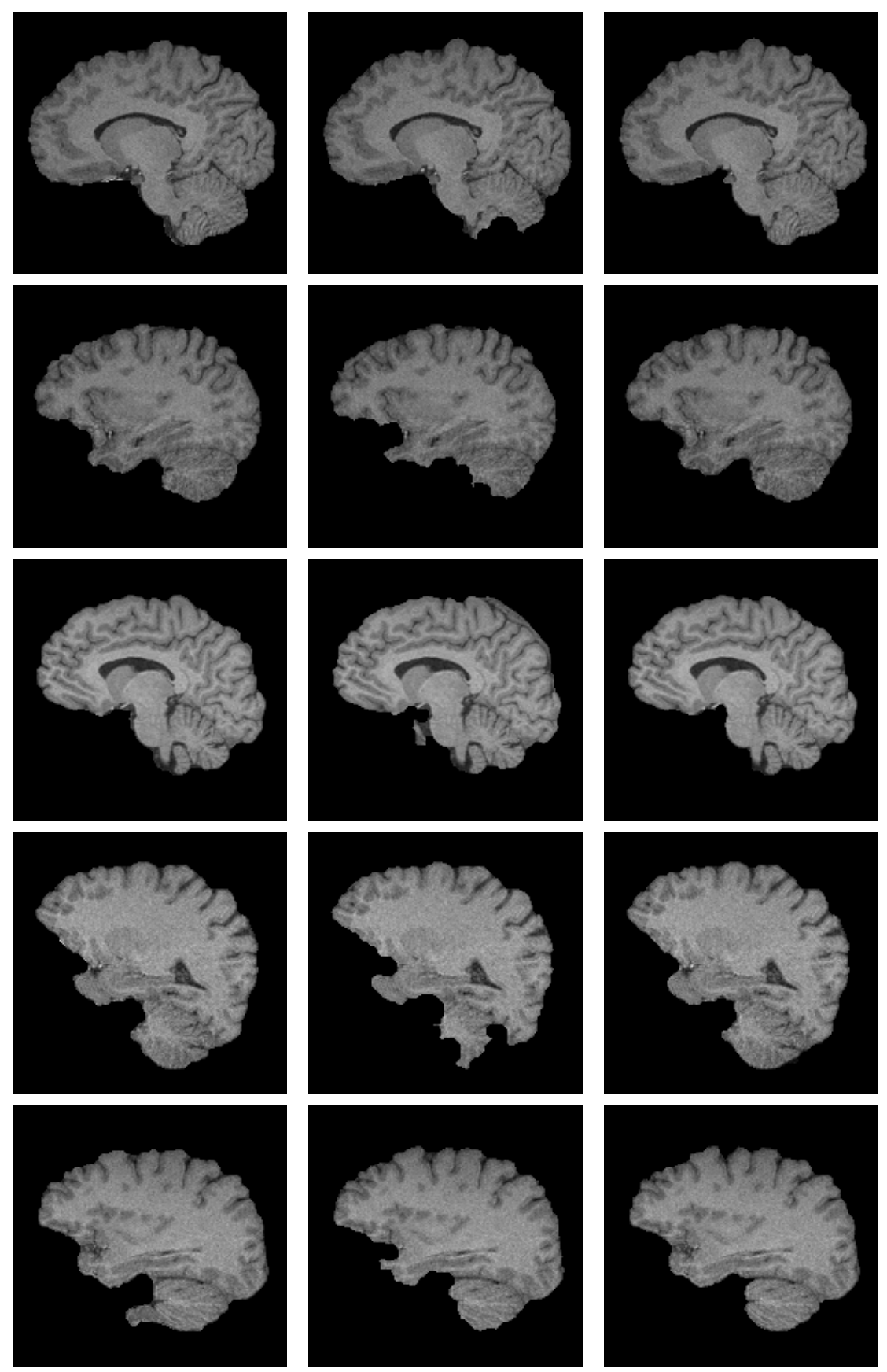

Figura 7.13: Exemplos de máscaras geradas pelos métodos HEAD e BSE (imagens reais)

\subsubsection{Imagens Sintéticas}

O método HEAD também foi experimentado em um conjunto de imagens sintéticas geradas pelo simulador BrainWeb [186] do Instituto de Neurologia de Montreal. Essas imagens 3D 
são geradas pela variação de parâmetros específicos da imagem e a inclusão de artefatos sobre dois modelos anatômicos: normal e esclerose múltipla. Os principais parâmetros disponíveis na interface web do gerador são: ponderação (T1, T2, Densidade de Próton), espessura do corte $(1,3,5,7$ e 9mm), intensidade de ruído (3\%, 5\%, $7 \%$ e 9\%) e intensidade do gradiente de brilho (20\% e 40\%). Para os níveis de gradiente de brilho vamos considerar nesta seção a notação INU (Intensity Non-Uniformity), em concordância com a notação utilizada na interface do simulador Brain Web.

Foram selecionadas oito imagens ponderadas em T1 com $1 \mathrm{~mm}$ de espessura de corte, baseadas no modelo anatômico normal, variando a intensidade de ruído e do gradiente de brilho (INU) para todos os valores pré-definidos. A Figura 7.14 ilustra a influência das diversas taxas de ruído sobre uma imagem sintética com $40 \%$ de INU.

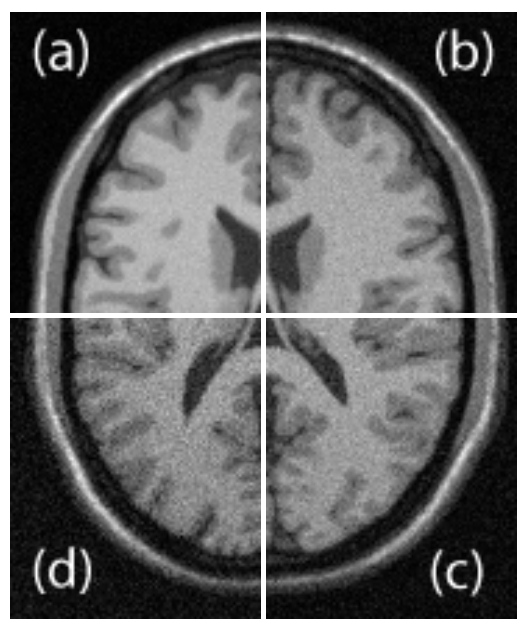

Figura 7.14: Mosaico ilustrando a influência da diferentes taxas de ruído gaussiano em imagens sintéticas do BrainWeb: (a) $3 \%$ (b) $5 \%$ (c) $7 \%$ (d) $9 \%$

Cada imagem sintética, contendo $181 \times 217 \times 181$ voxels, foi segmentada pelos dois métodos. As máscaras resultantes foram validadas com base em máscaras verdadeiras manualmente geradas com o auxílio de um especialista. Inicialmente, o método BSE não foi capaz de segmentar corretamente as imagens com seu conjunto de parâmetros padrão. Para alcançar resultados comparáveis, tivemos que aumentar em uma unidade o raio do elemento estruturante utilizado pelo BSE na operação de erosão binária. Este parâmetro está disponível na interface do sistema BrainSuite. Os demais parâmetros do método BSE não foram alterados. Diferentemente, o método HEAD foi aplicado a todas as imagens sem nenhuma modificação.

Primeiramente, a Tabela 7.2 apresenta os coeficientes de Jaccard obtidos pelo método BSE sobre o conjunto de oito imagens sintéticas. Observe que a precisão do método cai rapidamente para taxas de ruído acima de 5\%. Conforme mencionado anteriormente, um ajuste manual refinado dos parâmetros do BSE pode fazer com que o método gere melhores resultados. Entretanto, um conjunto particular de parâmetros é adequado apenas para poucas imagens, e isso pode ser observado claramente nos resultados da Tabela 7.2. Mesmo 
aplicando uma pré-filtragem na imagem com três iterações do filtro de difusão anisotrópica, o método BSE não consegue ser robusto sobre a variação de ruídos da imagem.

Tabela 7.2: Eficiência na segmentação de imagens sintéticas - BSE

\begin{tabular}{c|cccc}
\hline \multirow{2}{*}{ INU } & \multicolumn{4}{|c}{ Ruído } \\
\cline { 2 - 5 } & $3 \%$ & $5 \%$ & $7 \%$ & $9 \%$ \\
\hline $20 \%$ & 0.7830 & 0.9481 & 0.8451 & 0.1378 \\
$40 \%$ & 0.7922 & 0.9476 & 0.7977 & 0.2727 \\
\hline
\end{tabular}

Os coeficientes de Jaccard obtidos pelo método HEAD sobre o mesmo conjunto de imagens são apresentados na Tabela 7.3. Como é de se esperar, a precisão na segmentação tende à diminuir com o aumento da intensidade de ruído e INU. Entretanto, a precisão do método HEAD decai bem mais devagar que o BSE sob as mesmas condições de experimentação. Enfatizamos ainda o fato que o método HEAD não aplica sobre a imagem nenhuma operação de filtragem. Para visualização do comportamento de ambos os métodos neste experimento, são apresentadas na Figura 7.15 exemplos de máscaras geradas por eles. Nas imagens desta Figura, a intensidade de ruído é variada, enquanto o valor de INU é fixado em $40 \%$.

Tabela 7.3: Eficiência na segmentação de imagens sintéticas - método HEAD

\begin{tabular}{c|cccc}
\hline \multirow{2}{*}{ INU } & \multicolumn{4}{|c}{ Ruído } \\
\cline { 2 - 5 } & $3 \%$ & $5 \%$ & $7 \%$ & $9 \%$ \\
\hline $20 \%$ & 0.9859 & 0.9870 & 0.9691 & 0.9041 \\
$40 \%$ & 0.9871 & 0.9775 & 0.9752 & 0.8439 \\
\hline
\end{tabular}

\subsubsection{Tempo de processamento}

O algoritmo HEAD foi implementado como um toolbox do ambiente de programação Matlab, utilizando o pacote SDC de operações de morfologia matemática. Em um computador PC com processador principal de $3.4 \mathrm{GHz}$ e $1 \mathrm{~Gb}$ de memória RAM a $800 \mathrm{MHz}$ de freqüência de barramento, o método HEAD leva em média 14 segundos para segmentar uma imagem de $256 \times 256 \times 160$ voxels. Porém, uma implementação otimizada do método já está sendo preparada em $\mathrm{C}++$ para ser distribuída livremente, e acreditamos que ela segmentará as imagens ainda mais rapidamente.

\subsection{Considerações finais}

Neste Capítulo foi apresentado o método HEAD, the Human Encephalon Automatic Delimiter, um método rápido, preciso e robusto de delimitação do encéfalo em imagens MRI 3D 


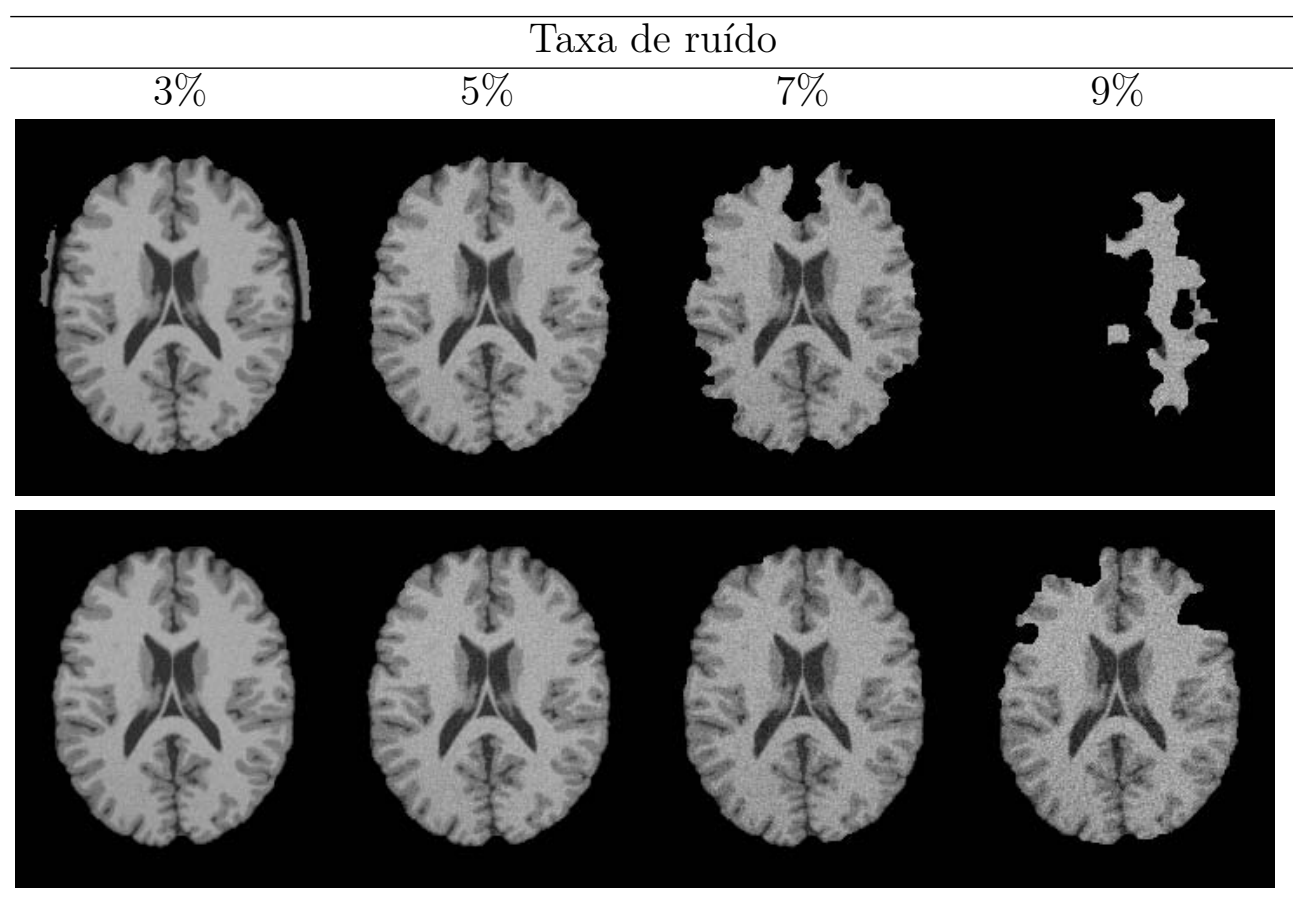

Figura 7.15: Máscaras do cérebro geradas pelo BSE (linha superior) e pelo método HEAD (linha inferior) na segmentação de imagens sintéticas com diferentes intensidades de ruído.

ponderadas em T1. Ao contrário da maioria dos métodos da mesma família, o HEAD emprega uma nova e eficiente análise de histograma, que pode encontrar corretamente a faixa dos níveis de cinza dos tecidos do cérebro, com mínimo esforço computacional. Nesta análise, um algoritmo de particionamento de histograma é responsável por localizar as concavidades da curva que compreendem essa faixa de níveis. Esta procura é realizada em diferentes partes do histograma, pré-definidas com base na morfometria geral da cabeça. O algoritmo de particionamento de histograma, por sua vez, apresenta diversas vantagens sobre outras técnicas conhecidas, incluindo menor complexidade computacional, baixa sensibilidade a ruídos na curva e a habilidade de operar em curvas com diferentes formatos.

Em nossos experimentos foram utilizadas 97 imagens reais de ressonância magnética ponderadas em T1 e 8 volumes sintéticos, todos eles apresentando consideráveis níveis de variância em ruído e gradientes de brilho. A precisão do método HEAD foi estimada com base em um conjunto de imagens segmentadas manualmente com auxílio de um profissional da área de radiologia do Hospital das Clínicas da FMRP-USP, e com métricas bem conhecidas como a de Jaccard e Dice. O método HEAD também foi comparado com o BSE (Brain Surface Extractor), um dos melhores métodos baseados em região e distribuído livremente. Nos experimentos com imagens reais o método HEAD obteve próximo de $99 \%$ de precisão enquanto o BSE alcançou menos de 95\%. Nos experimentos com imagens sintéticas ficou comprovado que nosso método é bastante robusto às altas variações de níveis de ruído, mesmo não utilizando nenhuma pré-filtragem da imagem. Ao contrário disto, o método BSE apresentou resultados ruins quando submetido à segmentação de imagens com alta variação de ruído, o que revela a sua alta dependência no ajuste manual de parâmetros. É importante 
enfatizar que em nenhum momento foram alterados os parâmetros originais definidos para o método HEAD. Deste modo, acreditamos que o HEAD é um excelente método que pode oferecer uma solução prática, rápida e precisa para o problema de delimitação automática do encéfalo em imagens de ressonância magnética de cabeça. Um artigo resumindo o método HEAD [14] foi recentemente aceito para publicação no CBMS'2007 (20th IEEE Symposium on Computer-Based Medical Systems). 



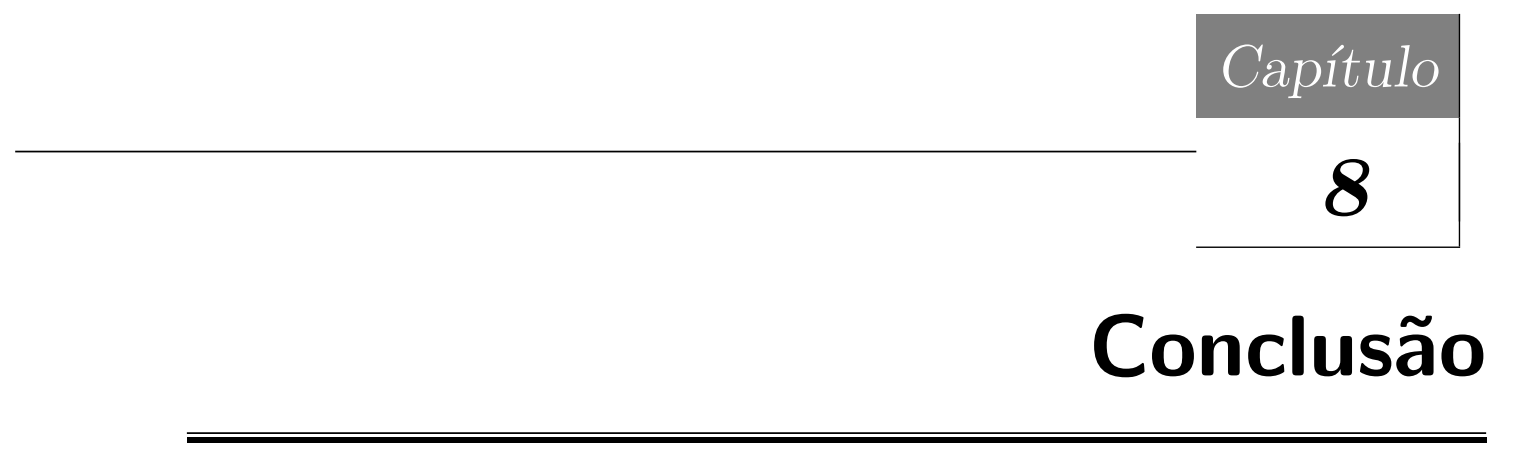

\subsection{Considerações finais}

Dos elementos que compõem um sistema CBIR, a extração de características de imagens é uma das tarefas que apresenta os maiores desafios, que estão principalmente relacionados à grande barreira que divide o funcionamento do cérebro humano do computador que ele mesmo criou. Este divisor, que pode ser considerado a fonte do problema conhecido como gap semântico, é o resultado da tentativa de fazer a máquina servir não só como um simples processador de números, mas também como um simulador da percepção humana. É o anseio de minimizar de alguma forma essa barreira que motiva a integração de diversas áreas de conhecimento científico, e faz com que um número cada vez maior de pesquisadores se dediquem a estudar e desenvolver algoritmos e técnicas para a recuperação de informação por conteúdo.

Neste trabalho, o tema de recuperação baseada em conteúdo é abordado para o domínio de imagens, e, mais especificamente para os domínios de imagens médicas e de imagens da biologia genética. O tema principal é a extração de características para representação sucinta do conteúdo visual das imagens, visando estabelecer medidas que possibilitem inferir computacionalmente níveis de similaridade. Uma idéia importante que defendemos é a de que a segmentação da imagem é uma etapa de extrema importância rumo à caracterização coerente da mesma. É o processo de segmentação que realiza a delimitação de regiões de interesse da imagem e possibilita a extração de características de forma objetiva. Diversas pesquisas, de fato, afirmam que o próprio sistema de visão humana realizada agrupamentos nas imagens captadas, buscando delimitar inicialmente os objetos para, posteriormente, identificá-los e inseri-los no contexto semântico.

Seguindo esta linha de pesquisa este trabalho apresenta novos métodos e soluções para segmentação e extração de características de imagens, buscando responder questões mais específicas dentro do contexto de cada domínio abordado. Em ordem de apresentação nesta 
tese, o primeiro domínio abordado no Capítulo 5 é o de imagens clínicas 2D proveniente de exames de ressonância magnética. Na seqüência, no Capítulo 6, vem o domínio de imagens de padrões espaciais de expressão genética, e, no Capítulo 7, as imagens 3D de exames clínicos de ressonância magnética do cérebro. Em cada domínio é apresentada uma solução inovadora e adequada para a tarefa de segmentação das imagens, visando o cálculo de medidas das regiões de interesse. Também são propostas novas técnicas e conceitos para representação das imagens em um espaço vetorial de características de baixa dimensão, obtido com base nos métodos de segmentação propostos. O objetivo principal é a realização de consultas de imagens por similaridade, ou seja, dada uma imagem de referência, qual o conjunto de imagens do repositório mais visualmente semelhantes àquela imagem?

\subsection{Principais contribuições}

O trabalho de pesquisa retratado nesta tese traz contribuições em dois níveis: em um escopo mais amplo de proposta e desenvolvimento de sistemas CBIR, e em um escopo mais centralizado na resolução de problemas que surgem na etapa de implementação das idéias. Em resumo, as principais contribuições para a área de CBIR são:

- Uma nova técnica de extração de características de imagens clínicas 2D de ressonância magnética. Sobre este trabalho foi publicado e apresentado um artigo no CBMS'2005 [12]. Nesta abordagem é proposto um vetor de características compacto e de tamanho fixo que se mostrou bem mais eficiente na tarefa de consulta por imagens similares do que a técnica de Zernike, reconhecida por sua excelente capacidade de representação, e os histogramas de brilho, ainda muito utilizados devido a sua praticidade de cálculo. Uma versão mais eficiente do método EM/MPM foi desenvolvida para segmentar as imagens e criar regiões relacionadas aos diversos tecidos. A idéia de variar iterativamente o parâmetro $\beta$ proporciona maior velocidade na convergência do processo, produzindo imagens segmentadas com baixo nível de ruído. Para extração de características é utilizada a abordagem de tratar as regiões compostas da imagem segmentada para produzir um vetor de características de tamanho fixo, diferentemente dos métodos mais tradicionais que buscam representar os componentes conexos um a um, e por isso precisam lidar com funções de distância mais complexas. Outra idéia que se destaca é a utilização da Dimensão Fractal como medida de formato das regiões, que possibilita com um único valor numérico, diferenciar regiões de formato linear, planares e puntiformes. Os experimentos com a nova técnica foram realizados sobre uma base de imagens de ressonância magnética de diversas partes do corpo, em diversas orientações (axial, coronal e sagital) e com diversas alturas de corte. A qualidade dos resultados em operações de consultas foi estimada com as curvas de precisão e revocação. Considerando-se o somatório de área sobre essas curvas, observa-se uma ampla vantagem da técnica proposta sobre os métodos comparados, sendo que esta obtém mais de 
90\% de precisão contra 74\% dos momentos de Zernike e $61 \%$ dos histogramas de brilho. Vale observar que esta vantagem é obtida com um vetor de características de apenas 20 valores numéricos, contra os 256 valores das técnicas de Zernike e histogramas. Isto favorece fortemente a utilização de técnicas eficientes de indexação espacial que constantemente se deparam com o problema de "alta dimensionalidade" dos dados.

- Um sistema para segmentação e extração de características de imagens de padrões de expressão genética contidos em imagens embrionárias da "mosca da fruta". Sobre este trabalho foi publicado e apresentado um artigo no ACM KDD'2006 [13]. O sistema desenvolvido, denominado FEMine (Fly Embryo Miner), representa uma solução completa e inovadora para o um problema de grande relevância na área da biologia genética e ainda inclui técnicas inovadoras por si só. Este é o caso da técnica de separação de partículas sobrepostas em imagens binárias baseada nos conceitos da técnica de watershed e na seleção automática de marcadores das partículas. Em poucas palavras, a técnica consiste em "encolher" e "expandir" iterativamente as regiões da imagem binária separando os embriões em um processo recursivo. A utilização desta técnica permitiu a representação de mais de $64 \%$ de imagens embrionárias da FlyBase (base de imagens da Universidade de Berkeley), quando em pesquisas anteriores menos de $30 \%$ da imagens eram aproveitadas. Com relação à extração de característica das imagens, o sistema FEMine introduz os Eigen-Embryos, um novo espaço de características para os padrões de expressão genética em embriões que permite a caracterização coerente e compacta das imagens. Observa-se pelos experimentos realizados que um número médio de 20 Eigen-Embryos é capaz de representar muito bem os diversos padrões de expressão genética contidos nas mais de 56.000 imagens da FlyBase. Da mesma maneira, a qualidade dos resultados nas operações de consultas foi estimada com medidas de precisão e revocação envolvendo um conjunto de teste com imagens dos padrões mais relevantes selecionados por um especialista. Os valores de precisão superam $90 \%$ para mais de $80 \%$ dos valores de revocação.

- Um novo método para segmentação de imagens 3D de exames RM de cabeça. Sobre este trabalho, um artigo [14] foi recentemente aceito para publicação no CBMS'2007, enquanto outro artigo submetido [15] está sob avaliação. O método desenvolvido, denominado HEAD - the Human Encephalon Automatic Delimiter, é uma proposta inovadora para o problema de delimitação automática do cérebro em exames clínicos. Merece destaque neste trabalho a proposta e desenvolvimento de uma nova técnica de particionamento automático de histogramas que apresenta grandes vantagens sobre as conhecidas e conceituadas técnicas de Otsu e Rosenfeld, incluindo menor complexidade computacional ( $\Theta(n)$, onde $n$ indica o tamanho do histograma), baixa sensibilidade a ruídos e a capacidade de particionar corretamente curvas com diversos formatos, diferentemente da técnica de Otsu por exemplo, que não é adequada para lidar com mais de duas saliências na curva ou com curvas onde as saliências possuem tamanhos muito 
diferentes. O método HEAD foi avaliado em 97 imagens 3D do Hospital das Clínicas da Faculdade de Medicina de Ribeirão Preto, obtendo uma precisão de $99 \%$ contra 95\% do Brain Surface Extractor (BSE), um dos melhores e mais conhecidos métodos de delimitação do cérebro distribuído livremente. Além disso o método HEAD também possui baixa sensibilidade a ruídos que são muito comuns nas imagens de ressonância magnética, possibilitando a delimitação rápida e precisa do encéfalo sem a utilização de técnicas de filtragem. O método HEAD constitui uma excelente base para análises de estudo do cérebro humano, podendo ser aplicado na extração de características de mais alto nível das imagens, incluindo a volumetria de tecidos, medidas de simetria, e determinação de propriedades das estruturas anatômicas mais importantes no contexto médico.

Além dessas contribuições também foram desenvolvidos outros trabalhos em cooperação com membros do GBDI, no desenvolvimento de técnicas de mineração de imagens [187, 188, 189] e propostas de funções de distância em espaços métricos [190].

\subsection{Trabalhos de extensão}

O trabalho apresentado nesta tese propicia diversas e relevantes alternativas de extensão que incluem:

- A integração do método HEAD e da nova técnica de particionamento de histogramas para desenvolvimento de um sistema de classificação de tecidos do cérebro e extração de características de mais alto nível da imagem, para integrar um sistema CBIR completo para este domínio. Este trabalho de extensão seria de grande auxílio ao CIREP, o Centro de Cirurgia de Epilepsia do HC da Faculdade de Medicina da Ribeirão Preto que, desde 2001, atua como centro regulador de cirurgias de epilepsia para todo o país. Os exames RM de cabeça auxiliam no tratamento e acompanhamento pré/pós operatório de pacientes e no estudo de patologias que incluem a epilepsia, o mal de Alzheimer, esclerose múltipla, hidrocefalia, esquizofrenia e câncer. Um sistema capaz de medir automaticamente características relevantes dessas imagens no contexto clínico e de pesquisa constitui uma ferramenta de grande importância para hospitais e centros médicos;

- Extensão do sistema FEMine para possibilitar a consulta de séries temporais de padrões de expressão genética. As bases de imagens embrionárias de padrões de expressão genética, especialmente a FlyBase, contêm imagens dos embriões em todos os estágios do seu desenvolvimento. Se pegarmos, por exemplo, todas as imagens referentes a um determinado gene, para todas as etapas de desenvolvimento embrionário, teremos uma série temporal que ilustra como o padrão espacial daquele gene se desenvolve com o passar do tempo. Assim, os mais de 3.000 genes catalogados na FlyBase formam uma 
grande base de séries temporais cuja extração de informação é um foco de pesquisa bastante relevante no contexto da biologia genética. O sistema FEMine pode ser utilizado como base para um sistema de caracterização das séries temporais possibilitando descobrir o relacionamento dos genes em nível espacial e temporal;

- Adaptação da nova técnica de particionamento de histogramas para segmentação de imagens médicas 2D de ressonância magnética. A técnica pode ser utilizada em conjunto com o método EM/MPM, para remover previamente o plano de fundo da imagem. Neste caso, a tarefa se segmentação seria bem mais rápida, pois não consideraria a região de plano de fundo, que é geralmente grande. Além disso, é de se esperar que o resultado da segmentação seja mais preciso com relação à classificação dos tecidos. Isto deve ocorrer porque as saliências do histograma da imagem, relacionadas com as classes de tecido, ficam mais evidentes sem a influência do plano de fundo;

- Suporte ao desenvolvimento e aprimoramento de algoritmos de mineração de imagens, os quais dependem fortemente da qualidade das características de imagens obtidas por extratores que consigam representar fielmente as propriedades mais relevantes das imagens. 



\section{Teoria dos Fractais}

A teoria dos fractais envolve diversos conceitos e medidas que têm sido amplamente aplicados a diferentes problemas tais como análise e reconhecimento de padrões [191], previsão de séries temporais [192], mineração de dados [193], indexação em bases de dados [194, 195, 196] e também CBIR [197, 198, 199, 12].

Um conjunto fractal é conhecido pela sua característica de auto similaridade, o que significa que os dados do conjunto apresentam o mesmo padrão de distribuição espacial em uma ampla e indefinida faixa de escala ou, em outras palavras, qualquer fragmento do fractal é similar ao fractal como um todo, exatamente ou estatisticamente. O termo, fractal, foi definido em 1975 por Benoît Mandelbrot, matemático francês que desenvolveu a geometria fractal na década de 1970. A palavra vem do latim fractus que significa "quebra". Um exemplo clássico de fractal é ilustrado na Figura A.1. A partir de um triângulo preenchido em um espaço 2D, um recorte triangular ao centro do mesmo determina a existência de três novos triângulos menores. Aplicando-se o mesmo recorte nos triângulos menores, em um processo recursivo de duração indefinida, o fractal conhecido como "triângulo de Sierpinsky" é criado.
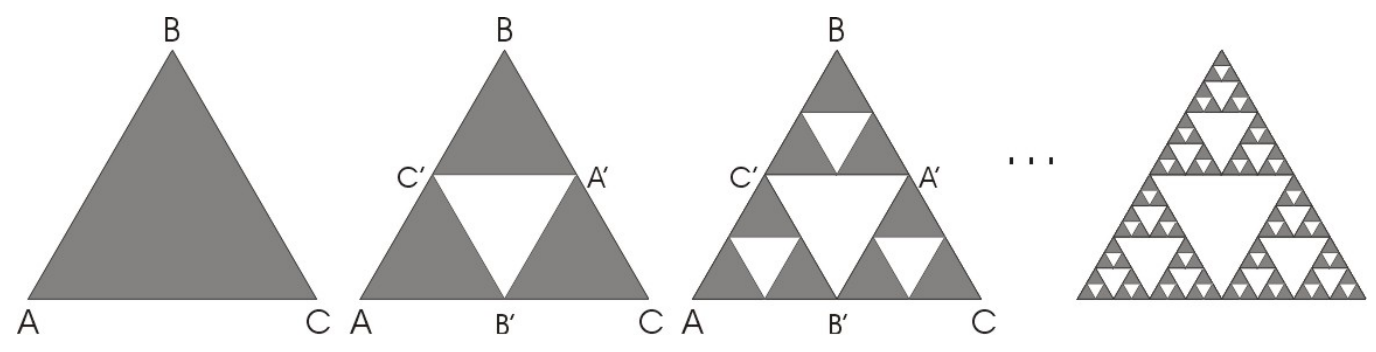

Figura A.1: Exemplo de fractal - o Triângulo de Sierpinsky

Mesmo que os fractais estejam imersos em espaços euclidianos, devido a suas propriedades recursivas e características incomuns eles não são classificados segundo à geometria euclidiana, que define objetos elementares e finitos de onde é possível extrair medidas de 
comprimento (linha), área (plano) e volume (sólido). Assim, a geometria dos fractais defini um medida estatística para interpretação dos fractais: a dimensão fractal, que indica o quanto um determinado fractal preenche o espaço no qual ele está imerso. O triângulo de Sierpinsky da figura A.1, por exemplo, é um fractal imerso no espaço 2D mas não é considerado um objeto euclidiano 2D, pois possui área nula. Por outro lado, ele também não é considerado um objeto euclidiano unidimensional, pois possui perímetro infinito. Assim, é intuitivo pensar que o fractal está em algum lugar entre linha e plano, ou seja, ele possui uma dimensão fractal fracionária entre 1 e 2.

A dimensão fractal é um conceito que se aplica não só aos fractais que possuem uma autosimilaridade perfeita, ou exata, como o triângulo de Sierpinsky, mas ela se aplica à maior parte dos conjuntos de pontos em um espaço $N$ dimensional. De maneira muito interessante, a dimensão fractal pode ser utilizada para revelar a dimensão intrínseca de um conjunto de pontos. Para entender a dimensão intrínseca, imagine um conjunto de pontos imersos em um espaço 3D, dispostos de maneira a formar um segmento de reta perfeito. A dimensão de imersão do conjunto é 3 mas sua dimensão intrínseca é 1 . Ou seja, o conjunto pode ser perfeitamente transferido para o espaço uni-dimensional, sem que as distâncias entre os pontos sejam alteradas. Por isso, muitos métodos de redução de dimensionalidade dos dados utilizam o conceito de dimensão fractal.

Há várias definições teóricas para o conceito de dimensão fractal e a maneira de como ela é calculada. As definições mais importantes incluem as dimensões de Hausdorff e Rényi e as dimensões de informação, correlação e box-counting. Embora para alguns fractais clássicos todas essas dimensões coincidam, em geral elas não são equivalentes. A dimensão de correlação de Grassberger e Procaccia [145] é uma das formas mais simples de se computar a dimensão fractal, e também a mais adequada para conjuntos discretos, finitos e com um número relativamente pequeno de pontos, como é o caso da aplicação que aqui propomos. Nesta breve revisão de conceito dos fractais vamos então abordar apenas a dimensão de correlação como forma de se computar a dimensão fractal de um conjunto finito de pontos.

Definição A.1 Dado um conjunto de $M$ pontos $\left[p_{1}, \ldots, p_{M}\right]$ onde a mínima e a máxima distância entre dois pontos quaisquer correspondem a $r_{\min }$ e $r_{\max }$, a dimensão de correlação $D_{2}$ é definida como:

$$
D_{2}=\frac{\log C(r)}{\log r} \quad, r \in\left[r_{\text {min }}, r_{\text {max }}\right]
$$

onde $C(r)$ é a função denominada integral de correlação, definida como:

$$
C(r)=\frac{1}{N^{2}} \sum_{i=1}^{N} \sum_{j=i+1}^{N} H\left(r-\left\|p_{i}-p_{j}\right\|\right)
$$

onde $H(\alpha)$ é a função Heaviside, definida como

$$
H\left(r-\left\|p_{i}-p_{j}\right\|\right)=\left\{\begin{array}{ccc}
0 & \text { se } & \left(r-\left\|p_{i}-p_{j}\right\|\right) \leq 0 \\
1 & \text { se } & \left(r-\left\|p_{i}-p_{j}\right\|\right)>0
\end{array}\right.
$$


Em outras palavras, a integral de correlação $C(r)$, é uma função que contabiliza o número de pares $\left(p_{i}, p_{j}\right)$ cuja distância entre os pontos é menor ou igual a $r$. Se o número $N$ de pontos do conjunto for bem maior que a dimensão de correlação $D_{2}$, a função $\log C(r)$, deve ser linear para uma ampla faixa de valores de $\log r$ [145]. Assim, a dimensão de correlação $D_{2}$ é estimada como a inclinação da reta no gráfico $\log C(r)$ vs. $\log r$ [200, 201]. 



\section{Revisão dos principais conceitos de genética}

Os genes são fragmentos da molécula de DNA que contém informação necessária para criar as proteínas, compostos orgânicos essenciais para formação da vida, e também moléculas de RNA. As proteínas são o principal material de construção das células de um organismo e ainda realizam as principais funções dentro das mesmas, como por exemplo alimentação, síntese de energia, interação com o meio e auxílio na criação de novas proteínas. Para se manter viva a célula necessita constantemente de novas cópias de suas proteínas, porém, embora as proteínas se encarreguem de quase todo o serviço na célula, elas não podem criar sozinhas cópias de si mesma. Para fazer mais proteínas as células usam as instruções específicas de produção codificadas nos genes das moléculas de DNA.

O DNA, ou ácido desoxiribonucléico, por sua vez, é formado por duas longas cadeias de nucleotídeos que se unem em forma de espiral. O nucleotídeo contém, entre outros elementos, uma base que é considerada a menor unidade de informação do DNA e pode assumir os valores A (adenina), C (citozina), G (guanina) e T (timina). A seqüência de letras nas cadeias do DNA informam precisamente a ordem na qual os aminoácidos devem ser combinados para formar uma determinada proteína, e esse processo de formação é diretamente auxiliado pela molécula de RNA, através do denominado RNA mensageiro (mRNA). Como nenhum sistema de armazenamento de dados é plenamente confiável, pode ocorrer, por exemplo, um erro no armazenamento da seqüência de bases no DNA, algo parecido com um erro tipográfico, e conseqüentemente, uma proteína desconhecida venha a ser produzida. Este "erro" na informação contida no DNA é chamado de mutação.

A molécula de DNA é embalada em estruturas chamadas cromossomos que ficam no núcleo de cada célula e só podem ser observados por microscópio quando a célula se encontra em momento de divisão. Os cromossomos variam em tamanho, forma, e quantidade de genes. O ser humano, por exemplo, possui 23 pares de cromossomos, sendo que o último par 
é responsável pela determinação do sexo do indivíduo.

O fato interessante é que todas as células de um organismo possuem os mesmos cromossomos em seus núcleos e exatamente o mesmo conjunto de instruções codificado nos genes da molécula de DNA. Sendo assim, como uma célula do sangue poderia ser tão diferente de uma célula do sistema nervoso, por exemplo? A resposta está no fato de que cada célula "liga", ou, em linguagem científica, "expressa" apenas um subconjunto dos genes do DNA em um determinado momento de sua vida. A combinação de genes ligados e desligados é que dá origem aos mais variados tipos de células.

Uma simples metáfora para os genes consiste em imaginá-los como livros em uma estante, que contém instruções para se criar uma proteína específica. Em algum momento os livros serão retirados da estante para serem lidos e suas instruções seguidas, produzindo uma determinada proteína. Diferentes leitores lêem um conjunto diferente de livros e determinados livros são mais acessados que outros. Esse processo de seleção do gene e produção da proteína recebe o nome "expressão genética" (gene expression) e o mecanismo celular responsável por decidir quais genes serão expressos em determinado momento é denominado "regulação genética". Alguns genes são expressos em todas as células o tempo todo. Eles são conhecidos como "domésticos" e são essenciais para funções bem básicas das células. Outros genes, no entanto, são expressos apenas em determinadas células ou em um determinado estágio de desenvolvimento do organismo. Por exemplo, os genes que codificam informação para criação de proteínas musculares, como a actina e miosina, são expressos somente nas células musculares e não nas células do sistema nervoso. Algumas doenças, por exemplo, são desenvolvidas a partir de uma pequena falha na ativação dos genes.

\section{B.1 Análise de expressão genética}

O conhecimento acerca dos papéis de cada gene de determinado organismo na formação de estruturas orgânicas, desde as mais elementares, como as proteínas, até as mais complexas, como os tecidos e órgãos, constitui uma peça chave para a compreensão de diversos aspectos relacionados à vida. Dentre estes aspectos, as doenças tem sido foco de maior atenção.

Estudar a expressão genética nas células de um determinado organismo é a forma mais direta que os cientistas descobriram para capturar conhecimento sobre os genes e interação que existe entre eles. Tal abordagem consiste em verificar quais genes estão ativos em quais células do organismo em um determinado momento ou intervalo da vida do mesmo. Comumente o intervalo mais estudado é a embriogênese, o intervalo de desenvolvimento do embrião, pois é quando a atividade de multiplicação celular é mais intensa.

A utilização de cobaias animais tem grande importância na análise genética. Com a ajuda deles é possível determinar modelos de estudo importantes para expressão e regulação genética. Diferentes organismos podem ser estudados e seus modelos utilizados diretamente para o estudo de doenças humanas. Os primatas são os animais mais próximos do ser humano, porém eles possuem um ciclo de vida muito longo para serem utilizados nesse tipo 
de pesquisa. Além do mais, o custo de criação de cobaias primatas é muito alto e não há aceitação na sociedade para utilização desses animais em experiências. Como conseqüência, animais menores, como os ratos e moscas, têm sido utilizados no estudo das funções genéticas. A popularmente denominada mosca da fruta (fruit fly), cujo nome científico é Drosophila Melanogaster, têm se mostrado útil neste contexto por muitos anos, por ser um organismo simples, com ciclos de vida e reprodutivo notoriamente curtos e por ser um dos primeiros a ter seu genoma completamente mapeado.

\section{B.1.1 Microarray de DNA}

Os principais métodos empregados no estudo de expressão genética são dois. O mais popular é baseado em um chip denominado microarray de DNA, que também é conhecido como o chip genético ou chip de DNA. Este chip consiste em uma base retangular de alguns centímetros de diâmetros, de vidro ou de plástico, onde é depositado um grande número de fragmentos de moléculas de DNA, os genes, distribuídas de forma matricial. Seleciona-se então, em um determinado momento da vida do organismo, as células do mesmo que serão analisadas, ou, até mesmo todo o organismo. Dessas células são extraídas todas as moléculas de mRNA (o RNA mensageiro), sendo que cada molécula representa um gene ativo naquele momento. As moléculas de mRNA são então marcadas com moléculas fluorescentes e a solução que as contém é espalhada na superfície do chip de microarray. Cada molécula marcada irá se unir com seu respectivo gene na matriz fazendo com que aquele ponto fique aceso sob incidência de luz. Isso representa que aquele gene estava ativo no organismo e, com a intensidade de luz do ponto pode-se estimar o número de células que possuía aquele gene ativo. Entretanto, apesar da técnica de microarray ainda suscitar grande interesse pelos biólogos, ela apresenta como principal limitação o fato de não distinguir quais as células que apresentam este o aquele gene ativo no momento determinado. Em outras palavras, ela pode fornecer apenas uma descrição quantitativo-temporal para cada gene desconsiderando a informação espacial.

\section{B.1.2 Hibridização in situ}

O outro método para análise de expressão genética é conhecido como Hibridização in situ (in situ Hybridization - ISH) e, diferentemente da técnica de microarray, as moléculas de mRNA não são removidas das células do tecido em estudo, mas, ao invés disso, elas são analisadas dentro da própria célula (daí o nome in situ que em latim significa "no lugar de origem"). A cada análise, é estudado o comportamento de apenas um gene, porém, além de determinar se o gene está ativo ou não também é possível saber quais células estão expressando aquele gene no momento da análise. A técnica também consiste em fazer com que moléculas de DNA, rotuladas por algum processo, se "encaixem" nas moléculas de mRNA por meio de associação de bases complementares. Primeiramente, o tecido a ser analisado sofre um tratamento químico para que as células e seus núcleos se tornem permeáveis. Uma mistura contendo fragmentos de DNA rotulados e complementares ao mRNA do gene em estudo é 
preparada e misturada (daí o nome hibridização) ao tecido permeabilizado fazendo com que as moléculas rotuladas se prendam somente dentro das células que expressam o determinado gene. Depois de um tempo, o tecido é lavado para retirar o excesso da solução rotulada e uma análise microscópica revela o mapa das células que expressavam o gene.

A Figura B.1 apresenta duas imagens provenientes da análise ISH. Neste exemplo os organismos analisados são embriões da Drosophila Melanogaster, a mosca da fruta. As regiões escuras revelam os aglomerados de células que expressam o gene analisado.
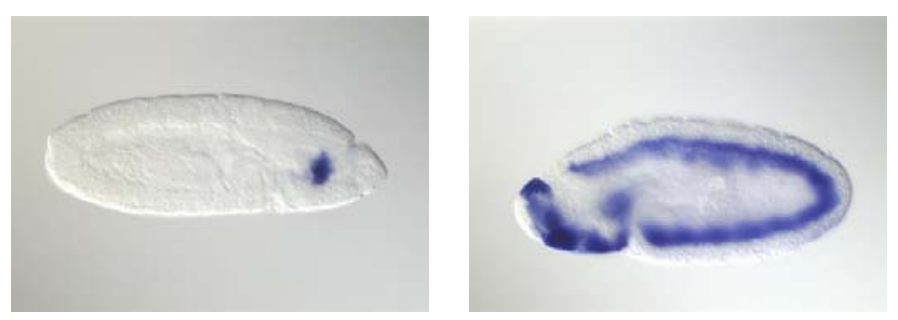

Figura B.1: Imagens provenientes da análise de Hibridização in situ (ISH) de embriões da Drosophila Melanogaster, a mosca da fruta. 


\section{Referências Bibliográficas}

[1] R. Baeza-Yates and B. Ribeiro-Neto, Modern Information Retrieval. Addison Wesley Longman Publishing Co. Inc, 1999.

[2] M. Sonka, V. Hlavac, and R. Boyle, Image Processing, Analysis and Machine Vision, 3rd ed. Thomson-Engineering, 2007.

[3] E. Albuz, E. Kocalar, and A. A. Khokhar, "Scalable color image indexing and retrieval using vector wavelets," IEEE Transactions on Knowledge and Data Engineering, vol. 13, no. 5, pp. 851-861, 2001.

[4] C. Xu and J. L. Prince, "Snakes, shapes, and gradient vector flow," IEEE Transactions on Image Processing, vol. 7, no. 3, pp. 359-369, 1998.

[5] S. Beucher, "The watershed transformation applied to image segmentation," in Proceedings of the Conference on Signal and Image Processing in Microscopy and Microanalysis, ser. Scanning Microscopy International, vol. 6, Cambridge, UK, 1992, pp. 299-314.

[6] P. Brodatz, "Textures: a photographic album for artists and designers," 1966, Dover, New York.

[7] N. Lundberg and M. Bergquist, "Impacts of PACS on Radiological Work," in Proceedings of the ACM SIGGROUP Conference on Supporting Group Work, Phoenix, Arizona, USA, 1999, pp. 169-178.

[8] E. Chávez, G. Navarro, R. A. Baeza-Yates, and J. L. Marroquín, "Searching in metric spaces," ACM Computing Surveys, vol. 33, no. 3, pp. 273-321, 2001.

[9] F. Santos, Roberto Figueira, A. J. M. Traina, J. Traina, Caetano, and C. Faloutsos, "Similarity search without tears: The OMNI family of all-purpose access methods," in Proceedings of the International Conference on Data Engineering (ICDE'2001), Heidelberg, Germany, 2001, pp. 623-630. 
[10] E. G. Petrakis and C. Faloutsos, "Similarity searching in medical image databases," IEEE Transactions on Knowledge and Data Engineering, vol. 9, no. 3, pp. 435-447, 1997.

[11] N. Lundberg and M. Bergquist, "Impacts of PACS on radiological work," in Proceedings of ACM SIGGROUP Conference on Supporting Group Work, Phoenix, Arizona, 1999, pp. 169-178.

[12] A. G. R. Balan, A. J. M. Traina, C. Traina-Jr., and P. M. d. Azevedo-Marques, "Fractal analysis of image textures for indexing and retrieval by content," in Proceedings of the 18th IEEE Symposium on Computer-Based Medical Systems (CBMS'2005). Dublin, Ireland: IEEE Press, 2005, pp. 581-586.

[13] J. Y. Pan, A. G. R. Balan, E. P. Xing, A. J. M. Traina, and C. Faloutsos, "Automatic mining of fruit fly embryo images," in Proceedings of the 12th ACM SIGKDD International Conference on Knowledge Discovery and Data Mining (KDD'06), Philadelphia, PA, USA, 2006, pp. 693-698.

[14] A. G. R. Balan, A. J. M. Traina, M. X. Ribeiro, P. M. A. Marques, and C. Traina-Jr., "Head: the human encephalon automatic delimiter," in Proceedings of the 20th IEEE Symposium on Computer-Based Medical Systems (CBMS'2007). Maribor, Slovenia: IEEE Press, 2007, pp. 1-6, artigo completo aceito para publicação em Março de 2007.

[15] — - "Smart histogram analysis applied to the skull-stripping problem in t1-weighted mri," IEEE Transactions on Medical Imaging, pp. 1-10, 2007, artigo submetido em Dezembro de 2006.

[16] J. Z. Wang, N. Boujemaa, A. D. Bimbo, D. Geman, A. G. Hauptmann, and J. Tesic, "Diversity in multimedia information retrieval research," in Proceedings of the 8th International Workshop on Multimedia Information Retrieval, Santa Barbara, CA, USA, 2006, pp. 5-12.

[17] A. Smeulders, M. Worring, S. Santini, A. Gupta, and R. Jain, "Content-based image retrieval at the end of the early years," IEEE Transactions on Pattern Analysis and Machine Intelligence, vol. 22, no. 12, pp. 1349-1380, 2000.

[18] Y. Rui, T. Huang, and S.-F. Chang, "Image retrieval: Current techniques, promising directions and open issues," J. Visual Communication and Image Representation, vol. 10, no. 4, pp. 39-62, 1999.

[19] P. Aigrain, H. Zhang, and D. Petkovic, "Content-based representation and retrieval of visual media: A review of the state-of-the-art," Multimedia Tools and Applications, vol. 3, no. 3, pp. 179-202, 1996. 
[20] C. G. M. Snoek and M. Worring, "Multimodal video indexing: A review of the stateofthe-art," Multimedia Tools and Applications, vol. 25, no. 1, pp. 5-35, 2005.

[21] Y. Liu, D. Zhang, G. Lu, and W.-Y. Ma, "A survey of content-based image retrieval with high-level semantics," Pattern Recognition, vol. 40, pp. 262-282, 2007.

[22] X. S. Zhou and T. S. Huang, "Relevance feedback in image retrieval: A comprehensive review," Multimedia Systems, vol. 8, pp. 536-544, 2003.

[23] W. Zhao, R. Chellappa, P. J. Phillips, and A. Rosenfeld, "Face recognition: A literature survey," ACM Computing Surveys, vol. 35, no. 4, pp. 399-458, 2003.

[24] H. Muller, N. Michoux, D. Bandon, and A. Geissbuhler, "A review of content-based image retrieval systems in medical applications - clinical benefits and future directions," International Journal of Medical Informatics, vol. 73, no. 1, pp. 1-23, 2004.

[25] R. Datta, D. Joshi, J. Li, and J. Z. Wang, "Image retrieval: Ideas, influences, and trends of the new age," Penn State University, Tech. Rep., 2006.

[26] J. P. Eakins, "Automatic image content retrieval: Are we getting anywhere?" in Proceedings of 3rd International Conference on Electronic Library and Visual Information Research (ELVIRA3), 1996, pp. 123-135.

[27] J. L. Bentley, "Multidimensional binary search trees used for associative searching," Communication of the ACM, vol. 18, no. 9, pp. 509-517, 1975.

[28] J. Traina, Caetano, A. J. M. Traina, C. Faloutsos, and B. Seeger, "Fast indexing and visualization of metric datasets using Slim-Trees," IEEE Transactions on Knowledge and Data Engineering, vol. 14, no. 2, pp. 244-260, 2002.

[29] J. Traina, Caetano, A. J. M. Traina, B. Seeger, and C. Faloutsos, "Slim-trees: High performance metric trees minimizing overlap between nodes," in Proceedings of the International Conference on Extending Database Technology, ser. Lecture Notes in Computer Science, vol. 1777. Konstanz, Germany: Springer, 2000, pp. 51-65.

[30] A. Guttman, "R-trees: A dynamic index structure for spatial searching," in Proceedings of ACM SIGMOD Conference of Management of Data, Boston, MA, USA, 1984.

[31] N. Beckmann, H.-P. Kriegel, R. Schneider, and B. Seeger, "The R*-tree: An efficient and robust access method for points and rectangles," in Proceedings of the 1990 ACM SIGMOD International Conference on Management of Data, Atlantic City, NJ, USA, 1990, pp. 322-331.

[32] R. A. Finkel and J. L. Bentley, "Quadtrees: A data structure for retrieval on composite keys," Acta Informatica, vol. 4, pp. 1-9, 1974. 
[33] M. Flickner, H. Sawhney, W. Niblack, J. Ashley, Q. Huang, B. Dom, M. Gorkani, J. Hafner, D. Lee, D. Petkovic, D. Steele, and P. Yanker, "Query by Image and Video Content: The QBIC System," IEEE Computer, vol. 28, no. 9, pp. 23-32, 1995.

[34] W. Niblack, R. Barber, W. Equitz, M. Flickner, E. Glasman, D. Petkovic, P. Yanker, C. Faloutsos, and G. Taubin, "The QBIC project: querying images by content, using color, texture, and shape," in Proceedings of the SPIE Conference on Storage and Retrieval for Image and Video Databases, vol. 1908, San Jose, CA, USA, 1993, pp. $173-187$.

[35] J. Bach, C. Fuller, A. Gupta, A. Hampapur, B. Horowitz, R. Humphrey, R. Jain, and C.-F. Shu, "The Virage image search engine: an open framework for image management," in Proceedings of the SPIE Conference on Storage and Retrieval for Image and Video Databases IV, vol. 2670, San Jose, CA, USA, 1996, pp. 76-87.

[36] A. Gupta and R. Jain, "Visual information retrieval," Communications of the ACM, vol. 40, no. 5, pp. 70-79, 1997.

[37] S. Mukherjea, K. Hirata, and Y. Hara, "AMORE: A World Wide Web Image Retrieval Engine," World Wide Web, vol. 2, no. 3, pp. 115-132, 1999.

[38] P. Kelly, M. Cannon, and D. Hush, "Query by image example: the Candid approach," in Proceedings of the SPIE Conference on Storage and Retrieval for Image and Video Databases III, vol. 2420, San Jose, CA, USA, 1995, pp. 238-248.

[39] A. Pentland, R. Picard, and S. Sclaroff, "Photobook: tools for content-based manipulation of image databases," International Journal of Computer Vision, vol. 18, no. 3, pp. 233-254, 1996.

[40] W. Ma, Y. Deng, and B. Manjunath, "Tools for texture and color-based search of images," in Proceedings of the SPIE Conference on Human Vision and Electronic Imaging II, vol. 3016, San Jose, CA, USA, 1997, pp. 496-507.

[41] C. Carson, M. Thomas, S. Belongie, J. M. Hellerstein, and J. Malik, "Blobworld: A system for region-based image indexing and retrieval," in Proceedings of the 3rd International Conference on Visual Information Systems, Amsterdam, The Netherlands, 1999, pp. 509-516.

[42] S. Belongie, C. Carson, H. Greenspan, and J. Malik, "Color- and texture-based image segmentation using EM and its application to content-based image retrieval," in Proceedings of the International Conference on Computer Vision (ICCV'1998), Bombay, India, 1998, pp. 675-682. 
[43] Y. Chen, J. Z. Wang, and R. Krovetz, "CLUE: Cluster-based retrieval of images by unsupervised learning," IEEE Transactions on Image Processing, vol. 14, no. 8, pp. 1187-1201, 2005.

[44] J. Li and J. Z. Wang, "Automatic linguistic indexing of pictures by a statistical modeling approach," IEEE Transactions on Pattern Analysis and Machine Intelligence, vol. 25, no. 9, pp. 1075-1088, 2003.

[45] J. Z. Wang, J. Li, and G. Wiederhold, "SIMPLIcity: Semantics-sensitive Integrated Matching for Picture Libraries," IEEE Transactions on Pattern Analysis and Machine Intelligence, vol. 23, no. 9, pp. 947-963, 2001.

[46] D. M. Squire, W. Müller, H. Müller, and T. Pun, "Content-based query of image databases: inspirations from text retrieval," Pattern Recognition Letters, vol. 21, no. 13-14, pp. 1193 - 1198, 2000.

[47] S. Sclarok, L. Taycher, and M. L. Cascia, "ImageRover: A Content-based browser for the world wide web," in Proceedings of the IEEE Workshop on Content-Based Access of Image and Video Libraries, San Juan, Puerto Rico, 1997, pp. 2-9.

[48] A. J. M. Traina, J. Traina, Caetano, J. M. Bueno, and P. M. d. A. Marques, "The metric histogram: A new and efficient approach for content-based image retrieval," in Proceedings of the 6th Working Conference on Visual Database Systems (IFIP'2002), ser. IFIP Conference Proceedings, vol. 216, Brisbane, Australia, 2002, pp. 297-311.

[49] A. J. M. Traina, J. Traina, Caetano, J. M. Bueno, F. J. T. Chino, and P. M. d. AzevedoMarques, "Efficient content-based image retrieval through metric histograms," World Wide Web Journal, Kluwer Academic Publishing Co., vol. 6, no. 2, pp. 157-185, 2003.

[50] A. K. Jain, Fundamentals of Digital Image Processing. Prentice Hall, 1993.

[51] B. Jahne, Digital Image Processing. Springer-Verlag, 1993.

[52] J. Z. Wang, G. Wiederhold, O. Firschein, and S. X. Wei, "Wavelet-based image indexing techniques with partial sketch retrieval capability," in Proceedings of the 4th Forum on Research and Technology Advances in Digital Libraries, Washington D.C., USA, 1997, pp. 13-24.

[53] J. G. Daugman, "High confidence visual recognition of persons by a test of statistical independence," IEEE Transactions on Pattern Analysis and Machine Intelligence, vol. 15, no. 11, pp. 1148-1161, 1993.

[54] J. S. Weszka, C. R. Dyer, and A. Rosenfeld, "A comparative study of texture measures for terrain classication," IEEE Transactions on Systems, Man and Cybernetics, vol. 6, no. 4, pp. 269-285, 1976. 
[55] T. R. Reed and J. M. H. D. Buf, "A review of recent texture segmentation and feature extraction techniques," Image Understanding, vol. 57, no. 3, pp. 359-372, 1993.

[56] R. Milanese and M. Cherbuliez, "A rotation, translation and scale-invariant approach to content-based image retrieval," Journal of Visual Communication and Image Representation, vol. 10, pp. 186-196, 1999.

[57] B. Manjunath and W. Y. Ma, "Texture features for browsing and retrieval of image data," IEEE Transactions Pattern Analysis and Machine Intelligence, vol. 18, no. 8, pp. 837-842, 1996.

[58] I. Biederman, "Recognition-by-components: a theory of human image understanding," Psychological Review, vol. 94, no. 2, pp. 115-147, 1987.

[59] D. M. Levi and S. A. Klein, "Seeing circles: what limits shape perception?" Vision Research, vol. 40, no. 17, pp. 2329-2339, 2000.

[60] G. Loffler, H. R. Wilson, and F. Wilkinson, "Local and global contributions to shape discrimination," Vision Research, vol. 43, no. 5, pp. 519-530, 2003.

[61] B. Ko, J. Peng, and H. Byun, "Region-based image retrieval using probabilistic feature relevance learning," Pattern Analysis and Applications, vol. 4, no. 2-3, pp. 174-184, 2001.

[62] B. Ko and H. Byun, "Integrated region-based image retrieval using regionś spatial relationships," in Proceedings of the 16th International Conference on Pattern Recognition (ICPR'2002), vol. 1, Quebec, Canada, 2002, pp. 196-199.

[63] I. Bartolini, P. Ciaccia, and Patella, "Warp: Accurate retrieval of shapes using phase of fourier descriptors and time warping distance," IEEE Transactions Pattern Analysis and Machine Intelligence, vol. 27, no. 1, pp. 142-147, 2005.

[64] F. Zernike, "Beugungstheorie des schneidenverfahrens und seiner verbesserten form, der phasenkontrastmethode," Physica, vol. 1, pp. 689-704, 1934.

[65] J. C. Felipe, J. B. Olioti, A. J. M. Traina, M. X. Ribeiro, E. P. M. Sousa, and C. J. Traina, "A low-cost approach for effective shape-based retrieval and classification of medical images," in Proceedings of the rth IEEE International Symposium on Multimedia (ISM'2005), Irvine, CA, USA, 2005, pp. 565-570.

[66] A. X. Falcão and F. P. G. Bergo, "Interactive volume segmentation with differential image foresting transforms," IEEE Transactions On Medical Imaging, vol. 23, no. 9, pp. 1100-1108, 2004.

[67] A. Falcao, R. Lotufo, and G. Araujo, "The image foresting transformation," 2000. [Online]. Available: http://citeseer.ist.psu.edu/falcao00image.html 
[68] S. Belongie, J. Malik, and J. Puzicha, "Shape matching and object recognition using shape contexts," IEEE Transactions Pattern Analysis and Machine Intelligence, vol. 24, no. 4, pp. 509-522, 2002.

[69] H. Müller, N. Michoux, D. Bandon, and A. Geissbuhler, "A review of content-based image retrieval systems in medical applications-clinical benefits and future directions," International Journal of Medical Informatics, vol. 73, no. 1, pp. 1-23, 2004.

[70] J. Smith, "Integrated spatial and feature image systems: Retrieval," Ph.D. dissertation, Columbia University, New York, 1997.

[71] D. Zhang, "Image retrieval based on shape," Ph.D. dissertation, Monash University, 2002 .

[72] M. J. Swain and D. H. Ballard, "Color indexing," International Journal of Computer Vision, vol. 7, no. 2, pp. 11-32, 1991.

[73] H. L. Van Trees, Detection, estimation, and modulation theory. New York, USA: Wiley, 1968.

[74] G. Salton and M. J. McGill, Introduction to Modern Information Retrieval. New York, USA: McGraw-Hill Inc., 1986.

[75] D. S. Zhang and G. J. Lu, "Shape retrieval using Fourier descriptors," Fargo, ND, USA, 2001.

[76] H. Shatkay, "The Fourier transform - A primer," Department of Computer Science, Brown University, Tech. Rep. CS-95-37, 1995.

[77] R. C. Gonzalez and R. E. Woods, Digital Image Processing, 2nd ed. Prentice Hall, 2002.

[78] M. Teague, "Image analysis via the general theory of moments," Journal of the Optical Society of America, vol. 70, no. 8, pp. 920-930, 1980.

[79] C. Teh and R. T. Chin, "On image analysis by the method of moments," IEEE Transaction on Pattern Analysis and Machine Intelligence, vol. 10, no. 4, pp. 496-513, 1988.

[80] R. M. Haralick, K. Shanmugam, and I. Dinstein, "Textural features for image classification," IEEE Transactions on Systems, Man, and Cybernetics, vol. 3, no. 6, pp. 610-621, 1973.

[81] E. J. Stollnitz, T. D. DeRose, and D. H. Salesin, Wavelets for Computer Graphics: Theory and Applications. San Francisco, California: Morgan Kaufmann Publishers Inc., 1996. 
[82] C. Blatter, Wavelets: A Primer. AK Peters, Ltd., 1998.

[83] S. G. Mallat, "A theory for multiresolution signal decomposition : The wavelet representation," IEEE Transactions on Pattern Analysis and Machine Intelligence, vol. 11, no. 7 , pp. 674-693, 1989.

[84] C. A. B. Castañón and A. J. M. Traina, "Caracterização de imagens através de análise multiresolução por wavelets para sistemas CBIR," in Anais da XXIV Conferência Latino-Americana de Informática (CLEI'2003), La Paz, Bolivia, 2003, pp. 1-12 in CDROM.

[85] C. A. B. Castanon and A. J. M. Traina, "Extração de características de imagens médicas baseadas na distribuição de cor dos espaços de wavelets," in Anais do II Workshop de Informática Médica (WIM'2001), Gramado, RS, 2002, pp. 1-4 in CDROM.

[86] C. Maaoui, H. Laurent, and C. Rosenberger, "2D color shape recognition using zernike moments," in Proceedings of the International Conference on Image Analysis and Recognition, Toronto, Canada, 2005, pp. 976-979.

[87] N. Kamila, S. Mahapatra, and S. Nanda, "Invariance image analysis using modified zernike moments," Pattern Recognition Letters, vol. 26, no. 6, pp. 747-753, 2005.

[88] M. Zhenjiang, "Zernike moment-based image shape analysis and its application," Pattern Recognition, vol. 21, no. 2, pp. 169-177, 2000.

[89] A. Wallin and O. Kubler, "Complete sets of complex zernike moment invariants and the role of the pseudoinvariants," IEEE Transactions on Pattern Analysis and Machine Intelligence, vol. 17, no. 11, pp. 1106-1110, 1995.

[90] J. Facon, "Processamento e análise de imagens," Universidad Nacional de Córdoba, Tech. Rep., 1993.

[91] W. Skarbek and A. Koschan, "Colour image segmentation - A survey -," Technical University of Berlin, Tech. Rep., 1994.

[92] Q. Luo and T. Khoshgoftaar, "Unsupervised multiscale color image segmentation based on mdl principle," IEEE Transactions on Image Processing, vol. 15, no. 9, pp. 2755$2761,2006$.

[93] Z. Al Aghbari and R. Al Haj, "Hill-manipulation: An effective algorithm for color image segmentation," Image and Vision Computing, vol. 24, no. 8, pp. 894-903, 2006.

[94] M. L. Comer and E. J. Delp, "The EM/MPM algorithm for segmentation of textured images: Analysis and further experimental results," IEEE Transactions on Image Processing, vol. 9, no. 10, pp. 1731-1744, 2000. 
[95] S.-J. Lee, C.-S. Ouyang, and S.-H. Du, "A Neuro-Fuzzy approach for segmentation of human objects in image sequences," IEEE Transactions on Systems, Man, and Cybernetics-Part B: Cybernetics, vol. 33, no. 3, pp. 420-437, 2003.

[96] J. C. Bezdek and S. K. Pal, Fuzzy Models for Pattern Recognition: Methods That Search for Structures in Data, 1st ed. IEEE Press, 1992.

[97] K. E. Melkemi, M. Batouche, and S. Foufou, "A multiagent system approach for image segmentation using genetic algorithms and extremal optimization heuristics," Pattern Recogition. Letters, vol. 27, no. 11, pp. 1230-1238, 2006.

[98] C.-T. Li and R. Chiao, "Unsupervised texture segmentation using multiresolution hybrid genetic algorithm," in Proceedings of the 2003 International Conference on Image Processing (ICIP'2003), vol. 2, Barcelona, Spain, 2003, pp. II - 1033-6 vol.3.

[99] Y. Fan, T. Jiang, and D. J. Evans, "Volumetric segmentation of brain images using parallel genetic algorithms," IEEE Transactions on Medical Imaging, vol. 21, no. 8, pp. 904-909, 2002.

[100] H. Peng, F. Long, Z. Chen, D. D. Feng, and W. Siu, "Hierarchical genetic image segmentation algorithm based on histogram dichotomy," Electronics Letters, vol. 36, pp. 872-874, 2000.

[101] M. Yoshimura and S. Oe, "Texture image segmentation by genetic algorithms," in Proceedings of IEEE International Conference on Evolutionary Computation, Nagoya, Japan, 1996, pp. 125-130.

[102] P. Sahoo, S. Soltani, A. Wong, and Y. Chen, "A survey of thresholding techniques," Computer Vision, Graphics and Image Processing, vol. 41, pp. 233-260, 1988.

[103] M. Kass, A. Witkin, and D. Terzopoulos, "Snakes: Active contour models," International Journal of Computer Vision, vol. 1, no. 4, pp. 321-331, 1987.

[104] D. Freedman, R. Radke, T. Zhang, Y. Jeong, D. Lovelock, and G. Chen, "Modelbased segmentation of medical imagery by matching distributions," IEEE Transactions Medical Imaging, vol. 24, no. 3, pp. 281-292, 2005.

[105] D. Freedman and T. Zhang, "Active contours for tracking distributions," IEEE Transactions on Image Processing, vol. 13, no. 4, pp. 518-526, 2004.

[106] T. McInerney and D. Terzopoulos, "A dynamic finite element surface model for segmentation and tracking in multidimensional medical images with application to cardiac 4D image analysis," Journal of Computerized Medical Imaging and Graphics, vol. 19, no. 1, pp. 69-83, 1995. 
[107] V. Caselles, R. Kimmel, and G. Sapiro, "Geodesic active contours," in Proceedings of the 5th International Conference on Computer Vision (ICCV'1995), Boston, MA, USA, 1995, pp. 694-699.

[108] T. McInerney and D. Terzopoulos, "Topologically adaptable snakes," in Proceedings of the IEEE 5th International Conference on Computer Vision, Cambridge, MA, USA, 1995, pp. 840-845.

[109] J. Park and J. M. Keller, "Snakes on the watershed," IEEE Transactions On Pattern Analysis And Machine Intelligence, vol. 23, no. 10, pp. 1201-1205, 2001.

[110] H. Park, T. Schoepflin, and Y. Kim, "Active contour model with gradient directional information: Directional snake," IEEE Transactions On Circuits And Systems For Video Technology, vol. 11, no. 2, pp. 252-256, 2001.

[111] S. D. Fenster and J. R. Kender, "Sectored snakes: Evaluating learned-energy segmentations," IEEE Transactions On Pattern Analysis And Machine Intelligence, vol. 3, no. 9, pp. 1028-1034, 2001.

[112] A. Dumitras and A. N. Venetsanopoulos, "Angular map-driven snakes with application to object shape description in color images," IEEE Transactions On Image Processing, vol. 10, no. 12, pp. 1851-1859, 2001.

[113] X. Xie and M. Mirmehdi, "RAGS: Region-aided geometric snake," IEEE Transactions On Image Processing, vol. 13, no. 5, pp. 640-652, 2004.

[114] M. Jacob, T. Blu, and M. Unser, "Efficient energies and algorithms for parametric snakes," IEEE Transactions On Image Processing, vol. 13, no. 9, pp. 1231-1244, 2004.

[115] J. Tang and S. T. Acton, "Vessel boundary tracking for intravital microscopy via multiscale gradient vector flow snakes," IEEE Transactions on Biomedical Engineering, vol. 51, no. 2, pp. 316-324, 2004.

[116] A. A. Amini, T. E. Weymouth, and R. C. Jain, "Using dynamic programming for solving variational problems in vision," IEEE Transactions on Pattern Analysis and Machine Intelligence, vol. 12, no. 9, pp. 855-867, 1990.

[117] D. J. Williams and M. Shah, "A fast algorithm for active contours and curvature estimation," CVGIP: Image Understanding, vol. 55, no. 1, pp. 14-26, 1992.

[118] C. Brice and C. Fennema, "Scene analysis using regions," Artificial Intelligence, vol. 1, no. 3-4, pp. 205-226, 1970.

[119] L. Grady, "Random walks for image segmentation," IEEE Transactions on Pattern Analysis and Machine Intelligence, vol. 28, no. 11, pp. 1768-1783, 2006. 
[120] A. Dupuis and P. Vasseur, "Image segmentation by cue selection and integration," Image and Vision Computing, vol. 24, no. 10, pp. 1053-1064, 2006.

[121] S. Horowitz and T. Pavlidis, "Picture segmentation by a tree traversal algorithm," Segmentation, Split and Merge, vol. 23, no. 2, pp. 368-388, 1976.

[122] J. Pichel, D. Singh, and F. Rivera, "Image segmentation based on merging of suboptimal segmentations," Pattern Recognition Letters, vol. 27, no. 10, pp. 1105-1116, 2006.

[123] S. Kumar, S. Ong, S. Ranganath, T. Ong, and F. Chew, "A rule-based approach for robust clump splitting," Pattern Recognition, vol. 39, no. 6, pp. 1088-1098, 2006.

[124] J. B. Roerdink and A. Meijster, "The watershed transform: Definitions, algorithms and parallelization strategies," Fundamenta Informaticae, vol. 41, pp. 187-228, 2000.

[125] P. A. Maragos, M. A. Butt, and R. W. Schafer, Mathematical Morphology and its Applications to Image and Signal Processing. Springer, 2002.

[126] H. Digabel and C. Lantuéjoul, "Iterative algorithms," Actes du 2nd Symposium Européen d'Analyse Quantitative des Microstructures en Sciences des Matériaux, Biologie et Médecine, pp. 85-99, 1978.

[127] S. Beucher and C. Lantuéjoul, "Use of watersheds in contour detection," in Proceedings od the International Workshop on Image Processing, Real-Time Edge and Motion Detection/Estimation, Rennes, France, 1979.

[128] L. Vincent and P. Soille, "Watersheds in digital spaces: an eficient algorithm based on immersion simulations," IEEE Transactions on Pattern Analysis and Machine Intelligence, vol. 13, no. 6, pp. 583-598, 1991.

[129] L. V. Gool, P. Dewaele, and A. Oosterlinck, "Texture analysis anno 1983," Computer Vision, Graphics, and Image Processing, vol. 29, pp. 336-357, 1985.

[130] A. Rosholm, "Statistical methods for segmentation and classification of images," Ph.D. dissertation, Technical University of Denmark, 1997.

[131] M. L. Comer, S. Liu, and E. J. Delp, "Statistical segmentation of mammograms," Proceedings of the 3rd International Workshop on Digital Mammography, pp. 475-478, 1996.

[132] P. M. Lee, Bayesian Statistics: An Introduction, 3rd ed. Hodder Arnold, 2004.

[133] E. R. Dougherty, Random Processes for Image and Signal Processing, ser. SPIE-IEEE Series on Imaging Science and Engineering. Wiley-IEEE Press, 1998. 
[134] J. Besag, "Spatial interaction and the statistical analysis of lattice systems (with discussion)," Journal of Royal Statistical Society, vol. 36, no. 2, pp. 192-326, 1974.

[135] S. Lakshmanan and H. Derin, "Simultaneous parameter estimation and segmentation of gibbs random field using simulated annealing," IEEE Transactions on Pattern Analysis and Machine Intelligence, vol. 11, pp. 799-813, 1989.

[136] P. A. Kelly, H. Derin, and K. D. Hart, "Adaptive segmentation of speckled images using a hierarchical random field model," IEEE Transactions on Acoustics, Speech and Signal Processing, vol. 36, pp. 1626-1641, 1988.

[137] T. N. Pappas, "An adaptive clustering algorithm for image segmentation," IEEE Transactions on Signal Processing, vol. 40, pp. 901-914, 1992.

[138] G. Casella and E. I. George, "Explaining the Gibbs Sampler," The American Statistician, vol. 46, no. 3, pp. 167-174, 1992.

[139] J. A. Bilmes, "A gentle tutorial of the EM algorithm and its application to parameter estimation for gaussian mixture and hidden Markov models," International Computer Science Institute, Tech. Rep., 1998.

[140] A. P. Dempster, N. M. Laird, and D. B. Rubin, "Maximum likelihood for incomplete data via EM algorithm," Journal of the Royal Statistical Society: Series B, vol. 39, no. 1, pp. 1-38, 1977.

[141] C. F. J. Wu, "On the convergence properties of the EM algorithm," The Annals Statistics, vol. 11, no. 1, pp. 95-103, 1983.

[142] R. A. Redner and H. F. Walker, "Mixture densities, maximum likelihood and the EM algorithm," Soc. Ind. Appl. Math. Rev., vol. 26, pp. 195-239, 1984.

[143] K. Fu and E. Persoon, "Shape discrimination using fourier descriptors," IEEE Transactions on Pattern Analysis and Machine Intelligence, vol. 8, no. 3, pp. 388-397, 1986.

[144] S. Geman and D. Geman, "Stochastic relaxation, gibbs distribuition, and the bayesian restoration of images," IEEE Transactions on Pattern Analysis, vol. 6, no. 6, pp. 721-741, 1984.

[145] P. Grassberger and I. Procaccia, "Characterization of strange attractors," Physical Review Letters, vol. 50, no. 5, pp. 346-349, 1983.

[146] J. C. Felipe, A. J. M. Traina, and C. Traina-Jr., "Global warp metric distance: Boosting content-based image retrieval through histograms," in Proceedings of the IEEE International Symposium on Multimedia (ISM'2005), Irvine, USA, 2005, pp. 295-302. 
[147] "The FlyBase database of the Drosophila Genome Projects and community literature. The FlyBase Consortium," Nucleic Acids Research, vol. 27, no. 1, pp. 85-88, 1999.

[148] W. Janning, "Flyview, a drosophila image database, and other drosophila databases," Seminars in Cell and Developmental Biology, vol. 8, pp. 469-475, 1997.

[149] P. Thévenaz, U. E. Ruttimann, and M. Unser, "A pyramid approach to subpixel registration based on intensity," IEEE Transactions On Image Processing, vol. 7, no. 1, pp. 27-41, 1998.

[150] R. Gurunathan, B. V. Emden, S. Panchanathan, and S. Kumar, "Identifying spatially similar gene expression patterns in early stage fruit fly embryo images: binary feature versus invariant moment digital representations," BMC Bioinformatics, vol. 5, no. 202, p. $13,2004$.

[151] K. Jayaraman, S. Panchanathan, and S. Kumar, "Classification and indexing of gene expression images," in Proceedings of SPIE - Applications of Digital Image Processing XXIV, vol. 4472, San Diego, CA, USA, 2001, pp. 471-481.

[152] S. Kumar, K. Jayaraman, S. Panchanathan, R. Gurunathan, A. Marti-Subirana, and S. J. Newfeld, "BEST: a novel computational approach for comparing gene expression patterns from early stages of drosophila melanogaster development," Genetics, vol. 162, no. 4, pp. 2037-2047, 2002.

[153] H. Peng and E. W. Myers, "Comparing in situ mRNA expression patterns of Drosophila embryos," in Proceedings of the 8th annual international conference on Research in computational molecular biology, San Diego, CA, USA, 2004, pp. 157-166.

[154] T. Cover and J. Thomas, Elements of Information Theory. New York: Wiley, 1991.

[155] C. C. Fowlkes, C. L. L. Hendriks, S. V. E. Keranen, M. D. Biggin, D. W. Knowles, D. Sudar, and J. Malik, "Registering Drosophila embryos at cellular resolution to build a quantitative 3D map of gene expression patterns and morphology," in Proceedings of the Workshop on BioImage Data Mining and Informatics (CSB'2005), Palo Alto, CA, USA, 2005, p. 3.

[156] C. S. Sorzano, P. Thévenaz, and M. Unser, "Elastic registration of biological images using vector-spline regularization," IEEE Transactions On Biomedical Engineering, vol. 52, no. 4, pp. 652-663, 2005.

[157] M. A. Turk and A. P. Pentland, "Face recognition using eigenfaces," in Proceedings of the IEEE Conference on Computer Vision and Pattern Recognition, Maui, HI, USA, 1991, pp. 586-591. 
[158] B. Zitová and J. Flusser, "Image registration methods: a survey," Image and Vision Computing, vol. 21, no. 11, pp. 977-1000, 2003.

[159] P.-N. Tan, M. Steinbach, and V. Kumar, Introduction to Data Mining. Addison Wesley, 2005.

[160] Y.-Y. Sitoh, J. Karthip, J. C. Rajapahe, W.-T. Hong, W.-L. Lee, S. Sahadevan, and J.-J. Chin, "Cerebral and hippocampal volumetry in early Alzheimer's disease," in Proceedings of the 9th International Conference on Neural Information Processing (ICONIP'02), vol. 3, Orchid Country Club, Singapore, 2002, pp. 1523-1526.

[161] J. Natsume, N. Bernasconi, F. Andermann, and A. Bernasconi, "MRI volumetry of the thalamus in temporal, extratemporal, and idiopathic generalized epilepsy," Neurology, vol. 60, no. 8, pp. 1296-1300, 2003.

[162] P. Kalus, C. Buri, J. Slotboom, J. Gralla, L. Remonda, T. Dierks, W. K. Strik, G. Schroth, and C. Kiefer, "Volumetry and diffusion tensor imaging of hippocampal subregions in schizophrenia," Neuroreport, vol. 15, no. 5, pp. 867-871, 2004.

[163] C. Lukas, H. K. Hahn, B. Bellenberg, J. Rexilius, G. Schmid, S. K. Schimrigk, H. Przuntek, O. Köster, and H.-O. Peitgen, "Sensitivity and reproducibility of a new fast 3D segmentation technique for clinical MR-based brain volumetry in multiple sclerosis," Neuroradiology, vol. 46, no. 11, pp. 906-915, 2004.

[164] N. Otsu, "A threshold selection method from gray-level histograms," IEEE Transactions on Systems, Man and Cybernetics, vol. 9, no. 1, pp. 62-66, 1979.

[165] A. Rosenfeld and P. D. la Torre, "Histogram concavity analysis as an aid in threshold selection," IEEE Transactions on Systems, Man, and Cybernetics, vol. 13, no. 3, pp. 231-235, 1983.

[166] S. Sandor and R. M. Leahy, "Surface-based labeling of cortical anatomy using a deformable atlas," IEEE Transactions on Medical Imaging, vol. 16, no. 1, pp. 41-54, 1997.

[167] C. Fennema-Notestine, I. B. Ozyurt, C. P. Clark, S. Morris, A. Bischoff-Grethe, M. W. Bondi, T. L. Jernigan, B. Fischl, F. Segonne, D. W. Shattuck, R. M. Leahy, D. E. Rex, A. W. Toga, K. H. Zou, , and G. G. Brown, "Quantitative evaluation of automated skull-stripping methods applied to contemporary and legacy images: effects of diagnosis, bias correction, and slice location," Human Brain Mapping, vol. 27, no. 2, pp. 99-113, 2006.

[168] L. Lemieux, G. Hagemann, K. Krakow, and F. G. Woermann, "Fast, accurate, and reproducible automatic segmentation of the brain in T1-weighted volume MRI data," Magnetic Resonance in Medicine, vol. 42, no. 1, pp. 127-135, 1999. 
[169] M. S. Atkins and B. T. Mackiewich, "Fully automatic segmentation of the brain in MRI," IEEE Transactions On Medical Imaging, vol. 17, no. 1, pp. 98-107, 1998.

[170] B. D. Ward, "Intracranial segmentation," Biophysics Research Institute, Medical College of Wisconsin, Technical Report, 1999.

[171] R. Stokking, K. L. Vincken, and M. A. Viergever, "Automatic morphology-based brain segmentation (MBRASE) from MRI-T1 Data," NeuroImage, vol. 12, no. 6, pp. 726$738,2000$.

[172] Y. Hata, S. Kobashi, S. Hirano, H. Kitagaki, and E. Mori, "Automated segmentation of human brain MR images aided by fuzzy information granulation and fuzzy inference," IEEE Transactions on Systems, Man, and Cybernetics-Part C: Applications and Reviews, vol. 30, no. 3, pp. 381-395, 2000.

[173] M. Kass, A. Witkin, and D. Terzopoulos, "Snakes: Active contour models," International Journal of Computer Vision, vol. 1, no. 4, pp. 321-331, 1987.

[174] R. W. Cox, "AFNI: software for analysis and visualization of functional magnetic resonance neuroimages," Computers and Biomedical Research, vol. 29, no. 3, pp. 162173, 1996.

[175] D. W. Shattuck, S. R. Sandor-Leahy, K. A. Schaper, D. A. Rottenberg, and R. M. Leahy, "Magnetic resonance image tissue classification using a partial volume model," NeuroImage, vol. 13, no. 5, pp. 856-876, 2001.

[176] D. W. Shattuck and R. M. Leahy, "BrainSuite: An automated cortical surface identification tool," Medical Image Analysis, vol. 6, no. 2, pp. 29-142, 2002.

[177] B. Dogdas, D. W. Shattuck, and R. M. Leahy, "Segmentation of skull and scalp in 3-D human MRI using mathematical morphology," Human Brain Mapping, vol. 26, no. 4, pp. 273-285, 2005.

[178] A. Huang, R. Abugharbieh, R. Tam, and A. Traboulsee, "MRI brain extraction with combined expectation maximization and geodesic active contours," in Proceedings of the 6th IEEE International Symposium on Signal Processing and Information Technology, Vancouver, BC, Canada, 2006, pp. 107-111.

[179] S. M. Smith, "Fast robust automated brain extraction," Human Brain Mapping, vol. 17, no. 3, pp. 143-155, 2002.

[180] F. Segonne, A. Dale, E. Busa, M. Glessner, D. Salat, H. Hahn, and B. Fischl, "A hybrid approach to the skull stripping problem in MRI," NeuroImage, vol. 22, no. 3, pp. 1060-1075, 2004. 
[181] D. E. Rex, D. W. Shattuck, R. P. Woods, K. L. Narr, E. Luders, K. Rehm, S. E. Stolzner, D. A. Rottenberg, and A. W. Toga, "A meta-algorithm for brain extraction in MRI," NeuroImage, vol. 23, no. 2, pp. 625-637, 2004.

[182] K. Rehm, K. Schaper, J. Anderson, R. Woods, S. Stoltzner, and D. Rottenberg, "Putting our heads together: a consensus approach to brain/non-brain segmentation in T1-weighted MR volumes," NeuroImage, vol. 22, no. 3, pp. 1262-1270, 2004.

[183] A. C. C. Yao, "A lower bound for finding convex hulls," Journal of ACM, vol. 28, pp. 780-787, 1981.

[184] F. P. Preparata and S. J. Hong, "Convex hulls of finite sets of points in two and three dimensions," Communications of the ACM archive, vol. 20, no. 2, pp. 87-93, 1977.

[185] M. Sezgin and B. Sankur, "Survey over image thresholding techniques and quantitative performance evaluation," Journal of Electronic Imaging, vol. 13, no. 1, pp. 146-168, 2004.

[186] C. A. Cocosco, V. Kollokian, R. K.-S. Kwan, G. B. Pike, and A. C. Evans, "BrainWeb: Online interface to a 3D MRI simulated brain database," NeuroImage, vol. 5, no. 4, p. S425, 1997.

[187] M. X. Ribeiro, A. J. M. Traina, A. G. R. Balan, C. Traina Junior, and P. M. A. Marques, "SuGAR: A Framework to Support Mammogram Diagnosis," in Proceedings of the 20th IEEE International Symposium on Computer-Based Medical Systems (CBMS'200\%, Maribor, Slovenia, 2007, pp. 1-6.

[188] M. X. Ribeiro, C. Y. V. W. Silva, J. C. Felipe, A. G. R. Balan, A. J. M. Traina, and C. Traina-Junior, "Apoiando a busca por conteúdo em imagens médicas através da mineração de regras de associação estatísticas," in Anais do II Workshop sobre Algoritmos de Mineração de Dados (WAAMD'2005), Florianópolis, SC, Brazil, October 2006, pp. 1-8.

[189] M. X. Ribeiro, A. G. R. Balan, J. C. Felipe, A. J. M. Traina, and C. Traina-Junior, "Mining statistical association rules to select the most relevant medical image features," in Proceedings of the First International Workshop on Mining Complex Data (MCD'2005), Houston, TX, USA, November 2005.

[190] J. C. Felipe, A. J. M. Traina, A. G. R. Balan, P. M. de Azevedo-Marques, and C. Traina-Junior, "A new family of perceptual distance functions for similarity retrieval of images," in Proceedings of the 21st Annual ACM Symposium on Applied Computing (SAC'2006), Dijon, France, 2006.

[191] L. da Fontoura Costa and R. M. C. Junior, Shape Analysis and Classification - Theory and Practice. CRC Press, 2001. 
[192] D. Chakrabarti and C. Faloutsos, "F4: large-scale automated forecasting using fractals," in Proceedings of the 2002 ACM CIKM International Conference on Information and Knowledge Management (CIKM'2002), vol. 1, McLean, VA, EUA, 2002, pp. 2-9.

[193] C. Traina, Jr., E. P. M. d. Sousa, and A. J. M. Traina, "Using fractals in data mining," in New Generation of Data Mining Applications. Wiley/IEEE Press, 2004, vol. 1, pp. $1-30$.

[194] I. Kamel and C. Faloutsos, "Hilbert r-tree: An improved r-tree using fractals," in Proceedings of the 20th International Conference on Very Large Data Bases (VLDB'1994). Santiago del Chile, Chile: Morgan Kaufmann, 1994, pp. 500-509.

[195] A. S. Arantes, M. R. Vieira, A. J. M. Traina, and J. Traina, Caetano, "The fractal dimension making similarity queries more efficient," in Proceedings of the 2nd Workshop on Fractals and Self-similarity in Data Mining: Issues and Approaches (in conjunction with 9th ACM SIGKDD International Conference on Knowledge Discovery and Data Mining). Washington, DC, USA: ACM Press, 2003, pp. 12-17.

[196] F. Korn, B.-U. Pagel, and C. Faloutsos, "On the 'dimensionality curse' and the 'selfsimilarity blessing'," IEEE Transactions on Knowledge and Data Engineering, vol. 13, no. 1, pp. 96-111, 2001.

[197] R. Distasi, M. Nappi, and M. Tucci, "FIRE: Fractal indexing with robust extensions for image databases," IEEE Transactions on Image Processing, vol. 12, no. 3, pp. 373-384, 2003.

[198] J. Traina, Caetano, A. J. M. Traina, L. Wu, and C. Faloutsos, "Fast feature selection using fractal dimension," in Anais do XV Simpósio Brasileiro de Baco de Dados, João Pessoa, PA, Brazil, 2000, pp. 158-171.

[199] M. Pi, M. K. Mandal, and A. Basu, "Image retrieval based on histogram of fractal parameters," IEEE Transactions on Multimedia, vol. 7, no. 4, pp. 597-605, 2005.

[200] M. Schroeder, Fractals, Chaos, Power Laws: Minutes from an infinite paradise, 6th ed. New York: W.H. Freeman and Company, 1991.

[201] B. B. Mandelbrot, The Fractal Geometry of Nature. New York: W. H. Freedman and Co., 1983. 